FACULDADE DE CIÊNCIAS FARMACÊUTICAS DE RIBEIRÃO PRETO

Francine Attié de Castro

Enantiosseletividade na disposição cinética e no metabolismo da ciclofosfamida e ajuste de dose do bussulfano em pacientes submetidos a transplante de células tronco hematopoéticas

Ribeirão Preto

-2013- 


\section{FRANCINE ATTIÉ DE CASTRO}

\section{Enantiosseletividade na disposição cinética e no metabolismo da ciclofosfamida e ajuste de dose do bussulfano em pacientes submetidos a transplante de células tronco hematopoéticas}

Tese de Doutorado apresentada ao Programa de PósGraduação em Toxicologia da Faculdade de Ciências Farmacêuticas de Ribeirão Preto da Universidade de São Paulo para obtenção do título de Doutor em Ciências.

Área de Concentração: Toxicologia

Orientadora: Profa. Dra. Vera Lucia Lanchote

Ribeirão Preto 
Autorizo a reprodução e divulgação total ou parcial deste trabalho, por qualquer meio convencional ou eletrônico, para fins de estudo e pesquisa, desde que citada a fonte.

De Castro, Francine Attié

Enantiosseletividade na disposição cinética e no metabolismo da ciclofosfamida e ajuste de dose do bussulfano em pacientes submetidos a transplante de células tronco hematopoéticas. Ribeirão Preto, 2013.

174p. : il; $30 \mathrm{~cm}$

Tese de Doutorado apresentada ao Programa de Pós-Graduação em Toxicologia da Faculdade de Ciências Farmacêuticas de Ribeirão Preto/ USP. Área de Concentração: Toxicologia.

Orientadora: Lanchote, Vera Lucia.

1- Bussulfano. 2- Ciclofosfamida. 3- Metabolismo 4- Transplante de Células Tronco Hematopoéticas 


\section{FOLHA DE APROVAÇÃO}

Francine Attié de Castro

Enantiosseletividade na disposição cinética e no metabolismo da ciclofosfamida e ajuste de dose do bussulfano em pacientes submetidos a transplante de células tronco hematopoéticas.

Tese de Doutorado apresentada ao Programa de PósGraduação em Toxicologia, da Faculdade de Ciências Farmacêuticas de Ribeirão Preto- USP para a obtenção do Título de Doutor em Ciências

Área de Concentração: Toxicologia

Orientada: Francine Attié de Castro

Orientadora: Profa. Dra. Vera Lucia Lanchote

Aprovado em:

BANCA EXAMINADORA

Prof. Dr.

Instituição:

Assinatura:

Prof. Dr.

Instituição:

Assinatura:

Prof. Dr.

Instituição:

Assinatura:

Prof. Dr.

Instituição:

Assinatura:

Prof. Dr.

Instituição:

Assinatura: 


\section{DEDICATÓRIA}

Aos meus pais,
alicerces da minha vida... 


\section{AGRADECIMENTOS}

À minha orientadora, Profa. Dra. Vera Lucia Lanchote, pela oportunidade, auxílio, dedicação e ensinamentos. Por sua disponibilidade, horas, finais de semana e feriados dispensados entre as leituras e correções...

Ao Prof. Dr. Júlio César Voltarelli (in memorian), por me abrir as portas da pós-graduação e da Unidade de Transplante de Medula Óssea do Hospital das Clínicas da Faculdade de Medicina de Ribeirão Preto- HCFMRP-USP. Por me ensinar o que é pesquisa, pela oportunidade de trabalhar com um líder e não um chefe. Por acreditar em mim até mais do que eu mesma, por todo apoio e confiança depositados, que foram essenciais!

Ao Prof. Dr. Eduardo Barbosa Coelho, pela colaboração, ensinamentos e por permitir que as análises de genotipagem fossem feitas em seu laboratório.

Ao Prof. Dr. Oscar Della Pasqua, pela oportunidade de estagiar em seu laboratório na Universidade de Leiden por 6 meses, período em que aprendi muito (cientificamente e pessoalmente), conheci pessoas maravilhosas e vivi momentos inesquecíveis.

Agradeço imensamente a todos os pacientes, pela participação indispensável para a realização deste trabalho. Pacientes que me ensinaram muito, e que mesmo em se tratando de um momento extremamente difícil e delicado foram sempre solícitos e abertos à pesquisa.

Agradeço à toda a equipe da Unidade de Transplante de Medula Óssea e Terapia Imunológica do HCFMRP-USP por todo apoio e confiança depositados.

À Dra. Maria Paula Marques Pereira, funcionária do Laboratório de Farmacocinética e Metabolismo da Faculdade de Ciências Farmacêuticas de Ribeirão Preto - FCFRP-USP, por todos os ensinamentos e constante auxílio científico. 
Ao Sr. Natalino Bocardo, funcionário do Laboratório de Farmacocinética e Metabolismo da FCFRP- USP, por seu auxílio e alegria contagiante, transformando o ambiente de trabalho sempre mais leve e agradável.

Aos funcionários Dra. Adriana Rocha e Dr. Eduardo Tozatto pelos ensinamentos e amizade.

À técnica Juliana Abumansur e à colaboradora Ms. Fernanda M. Trigo pela ajuda nas análises de genotipagem.

Às secretarias da Pós-Graduação Rose e Rosana por auxiliar e torcer pelo sucesso de todos os alunos.

Aos amigos de laboratório, Ms. Carolina P. Vieira, Dra. Carolina M. Silva, Ms. Glauco Nardotto, Dr. Daniel V. Neves, Ms. Natalícia J. Antunes, Ms. Leonardo Pinto, Ms Diego Cusinato, Roberta Cestari, Marília Oliveira, Milena Oliveira e Gabriel Tavares pelos ensinamentos, trocas de experiências e companhia. $E$, em especial, aos que trabalharam mais próximos de mim: Dra. Ana Leonor P.C. Godoy, Dra. Natália V. de Moraes (hoje já Professora, que orgulho!) e Ms. Otávio P. Rocha. Muito obrigada por tudo!

Aos meus amigos da Universidade de Leiden, os quais levarei para sempre em meu coração: Chiara Piana (quem me ensinou tudo sobre modelling), Francesco Bellanti, Sven van Dijkamn, Erwin Lavalliére e Risha Smeding (que me acolheram quando mais precisei), Isaac Cespedes (amigo de todas as horas), Li Qin e Zuzzana Baranski.

Que honra, Professores, técnicos, amigos e colegas por ter trabalhado com todos vocês!

Aos meus pais, Jales Amâncio de Castro e Sheila Bulamah Attié, a eterna gratidão pelos valores ensinados, amor incondicional, confiança e dedicação.

Aos meus irmãos Jorge e Catherine, pela paciência, amizade, cumplicidade e por cumprirem tão bem o verdadeiro papel de irmãos. 
Aos meus maiores incentivadores: Profa. Dra. Fabíola Attié de Castro e Dr. Rendrik França Franco. Obrigada por me incentivarem, por todo auxílio de sempre (emocional, intelectual e até financeiro quando foi preciso). Obrigada por iluminarem meu caminho profissional e abrirem as portas da Universidade e da Pesquisa. Agradeço, principalmente, por acreditarem que eu seria capaz.

Aos meus amados Tio Zé, Tia Sandra e prima Dra. Flávia A. Attié de Castro agradeço pela companhia e incentivos.

$E$ àqueles que aqui não foram citados, mas que também contribuiram na realização deste trabalho.

Agradeço a FAPESP pela bolsa concedida e auxílio financeiro.

Sou, certamente, uma pessoa de muita sorte por ter tido a oportunidade de conviver com todos vocês! Assim, agradeço a DEUS, ACIMA DE TUDO, SEMPRE presente em minha vida! Se cheguei até aqui, devo muito a vocês! Sou e sempre serei muito grata! MUITO OBRIGADA!!! 


\title{
A PEDRA
}

\author{
O distraído, nela tropeçou, \\ o bruto a usou como projétil, \\ o empreendedor, usando-a construiu, \\ o campônio, cansado da lida, dela fez assento. \\ Drummond a poetizou, \\ Davi matou Golias... \\ Por fim: \\ - artista concebeu a mais bela escultura. \\ Em todos os casos, \\ a diferença não era a pedra. \\ Mas o homem.
}

Antonio Pereira (Apon) 


\section{RESUMO}

DE CASTRO, F.A. Enantiosseletividade na disposição cinética e no metabolismo da ciclofosfamida e ajuste de dose do bussulfano em pacientes submetidos a transplante de células tronco hematopoéticas. 2013. 174 f. Tese (Doutorado). Faculdade de Ciências Farmacêuticas de Ribeirão Preto, Universidade de São Paulo, Ribeirão Preto, 2013

O bussulfano (BU) e a ciclofosfamida (CY) são fármacos utilizados nos regimes de condicionamento pré-transplante de células tronco hematopoéticas (TCTH). O BU apresenta estreito intervalo terapêutico, alta variabilidade interindividual na farmacocinética e graves reações adversas. O presente estudo avaliou a administração de uma dose teste de BU oral para a individualização do regime de dosagem, definiu o melhor tempo de coletas esparsas para o monitoramento terapêutico do BU e validou um algoritmo baseado em modelo compartimental e farmacocinética populacional em pacientes submetidos ao TCTH. Trinta pacientes portadores de doenças hematológicas tiveram o tratamento com BU individualizado baseado em uma dose teste oral de $0,25 \mathrm{mg} / \mathrm{Kg}$ de BU. As doses foram baseadas no clearance aparente calculado na dose teste e as concentrações plasmáticas foram confirmadas após a quinta dose de tratamento. Os coeficientes de variação obtidos entre os valores de clearance avaliados na dose teste e na quinta dose foram $\leq 30 \%$, exceto para 5 pacientes. Não foram observadas associação entre os parâmetros farmacocinéticos do BU e a evolução clínica dos pacientes. Com a finalidade de estimar os melhores tempos de coletas ideais para aplicação no monitoramento terapêutico do BU, um modelo farmacocinética populacional foi utilizado e um esquema de coletas esparsas com não mais de cinco amostras por paciente $(\mathrm{t}=0,5 ; 2,25$; 3; 4 e 5 horas após a dose) demonstrou ser suficiente para a caracterização da farmacocinética do BU. O presente estudo avaliou também a farmacocinética dos enantiômeros da ciclofosfamida (CY) e seus metabólitos (4-hidroxiciclofosfamida e carboxiciclofosfamida), em pacientes submetidos ao TCTH. Foram investigados pacientes portadores de esclerose sistêmica $(n=10)$ e esclerose múltipla $(n=10)$ em regime de condicionamento com $50 \mathrm{mg} C Y$ $/ \mathrm{kg} /$ dia durante 4 dias. Dois ensaios específicos baseados na análise por LC-MS/MS foram desenvolvidos e validados para analisar os enantiômeros da CY e seus metabólito 4hidroxiciclofosfamida (HCY) e carboxiciclofosfamida (CEPM) em plasma humano. Os parâmetros farmacocinéticos dos enantiômeros da CY e seus metabólitos foram calculados empregando o programa WinNonlin e mostraram acúmulo plasmático dos enantiômeros (S)(-)-CY (AUC 215, 0 vs 186,2 $\mu$ g.h/mL para os paciente EM e 219,1 vs 179,2 $\mu \mathrm{g} . \mathrm{h} / \mathrm{mL}$ para os 
paciente ES) e HCY (1), provavelmente o (R)-(+)-HCY (AUC 5,6 vs 3,7 $\mu \mathrm{g} . \mathrm{h} / \mathrm{mL}$ para os paciente EM e 6,3 vs 5,6 $\mu \mathrm{g} \cdot \mathrm{h} / \mathrm{mL}$ para os paciente ES) em ambos os grupos de pacientes investigados. A disposição cinética do metabólito CEPM não mostrou enantiosseletividade. A farmacocinética da $\mathrm{CY}$ e seus metabólitos HCY e CEPM não diferiu entre os pacientes portadores de EM ou ES. Não foi observado correlação entre o metabolismo da CY e os genótipos avaliados (CYP2B6 e CYP2C9). Não foi possível correlacionar os valores de AUC0- $\infty$ dos enantiômeros da CY e/ou dos metabólitos HCY e CEPM com a toxicidade ao uso de CY em virtude do pequeno número de pacientes investigados.

Palavras-Chave: Bussulfano; Ciclofosfamida; Metabolismo; Farmacocinética; Transplante de Células Tronco Hematopoéticas 


\begin{abstract}
DE CASTRO, F.A. Enantioselectivity on the kinetic disposition and metabolism of cyclophosphamide and busulfan dose adjustment in patients who underwent stem cell marrow transplantation. 2013. 174 p. Doctoral Thesis. Faculdade de Ciências Farmacêuticas de Ribeirão Preto, Universidade de São Paulo, Ribeirão Preto, 2013.
\end{abstract}

Busulfan (BU) and cyclophosphamide (CY) are drugs used during conditioning treatment for hematopoietic stem cell transplantation (HSCT). BU presents narrow therapeutic window, high interindividual variability in the pharmacokinetics and serious adverse effects. The present study evaluated the administration of a BU test dose for dose individualization, set the best sparse sampling scheme for BU therapeutic monitoring and validated an algorithm based on compartmental and population pharmacokinetics model in HSCT patients. Thirty patients received BU individualized treatment based on an oral test dose of $0.25 \mathrm{mg} / \mathrm{kg}$. Doses were based on apparent clearance calculated with BU test dose. Plasma concentrations were confirmed after the fifth treatment dose. Coefficients of variation obtained between the clearance values evaluated in the test dose and fifth dose were $\leq 30 \%$, except for 5 patients. No association between BU pharmacokinetic parameters and clinical outcome was observed. To estimate the ideal sampling scheme for BU therapeutic drug monitoring, a population pharmacokinetic model was used. Sparse sampling scheme with no more than five samples per patient ( $\mathrm{t}=0.5,2.25,3,4$ and 5 hours after dosing) was shown to be sufficient to characterize the BU pharmacokinetics. This study also evaluated the pharmacokinetics of the cyclophosphamide enantiomers and its metabolites (4-hydroxycyclophosphamide and carboxicyclophosphamide) in HSCT patients. We investigated patients with systemic sclerosis $(\mathrm{SS})(\mathrm{n}=10)$ and multiple sclerosis $(\mathrm{MS})(\mathrm{n}=10)$ in the conditioning regimen with CY 50 $\mathrm{mg} / \mathrm{kg} /$ day for 4 days. Two specific tests based on LC-MS/MS analysis were developed and validated to analyze the $\mathrm{CY}$ enantiomers and its metabolite 4-hydroxycyclophosphamide (HCY) and carboxicyclophosphamide (CEPM) in human plasma. Pharmacokinetics of CY enantiomers and its metabolites were calculated using WinNonlin software and showed plasma accumulation of (S)-(-)-CY (AUC $215.0 \mathrm{vs} 186.2 \mu \mathrm{g} . \mathrm{h} / \mathrm{mL}$ for the MS patient and 219.1 vs. $179.2 \mu \mathrm{g} . \mathrm{h} / \mathrm{mL}$ for the SS patient) and HCY (1), probably the (R)-(+)-HCY (AUC 5.6 vs $3.7 \mu \mathrm{g} . \mathrm{h} / \mathrm{mL}$ for MS patients and $6.3 \mathrm{vs} 5.6 \mu \mathrm{g} . \mathrm{h} / \mathrm{mL}$ for the SS patients) enantiomers in both groups of investigated patients. CEPM kinetics disposition showed lack of enantioselectivity. The pharmacokinetics of CY and its metabolites (HCY and CEPM) did not 
differ between patients with MS or SS. There was no correlation between the metabolism of

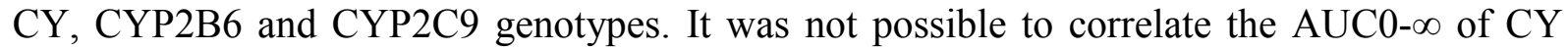
enantiomers and/or its metabolites (HCY and CEPM) with CY toxicity due to the small number of patients investigated.

Key-words: Busulfan; Cyclophosphamide; Pharmacokinectics; Hematopoietic stem cell transplantation. 


\section{LISTA DE ILUSTRAÇÕES}

Figura 1. Estrutura química do bussulfano (CHOW et al., 1997) ...........................................30

Figura 2. Procedimento de extração líquido-líquido do BU em plasma humano....................41

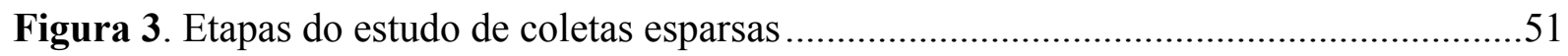

Figura 4. Cromatogramas referentes ao (A) Plasma Branco, (B) Plasma enriquecido com BU $1250 \mathrm{ng} / \mathrm{mL}$ de plasma, (C) Plasma de voluntário após 45 minutos da administração oral da dose teste de BU, (D) Plasma de voluntário após 45 minutos da administração oral da 5a dose

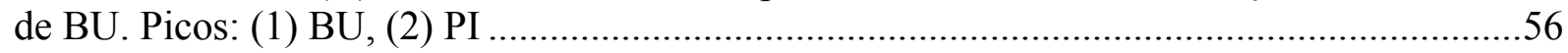

Figura 5. Concentração plasmática do BU versus tempo. Dados apresentados como medianas

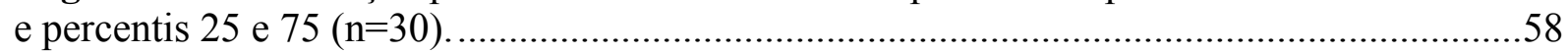

Figura 6. Frequência das Css de BU de todos os pacientes incluídos no estudo....................62

Figura 7. Variabilidade do clearance aparente do BU entre a dose teste e a quinta dose .......64

Figura 8. Associação entre o polimorfismo da GSTM1 (presença ou deleção) e os parâmetros farmacocinéticos clearance aparente e AUC avaliados na dose teste e na quinta dose.

Figura 9. Associação entre os polimorfismos da GSTP1 e os parâmetros farmacocinéticos clearance aparente e AUC avaliados na dose teste e na quinta dose.....

Figura 10. Associação entre os polimorfismos da GSTA1 e os parâmetros farmacocinéticos clearance aparente e AUC avaliados na dose teste e na quinta dose..... 68

Figura 11. Gráficos de diagnósticos de qualidade do modelo final. Concentrações observadas (DV) versus concentrações populacionais previstas (PRED), concentrações observadas (DV) versus concentrações individuais previstas (IPRED), resíduos ponderados condicionais (CWRES) versus predições populacionais e resíduos ponderados condicionais (CWRES) versus tempo após a administração do BU

Figura 12. VPC de validação interna $(n=20)$ 73

Figura 13. Distribuição dos valores de AUC preditos pelo modelo (1000 replicatas) por ocasião da dose teste e quinta dose para o grupo de 20 pacientes investigados. As linhas vermelhas representam a mediana dos dados dos pacientes reais.

Figura 14. Resultados da validação interna com NPDE. (A) Gráfico quantil-quantil do NPDE versus distribuição normal padrão esperada, (B) Histograma do NPDE com a distribuição normal, (C) distribuição do NPDE versus tempo após a administração da dose teste e após a administração da quinta dose de BU e (D) NPDE versus concentrações preditas. A distribuição normal é representada pela linha sólida. As linhas pontilhadas representam a média-2SD da distribuição normal.

Figura 15. Gráficos espelhos populacionais. Os gráficos à direita e à esquerda, relacionam as concentrações plasmáticas de BU observadas versus as concentrações plasmáticas 
populacionais previstas pelo modelo popPK. O gráfico à esquerda apresenta a qualidade do ajuste dos dados originais. Os gráficos populacionais à direita foram selecionados de forma aleatória à partir dos dados simulados pelo modelo.

Figura 16. Gráficos espelhos individuais. Os gráficos à direita e à esquerda, relacionam as concentrações plasmáticas de BU observadas versus as concentrações plasmáticas individuais previstas pelo modelo popPK. O gráfico à esquerda apresenta a qualidade do ajuste dos dados originais. Os gráficos de predições individuais à direita foram selecionados de forma aleatória à partir dos dados simulados pelo modelo

Figura 17. VPC de validação externa $(n=9)$. Linha sólida: mediana dos dados simulados; Linhas tracejadas: percentis 25 e 75 dos dados simulados. 79

Figura 18. Porcentagem de desvio da estimativa do clearance aparente individual do BU quando calculado com 15 e com 5 amostras seriadas de sangue. As linhas azuis são os limites aceitáveis de \% de desvio na estimativa do clearance individual com 5 amostras

Figura 19. Frequências dos valores de AUC calculados na dose teste para os dois cenários de coletas de amostras seriadas de sangue. As barras azuis representam os valores de AUC calculados com 15 amostras de sangue, as barras rosas representam os valores de AUC calculados com 5 amostras de sangue e as barras verdes são a sobreposição das duas distribuições.

Figura 20. Frequências dos valores de AUC calculados na quinta dose para os dois cenários de amostras seriadas de sangue. As barras azuis representam os valores de AUC calculados com 15 amostras seriadas de sangue, as barras rosas representam os valores de AUC calculados com 5 amostras seriadas de sangue e as barras verdes são a sobreposição das duas distribuições.

Figura 21. Valores de AUC0-6 baseados nos diferentes protocolos $(n=20)$. CP- protocolo clinico; TDM- monitoramento terapêutico baseado na farmacocinética não compartimental e dose baseada no peso ideal ajustado; MB- aproximação baseada no modelo populacional. As linhas vermelhas representam o intervalo terapêutico.

Figura 22. Metabolismo da ciclofosfamida (adaptado de ZHANG et al., 2006) .98

Figura 23. Mecanismo de inibição do CYP e de transportadores durante a inflamação. HNFfator nuclear de hepatócitos; NF- fator nuclear (adaptado de MORGAN et al., 2008).

Figura 24. Procedimento de extração líquido-líquido da CY e CEPM em plasma humano..110 Figura 25. Procedimento de extração líquido-líquido do HCY em solução de plasma humano.

Figura 26. Perfil das bandas na análise das variantes alélicas CYP2B6. 117

Figura 27. Cromatogramas referentes a (A) Plasma enriquecido com $1000 \mathrm{ng} / \mathrm{mL}$ de cada enantiômero da CY, (B) Plasma enriquecido com $1000 \mathrm{ng} / \mathrm{mL}$ de cada enantiômero do CEPM, (C) Padrão Interno, (D) Plasma de voluntário após infusão de CY. 
Figura 28. Cromatogramas referentes ao (A) Plasma Branco, (B) Padrão Interno antipirina, (C) Plasma enriquecido com $1000 \mathrm{ng} / \mathrm{mL}$ do derivado de HCY, (D) Plasma de voluntário $1 \mathrm{~h}$ e 30 minutos após o início da infusão de CY.

Figura 29. Concentrações plasmáticas versus tempo dos enantiômeros da CY nos pacientes investigados até 24 horas após a infusão de CY racêmica durante 60 minutos. Dados apresentados como mediana para os grupos EM $(A ; n=10)$ e $E S(B ; n=10)$.

Figura 30. Curvas concentração plasmática versus tempo referentes aos enantiômeros da CY para os pacientes dos grupos EM e ES. Dados apresentados como mediana 130

Figura 31. Concentrações plasmáticas versus tempo dos enantiômeros do CEPM nos pacientes dos grupos EM (A) e ES (B) investigados até 24 horas após a infusão de CY racêmica durante 60 minutos. Dados apresentados como mediana

Figura 32. Concentrações plasmáticas versus tempo dos enantiômeros do CEPM nos pacientes dos grupos investigados. Dados apresentados como mediana

Figura 33. Concentrações plasmáticas versus tempo dos enantiômeros do HCY nos pacientes do grupo EM (A) e ES (B) investigados até 24 horas após a infusão de CY racêmica durante 60 minutos. Dados apresentados como mediana. 134

Figura 34. Concentrações plasmáticas versus tempo dos enantiômeros do HCY nos pacientes dos grupos ES e EM investigados. Dados apresentados como mediana.

Figura 35. Associação entre os polimorfismos do CYP2B6*9 (A, B), CYP2C9*2 (C, D) e

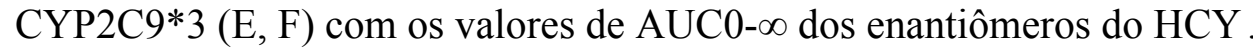
138

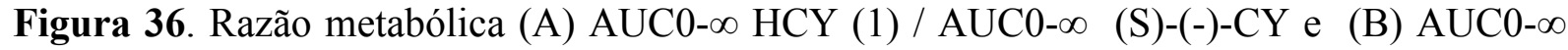

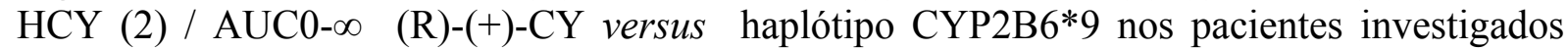
portadores de esclerose múltipla ou esclerose sistêmica $(n=20)$. 139

Figura 37. Curvas individuais da concentração plasmática versus tempo para os enantiômeros da CY e seus metabólitos (HCY e CEPM) nos pacientes portadores de EM ou ES 


\section{LISTA DE TABELAS}

Tabela 1. Algumas doenças tratadas com TCTH ............................................................22

Tabela 2. Esquema da dose teste e regime de condicionamento do BU ..................................38

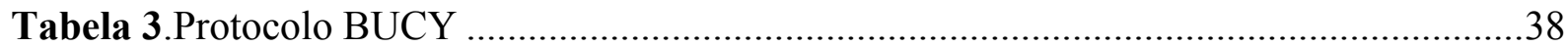

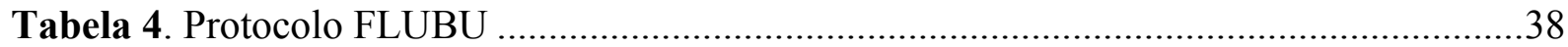

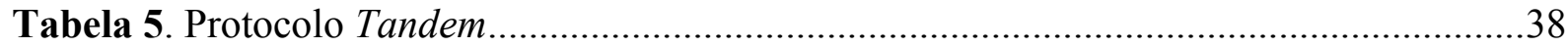

Tabela 6. Sonda utilizada no ensaio de genotipagem para GSTP1 .....................................44

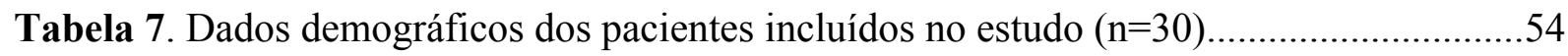

Tabela 8. Lista de fármacos associados ao BU durante as coletas de sangue seriadas ............55

Tabela 9. Efeito matriz para o BU e PI em seis diferentes lotes de plasma humano. Resultados apresentados como porcentagem $(\%)$ em relação ao sinal original ........................................56

Tabela 10. Limites de confiança do método de análise do BU por LC-MS/MS......................57

Tabela 11. Disposição cinética do BU após a administração de dose teste de $0,25 \mathrm{mg} / \mathrm{kg}$

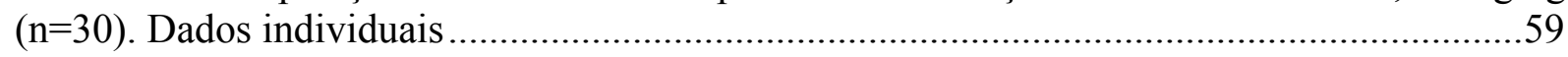

Tabela 12. Disposição cinética do BU na quinta dose $(n=30)$. Dados individuais ..................60

Tabela 13. Valores de Css observados na 5a dose versus valores de Css esperados $(\mathrm{n}=30)$. Dados individuais

Tabela 14. Variabilidade do clearance aparente do BU oral na dose teste e na quinta dose $(\mathrm{n}=30)$

Tabela 15. Associação dos polimorfismos da GST com o clearance aparente após dose teste de BU e AUC0-6 após a quinta dose de BU. Os dados de $\mathrm{Cl} / \mathrm{f}$ e AUC0-6 estão apresentados como mediana $(\mathrm{n}=30)$

Tabela 16. Toxicidade do BU avaliada na evolução pós-TCTH (n=30).

Tabela 17. Distribuição de frequências e testes de associação entre a Css do BU e os efeitos

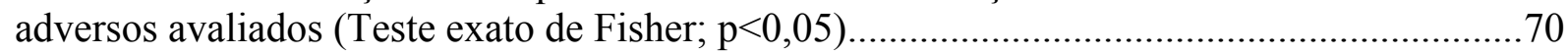

Tabela 18. Parâmetros farmacocinéticos do modelo populacional final................................71

Tabela 19. Sondas utilizadas nos ensaios de genotipagem para o CYP2C9 ........................118

Tabela 20. Dados demográficos dos pacientes portadores de EM incluídos no estudo ( $\mathrm{n}=10)$ 
Tabela 21. Dados demográficos dos pacientes portadores de ES incluídos no estudo $(n=10)$

Tabela 22. Efeito matriz para os enantiômeros da CY e do metabólito CEPM em oito diferentes lotes de plasma humano. Resultados apresentados como CV (\%) dos valores FMN

Tabela 23. Limites de confiança do método de análise dos enantiômeros da CY 125

Tabela 24. Limites de confiança do método de análise dos enantiômeros do CEPM em plasma

Tabela 25. Estudo de estabilidade do método de análise dos enantiômeros da CY e do CEPM em plasma humano.

Tabela 26. Limites de confiança do método de análise dos enantiômeros do HCY

Tabela 27. Parâmetros farmacocinéticos dos enantiômeros da CY nos grupos EM e ES, tratados com $50 \mathrm{mg} / \mathrm{Kg}$ de CY racêmica. Os dados estão expressos como mediana e percentis 25 e 75 131

Tabela 28. Parâmetros farmacocinéticos dos enantiômeros do CEPM nos grupos investigados, tratados com $50 \mathrm{mg} / \mathrm{Kg}$ de CY racêmica. Os dados estão expressos como mediana e percentis 25 e 75

Tabela 29. Parâmetros farmacocinéticos dos enantiômeros do HCY nos grupos EM (n=10) e ES $(n=10)$, tratados com $50 \mathrm{mg} / \mathrm{Kg}$ de CY racêmica. Os dados estão expressos como mediana e percentis 25 e 75 . 135

Tabela 30. Frequência dos polimorfismos dos genes CYP2B6 e CYP2C9 nos pacientes investigados $(\mathrm{n}=20)$. 137

Tabela 31. Toxicidade relacionada o CEPM nos pacientes portadores de EM ou ES ( $\mathrm{n}=20)$ 140

Tabela 32. Valores individuais de AUC de CEPM e HCY como mistura enantiomérica. Os resultados estão apresentados em $\mu \mathrm{g} . \mathrm{h} / \mathrm{ml}$ e $\mu \mathrm{mol} . \mathrm{h} / \mathrm{l}$. 141 


\section{SUMÁRIO}

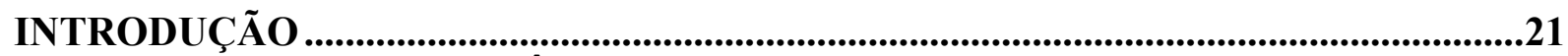

JUSTIFICATIVA E RELEVÂNCIA .......................................................................24

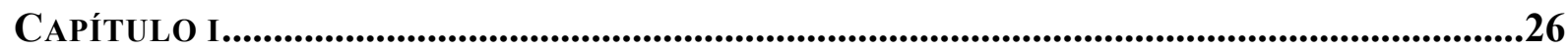

Validação de dose teste oral do bussulfano empregando farmacocinética individual e populacional em pacientes submetidos ao transplante de células tronco hematopoéticas

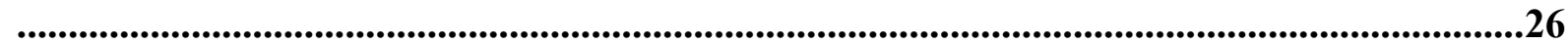

Resumo

1. Introdução ...............................................................................................................................................29

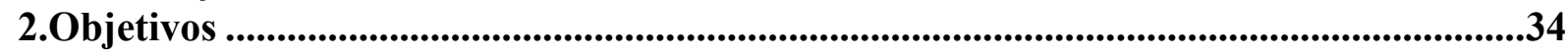

Objetivo Geral..............................................................................................................................35

Objetivos Específicos ..............................................................................................35

3. Casuística e Métodos.................................................................................................................36

3.1 Casuística e Protocolo Clínico ..........................................................................................37

3.2 Análise do BU em plasma por LC-MS/MS........................................................................39

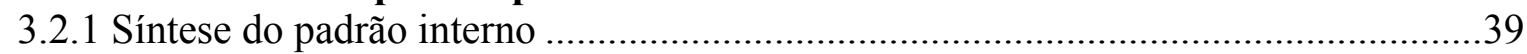

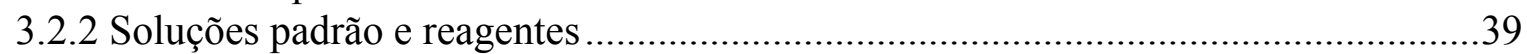

3.2.4 Procedimento de preparo das amostras .................................................................40

3.2.5 Determinação do efeito matriz .............................................................................4

3.2.6 Validação do método análise do BU .....................................................................41

3.3 Análise dos polimorfismos do gene GST e presença ou deleção do gene GSTM1 ...43

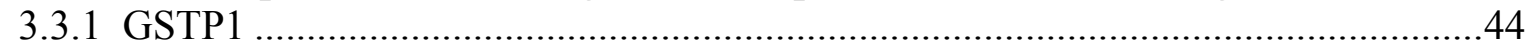

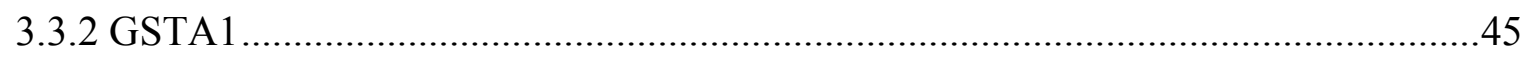

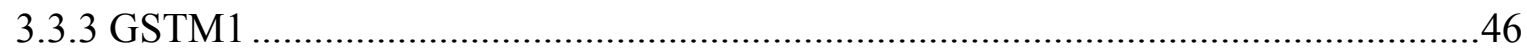

3.4 Análise Farmacocinética e Estatística..............................................................................46

3.5 Avaliação do modelo de farmacocinética populacional...................................................48

3.6 Otimização Experimental do tempo de coletas esparsas.................................................49

3.7 Simulações .....................................................................................................................................50

4. Resultados ….......................................................................................................................52

4.1 Dados demográficos ................................................................................................................53

4.2 Fármacos associados ao BU ..................................................................................................55

4.3 Análise do BU em plasma humano...........................................................................56

4.3.1 Efeito matriz na análise do BU em plasma …………………………………......56

4.3.2 Validação do método de análise do BU em plasma humano ………………………....57

4.4 Farmacocinética do BU ......................................................................................................58

4.5 Polimorfismos no gene GST ........................................................................................................65

4.6 Evolução Clínica ............................................................................................................68

4.7 Farmacocinética Populacional do BU (Análise Compartimental) ................................70

4.7.1 Validação externa do modelo de Farmacocinética Populacional do BU ....................78

4.8 Estratégia de amostragem esparsa .........................................................................................80

4.9 Avaliação das implicações clínicas ....................................................................................83

5.Discussão _...............................................................................................................................85

6. Conclusões............................................................................................................................................91 
Enantiosseletividade na disposição cinética e no metabolismo da ciclofosfamida em pacientes portadores de esclerose submetidos a transplante de células tronco hematopoéticas ...........................................................................................................................93

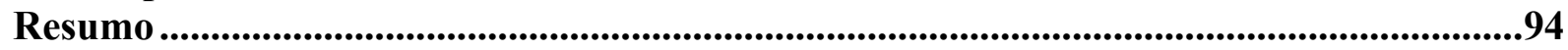

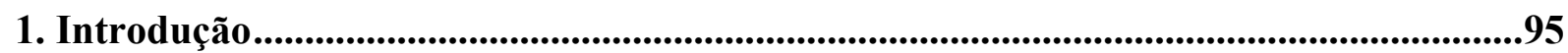

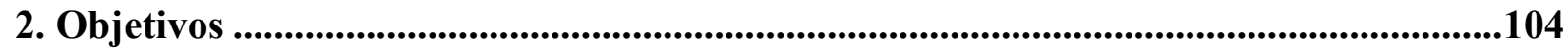

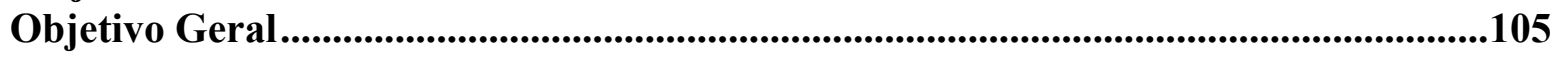

Objetivos Específicos .............................................................................................................105

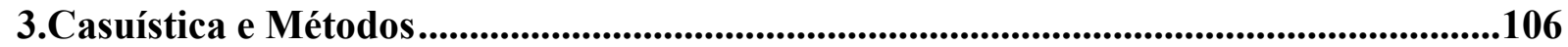

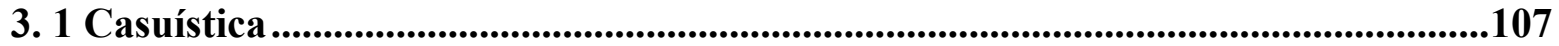

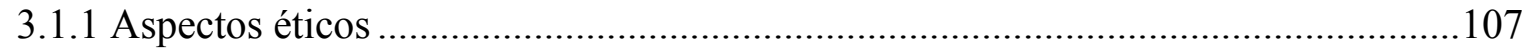

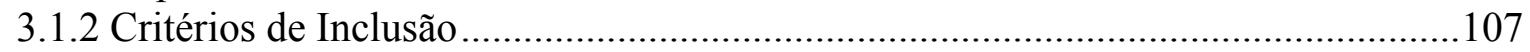

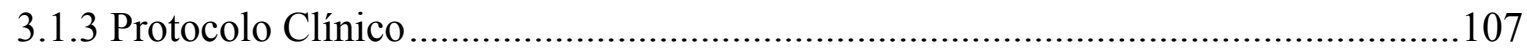

3.2 Análise enantiosseletiva da CY e seu metabólito CEPM em plasma humano empregando LC-MS/MS ......................................................................................108

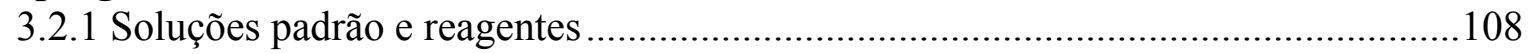

3.2.2 Separação cromatográfica e condições do sistema LC-MS/MS..............................108

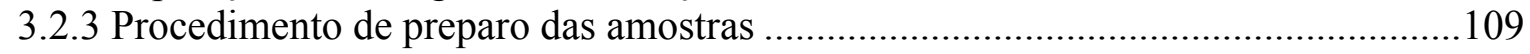

3.2.4. Determinação da ordem de eluição dos enantiômeros da CY ...............................110

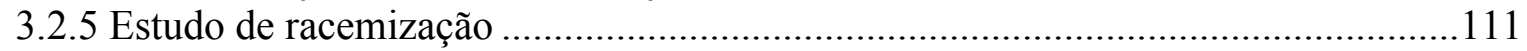

3.2.6 Validação do método de análise dos enantiômeros da CY e do metabólito CEPM em

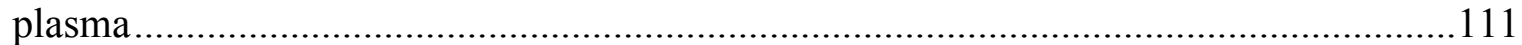

3.3 Análise dos enantiômeros da HCY em plasma humano empregando LC-MS/MS

3.3 .1 Soluções padrão e reagentes

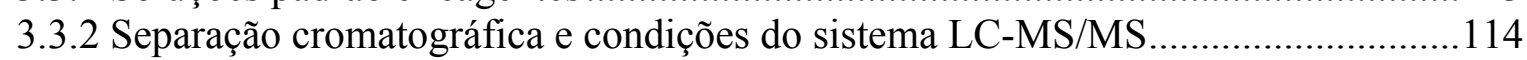

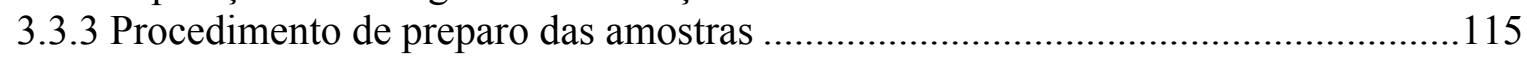

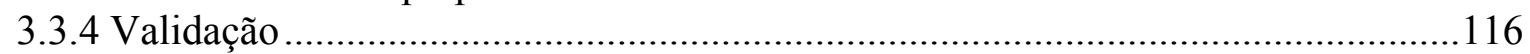

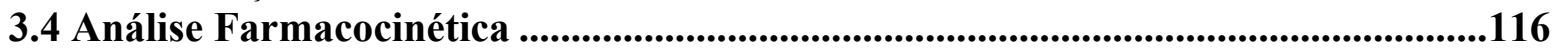

3.5 Análise das variantes alélicas do CYP2B6 e do CYP2C9.....................................116

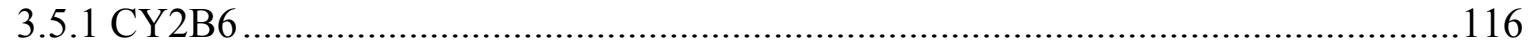

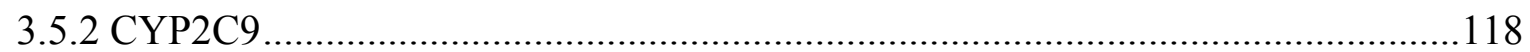

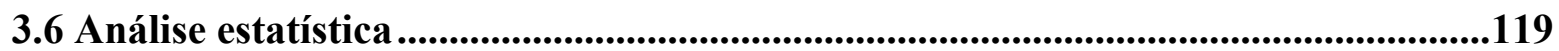

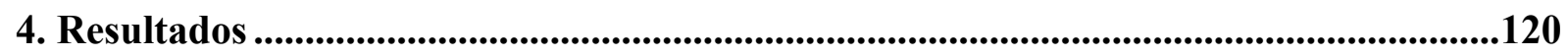

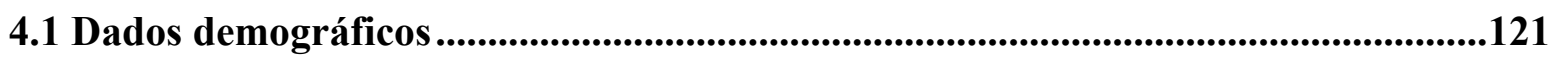

4.2 Análise dos enantiômeros da CY e do metabólito CEPM em plasma......................122

4.2.1 Validação do método de análise dos enantiômeros da CY e do CEPM em plasma 123

4.3 Análise dos enantiômeros do metabólito HCY em plasma ........................................127

4.4.Análise farmacocinética e estatística .................................................................130

4.4.1 Avaliação da disposição cinética dos enantiômeros da CY ....................................130

4.4.2 Avaliação da disposição cinética dos enantiômeros do metabólito CEPM..............132

4.4.3 Avaliação da disposição cinética dos enantiômeros do metabólito HCY ................134

4.5 Análise dos polimorfismos CYP2B6*9, CYP2C9*2 e CYP2C9*3 .........................136

4.6 Evolução Clínica ....................................................................................................140

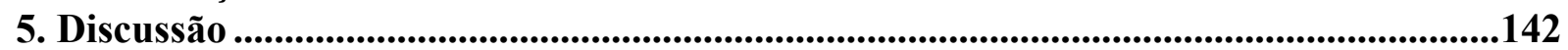

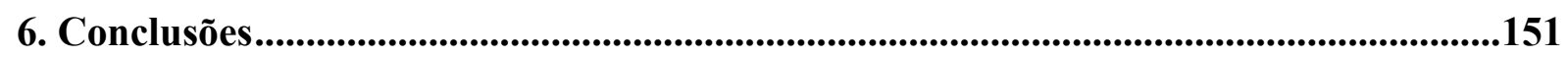

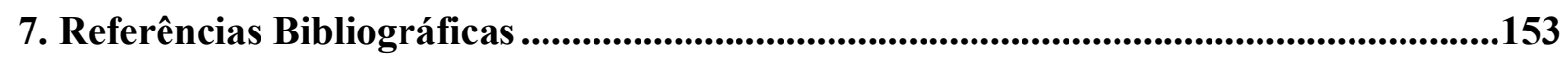

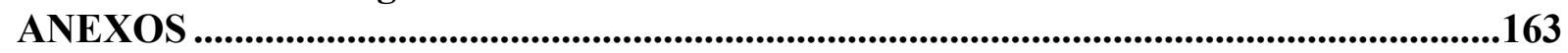




\section{INTRODUÇÃO}

O Transplante de células tronco hematopoéticas (TCTH) é uma modalidade terapêutica que envolve a transferência da célula primordial hematopoética pluripotencial, do doador para o receptor e que, sob a influência de um microambiente adequado, é capaz de regenerar todos os elementos celulares sanguíneos, normalmente derivados da medula óssea, além do sistema linfóide (COURI; DE OLIVEIRA; SIMÕES, 2012; LIU et al., 2010).

Os pacientes considerados para o TCTH devem ter uma doença, na qual as opções de terapêutica convencional resultem em sobrevida livre de doença nitidamente menor do que aquela esperada no transplante, consideradas as condições particulares do paciente (BOUZAS, 2000).

As principais etapas do TCTH consistem em: mobilização e coleta da medula óssea ou células tronco do doador; condicionamento do receptor com quimioterapia e/ou radioterapia; pega e recuperação medular no receptor. Quando um paciente é selecionado para fazer o TCTH, após a identificação do doador, o paciente é então, hospitalizado em isolamento e preparado ou condicionado para o transplante com quimioterapia em altas doses associada ou não à radioterapia (DELANEY; BALLEN, 2013; PATON; COUTINHO; VOLTARELLI, 2000).

O regime de condicionamento clássico provoca mieloablação, o que permite criar espaço na cavidade da medula óssea, induz a imunossupressão e trata a doença residual. Deste modo, permite a enxertia das células tronco hematopoéticas transplantadas, que são responsáveis pela reconstituição da hematopoese, que começa a se revelar no sangue periférico de duas a quatro semanas após a infusão das células, período este caracterizado por intensa aplasia medular e pancitopenia periférica. Em doenças autoimunes e algumas deficiências imunológicas, apenas a imunossupressão é necessária para o sucesso do transplante (BOWEN et al., 2013; STRACIERI, 2000).

O TCTH é empregado clinicamente para a terapia de uma grande variedade de doenças congênitas e adquiridas, neoplásica e não neoplásicas, como, por exemplo, as incluídas na Tabela 1. 
Tabela 1. Algumas doenças tratadas com TCTH

DOENÇAS NEOPLÁSICAS

DOENÇAS NÃO NEOPLÁSICAS

\section{Leucemias}

Leucemia mielóide aguda

Leucemia linfóide aguda

Leucemia mielóide crônica

Leucemia linfóide crônica

Síndromes mielodisplásicas (SMD)

Leucemias e SMD secundárias

\section{Doenças linfoproliferativas}

Linfoma de Hodgkin

Linfomas não-Hodgkin

Mieloma Múltiplo

\section{Falências medulares adquiridas}

Anemia aplástica grave

Hemoglobinúria paroxística noturna

Falências medulares hereditárias

Anemia de Fanconi

Síndrome de Diamond-Blackfan

Agranulocitose de Kostmann

Histocitose eritrofagocítica familiar

Disceratose congênita

Síndrome de Scwachman-Diamond

\section{Hemoglobinopatias}

Talassemia maior

Anemia falciforme

\section{Deficiências imunológicas}

Imunodeficiência combinada grave

Síndrome de Wiskott-Aldrich

Doença granulomatosa crônica infantil

\section{Doenças auto-imunes}

Artrite reumatóide

Esclerose múltipla

Esclerose sistêmica

Lupus eritematoso sistêmico

Doença de Crohn

Diabetes mellitus

\section{Erros inatos do metabolismo}

Doença de Gaucher

Síndrome de Hunter 
Diferentemente do TCTH para doenças onco-hematológicas, no tratamento de doenças autoimunes o TCTH autólogo (que utiliza células tronco periféricas retiradas do próprio paciente e que são reinfundidas após o regime de condicionamento) parte do princípio de que a doença possa ser corrigida pela regeneração de um novo sistema imune, a partir de células tronco hematopoéticas não comprometidas imunologicamente com o estímulo da doença desencadeante. Conceitualmente, a doença deve ter sido desencadeada pelo surgimento de uma resposta imune alterada frente a um agente ambiental que, muito provavelmente, não está mais presente. A regeneração de um sistema imunológico "virgem" e tolerante aos autoantígenos faria com que a resposta anormal desaparecesse. O procedimento funcionaria como um novo início para o sistema imunológico. O papel das células tronco hematopoéticas é o de reconstituir o sistema linfo-hematopoético, destruído pelos quimioterápicos. Com essa abordagem, as células do sistema imune são regeneradas a partir de células tronco hematopoéticas autólogas, não havendo risco de desenvolvimento da doença do enxerto contra o hospedeiro (BURT et al., 2004; HOMSI, 2006)

De modo geral, durante os regimes de condicionamento pré-TCTH, seja para o tratamento de doenças onco-hematológicas ou para o tratamento de doenças autoimunes, os pacientes são submetidos à administração de altas doses de agentes quimioterápicos. Dentre os agentes utilizados no regime de condicionamento pré TCTH alogênico, destaca-se o bussulfano e a ciclofosfamida, focos deste estudo. 


\section{JUSTIFICATIVA E RELEVÂNCIA}

Inúmeras são as doenças que provocam alterações nos processos farmacocinéticos enantiosseletivos. Com ênfase nas doenças inflamatórias, essas alterações se devem principalmente a modificações nas concentrações de proteínas plasmáticas como a albumina, alterações na atividade das enzimas responsáveis pelo metabolismo de fármacos tais como as diferentes isoformas do CYP, alterações nos transportadores de fármacos tais como a Pgp e alterações das funções renal e hepática, entre outras (MACHAVARAM et al., 2013, MORGAN, 2001, 2009; MORGAN et al., 2008).(BOWEN et al., 2013)

A esclerose múltipla (EM) e a esclerose sistêmica (ES) são doenças inflamatórias graves, caracterizadas pela produção de auto-anticorpos e consideradas como incuráveis. Em situações específicas o TCTH é indicado como modalidade terapêutica e seu regime de condicionamento é baseado na utilização de CY (HOLLOMAN et al., 2013; VAN LAAR et al., 2013)

A farmacocinética da CY como mistura enantiomérica encontra-se bem definida na administração intravascular a pacientes portadores de câncer. No entanto, os estudos relativos a enantiosseletividade e a farmacocinética dos metabólitos 4-hidroxiciclofosfamida e carboxifosfamida ainda são escassos e exclusivamente realizados em pacientes portadores de câncer.

Considerando a importância do tratamento com CY no regime de condicionamento pré TCTH, o presente estudo visa avaliar a enantiosseletividade da CY e seus metabólitos em pacientes portadores de EM e ES. A investigação dos pacientes portadores de EM e ES foi proposta considerando que tais pacientes são tratados com o mesmo regime de dosagem de CY e com os mesmos fármacos associados, e considerando que tais doenças são inflamatórias podendo resultar em down-regulation das isoformas do CYP associadas com o metabolismo da CY. Ressalta-se ainda os relatos de seletividade quanto a citocina induzida em função da doença inflamatória (ES e EM) assim como quanto a seletividade da isoforma do CYP que sofre down-regulation em função da citocina induzida (MORGAN, 2001, 2009; MORGAN et al., 2008; RENTON, 2001)

O TCTH para doenças hematológicas exige, entre outros protocolos, o condicionamento com BU, no qual são observados efeitos colaterais indesejáveis que podem eventualmente comprometer o sucesso do transplante (LEE et al., 2012; PATON; COUTINHO; VOLTARELLI, 2000; TRAME et al., 2011). 
A farmacocinética do BU apresenta alta variabilidade interpacientes, especialmente com o uso do BU oral. Atualmente, no Brasil, o BU ainda é administrado de forma oral em muitas situações devido ao alto custo do BU endovenoso. Altas concentrações plasmáticas de BU podem ser tóxicas e causar graves alterações no organismo dos pacientes em regime de condicionamento, além de aumentar o índice de mortalidade. Porém, sua baixa concentração plasmática pode levar à recidiva da doença. Considerando-se o estreito intervalo terapêutico de concentrações plasmáticas do BU (600-900 ng/mL) e sua influência na evolução dos pacientes no pré e pós TCTH (seja no desencadeamento de reações tóxicas, muitas vezes fatais, seja na recidiva da doença), sua monitorização terapêutica, durante o regime de condicionamento, juntamente com a correlação das respostas clínicas, podem ser de extrema importância no tratamento do paciente (OLSON; LOMBARDI; CLARKE, 2011; TAKAMATSU et al., 2005; TRAME et al., 2011). 


\section{Capítulo I}

Validação de dose teste oral do bussulfano empregando farmacocinética individual e populacional em pacientes submetidos ao transplante de células tronco hematopoéticas 


\section{Resumo}

O bussulfano (BU), agente mielossupressor presente nos regimes de condicionamento prétransplante de células tronco hematopoéticas (TCTH), apresenta estreito intervalo terapêutico, alta variabilidade interindividual na farmacocinética e graves reações adversas, dentre elas a síndrome obstrutiva sinusoidal. O regime de dosagem do BU associado com eficácia e minimização de reações adversas deve atingir concentrações plasmáticas médias no estado de equilíbrio $\left(\mathrm{C}^{\mathrm{ss}}\right)$ de 600 a $900 \mathrm{ng} / \mathrm{mL}$. O presente estudo avaliou a administração de uma dose teste de BU oral para a individualização do regime de dosagem, definiu o melhor tempo de coletas esparsas para o monitoramento terapêutico do BU e validou um algoritmo baseado em modelo compartimental e farmacocinética populacional em pacientes submetidos ao TCTH. Foram investigados 30 pacientes portadores de doenças hematológicas com idade de 3-58 anos. No dia anterior ao início do regime de condicionamento, após a administração de dose única oral de $0,25 \mathrm{mg} / \mathrm{Kg}$ de BU, foram coletadas amostras seriadas de sangue no período de 0-6h. O BU foi quantificado nas amostras de plasma empregando LC-MS/MS. A resposta do detector foi linear no intervalo de concentrações plasmáticas de 5-2500 ng/mL ( $>0$ 0,99), com corridas cromatográficas de 3 min. Para a confirmação da $\mathrm{C}^{\mathrm{ss}}$, foram realizadas coletas seriadas de sangue no intervalo entre a $5^{\mathrm{a}}$ e $6^{\mathrm{a}}$ doses administradas $(\sim 1 \mathrm{mg} / \mathrm{Kg}$ a cada $6 \mathrm{~h}$, durante 4 dias). A análise farmacocinética foi realizada com auxílio do programa WinNonlin. O emprego da dose teste de BU em 30 pacientes resultou em valores de clearance variando de 3,2-29,9 L/h. Os valores de clearance observados entre a $5^{\mathrm{a}}$ e $6^{\mathrm{a}}$ doses variaram de 2,9-18,6 L/h. Os coeficientes de variação obtidos entre os valores de clearance avaliados na dose teste e na quinta dose foram $\leq 30 \%$, exceto para 5 pacientes. Ressalta-se, alta variabilidade nos valores de clearance entre os pacientes tanto durante o uso da dose teste (CV 42,1\%) quanto no intervalo entre a $5^{\mathrm{a}}$ e $6^{\mathrm{a}}$ doses (CV 33,0\%). Dentre os 21 pacientes que receberam a dose de $\mathrm{BU}$ de acordo com a dose baseada no clearance calculado na dose teste, $67 \%$ apresentaram concentrações no estado de equilíbrio (entre a $5^{\mathrm{a}}$ e $6^{\mathrm{a}}$ doses) dentro do intervalo de concentrações alvo de $600-900 \mathrm{ng} / \mathrm{mL}$ e $33 \%$ dos pacientes apresentaram concentrações pouco acima do intervalo terapêutico. Em relação aos 9 pacientes que não receberam as doses de $\mathrm{BU}$ de acordo com os valores de clearance calculados na dose teste, apenas 33\% deles mostraram valores de $C^{\text {ss }}$ dentro do intervalo de concentrações alvo de 600-900 ng/mL, 55\% deles apresentaram concentrações acima de $900 \mathrm{ng} / \mathrm{mL}$ e apenas 1 paciente apresentou concentração abaixo de $600 \mathrm{ng} / \mathrm{mL}$. Não foram observadas associação entre os parâmetros farmacocinéticos do BU e a evolução clínica dos pacientes. 
A otimização do esquema de coletas de amostras de sangue e o desenvolvimento do algoritmo para o ajuste de dosagem do BU foram realizados com base em um modelo previamente publicado considerando farmacocinética de primeira ordem e modelo monocompartimental. Os procedimentos de validação interna e externa do modelo farmacocinético populacional foram realizados usando o programa computacional PopED (Population Experimental Design) versão 2.1. com o critério ED (ED-optimality) para a otimização do desenho experimental. O clearance aparente e o volume de distribuição aparente foram considerados como parâmetros de interesse. O esquema de coletas esparsas para o monitoramento terapêutico do $\mathrm{BU}$ e o algoritmo baseado em farmacocinética populacional foram selecionados com base nos desvios dos valores de área sob a curva concentração plasmática do $\mathrm{BU}$ vs tempo no intervalo de dose $\left(\mathrm{AUC}^{0-6}\right)$ previstos à partir de cenários de simulações. O esquema de coletas esparsas com não mais de cinco amostras por paciente $(\mathrm{t}=0,5 ; 2,25 ; 3 ; 4$ e 5 horas após a dose) demonstrou ser suficiente para a caracterização da farmacocinética do BU. A exposição ao BU oral foi descrita com precisão empregando o modelo monocompartimental com as covariáveis peso ideal ajustado e valores séricos de alanina transferase. Os resultados mostram uma correlação linear entre a eliminação do fármaco traduzida pelos valores de clearance aparente com o peso ideal ajustado do paciente e a função hepática. $\mathrm{O}$ uso do algoritmo baseado em modelo paramétrico de dosagem contribui para a melhoria considerável do perfil de segurança e eficácia dos pacientes submetidos ao tratamento com BU para o TCTH. 
1. Introdução 
O bussulfano (BU) é um agente alquilante bifuncional, muito utilizado nos regimes de condicionamento para o transplante de células tronco hematopoéticas (TCTH), no tratamento de leucemias, mieloma múltiplo, linfomas não-Hodghin, entre outras doenças (GALAUP; PACI, 2013).

Nos regimes de condicionamento para o $\mathrm{TCTH}$, o tratamento preconizado com $\mathrm{BU}$ consiste em 16 doses de $1 \mathrm{mg} / \mathrm{Kg}$, administradas oralmente ou, $0,8 \mathrm{mg} / \mathrm{Kg}$ na forma endovenosa, de 6 em 6 horas, durante 4 dias ou em dose única diária endovenosa de 3,2 $\mathrm{mg} / \mathrm{kg}$ durante 4 dias (ANDERSSON et al., 2002; MALÄR et al., 2011; MCCUNE; GIBBS; SLATTERY, 2000; RUSSELL et al., 2002; TRAME et al., 2011).

Estudos da farmacocinética do BU oral (doses de $1 \mathrm{mg} / \mathrm{Kg}$ ) em pacientes com doenças onco-hematológicas mostram que a concentração plasmática máxima $\left(\mathrm{C}_{\max }\right)$ varia de $609 \pm$ 225 a $1730 \pm 845 \mathrm{ng} / \mathrm{mL}$ e que o tempo para a observação do $C_{\max }\left(t_{\max }\right)$ ocorre em aproximadamente 1,5 a 2,5 horas. A meia-vida de eliminação $\left(t_{1 / 2}\right)$ do BU é de 2,3 a 2,8 horas. O BU atravessa a barreira hematoencefálica e se distribui no fluido cérebro-espinhal, com aproximadamente a mesma concentração presente no plasma, o que talvez explique as crises convulsivas dos pacientes (CIUREA; ANDERSSON, 2009; MCCUNE; GIBBS; SLATTERY, 2000).

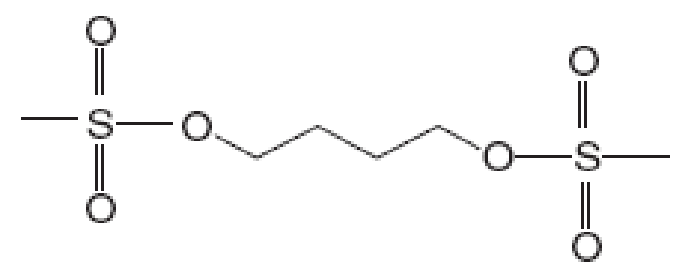

Figura 1. Estrutura química do bussulfano (CHOW et al., 1997)

O BU é metabolizado pela conjugação com a glutationa mediada pela glutationa-Stransferase (GST) seguida por oxidação pelo CYP3A4 (BERI et al., 2010; JOHNSONDAVIS et al., 2010; MCCUNE; GIBBS; SLATTERY, 2000; NATH; SHAW, 2007; NATH et al., 2008). Os principais metabólitos do BU são o 3-hidroxi sulfolano e o 1-óxido de tetra hidrotiofeno, os quais não contribuem significativamente na eficácia ou na toxicidade do fármaco (MCCUNE; GIBBS; SLATTERY, 2000). Em humanos, a isoforma GSTA1 é a principal responsável pela conjugação da glutationa com o BU (80-90\%), embora outras isoformas (GSTM1-1, GSTP1-1, GSTA1-2 e GSTA2-2) também sejam capazes, ainda que em menor extensão de catalisar esta reação (CZERWINSKI; GIBBS; SLATTERY, 1996). Autores sugerem que os polimorfismos nos genes GSTA1, GSTM1 ou GSTP1, que são genes 
que codificam as GST $\alpha$, GST $\mu$ e GSTp, respectivamente, poderiam também influenciar a farmacocinética do BU (JOHNSON et al., 2008; KIM et al., 2011; NATH et al., 2008).

A farmacocinética do BU apresenta grande variabilidade interpacientes. A absorção intestinal do BU pode ocorrer de forma errática e sua alta concentração plasmática pode ser tóxica e causar graves alterações no organismo dos pacientes em regime de condicionamento, além de aumentar o índice de mortalidade. Porém, sua baixa concentração plasmática pode levar à recidiva da doença e rejeição do enxerto (GEDDES et al., 2008; TAKAMATSU et al., 2005).

$\mathrm{Na}$ tentativa de reduzir a variabilidade da exposição ao BU, foram desenvolvidas formulações endovenosas, as quais foram disponibilizadas no Brasil a partir de março de 2012. Geddes et al. (2008) observaram redução na variabilidade na farmacocinética do BU endovenoso quando comparada ao BU oral. Porém, Nath et al. (2008) relatam que a variação na farmacocinética do BU oral é comparável com a do BU endovenoso. Mais recentemente, alguns autores relatam que considerável variabilidade inter-individual na farmacocinética do BU endovenoso persiste em adultos e, em um grau ainda maior, em crianças, reforçando a necessidade do monitoramento terapêutico do BU mesmo durante a utilização de sua formulação endovenosa (BARTELINK et al., 2009, 2012).

O BU é um fármaco de estreito intervalo terapêutico, 600 a $900 \mathrm{ng} / \mathrm{mL}$, concentrações plasmáticas que resultam no sucesso do transplante em 74 a $96 \%$ dos pacientes (GEDDES et al., 2008; MCCUNE; GIBBS; SLATTERY, 2000). A alta exposição ao BU está relacionada à síndrome obstrutiva sinusoidal (SOS), enquanto a sua baixa exposição está atribuída à recaída da doença e rejeição do enxerto (GALAUP; PACI, 2013; GEDDES et al., 2008; KIM et al., 2009; NATH et al., 2008; REZVANI et al., 2013; TAKAMATSU et al., 2005). A relação entre a concentração plasmática média no estado de equilíbrio $\left(\mathrm{C}^{\mathrm{sS}}\right)$ do $\mathrm{BU}$ e a manifestação da SOS mostra maiores valores de $\mathrm{C}^{\mathrm{SS}}$ nos pacientes que desenvolvem SOS, quando comparados aos pacientes que não apresentam esta reação adversa (MCCUNE; GIBBS; SLATTERY, 2000; TRAME et al., 2011). Dentre as possíveis complicações inerentes aos altos valores de $\mathrm{C}^{\mathrm{ss}}$ do BU, além da SOS, podem-se destacar as alterações gastrointestinais, crises convulsivas, cardiotoxicidade, lesões pulmonares, cutâneas e hepáticas (PERKINS et al., 2012).

A confirmação da associação entre a $C^{\mathrm{sS}}$ do $\mathrm{BU}$ e a resposta clínica dos pacientes submetidos ao TCTH incentivou a utilização da monitorização terapêutica (CIUREA; ANDERSSON, 2009; MCCUNE et al., 2012). 
Devido a necessidade de rápidas determinações das concentrações plasmáticas do BU, além das dificuldades em estimar seu clearance durante o monitoramento terapêutico, na tentativa de controlar a variabilidade da farmacocinética do BU e sua toxicidade, Bleyzac et al. (2001) instituíram um esquema de utilização de uma dose teste de BU $(0,5 \mathrm{mg} / \mathrm{Kg})$ com a finalidade de ajustar as doses do condicionamento com base nos valores de clearance obtidos a partir da dose teste. Os autores observaram correlação entre os valores esperados e observados de AUC do BU e, portanto, a viabilidade do uso de doses testes como individualização terapêutica. Lindley et al. (2004) relatam que a individualização do regime de dosagem do BU com base nos valores de clearance avaliados na dose teste de $0,25 \mathrm{mg} / \mathrm{kg}$ ou durante a primeira dose do tratamento $(1 \mathrm{mg} / \mathrm{kg})$ resulta em melhores estimativas do que o estabelecimento do regime de dosagem apenas com base no peso corporal. No entanto, os autores ressaltam que a ampla variabilidade intraindividual na farmacocinética do BU administrado por via oral exige a monitorização terapêutica durante todo o tratamento.

Com o desenvolvimento da formulação endovenosa, Kletzel; Jacobsohn; Duerst (2006) propuseram o uso da dose teste de $\mathrm{BU}$ endovenoso e o tratamento com dose única diária durante 4 dias. Em um estudo também com BU endovenoso, Beri et al. (2010) observaram significante correlação entre a AUC do BU obtida na primeira dose e nas subseqüentes dosagens, em pacientes que haviam recebido dose teste de BU.

O uso da dose teste de BU está bem descrito quando administrada como BU endovenoso, porém dados com o BU oral são escassos e de extrema importância considerando a baixa acessibilidade do Brasil à sua formulação endovenosa, devido ao alto custo do medicamento.

Além disso, o monitoramento terapêutico convencional para quimioterápicos está limitado pela variabilidade inter e intraindividual (MCCUNE; HOLMBERG, 2009). Dessa forma, atualmente, muitos centros utilizam modelos de farmacocinética populacional (popPK). Estes modelos de popPK apresentam muitas vantagens em relação aos métodos tradicionais, pois apresentam potencial para individualização e simulação de regimes de dosagem de fármacos sob diferentes condições, como por exemplo, em estados de doenças, na combinação de medicamentos, entre outros fatores. Os modelos de popPK quantificam a variabilidade inter e intraindividual, processo crucial para se obter uma descrição precisa de um paciente dentro de uma população (JOERGER, 2012).

Já existem modelos de popPK para o BU oral e endovenoso descritos na literatura (NGUYEN, 2008; SANDSTRÖM et al., 2001; TRAME et al., 2011) porém, os tempos de coleta de amostras de sangue necessárias para o monitoramento terapêutico, até os dias atuais, não estão definidos (MCCUNE et al., 2012). Dessa forma, o presente trabalho avaliou a 
viabilidade e segurança da utilização da dose teste de BU oral como forma de individualização terapêutica e propôs a definição de um esquema de coletas ideal para amostragem farmacocinética e monitoramento terapêutico, além do desenvolvimento de um algoritmo de dosagem baseado em modelo para BU oral em pacientes submetidos ao TCTH. 
2. Objetivos 


\section{Objetivo Geral}

Avaliar a utilização da dose teste oral, definir um esquema de coletas ideal na individualização do regime de dosagem do BU em pacientes submetidos ao TCTH e associar as resultantes concentrações plasmáticas médias no estado de equilíbrio do BU com parâmetros clínicos (remissão da doença e efeitos adversos).

\section{Objetivos Específicos}

- Desenvolver e validar micrométodo de análise do BU em plasma empregando LC-MS/MS;

- Investigar a disposição cinética do BU oral em pacientes submetidos ao TCTH com o objetivo de individualização do regime de dosagem;

- Investigar a influência dos polimorfismos da glutationa-S-transferase na farmacocinética do $\mathrm{BU}$;

- Avaliar se a dose proposta de BU com base na farmacocinética da dose teste resulta em concentrações plasmáticas médias no estado de equilíbrio dentro do intervalo de referência (600-900 ng/mL);

- Associar as concentrações plasmáticas médias no estado de equilíbrio do BU com parâmetros clínicos em pacientes submetidos ao TCTH;

- Definir um esquema ideal de coletas esparsas para amostragem farmacocinética e monitoramento terapêutico;

- Desenvolver um algoritmo de dosagem baseado em modelo de farmacocinética populacional compartimental para BU oral em pacientes submetidos ao TCTH. 
3. Casuística e Métodos 


\subsection{Casuística e Protocolo Clínico}

O estudo foi aprovado pelo Comitê de Ética em Pesquisa do Hospital das Clínicas da Faculdade de Medicina de Ribeirão Preto da Universidade de São Paulo (HCFMRP-USP), de acordo com o Processo $n^{\circ} 911 / 2010$ (ANEXO 1). Os pacientes receberam explicação detalhada dos procedimentos e foram incluídos no estudo após a assinatura do Termo de Consentimento Livre e Esclarecido (ANEXO 2). Foi garantida a liberdade ao paciente de recusar sua participação ou retirar seu consentimento, em qualquer fase da pesquisa, sem penalização ou prejuízo ao seu tratamento.

Foram investigados 30 pacientes que foram submetidos ao TCTH na Unidade de Transplante de Medula Óssea do Hospital das Clínicas da Faculdade de Medicina de Ribeirão Preto (HCFMRP-USP). Treze pacientes receberam o regime de condicionamento constituído por BU (1mg/kg 6/6 h durante quatro dias) e CY $(60 \mathrm{mg} / \mathrm{kg} / \mathrm{d}$ durante dois dias após finalizado o tratamento com BU), quinze pacientes foram condicionados com BU $(1 \mathrm{mg} / \mathrm{kg} 6 / 6$ $\mathrm{h}$ durante quatro dias) e fludarabina $\left(30 \mathrm{mg} / \mathrm{m}^{2}\right.$ durante quatro dias) e os demais foram incluídos no protocolo de condicionamento Tandem, constituído por fludarabina $\left(30 \mathrm{mg} / \mathrm{m}^{2}\right.$ durante quatro dias), citarabina $\left(2 \mathrm{~g} / \mathrm{m}^{2}\right.$ durante quatro dias), mitoxantrone $\left(10 \mathrm{mg} / \mathrm{m}^{2}\right.$ durante quatro dias), BU (1mg/kg 6/6 h durante 2 dias) e CY $(80 \mathrm{mg} / \mathrm{kg} / \mathrm{d}$ durante dois dias após finalizado o tratamento com BU).

Os pacientes investigados receberam uma dose teste de $0,25 \mathrm{mg} / \mathrm{kg}$ de $\mathrm{BU}$ oral (Myrelan $^{\circledR}$, GlaxoSmithKline, Rio de Janeiro) um dia antes do início do regime de condicionamento constituído por doses de aproximadamente $1 \mathrm{mg} / \mathrm{kg} / 6 \mathrm{~h}$ de $\mathrm{BU}$, durante 4 dias. As amostras seriadas de sangue com volumes de aproximadamente $1 \mathrm{~mL}$ foram coletadas após a administração da dose teste nos tempos $0,15,30,45,60,75,90,105,120$, 135, 150, 180, 240, 300 e 360 minutos, em seringas com heparina (Liquemine ${ }^{\circledR} 5000$ UI, Roche Produtos Químicos e Farmacêuticos AS, São Paulo, SP). As amostras de plasma foram imediatamente analisadas para a determinação dos parâmetros farmacocinéticos e a dose foi individualizada de acordo com o clearance aparente do BU obtido na dose teste. Amostras seriadas de sangue (0-6h) com volumes de $1 \mathrm{~mL}$ também foram coletadas após a administração da quinta dose de BU durante o condicionamento para verificar se a $\mathrm{C}^{\mathrm{ss}}$ do $\mathrm{BU}$ encontrava-se dentro do intervalo terapêutico de 600-900 ng/mL, conforme a Tabela 2. 
Tabela 2. Esquema da dose teste e regime de condicionamento do BU

\begin{tabular}{cccccc}
\hline \hline Protocolo & Dose teste & dia -7 & dia -6 & dia -5 & dia -4 \\
\hline BU & $\mathrm{BU}$ & $1^{\mathrm{a}}-4^{\mathrm{a}}$ doses & $5^{\mathrm{a}}-8^{\mathrm{a}}$ doses & $9^{\mathrm{a}}-12^{\mathrm{a}}$ doses & $13^{\mathrm{a}}-16^{\mathrm{a}}$ doses \\
\hline \hline
\end{tabular}

As Tabelas 3, 4 e 5 mostram, respectivamente, os dias de administração do BU nos protocolos BUCY (BU e CY), FLUBU (fludarabina e BU) e Tandem (fludarabina, citarabina, mitoxantrone, $\mathrm{BU}$ e $\mathrm{CY}$ ).

Tabela 3.Protocolo BUCY

\begin{tabular}{cccccccccc}
\hline \hline & -8 & -7 & -6 & -5 & -4 & -3 & -2 & -1 & 0 \\
\hline $\begin{array}{c}\text { BU oral } \\
1 \mathrm{mg} / \mathrm{kg} / 6 \mathrm{~h}\end{array}$ & Dose teste & $\mathrm{X}$ & $\mathrm{X}$ & $\mathrm{X}$ & $\mathrm{X}$ & & & & \multirow{2}{*}{ TCTH } \\
$\begin{array}{c}\mathrm{CY} \\
60 \mathrm{mg} / \mathrm{kg}\end{array}$ & & & & & & $\mathrm{X}$ & $\mathrm{X}$ & & \\
\hline \hline
\end{tabular}

Tabela 4. Protocolo FLUBU

\begin{tabular}{cccccccc}
\hline \hline & -6 & -5 & -4 & -3 & -2 & -1 & 0 \\
\hline $\begin{array}{c}\text { BU oral } \\
1 \mathrm{mg} / \mathrm{kg} / 6 \mathrm{~h}\end{array}$ & Dose teste & $\mathrm{X}$ & $\mathrm{X}$ & $\mathrm{X}$ & $\mathrm{X}$ & & TCTH \\
\hline $\begin{array}{c}\text { fludarabina } \\
30 \mathrm{mg} / \mathrm{kg} \mathrm{EV}\end{array}$ & & $\mathrm{X}$ & $\mathrm{X}$ & $\mathrm{X}$ & $\mathrm{X}$ & & \\
\hline \hline
\end{tabular}

Tabela 5. Protocolo Tandem

\begin{tabular}{|c|c|c|c|c|c|c|c|c|c|c|}
\hline & -17 & $-16 a-13$ & -7 & -6 & -5 & -4 & -3 & -2 & -1 & 0 \\
\hline $\begin{array}{c}\text { fludarabina } \\
30 \mathrm{mg} / \mathrm{kg} \mathrm{EV}\end{array}$ & & $\mathrm{X}$ & & & & & & & & \multirow{5}{*}{ ТCTH } \\
\hline $\begin{array}{l}\text { mitoxantrone } \\
10 \mathrm{mg} / \mathrm{m}^{2} \mathrm{EV}\end{array}$ & & $\mathrm{X}$ & & & & & & & & \\
\hline $\begin{array}{l}\text { citarabina } \\
2 \mathrm{~g} / \mathrm{m}^{2} \mathrm{EV}\end{array}$ & & $X$ & & & & & & & & \\
\hline $\begin{array}{c}\text { BU oral } \\
1 \mathrm{mg} / \mathrm{kg} / 6 \mathrm{~h}\end{array}$ & Dose teste & & $X$ & $X$ & $X$ & $X$ & & & & \\
\hline $\begin{array}{c}\mathrm{CY} \\
80 \mathrm{mg} / \mathrm{kg} / \mathrm{dia}\end{array}$ & & & & & & & $X$ & $X$ & & \\
\hline
\end{tabular}




\subsection{Análise do BU em plasma por LC-MS/MS}

\subsubsection{Síntese do padrão interno}

O padrão interno utilizado na análise de BU em plasma, 1,6-bis-(metanosulfoniloxi) hexano, foi sintetizado no laboratório de Química Farmacêutica da Faculdade de Ciências Farmacêuticas de Ribeirão Preto (FCFRP-USP), a partir do 1,6-hexanodiol e cloreto de metanosulfonila, de acordo com o procedimento descrito por Bleyzac; Barou; Aulagner (2000) e modificado pela adição de uma etapa de purificação usando coluna de sílica e hexano/acetato de etila $(1: 1, \mathrm{v} / \mathrm{v})$ como eluente. $O$ solvente foi evaporado usando rotaevaporador e o produto foi obtido como cristais brancos. A estrutura e pureza do produto foi confirmada (ANEXO 3) por ressonância magnética nuclear de ${ }_{1} \mathrm{H}$ (RMN) em clorofórmio deuterado $\left(\mathrm{CDCl}_{3}\right)$, usando instrumento de 300MHz (Bruker Avance DPX 300, Germany). Os deslocamentos químicos (d) foram: 1.4-1.5 $\left(-\mathrm{OCH}_{2} \mathrm{CH}_{2}\right.$, multipleto), 1.7-1.8 $\left(-\mathrm{CH}_{2}\right.$, tripleto) e $4.2\left(-\mathrm{CH}_{2} \mathrm{O}\right.$, tripleto).

\subsubsection{Soluções padrão e reagentes}

A solução estoque de BU (Sigma, St Louis, MO, EUA) foi preparada em acetato de etila na concentração de $1 \mathrm{mg} / \mathrm{mL}$. Posteriormente, a solução foi diluída para obtenção das concentrações de $20 ; 10 ; 4 ; 2 ; 2 ; 0,5 ; 0,4 ; 0,2$ e $0,04 \mu \mathrm{g} / \mathrm{mL}$ de acetato de etila.

A solução de 1,6-bis-(metanosulfoniloxi) hexano foi preparada na concentração de 10 $\mu \mathrm{g} / \mathrm{mL}$ de acetonitrila.

Os solventes utilizados no preparo das soluções, processo de extração do BU e os constituintes da fase móvel do sistema HPLC foram obtidos da Merck (Darmstadt, Alemanha) como grau cromatografia. A água passou pelo processo de purificação através do sistema Milli-Q Plus (Millipore, Bedford, MA, EUA).

\subsubsection{Separação cromatográfica e condições do sistema LC-MS/MS}

O método de análise do BU em plasma foi desenvolvido e validado empregando LCMS/MS (cromatografia líquida de alta eficiência com detecção por espectrometria de massas), 
constituído por bomba LC10AD e forno para acondicionamento de coluna CTO-10AS, provenientes da Shimadzu (Kyoto, Japão).

O BU foi separado na coluna de fase reversa Nova-Pak $\mathrm{C}_{18}$ (Waters, Irlanda; 150x3,9 $\mathrm{mm}$; tamanho de partícula de $4 \mu \mathrm{m}$ ) mantida a $25^{\circ} \mathrm{C}$ e com a fase móvel constituída por mistura de solução $1 \mathrm{mM}$ de acetato de amônio/metanol (60:40, v/v) adicionada de 0,1\% de ácido fórmico, na vazão de $1 \mathrm{~mL} / \mathrm{min}$. O efluente da coluna cromatográfica foi dirigido para o Espectrômetro de Massas (MS/MS) triplo quadrupolo Quattro Micro LC (Micromass, Manchester, Reino Unido), na vazão de $200 \mu \mathrm{L} / \mathrm{min}$. A análise por espectrometria de massas sequencial foi executada no modo eletronebulização positivo com voltagem do capilar de 3 $\mathrm{kV}$, voltagem do cone de $20 \mathrm{~V}$ e energia de colisão de $13 \mathrm{eV}$. A temperatura da fonte e a temperatura de dessolvatação foram mantidas a $120^{\circ}$ e $200^{\circ} \mathrm{C}$, respectivamente. $\mathrm{O}$ nitrogênio foi utilizado como gás de nebulização na vazão de 400 L/h e o gás argônio, empregado como gás de colisão, foi mantido na pressão de aproximadamente $1,72 \times 10^{-3} \mathrm{mbar}$.

As condições de otimização do MS-MS foram obtidas por infusão direta das soluções padrão de BU $(150 \mu \mathrm{g} / \mathrm{mL})$ preparadas na fase móvel e introduzidas com bomba de infusão na vazão de $20 \mu \mathrm{L} / \mathrm{min}$. As análises foram executadas no modo MRM (Multiple Reaction Monitoring).

As moléculas protonadas $[\mathrm{M}+\mathrm{H}]^{+}$e seus respectivos íons-produtos foram monitorados nas transições 264>151 para o BU e 292>83 para o do padrão interno, 1,6-bis(metanosulfoniloxi) hexano.

A aquisição de dados e a quantificação das amostras foram realizadas utilizando o programa MassLynx, versão 4,1 (Micromass, Manchester, Reino Unido).

\subsubsection{Procedimento de preparo das amostras}

Alíquotas de $200 \mu \mathrm{L}$ de plasma foram enriquecidas com $25 \mu \mathrm{L}$ da solução de padrão interno [1,6-bis- (metanosulfoniloxi) hexano] e $5 \mathrm{~mL}$ da mistura de acetato de etila/clorofórmio $(75: 25 ; \mathrm{v} / \mathrm{v})$. Os tubos foram agitados em agitador horizontal (agitador de mesa reciprocante modelo MA 139/CFT, Marconi) durante 30 minutos e, a seguir, centrifugados (centrífuga refrigerada Beckman, modelo TJ-6) a $5^{\circ} \mathrm{C}, 2000 \mathrm{rpm}$, por 10 minutos. As fases orgânicas foram transferidas para tubos cônicos e evaporadas até a secura pelo sistema de evaporação a vácuo (RCT90 e modo RC10.22 da Jouan AS, St Herblain, França). Os resíduos foram retomados em $200 \mu \mathrm{L}$ de fase móvel, agitados por 5 segundos e 
- mant: 1

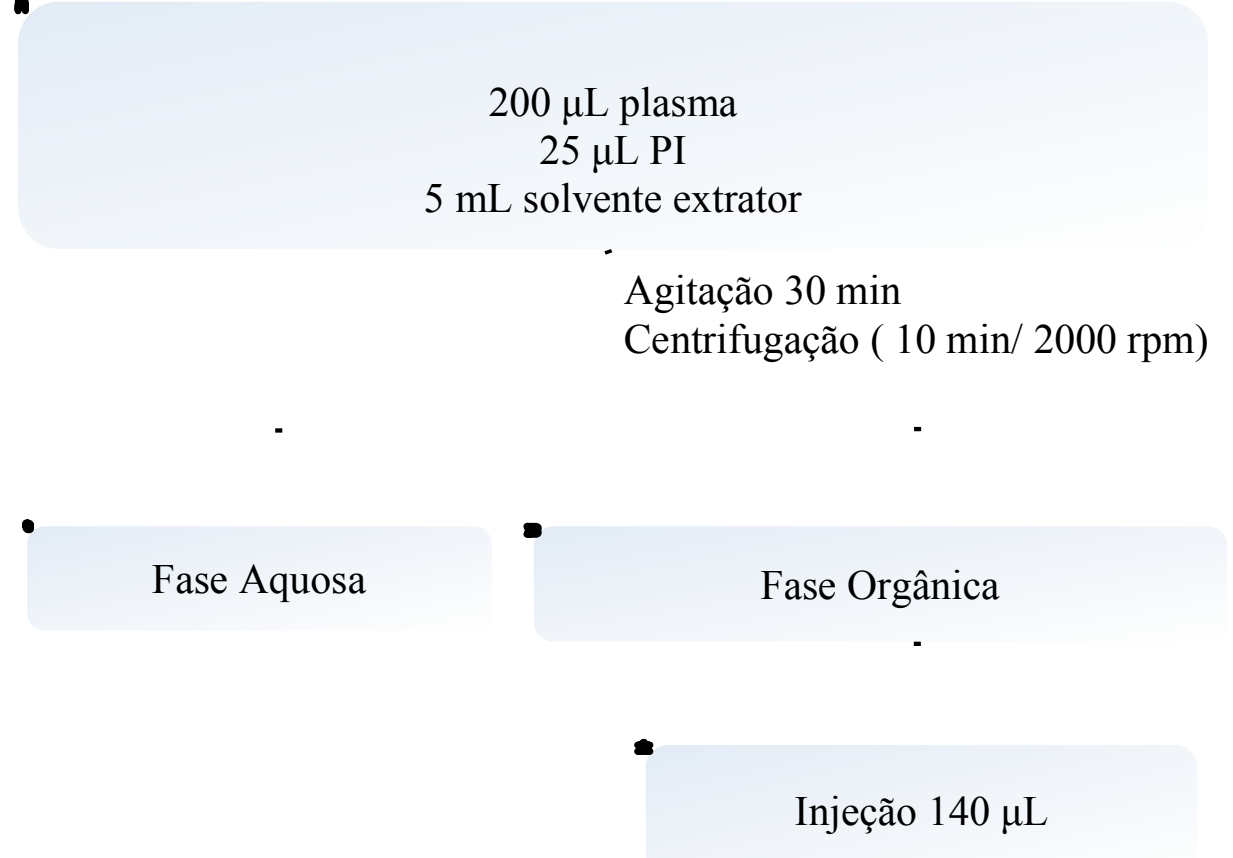

Figura 2. Procedimento de extração líquido-líquido do BU em plasma humano.

\subsubsection{Determinação do efeito matriz}

O efeito da matriz foi avaliado através da comparação direta das áreas dos picos do BU e do padrão interno, injetados diretamente na fase móvel, com as áreas dos picos obtidas de soluções padrão $(62,5 ; 1000$ e $2000 \mathrm{ng}$ do BU/ mL de plasma) adicionadas em extratos de plasma branco originários de 6 diferentes voluntários (procedimento descrito no item 3.2.4).

\subsubsection{Validação do método análise do BU}

O método para a análise de BU em plasma humano foi validado de acordo com as recomendações da ANVISA (Agência Nacional de Vigilância Sanitária - Resolução nº 899, 29 de maio de 2003) para validação de métodos bioanalíticos. O processo de validação inclui todos os procedimentos requeridos para demonstrar que o método desenvolvido é compatível com a aplicação em estudos de disposição cinética. 


\subsubsection{Linearidade}

As curvas de calibração foram realizadas em duplicatas utilizando alíquotas de $200 \mu \mathrm{L}$ de plasma branco enriquecidas com $25 \mu \mathrm{L}$ de cada solução padrão de BU e $25 \mu \mathrm{L}$ da solução de PI, sendo submetidas ao processo especificado anteriormente (item 3.2.4). Foram avaliadas amostras em oito diferentes concentrações plasmáticas de BU, construídas no intervalo de $5 \mathrm{a}$ $2500 \mathrm{ng}$ de BU/mL de plasma. As equações de regressão linear e os coeficientes de correlação foram obtidos das razões de áreas padrão/padrão interno plotadas em função das respectivas concentrações plasmáticas.

\subsubsection{Limite inferior de quantificação}

O limite inferior de quantificação (LIQ) foi definido como a menor concentração quantificada com precisão de até $20 \%$ e inexatidão de $\pm 20 \%$. Foram avaliadas sextuplicatas de amostras enriquecidas com BU em concentrações decrescentes àquelas empregadas na curva de calibração.

\subsubsection{Recuperação}

A recuperação do BU foi avaliada, em sextuplicata, nas concentrações de 2000; 1000 e $62,5 \mathrm{ng}$ de BU por $\mathrm{mL}$ de plasma, seguindo o protocolo descrito no item 3.2.4. A recuperação foi calculada através da comparação das áreas dos picos oriundos das amostras extraídas com as áreas obtidas na análise de soluções padrão adicionadas aos extratos de plasma branco, representando $100 \%$ de recuperação.

\subsubsection{Precisão e exatidão}

A precisão e a exatidão do método foram avaliadas através dos estudos intra e interensaios. As amostras de plasma branco enriquecidas com BU foram avaliadas em três concentrações: alta (2000 ng de BU por mL de plasma humano), média (1000 ng/ mL) e baixa $(62,5 \mathrm{ng} / \mathrm{mL})$. As soluções foram separadas em alíquotas e armazenadas a $-20{ }^{\circ} \mathrm{C}$ até a análise.

Para a avaliação da precisão e exatidão intraensaio foram analisadas 6 alíquotas de cada amostra através de uma única curva de calibração. Para que o método possa ser referido como 
preciso, o coeficiente de variação dos resultados obtidos na análise deve ser igual ou inferior a $15 \%$. A avaliação da precisão entre ensaios foi realizada através do cálculo do coeficiente de variação dos resultados obtidos e para que o método possa ser referido como preciso, o coeficiente de variação deve ser igual ou inferior a $15 \%$.

A exatidão é expressa pela relação entre a concentração média determinada experimentalmente e a concentração teórica correspondente, representada pela equação:

\section{Exatidão $=$ concentração média experimental $\times 100$ concentração teórica}

\subsubsection{Estabilidade}

Para verificar a estabilidade após ciclos de congelamento e descongelamento, amostras de plasma enriquecidas nas concentrações determinadas como alta $(2000 \mathrm{ng} / \mathrm{mL})$ e baixa $(62,5$ $\mathrm{ng} / \mathrm{mL}$ ) nos estudos de precisão e exatidão, em sextuplicatas, foram congeladas a $-20^{\circ} \mathrm{C}$ e após $24 \mathrm{~h}$ foram descongeladas e novamente congeladas por $24 \mathrm{~h}$. Este ciclo foi repetido por mais duas vezes, analisando-se os fármacos após o término do terceiro ciclo.

A estabilidade de curta duração foi avaliada utilizando-se amostras de plasma, em sextuplicatas para cada concentração citada anteriormente, que foram descongeladas e mantidas em temperatura ambiente por $5 \mathrm{~h}$. Os resultados dos testes de estabilidade foram comparados com os resultados de amostras recém preparadas, sendo aceitos \% de desvio com valores $\leq 15 \%$.

Para avaliação da estabilidade pós-processamento, as amostras foram mantidas no auto-injetor a $16^{\circ} \mathrm{C}$ por um período de 12 horas, sendo então injetadas no sistema cromatográfico.

Os resultados foram comparados com aqueles obtidos com as amostras recémpreparadas e foram expressos em porcentagem de desvio.

\subsection{Análise dos polimorfismos do gene GST e presença ou deleção do gene GSTM1}

Foram genotipadas amostras para os polimorfismos GSTP1 e GSTA1 no gene GST e a presença ou deleção do gene GSTM1 nos 30 pacientes investigados. As análises foram realizadas no Laboratório de Hematologia da Faculdade de Medicina de Ribeirão Preto da 
Universidade de São Paulo e a genotipagem foi realizada na Fundação Hemocentro de Ribeirão Preto. O DNA dos pacientes incluídos no estudo foi extraído da camada leucocitária do sangue através da técnica de salting out (MILLER; DYKES, POLESKY, 1988). A quantificação do DNA foi realizada por espectrofotometria (NanoVue Plus Spectrophotometer $^{\circledR}$, GE Healthcare UK Limited, Reino Unido). Alíquotas de soluções de $1000 \mu \mathrm{L}$, na concentração de $100 \mathrm{ng}$ de $\mathrm{DNA} / \mu \mathrm{L}$ de água, foram armazenadas em tubos Eppendorf e mantidas a $-20^{\circ} \mathrm{C}$ até a análise.

\subsubsection{GSTP1}

A identificação dos polimorfismos de base única ( $S N P$ - single nucleotide polymorfism) $313 \mathrm{~A}>\mathrm{G}$ (presente no exon 5) do gene GSTP (cromossomo 11) foi realizada por discriminação alélica através da reação da polimerase em cadeia em tempo real (RT-PCR), utilizando os ensaios do tipo TaqMan ${ }^{\circledR}$, Drug Metabolism Genotyping Assays (Applied Biosystems; Foster City, CA, EUA).

As sondas utilizadas nos ensaios foram desenhadas pela Applied Biosystems, conforme identificação na Tabela 6. A amplificação do PCR foi realizada utilizando o equipamento Roche LightCycler ${ }^{\circledR}$ 480, programa versão 1,5 (Roche Diagnostics GmbH, Mannheim, Alemanha).

O TaqMan ${ }^{\circledR}$ PCR foi realizado, conforme instruções do fabricante, para um volume final de $10 \mu \mathrm{L}$ contendo $1 \mu \mathrm{L}$ de DNA genômico $(30 \mathrm{ng} / \mu \mathrm{L}), 5 \mu \mathrm{L}$ de Master Mix (2X), 0,5 $\mu \mathrm{L}$ de $\operatorname{Taqman}^{\circledR}(20 \mathrm{X})$ e 3,5 $\mu \mathrm{L}$ de água Milli-Q.

A termociclagem consistiu de um ciclo de desnaturação inicial a $95^{\circ} \mathrm{C}$ por 10 minutos e 40 ciclos de amplificação $\left(95^{\circ} \mathrm{C}\right.$ por 10 segundos e a $60^{\circ} \mathrm{C}$ por 1 minuto), seguidos de um ciclo de resfriamento a $37^{\circ} \mathrm{C}$ por 10 segundos. A análise de controles negativos foi realizada em cada corrida e a discriminação alélica foi realizada pela medida da fluorescência final (Endpoint Genotying Analysis) dos cromóforos $\mathrm{VIC}^{\circledR}$ e $\mathrm{FAM}^{\circledR}$ ligados no final 5' da sonda Taqman $^{\circledR}$ e analisados utilizando o programa computacional do fabricante.

Tabela 6. Sonda utilizada no ensaio de genotipagem para GSTP1

\begin{tabular}{cccc}
\hline \hline Gene & Alelo & Polimorfismo & Sequência \\
\hline GSTP1 & A $/ \mathrm{G}$ & $313 \mathrm{~A}>\mathrm{G}$ & CGTGGAGGACCTCCGCTGCAAATAC[A/G]TCTCCCTCA \\
Rs 1695 & & & TCTACACCAACTATGT \\
\hline \hline
\end{tabular}




\subsubsection{GSTA1}

A identificação dos polimorfismos SNP $-52 \mathrm{G}>\mathrm{A},-69 \mathrm{C}>\mathrm{T},-567 \mathrm{~T}>\mathrm{G},-631 \mathrm{G}>\mathrm{T}$ na região promotora do gene GSTA1 (cromossomo 6) foi realizada por sequenciamento genético. As reações de sequenciamento foram realizadas à partir de produtos de PCRs obtidos por sondas específicas desenvolvidas em equipamento ABI Prism 3100 Genetic Analyzer $^{\circledR}$ (Applied Biosystems, Foster, CA, EUA) empregando os reagentes do kit BigDye ${ }^{\circledR}$ Terminator (Applied Biosystems, Foster, CA, EUA). Os cromatogramas foram processados pelo programa Sequence Analyser, versão 3,0 (GE Healthcare, Buckinghamshire, Reino Unido) e analisados pelo programa CLC Main Workbench ${ }^{\circledR}$ (CLC Bio, Aarhus, Dinamarca).

O protocolo foi realizado da seguinte maneira:

O amplicon gerado para análise de 4 SNPs a serem avaliados possuíam o tamanho de 780 pb. Foram utilizadas as sondas F 5'-GAT CTA GGG ATT TCT ATA TGG ACC-3' e R 5'-AGG ACG GTG ACA GCG TTT AAC-3'. A reação de PCR foi desenvolvida em um volume final de $15 \mu \mathrm{L}$ contendo $2 \mathrm{ng}$ de DNA genômico, $0,4 \mu \mathrm{M}$ de cada sonda, $2 \mathrm{mM}$ de deoxinucleotídeos trifosfato e 0,1 U de Taq polimerase (LGC Biotecnologia, Cotia, Brasil). A termociclagem foi realizada no termociclador GeneAMP ${ }^{\circledR}$ PCR Systems 9700 (Applied Biosystems, Foster City, CA, EUA) e consistiu de 35 ciclos de 30 segundos a $94^{\circ} \mathrm{C}, 30$ segundos a $53,2^{\circ} \mathrm{C}$ e 60 segundos a $72^{\circ} \mathrm{C}$, seguidos de uma extensão final de 3 minutos a $72^{\circ} \mathrm{C}$. Após a obtenção do produto de PCR, estes foram testados em gel de agarose para verificar a qualidade do produto e posteriormente, à partir destes produtos, foram realizadas as reações de sequenciamento. As reações de sequenciamento foram realizadas utilizando o kit BigDye ${ }^{\circledR}$ Terminator (Applied Biosystems, Foster, CA, EUA) em um volume final de $10 \mu \mathrm{L}$ contendo 4,2 $\mu \mathrm{L}$ de água ultrapura, 2,0 $\mu \mathrm{L}$ de tampão (200mM de Tris $\mathrm{HCl}$ pH 9,0; $5 \mathrm{mM}$ $\left.\mathrm{MgCl}_{2}\right), 1,0 \mu \mathrm{L}$ de BigDye ${ }^{\circledR}$ Terminator, $1,3 \mu \mathrm{L}$ das sondas $\mathrm{F}$ ou $\mathrm{R}(2,5 \mu \mathrm{M})$ e $1,0 \mu \mathrm{L}$ do produto de PCR. As reações também foram realizadas no termociclador GeneAMP ${ }^{\circledR}$ PCR Systems 9700 e consistiu de 1 ciclo de 2 segundos a $95^{\circ} \mathrm{C}, 45$ ciclos de 10 segundos a $95^{\circ} \mathrm{C}$, 15 segundos a $51^{\circ} \mathrm{C}$ e 1 minuto a $60^{\circ} \mathrm{C}$, seguidos de uma extensão final a $4^{\circ} \mathrm{C}$.

As amostras produzidas na reação de sequenciamento foram submetidas ao processo de remoção dos dideoxinucleotídeos não incorporados e os fragmentos de DNA foram precipitados com álcool isopropílico 75\%, seguido por álcool etílico 70\%. Após esse processo, a amostra foi retomada em formamida, desnaturada à temperatura de $95^{\circ} \mathrm{C}$ por 2 minutos e posteriormente, colocada no gelo por 1 minuto, para causar um choque térmico. Após a realização dos processos descritos, as amostras foram aplicadas no equipamento de 
sequenciamento ABI Prism 3100 Genetic Analyzer (Applied Biosystems, Foster City, CA, EUA).

\subsubsection{GSTM1}

A genotipagem do gene GSTM1 (cromossomo 1) foi realizada utilizando também os reagentes do kit Taqman Gene Copy Number Assay ${ }^{\circledR}$ (Applied Biosystems, Foster City, CA, EUA) de acordo com o protocolo do fabricante. Este kit consiste em um ensaio composto por uma sonda detectante do gene a ser investigado e outra sonda detectante de um gene endógeno, ou seja, um gene que sempre encontra-se presente, que será utilizado como controle positivo da reação e na qual serão baseados os cálculos de CycleTresholds $(\mathrm{Ct})$ realizados pelo equipamento.

Para a reação, foram utilizados $25 \mathrm{ng}$ de DNA, $5 \mu$ l Taqman Universal MasterMix ${ }^{\circledR}(2 \mathrm{x})$ (Applied Biosystems, Foster City, CA, EUA), $1 \mu \mathrm{L}$ da sonda (20x) GSTM1 marcada com $\mathrm{FAM}^{\circledR}$ e $1 \mu \mathrm{L}$ da sonda (20x) RNaseP (gene endógeno) marcada com $\mathrm{VIC}^{\circledR}$ totalizando um volume final de reação de $10 \mu \mathrm{L}$. Todas as amostras foram realizadas em triplicata, utilizando placas óticas de PCR em Tempo-real de 96 poços e no equipamento 7900HT Real Time PCR System (Applied Biosystem, Foster City, CA, EUA). A reação foi realizada nas seguintes condições térmicas de ciclagem: $95^{\circ} \mathrm{C}$ durante 10 min e 40 ciclos de 15 segundos à $95^{\circ} \mathrm{C}$ e 1 minuto $60^{\circ} \mathrm{C}$. Os dados de $P C R$ em tempo real foram coletados pelo programa $A B I$ Sequence Detection System, versão 2,1 (Applied Biosystems, Foster City, CA, EUA) e os valores de Ct foram calculados para as triplicatas dos genes GSTM1 e RNaseP. Os valores de Ct para o gene da RNaseP serviram como referência na análise das amostras para detectar a presença ou ausência das sequências do gene GSTM1. Cada ensaio incluiu controles conhecidos por conter (ou não) o gene GSTM1, e os paciente foram denominados, de acordo com os genótipos, como sendo GSTM1 positivo ou GSTM1 nulo. Não foi determinada a zigosidade das amostras, uma vez que o efeito sobre a função da enzima independe desta.

\subsection{Análise Farmacocinética e Estatística}

Os cálculos de média, mediana, desvio padrão (DP), coeficiente de variação (CV) e percentis foram realizados com auxílio do programa Excel. Os testes estatísticos (MannWhitney, Wilcoxon, Kruskal-Wallis, Teste Exato de Fisher) foram realizados com o auxílio 
GraphPad Prisma ${ }^{\circledR}$. O teste qui-quadrado foi utilizado para avaliar o desvio das frequências alélicas dos genes estudados do equilíbrio de Hardy-Weinberg. As frequências alélicas e a determinação dos haplótipos foram realizadas com auxílio do programa PHASE, versão 2,0. Os parâmetros farmacocinéticos foram calculados com base nas curvas de concentração plasmática do BU versus tempo. Foi empregado o programa WinNonlin, versão 4,0 (Pharsight Corp, Mountain View, Calif, EUA). Os cálculos foram realizados empregando cinética de primeira ordem, modelo monocompartimental para a dose teste de BU e modelo não compartimental na quinta dose do tratamento pré-TCTH.

A dose teste de BU foi empregada para calcular o clearance aparente $(\mathrm{Cl} / \mathrm{f})$ de cada paciente investigado, de acordo com a equação: $\mathrm{Cl} / \mathrm{f}=\operatorname{dose} / \mathrm{AUC}^{0-\infty}$. A dose sugerida foi determinada para atingir $C^{\text {ss }}$ dentro do intervalo terapêutico de 600-900 ng/mL, de acordo com a equação: $\operatorname{dose} / \tau=\mathrm{Cl} / \mathrm{f} . \mathrm{C}^{\mathrm{ss}}$, onde $\tau$ representa o intervalo de dose de $6 \mathrm{~h}$ (TAKAMATSU et al., 2007).

A $\mathrm{C}^{\mathrm{ss}}$ observada foi calculada dividindo-se a $\mathrm{AUC}^{0-6} / \tau$, onde $\tau$ representa o intervalo de dose de 6 horas. No estudo de comparação da $C^{\text {ss }}$ esperada com a $C^{\text {ss }}$ observada foi utilizado o teste de Wilcoxon para dados pareados.

O estudo de coletas esparsas para utilização no monitoramento terapêutico do BU, foi realizado no laboratório LACDR (Leiden Academic Centre for Drug Research) na Universidade de Leiden, Holanda. Nesta parte do estudo, o modelo de farmacocinética populacional foi implementado usando o método de efeitos mistos não lineares com auxílio do programa NONMEM ${ }^{\circledR}$ 7.2.0 (Non-linear Mixed Effect Modelling, ICON Development Solutions) com GNU Fortran 4,6 compiler (Free Software Foundation, Inc.). A interface entre o motor de minimização utilizado por NONMEM e o processador de dados foi realizada com o auxílio do programa Perl-speaks-NONMEM (PsN). A visualização gráfica foi realizada com o programa $\mathrm{R}$ ( $R$ Development Core Team, 2011).

Devido ao reduzido número de pacientes investigados, optou-se pela utilização de um modelo de farmacocinética populacional do BU previamente publicado (SANDSTRÖM et al., 2001). A partir do modelo de Sandstrom et al. (2001), os parâmetros farmacocinéticos foram re-estimados usando o método FOCEI (First Order Conditional Estimation Method with Interaction), utilizando porém os dados de apenas 20 dos pacientes incluídos no estudo. Dos 29 pacientes incluídos no estudo, 20 deles foram utilizados para re-estimação dos parâmetros e 9 foram utilizados para validação externa. A influência das covariáveis peso, sexo, fenitoína associada e os valores séricos de alanina-transferase (ALT) foi avaliada na estimativa dos 
parâmetros farmacocinéticos. Assumiu-se que as variabilidades interindividual e interocasiões (IIV e IOV) apresentavam distribuição log-normal.

\subsection{Avaliação do modelo de farmacocinética populacional}

A alteração significativa da OFV (Objective Function Value) foi utilizada para definir as covariáveis que seriam empregadas no modelo final. O processo de re-estimação dos parâmetros farmacocinéticos foi guiado pela avaliação dos gráficos diagnósticos, incluindo a qualidade do ajuste (goodness-of-fit), os resíduos ponderados condicionais (conditional weighted residuals (CWRES- versus tempo, CWRES versus predições baseadas na estimativa pontual do modelo (PRED), predições baseadas na estimativa pontual modelo (PRED) versus concentrações (DV; dependent variable) e predições baseadas nas estimativas individuais do modelo (IPRED) versus DV.

Para avaliar a exatidão (confiabilidade) e a precisão (reprodutibilidade) dos parâmetros finais do modelo foi utilizada o método de bootstrap (ETTE; WILLIAMS; LANE, 2004; LINDBOM et al., 2005; PARKE; HOLFORD; CHARLES, 1999). Da planilha de dados original, 1000 planilhas foram geradas por re-amostragem com reposição, em modo a replicar o número total de pacientes incluídos na análise inicial. A mediana da estimativa dos parâmetros das 1000 análises foi comparada com a estimativa do modelo final a partir da planilha original. Os coeficientes de variação e os intervalos de confiança $90 \%$ obtidos foram comparados com aqueles gerados pelo NONMEM.

Além dos métodos diagnósticos numéricos, métodos gráficos foram utilizados para complementar o processo de validação do modelo. A verificação visual preditiva (visual predictive check) (VPC) foi executada usando simulações de 500 replicatas do estudo original para confirmar a adequação do modelo (tendência e variabilidade) e seu desempenho preditivo. A mediana e os 25 e 75 percentis dos dados simulados foram plotados contra o tempo, com estratificação em base no peso para melhor observação e comparação dos resultados.

Para avaliar o modelo também foi feita a análise gráfica de verificação visual preditiva posterior (posterior predictive check, PPC). O PPC foi realizado utilizando a AUC como medida de desempenho do modelo. Utilizando o modelo popPK final, 1000 simulações foram realizadas, para cada observação, da planilha original (concentrações plasmáticas de BU observadas) contendo os dados dos pacientes reais. Em seguida, os valores de AUC foram 
calculados e a distribuição nas diferentes ocasiões (dose teste e tratamento) foram observadas para avaliar se o modelo descreveria de forma adequada os dados reais observados. A distribuição dos valores de AUC preditos à partir do modelo foi apresentada como mediana e comparada com a mediana dos valores de AUC dos pacientes reais. Os dados estão apresentados em histogramas plotados com auxílio do programa $\mathrm{R}$.

O poder preditivo do modelo foi avaliado através cálculo da distribuição dos erros de predição normalizados ou NPDE (normalized prediction distribution errors). A análise NPDE foi realizada com auxílio do pacote NPDE do programa R (versão 2,15,1). Os gráficos de NPDE versus observações e versus tempo foram usados para avaliar se havia a presença de distorções ou tendências nos resultados. Os gráficos incluem gráfico quantil-quantil de NPDE versus distribuição normal padrão, histograma do NPDE com densidade da distribuição padrão normal, gráfico de dispersão do NPDE versus tempo e versus valores preditos.

Finalmente, o modelo popPK foi avaliado também pelo padrões de variação através dos gráficos espelhos (mirror-plots) que tem como finalidade avaliar o grau de similaridade entre os dados originais e os dados simulados à partir do modelo popPK final. Foram feitas 10 simulações em NONMEM e, de forma aleatória, foram escolhidas 3 realizações ou réplicas para serem comparadas com os dados originais e avaliar se a estrutura da matriz de variânciacovariância nas simulações seguiam os padrões dos dados originais para população e individual. Os gráficos espelhos foram executados através do pacote Xpose do programa R.

\subsection{Otimização Experimental do tempo de coletas esparsas}

As etapas desta fase do estudo estão esquematizadas na Figura 3.

Com auxílio do programa PoPED (Population Experimental Design), utilizando como método de otimização a expectativa da matriz de informação de Fisher ou simplesmente $E D$ Optimality, foram avaliados diferentes cenários de tempos de coletas para aplicação no monitoramento terapêutico do BU. Os cenários foram selecionados com base nos OFV do PoPED e nos coeficientes de variação entre os valores de clearance aparente do BU estimados com 15 amostras ou com o número de coletas esparsas proposto pelo programa.

Os cenários que apresentavam melhores OFV e CV para o clearance aparente do BU foram avaliados da seguinte maneira: na planilha original, contendo os dados dos pacientes reais, foram acrescentados um a um 80 pacientes virtuais. A cada novo paciente adicionado à 
planilha original, eram feitas novas estimativas dos parâmetros farmacocinéticos individuais e populacionais nos dois diferentes cenários (cenário com 15 coletas de sangue e cenário com coletas esparsas). Os desvios dos clearances individuais estimados nos dois cenários foram comparados, pois dessa forma foi possível avaliar o desempenho do esquema de coletas e a estabilidade do modelo.

\subsection{Simulações}

Foram feitas simulações com 80 pacientes virtuais em duas diferentes situações: durante a dose teste e no estado de equilíbrio de concentrações plasmáticas do BU após a administração da quinta dose. Os pacientes virtuais receberam a dose teste com base no modelo popPK, onde leva-se em consideração o peso ideal ajustado e os valores séricos de ALT. Os pacientes foram avaliados nos dois diferentes cenários de monitoramento terapêutico, com 15 coletas de sangue e no novo esquema de coletas esparsas. Os parâmetros farmacocinéticos foram calculados pelo NONMEM, usando método de máxima verossimilhança como descrito anteriormente. Os valores estimados de clearance e AUC foram comparados nos dois diferentes cenários. O cenário com coletas esparsas que melhor representou os valores de exposição observados no monitoramento terapêutico com 15 amostras plasmáticas de BU foi então validado utilizando-se o VPC. 


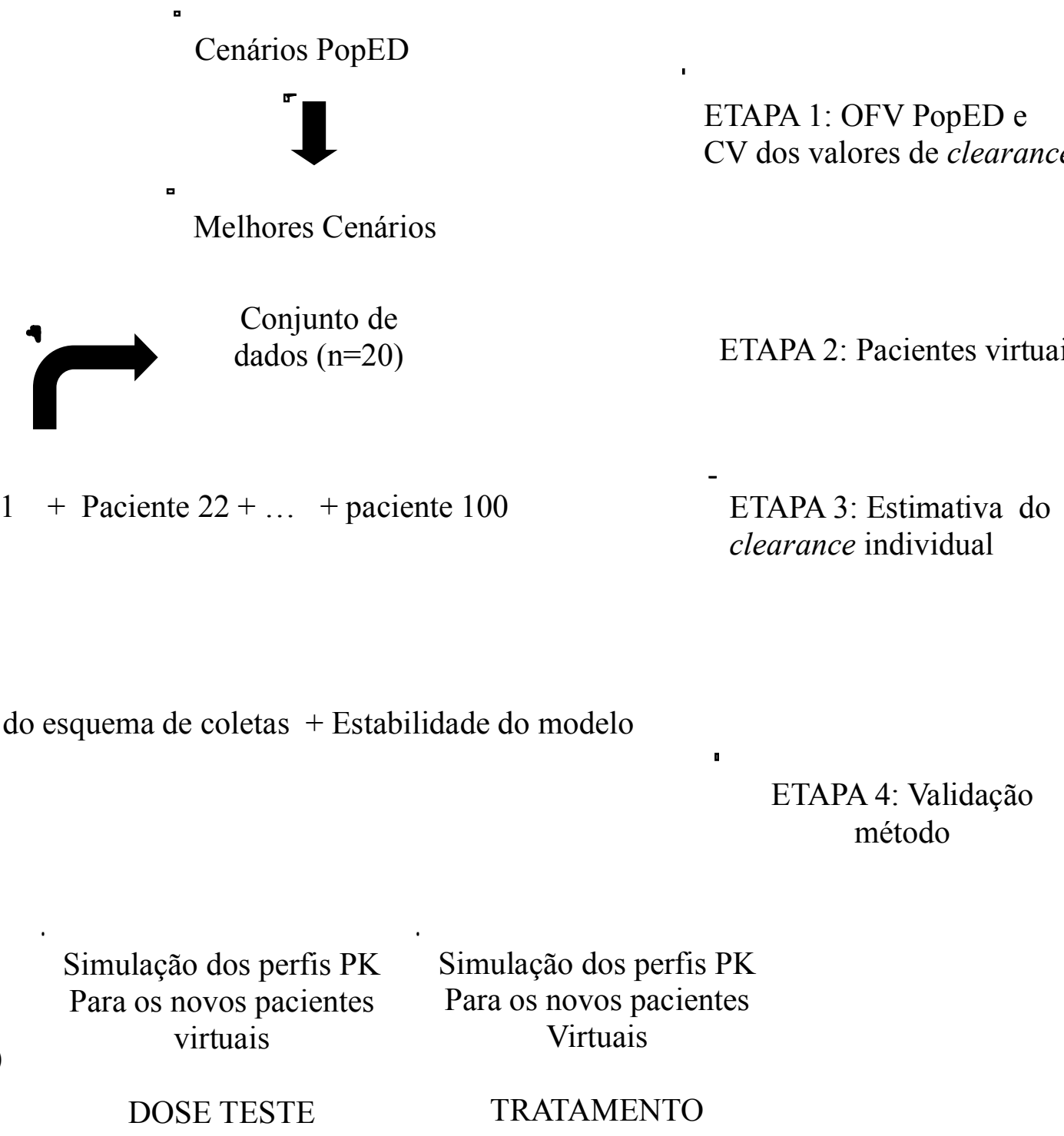

Desempenho do esquema de coletas + Estabilidade do modelo

$\begin{array}{cc} & \begin{array}{c}\text { Simulação dos perfis PK } \\ \text { Para os novos pacientes } \\ \text { virtuais }\end{array} \\ \text { do clearance }(\%) & \text { DOSE TESTE }\end{array}$

Simulação dos perfis PK

Paciente $21+$ Paciente $22+\ldots+$ paciente 100

ETAPA 3: Estimativa do clearance individual

Figura 3. Etapas do estudo de coletas esparsas 
4. Resultados 


\subsection{Dados demográficos}

Foram investigados 30 pacientes submetidos ao TCTH e com indicação de regime de condicionamento com BU. Todos os pacientes incluídos receberam o mesmo tratamento de profilaxia para a Doença do Enxerto Contra o Hospedeiro, realizada com metotrexato e ciclosporina.

A Tabela 7 apresenta os dados demográficos dos pacientes $(n=30)$ investigados. 
Tabela 7. Dados demográficos dos pacientes incluídos no estudo $(\mathrm{n}=30)$

\begin{tabular}{|c|c|c|c|c|c|c|c|c|}
\hline Paciente & Protocolo & Sexo & $\begin{array}{l}\text { Idade } \\
\text { (anos) }\end{array}$ & $\begin{array}{l}\text { Peso } \\
(\mathrm{Kg})\end{array}$ & $\begin{array}{c}\text { IMC } \\
\left(\mathrm{Kg} / \mathrm{m}^{2}\right)\end{array}$ & Diagnóstico & $\begin{array}{c}\text { Fase } \\
\text { doença }\end{array}$ & $\begin{array}{c}\text { Tipo } \\
\text { enxerto }\end{array}$ \\
\hline 1 & Tandem & $\mathrm{M}$ & 18 & 44,0 & 16,6 & LMA & $\mathrm{RC}$ & $\mathrm{MO}$ \\
\hline 2 & Tandem & $\mathrm{M}$ & 44 & 74,2 & 24,2 & LMA & $\mathrm{RC}$ & SP \\
\hline 3 & FLUBU & M & 22 & 48,7 & 17,1 & SMD & - & MO \\
\hline 4 & FLUBU & M & 50 & 60,0 & 21,8 & LMC & $\mathrm{RC}$ & SP \\
\hline 5 & BUCY & $\mathrm{F}$ & 3 & 16,0 & 17,0 & LMA & $\mathrm{RC}$ & SCU \\
\hline 6 & BUCY & $\mathrm{F}$ & 9 & 30,0 & 16,0 & $\mathrm{AF}$ & - & $\mathrm{MO}$ \\
\hline 7 & FLUBU & M & 20 & 46,0 & 17,1 & $\mathrm{AF}$ & - & MO \\
\hline 8 & FLUBU & $\mathrm{F}$ & 46 & 73,4 & 26,0 & LMA & $\mathrm{RC}$ & MO \\
\hline 9 & FLUBU & M & 35 & 69,3 & 23,4 & LMA & $\mathrm{RC}$ & SP \\
\hline 10 & BUCY & $\mathrm{F}$ & 31 & 49,0 & 20,0 & LMC & FA & SCU \\
\hline 11 & FLUBU & $\mathrm{F}$ & 27 & 62,0 & 21,4 & $\mathrm{AF}$ & - & $\mathrm{MO}$ \\
\hline 12 & BUCY & M & 14 & 80,0 & 33,3 & SMD & - & MO \\
\hline 13 & FLUBU & $\mathrm{F}$ & 43 & 66,8 & 28,2 & SMD & - & SP \\
\hline 14 & BUCY & $\mathrm{M}$ & 31 & 96,0 & 30,6 & SMD & - & MO \\
\hline 15 & FLUBU & M & 42 & 77,5 & 28,6 & LMA & $\mathrm{RC}$ & SP \\
\hline 16 & BUCY & $\mathrm{F}$ & 19 & 80,0 & 25,5 & LMA & $\mathrm{RC}$ & SP \\
\hline 17 & FLUBU & M & 58 & 90,0 & 31,5 & LMA & $\mathrm{RC}$ & SP \\
\hline 18 & FLUBU & $\mathrm{F}$ & 46 & 64,0 & 29,2 & LMA & $\mathrm{RC}$ & SP \\
\hline 19 & FLUBU & M & 12 & 63,0 & 22,6 & $\mathrm{AF}+\mathrm{LLA}$ & - & $\mathrm{MO}$ \\
\hline 20 & BUCY & M & 20 & 72,4 & 22,2 & LMA & $\mathrm{R}$ & SP \\
\hline 21 & BUCY & M & 20 & 62,0 & 21,5 & LMA & $\mathrm{R}$ & SP \\
\hline 22 & BUCY & $\mathrm{M}$ & 30 & 72,1 & 24,9 & LMC & $\mathrm{FC}$ & SP \\
\hline 23 & BUCY & M & 30 & 62,0 & 18,9 & LMC & $\mathrm{CB}$ & SP \\
\hline 24 & FLUBU & $\mathrm{F}$ & 17 & 43,2 & 16,9 & $\mathrm{AF}$ & - & MO \\
\hline 25 & BUCY & $\mathrm{F}$ & 30 & 98,0 & 38,8 & LMA & $\mathrm{RC}$ & SP \\
\hline 26 & BUCY & $\mathrm{F}$ & 24 & 50,0 & 17,3 & LMA & $\mathrm{RC}$ & SP \\
\hline 27 & FLUBU & M & 50 & 80,0 & 28,3 & LNH & - & SP \\
\hline 28 & FLUBU & M & 34 & 64,5 & 25,1 & LMA & $\mathrm{RC}$ & MO \\
\hline 29 & FLUBU & $\mathrm{F}$ & 25 & 45,0 & 17,2 & LMA & $\mathrm{RC}$ & MO \\
\hline 30 & BUCY & $\mathrm{F}$ & 32 & 88,0 & 30,3 & LMA & $\mathrm{RC}$ & MO \\
\hline
\end{tabular}

IMC- índice de massa corporal; TCTH- transplante de células tronco hematopoéticas; LMA- leucemia mielóide aguda; AF- anemia falciforme; LMC - leucemia mielóide crônica; SMD- síndrome mielodisplásica; LLA- leucemia linfoide aguda; LNH- Linfoma não Hodgkin; RC - remissão clínica; FA- fase acelerada; CB-crise blástica; SP sangue periférico; MO - medula óssea; SCU-sangue de cordão umbilical; R- recaída 


\subsection{Fármacos associados ao BU}

Para verificar se a concentração plasmática do BU encontrava-se dentro do intervalo terapêutico, as coletas foram feitas no estado de equilíbrio, durante a quinta dose de BU. Os fármacos associados durante as coletas, dose teste e quinta dose, estão descritos na Tabela 8.

Tabela 8. Lista de fármacos associados ao BU durante as coletas de sangue seriadas

\begin{tabular}{|c|c|c|}
\hline Paciente & $\begin{array}{c}\text { Fármacos associados } \\
\text { dose teste }\end{array}$ & $\begin{array}{l}\text { Fármacos associados } \\
5^{\mathrm{a}} \text { dose }\end{array}$ \\
\hline $\mathbf{1}$ & $5,6,7,17,29$ & $1,5,6,7,9,17,29,32$ \\
\hline 2 & $5,6,7,8,16,19$ & $1,5,6,7,8,9,15$ \\
\hline 3 & $4,5,6,7,8,9,10,11$ & $1,2,3,4,5,6,7,8,9,10,11$ \\
\hline 4 & $5,6,7,8$ & $1,2,5,6,7,8,9,14$ \\
\hline 5 & $5,7,13,16,18,19,23,33$ & $1,5,7,9,15$ \\
\hline 6 & $4,5,6,7,16,29,30$ & $1,4,5,6,7,9,23,29$ \\
\hline 7 & $4,5,6,7,29$ & $1,2,3,4,5,6,7,8,9,11,12,29,30$ \\
\hline 8 & $5,7,6,17,8,15,9,18,19,16$ & $1,2,3,6,7,8,9,15,16,17$ \\
\hline 9 & $5,7,8,13,14$ & $1,2,5,7,8,14,13$ \\
\hline 10 & $5,7,8,20$ & $5,6,7,9,20$ \\
\hline 11 & $5,6,7,9,15$ & $1,2,3,5,6,7,9,22,23$ \\
\hline 12 & $5,6,7,8,9,15,21$ & $1,5,6,7,8,9,15,17,29,32$ \\
\hline 13 & $5,7,8$ & $1,2,5,6,7,8,22$ \\
\hline 14 & $8,18,19,24$ & $1,3,5,9,15,22,23,25$ \\
\hline 15 & $5,7,8,26,27$ & $1,2,5,7,8,9,17,26,28$ \\
\hline 16 & $5,6,7,8,11,17,23$ & $1,5,6,7,8,9,15,17,23,31$ \\
\hline 17 & $5,6,7,8,9,17$ & $1,2,5,6,7,8,9,15,17,23,31$ \\
\hline 18 & $5,7,8,13,20,34,35,36,37$ & $1,2,5,7,8,9,13,15,17,36,37,38$ \\
\hline 19 & $5,6,7,8,17$ & $1,2,5,6,7,8,9,15,17,29,30,40$ \\
\hline 20 & $5,7,8,16,18,19,41$ & $1,5,7,8,15,18,19,41$ \\
\hline 21 & $5,7,8,13,15,28$ & $1,5,7,8,13,15$ \\
\hline 22 & $6,7,8,18,19,42$ & $1,2,4,5,6,7,8,22,29,30,38$ \\
\hline 23 & $5,6,7,8,39$ & $1,4,5,6,7,8,9,15,23,28,39$ \\
\hline 24 & $4,5,6,7,9,15,43$ & $1,2,4,5,6,7,8,22,29,30,38$ \\
\hline 25 & $5,7,8,13,28,39$ & $1,5,7,8,13,15,39$ \\
\hline 26 & $5,8,9,12,13$ & $1,5,8,12,13,28$ \\
\hline 27 & $5,8,18,19$ & $1,2,5,6,7,8,9,15,29$ \\
\hline 28 & $5,6,7,8$ & $1,2,5,7,6,8,9$ \\
\hline 29 & $5,6,7,8$ & $1,5,6,7,8,9,15,29,44$ \\
\hline 30 & $1,5,7,8,15,18,19,25$ & $1,2,5,7,8,9,15$ \\
\hline
\end{tabular}

1- fenitoína, 2- fludarabina, 3-metilprednisolona, 4- levofloxacino, 5- sulfametoxazol + trimetoprima, 6fluconazol, 7- aciclovir, 8- omeprazol, 9- ondansetrona, 10- sertralina, 11- lorazepam, 12-bromoprida, 13voriconazol, 14- furosemida, 15- alizaprida, 16- metronidazol, 17- ciprofloxacino, 18- mebendazol, 19tiabendazol, 20- alopurinol, 21- cefepime, 22- hidrocortisona, 23- dexclorfeniramina, 24- prednisona, 25itraconazol, 26- nistatina, 27- enoxaparina, 28- cloridrato de palonosetrona, 29- ácido ursodesoxicólico, 30lamotrigina, 31- dexametasona, 32- granisetrona, 33- ranitidina, 34- enalapril, 35- difosfato de cloroquina, 36fluoxetina, 37-clonazepam, 38- ciclosporina, 39- besilato de anlodipina, 40- tramadol, 41-rifampicina + isoniazida + pirazinamida + etambutol, 42- disatinib, 43- hidroxiuréia, 44- albendazol 


\subsection{Análise do BU em plasma humano}

A Figura 4 apresenta os cromatogramas referentes ao plasma branco (A), plasma humano enriquecido com $1250 \mathrm{ng}$ do $\mathrm{BU} / \mathrm{mL}$ de plasma (B), plasma de voluntário após 45 minutos da administração da dose teste de BU (C) e após a administração oral da $5^{\mathrm{a}}$ dose de BU (D). O pico 1 eluído em 1,72 min é referente ao BU e o pico 2 eluído em 2,44 min é referente ao PI.
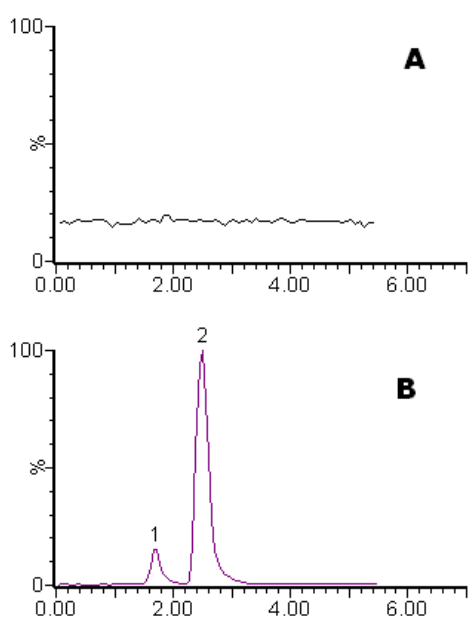
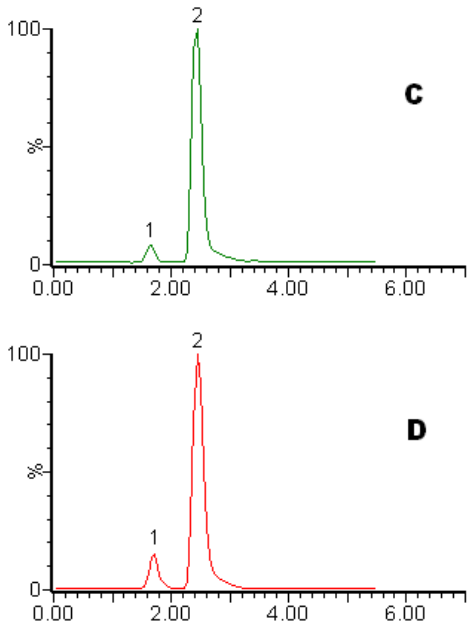

Figura 4. Cromatogramas referentes ao (A) Plasma Branco, (B) Plasma enriquecido com BU 1250 $\mathrm{ng} / \mathrm{mL}$ de plasma, (C) Plasma de voluntário após 45 minutos da administração oral da dose teste de BU, (D) Plasma de voluntário após 45 minutos da administração oral da $5^{\text {a }}$ dose de BU. Picos: (1) BU, (2) PI

\subsubsection{Efeito matriz na análise do BU em plasma}

Os dados apresentados na Tabela 9 indicam que o efeito matriz na ionização do BU e do padrão interno é praticamente ausente.

Tabela 9. Efeito matriz para o BU e PI em seis diferentes lotes de plasma humano. Resultados apresentados como porcentagem (\%) em relação ao sinal original

\begin{tabular}{ccc}
\hline \hline Concentração $(\mathbf{n g} / \mathbf{m L})$ & BU & PI \\
\hline 62,5 & 113 & \\
1000 & 87 & 97 \\
2000 & 88 & \\
\hline \hline
\end{tabular}




\subsubsection{Validação do método de análise do BU em plasma humano}

Os limites de confiança do método de análise do BU em plasma por LC-MS/MS estão apresentados na Tabela 10. Os estudos de precisão e exatidão apresentaram coeficientes de variação e \% de inexatidão menores que $15 \%$. A avaliação da estabilidade em ciclos de congelamento e descongelamento e estocagem à temperatura ambiente apresentou \% de desvio com valores $\leq 15 \%$.

Tabela 10. Limites de confiança do método de análise do BU por LC-MS/MS

\begin{tabular}{|c|c|}
\hline & BU \\
\hline \multicolumn{2}{|c|}{ Recuperação absoluta $(\%, n=6)$} \\
\hline $62,5 \mathrm{ng} / \mathrm{mL}$ & 89 \\
\hline $1000 \mathrm{ng} / \mathrm{mL}$ & 98 \\
\hline $2000 \mathrm{ng} / \mathrm{mL}$ & 91 \\
\hline Linearidade (ng/mL) & $5-2500$ \\
\hline Equação da reta & $0,000889771+5,12401 x$ \\
\hline $\mathrm{r}$ & 0,998966 \\
\hline \multicolumn{2}{|c|}{ Limite de quantificação ( $5 \mathrm{ng} / \mathrm{mL}$ ) } \\
\hline Precisão $(C V \%, n=6)$ & 7,3 \\
\hline Exatidão (\% inexatidão) & 7,0 \\
\hline \multicolumn{2}{|c|}{ Precisão entre ensaios $(C V \%, n=10)$} \\
\hline $62,5 \mathrm{ng} / \mathrm{mL}$ & 4,2 \\
\hline $1000 \mathrm{ng} / \mathrm{mL}$ & 4,9 \\
\hline $2000 \mathrm{ng} / \mathrm{mL}$ & 4,9 \\
\hline \multicolumn{2}{|c|}{ Precisão Intraensaio (CV\%, $n=6)$} \\
\hline $62,5 \mathrm{ng} / \mathrm{mL}$ & 4,9 \\
\hline $1000 \mathrm{ng} / \mathrm{mL}$ & 7,6 \\
\hline $2000 \mathrm{ng} / \mathrm{mL}$ & 5,7 \\
\hline \multicolumn{2}{|c|}{ Exatidão entre ensaios (\% inexatidão, $n=10)$} \\
\hline $62,5 \mathrm{ng} / \mathrm{mL}$ & 4,2 \\
\hline $1000 \mathrm{ng} / \mathrm{mL}$ & 5,4 \\
\hline $2000 \mathrm{ng} / \mathrm{mL}$ & $-9,5$ \\
\hline \multicolumn{2}{|c|}{ Exatidão Intraensaio (\% inexatidão, $n=6)$} \\
\hline $62,5 \mathrm{ng} / \mathrm{mL}$ & $-6,1$ \\
\hline $1000 \mathrm{ng} / \mathrm{mL}$ & $-4,6$ \\
\hline $2000 \mathrm{ng} / \mathrm{mL}$ & $-11,7$ \\
\hline \multicolumn{2}{|l|}{ Estabilidade $(\%$ desvio, $n=6)$} \\
\hline \multicolumn{2}{|c|}{3 Ciclos de descongelamento $\left(-20\right.$ a $\left.25^{\circ} \mathrm{C}\right)$} \\
\hline $62,5 \mathrm{ng} / \mathrm{mL}$ & 1,8 \\
\hline $2000 \mathrm{ng} / \mathrm{mL}$ & $-8,9$ \\
\hline \multicolumn{2}{|l|}{ Temperatura ambiente (5 h) } \\
\hline $62,5 \mathrm{ng} / \mathrm{mL}$ & 13,1 \\
\hline $2000 \mathrm{ng} / \mathrm{mL}$ & 14,0 \\
\hline \multicolumn{2}{|l|}{ Pós Processamento (12h) } \\
\hline $62,5 \mathrm{ng} / \mathrm{mL}$ & $-1,7$ \\
\hline $2000 \mathrm{ng} / \mathrm{mL}$ & 12,3 \\
\hline
\end{tabular}




\subsection{Farmacocinética do BU}

A farmacocinética do BU foi avaliada em três diferentes protocolos (FLUBU, BUCY e Tandem). As coletas de sangue foram realizadas no intervalo de 0-6 h após a administração da dose teste e durante o intervalo de dose de 6 horas da quinta dose do condicionamento préTCTH.

As curvas de decaimento das concentrações plasmáticas do BU em função do tempo, após a administração da dose teste e quinta dose do BU, estão apresentadas na Figura 5. Os resultados estão apresentados como medianas e percentis 25 e $75(n=30)$.

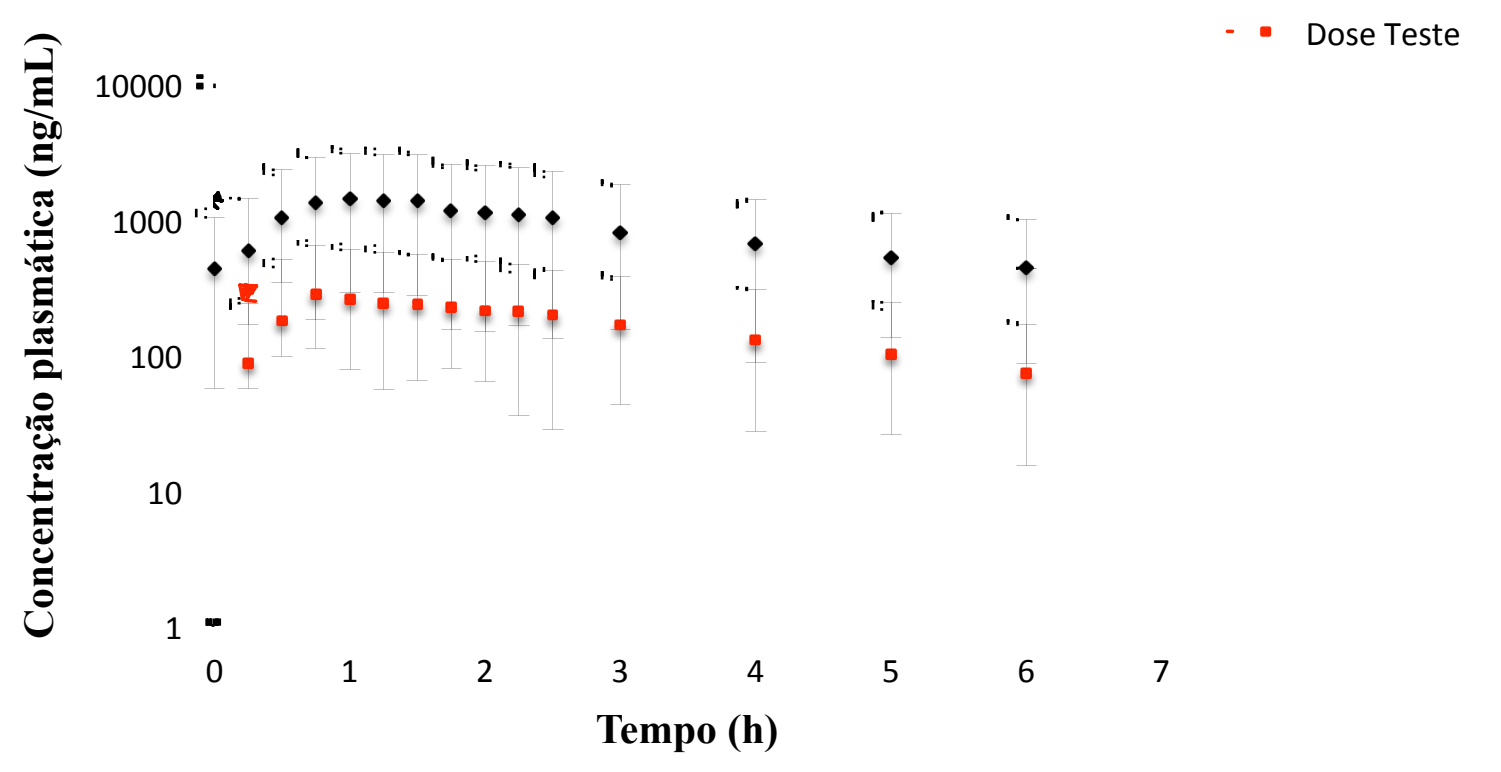

Figura 5. Concentração plasmática do BU versus tempo. Dados apresentados como medianas e percentis 25 e $75(n=30)$.

A disposição cinética do $\mathrm{BU}$, após a dose teste de $\mathrm{BU}$ e após a administração da $5^{\circ}$ dose de BU, está apresentada, respectivamente, nas Tabelas 11 e 12. 
Tabela 11. Disposição cinética do BU após a administração de dose teste de $0,25 \mathrm{mg} / \mathrm{kg}$ $(\mathrm{n}=30)$. Dados individuais

\begin{tabular}{|c|c|c|c|c|c|c|}
\hline Paciente & $\begin{array}{c}\mathrm{C}_{\max } \\
(\mathrm{ng} / \mathrm{mL})\end{array}$ & $\begin{array}{c}\mathrm{C}_{\min } \\
(\mathrm{ng} / \mathrm{mL})\end{array}$ & $\begin{array}{l}t_{\max } \\
\text { (h) }\end{array}$ & $\begin{array}{c}A U C^{0-\infty} \\
(n g . h / m L)\end{array}$ & $\begin{array}{c}\mathbf{C l} / \mathbf{f} \\
(\mathrm{L} / \mathrm{h})\end{array}$ & $\begin{array}{c}\text { Dose } \\
\text { sugerida } \\
(\mathrm{mg})\end{array}$ \\
\hline 1 & 276,8 & 11,6 & 1,7 & 921,9 & 10,8 & $38,9-58,3$ \\
\hline 2 & 256,9 & 74,1 & 0,6 & 1204,5 & 29,9 & $107,6-161,5$ \\
\hline 3 & 385,2 & 57,5 & 0,5 & 1436,4 & 8,3 & $29,9-44,8$ \\
\hline 4 & 637,4 & 112,6 & 0,5 & 2647,7 & 5,3 & $19,0-28,6$ \\
\hline 5 & 184,2 & 35,0 & 0,5 & 633,0 & 3,2 & $11,4-17,0$ \\
\hline 6 & 291,3 & 26,8 & 0,3 & 754,9 & 7,9 & $28,6-42,9$ \\
\hline 7 & 215,5 & 15,8 & 0,8 & 1050,0 & 9,5 & $34,3-51,4$ \\
\hline 8 & 347,7 & 75,8 & 0,5 & 1609,6 & 11,2 & $40,3-60,5$ \\
\hline 9 & 349,3 & 110,9 & 1,4 & 1901,2 & 9,1 & $32,6-48,9$ \\
\hline 10 & 265,2 & 72,1 & 1,7 & 1192,3 & 10,1 & $36,4-54,5$ \\
\hline 11 & 441,1 & 117,7 & 1,0 & 1727,9 & 9,3 & $33,0-50,0$ \\
\hline 12 & 186,3 & 94,3 & 1,0 & 1717,4 & 9,3 & $33,5-50,3$ \\
\hline 13 & 428,9 & 94,3 & 1,0 & 1840,7 & 7,6 & $27,4-41,0$ \\
\hline 14 & 326,0 & 46,6 & 1,5 & 1350,7 & 14,8 & $53,3-80,0$ \\
\hline 15 & 266,3 & 14,1 & 1,7 & 1296,6 & 13,9 & $50,0-75,0$ \\
\hline 16 & 409,7 & 173,7 & 0,6 & 2381,1 & 8,4 & $30,3-50,4$ \\
\hline 17 & 214,7 & 5,8 & 1,6 & 1116,6 & 16,1 & $58,0-87,0$ \\
\hline 18 & 315,0 & 44,2 & 0,5 & 1037,4 & 13,5 & $48,6-72,8$ \\
\hline 19 & 476,1 & 39,9 & 0,2 & 1269,4 & 12,6 & $45,4-68,0$ \\
\hline 20 & 211,7 & 9,7 & 1,7 & 973,3 & 18,5 & $66,6-100,0$ \\
\hline 21 & 175,5 & 92,5 & 2,6 & 1243,5 & 12,9 & $46,3-69,5$ \\
\hline 22 & 289,9 & 24,9 & 0,8 & 1296,6 & 13,9 & $50,0-75,0$ \\
\hline 23 & 409,6 & 7,7 & 3,3 & 1246,0 & 12,8 & $46,1-69,1$ \\
\hline 24 & 786,9 & 107,2 & 0,3 & 2453,2 & 4,1 & $14,7-22,1$ \\
\hline 25 & 297,6 & 78,5 & 1,1 & 1403,5 & 17,1 & $61,5-92,3$ \\
\hline 26 & 201,5 & 22,1 & 0,9 & 961,7 & 12,5 & $45,0-67,5$ \\
\hline 27 & 409,7 & 60,5 & 0,2 & 1231,1 & 14,6 & $52,5-78,8$ \\
\hline 28 & 148,5 & 37,1 & 1,7 & 872,7 & 18,3 & $65,8-98,8$ \\
\hline 29 & 235,5 & 29,3 & 1,1 & 1042,9 & 9,5 & $34,2-51,3$ \\
\hline 30 & 340,7 & 48,2 & 1,5 & 1444,2 & 13,8 & $49,7-74,5$ \\
\hline Mediana & 294,5 & 47,4 & 1,0 & 1257,7 & 11,9 & \\
\hline $\begin{array}{l}\text { Percentil } \\
(25 \text { e } 75)\end{array}$ & $(220,5-403,5)$ & $(25,4-89,0)$ & $(0,5-1,6)$ & $(1044,7-1568,2)$ & $(9,2-13,9)$ & \\
\hline Média & 326,0 & 58,0 & 1,1 & 1375,3 & 11,9 & \\
\hline CV $(\%)$ & 46,2 & 85,7 & 70,6 & 38,0 & 42,1 & \\
\hline
\end{tabular}

Cmax- concentração plasmática máxima; Cmin- concentração plasmática 6 h após a administração da dose teste; tmaxtempo necessário para atingir Cmax; AUC- área sob a curva concentração plasmática versus tempo; $\mathrm{Cl} / \mathrm{f}-$ clearance total aparente; CV-coeficiente de variação. 
Tabela 12. Disposição cinética do BU na quinta dose $(n=30)$. Dados individuais

\begin{tabular}{|c|c|c|c|c|c|c|}
\hline Paciente & $\operatorname{Cmax}(n g / m L)$ & $\underset{(\mathrm{ng} / \mathrm{mL})}{\mathrm{Cmin}}$ & $\begin{array}{c}\text { tmax } \\
\text { (h) } \\
\end{array}$ & $\begin{array}{c}\mathrm{AUC} \\
(\mathrm{ng} \cdot \mathbf{h} / \mathbf{m L})\end{array}$ & $\begin{array}{c}C^{s s} \\
(n g / m L) \\
\end{array}$ & $\begin{array}{c}\mathrm{Cl} / \mathbf{f} \\
(\mathrm{L} / \mathrm{h})\end{array}$ \\
\hline 1 & 2471,8 & 379,6 & 2,0 & 5984,0 & 997,4 & 7,4 \\
\hline 2 & 1217,9 & 270,7 & 2,5 & 4086,4 & 681,1 & 18,1 \\
\hline 3 & 1703,4 & 171,1 & 1,3 & 4291,6 & 715,2 & 11,2 \\
\hline 4 & 2481,0 & 712,4 & 1,5 & 9102,9 & 1517,1 & 6,4 \\
\hline 5 & 1605,6 & 441,6 & 1,0 & 5596,1 & 932,7 & 2,9 \\
\hline 6 & 1318,9 & 161,5 & 1,0 & 3275,2 & 545,9 & 7,9 \\
\hline 7 & 1573,0 & 380,0 & 1,0 & 4839,5 & 806,6 & 8,3 \\
\hline 8 & 2447,0 & 310,3 & 1,5 & 4778,8 & 796,5 & 12,5 \\
\hline 9 & 2470,7 & 480,9 & 0,5 & 6150,0 & 1025,0 & 11,7 \\
\hline 10 & 2267,7 & 249,4 & 1,0 & 6900,0 & 1150,0 & 7,5 \\
\hline 11 & 1624,4 & 215,1 & 1,3 & 5062,3 & 843,7 & 9,9 \\
\hline 12 & 2151,3 & 379,7 & 1,0 & 6202,0 & 1033,7 & 8,1 \\
\hline 13 & 1915,2 & 676,0 & 1,3 & 7577,4 & 1262,9 & 7,9 \\
\hline 14 & 1521,5 & 516,6 & 0,5 & 5565,3 & 927,5 & 14,7 \\
\hline 15 & 1758,5 & 642,3 & 1,0 & 6718,8 & 1119,8 & 10,4 \\
\hline 16 & 1603,0 & 309,2 & 1,3 & 4694,0 & 782,3 & 14,9 \\
\hline 17 & 910,6 & 417,7 & 2,5 & 4080,9 & 680,1 & 18,6 \\
\hline 18 & 1779,3 & 220,1 & 1,0 & 4415,0 & 735,8 & 12,7 \\
\hline 19 & 1245,1 & 672,8 & 2,5 & 4036,9 & 672,8 & 15,3 \\
\hline 20 & 1592,0 & 424,6 & 1,5 & 4475,7 & 745,9 & 16,1 \\
\hline 21 & 1704,2 & 584,6 & 2,2 & 6789,1 & 1131,5 & 9,4 \\
\hline 22 & 1270,1 & 318,8 & 0,5 & 4516,5 & 752,7 & 15,9 \\
\hline 23 & 938,9 & 289,6 & 1,7 & 3860,4 & 643,4 & 12,9 \\
\hline 24 & 1650,1 & 276,0 & 1,0 & 8157,7 & 1359,8 & 5,1 \\
\hline 25 & 1673,7 & 394,9 & 1,2 & 5790,1 & 965,0 & 12,8 \\
\hline 26 & 1941,4 & 270,9 & 1,0 & 4979,9 & 829,1 & 10,0 \\
\hline 27 & 1793,9 & 509,2 & 1,0 & 5763,0 & 960,5 & 12,5 \\
\hline 28 & 1647,4 & 351,6 & 1,0 & 5224,8 & 870,0 & 12,6 \\
\hline 29 & 1453,7 & 234,1 & 0,8 & 4081,6 & 680,3 & 10,8 \\
\hline 30 & 1542,0 & 431,2 & 1,2 & 5446,4 & 907,7 & 14,3 \\
\hline Mediana & 1648,7 & 379,6 & 1,1 & 5143,5 & 856,8 & 11,4 \\
\hline $\begin{array}{l}\text { Percentil } \\
(25 \text { e } 75)\end{array}$ & $(1526,6-1884,9)$ & $(272,2-471,1)$ & $(1,0-1,5)$ & $(4430,2-6108,5)$ & $(738,3-1018,1)$ & $(8,1-13,9)$ \\
\hline Média & 1709,1 & 389,7 & 1,3 & 5414,7 & 902,4 & 11,3 \\
\hline CV(\%) & 24,2 & 38,8 & 42,5 & 24,6 & 24,6 & 33,0 \\
\hline
\end{tabular}

Cmax- concentração plasmática máxima; Cmin-concentração plasmática $6 \mathrm{~h}$ após a administração; tmax- tempo necessário para atingir $\mathrm{Cmax}$; $\mathrm{C}^{\mathrm{ss}}$ - concentração plasmática no estado de equilíbrio; $\mathrm{AUC}^{0-6}$ - área sob a curva concentração plasmática versus tempo; $\mathrm{Cl} / \mathrm{f}$ - clearance total aparente; $\mathrm{CV}$ - coeficiente de variação. 
A Tabela 13 mostra os valores de $C^{\mathrm{ss}}$ observados no intervalo de doses entre a $5^{\mathrm{a}}$ e $6^{\mathrm{a}}$ doses e os valores de $\mathrm{C}^{\mathrm{sS}}$ esperados de acordo com o clearance aparente calculado na dose teste.

Tabela 13. Valores de $C^{\text {ss }}$ observados na $5^{\text {a }}$ dose versus valores de $C^{\text {ss }}$ esperados $(n=30)$. Dados individuais

\begin{tabular}{|c|c|c|c|c|}
\hline Paciente & $\begin{array}{l}\text { Dose sugerida } \\
\text { (mg) }\end{array}$ & $\begin{array}{c}C^{s s} \text { esperada } \\
(n g / m L)\end{array}$ & $\begin{array}{c}\text { Dose } \\
\text { administrada } \\
(\mathrm{mg})\end{array}$ & $\begin{array}{c}C^{\text {ss }} \text { observada } \\
(\mathrm{ng} / \mathrm{mL})\end{array}$ \\
\hline 1 & $38,9-58,3$ & $600-900$ & 44 & 997,4 \\
\hline 2 & $107,6-161,5$ & $600-900$ & 74 & 681,1 \\
\hline 3 & $29,9-44,8$ & $600-900$ & 48 & 715,2 \\
\hline 4 & $19,0-28,6$ & $600-900$ & 58 & 1517,1 \\
\hline 5 & $11,4-17,0$ & $600-900$ & 16 & 932,7 \\
\hline 6 & $28,6-42,9$ & $600-900$ & 26 & 545,9 \\
\hline 7 & $34,3-51,4$ & $600-900$ & 40 & 806,6 \\
\hline 8 & $40,3-60,5$ & $600-900$ & 60 & 796,5 \\
\hline 9 & $32,6-48,9$ & $600-900$ & 72 & 1025,0 \\
\hline 10 & $36,4-54,5$ & $600-900$ & 52 & 1150,0 \\
\hline 11 & $33,0-50,0$ & $600-900$ & 50 & 843,7 \\
\hline 12 & $33,5-50,3$ & $600-900$ & 50 & 1033,7 \\
\hline 13 & $27,4-41,0$ & $600-900$ & 60 & 1262,9 \\
\hline 14 & $53,3-80,0$ & $600-900$ & 82 & 927,5 \\
\hline 15 & $50,0-75,0$ & $600-900$ & 70 & 1119,8 \\
\hline 16 & $30,3-50,4$ & $600-900$ & 70 & 782,3 \\
\hline 17 & $58,0-87,0$ & $600-900$ & 76 & 680,1 \\
\hline 18 & $48,6-72,8$ & $600-900$ & 56 & 735,8 \\
\hline 19 & $45,4-68,0$ & $600-900$ & 62 & 672,8 \\
\hline 20 & $66,6-100,0$ & $600-900$ & 72 & 745,9 \\
\hline 21 & $46,3-69,5$ & $600-900$ & 64 & 1131,5 \\
\hline 22 & $50,0-75,0$ & $600-900$ & 72 & 752,7 \\
\hline 23 & $46,1-69,1$ & $600-900$ & 62 & 643,4 \\
\hline 24 & $14,7-22,1$ & $600-900$ & 42 & 1359,8 \\
\hline 25 & $61,5-92,3$ & $600-900$ & 74 & 965,0 \\
\hline 26 & $45,0-67,5$ & $600-900$ & 50 & 829,1 \\
\hline 27 & $52,5-78,8$ & $600-900$ & 72 & 960,5 \\
\hline 28 & $65,8-98,8$ & $600-900$ & 66 & 870,0 \\
\hline 29 & $34,2-51,3$ & $600-900$ & 44 & 680,3 \\
\hline 30 & $49,7-74,5$ & $600-900$ & 74 & 907,7 \\
\hline
\end{tabular}


Dentre os pacientes que receberam a dose de BU de acordo com a dose baseada no clearance aparente calculado na dose teste $(\mathrm{n}=21$; Pacientes $1,5,7,8,10,11,12,15,17,18$, 19, 20, 21, 22, 23, 25, 26, 27, 28, 29 e 30), 12 deles (57\%) apresentaram concentrações no estado de equilíbrio (entre a $5^{\mathrm{a}}$ e $6^{\mathrm{a}}$ doses) dentro do intervalo de concentrações alvo de 600$900 \mathrm{ng} / \mathrm{mL}$ e 9 pacientes (Pacientes 1, 5, 10, 12, 15, 21, 25 e 27) apresentaram concentrações pouco acima do intervalo terapêutico (valor máximo de 1131,5 ng/mL). Em relação aos 9 pacientes que não receberam as doses de BU de acordo com os valores de clearance aparente calculados na dose teste (Pacientes 2, 3, 4, 6, 9, 13, 14, 16 e 24), 44\% deles (Pacientes 2, 3, 14 e 16) mostraram valores de $C^{\text {SS }}$ dentro do intervalo de concentrações alvo de 600-900 ng/mL, 5 pacientes (55\%) apresentaram concentrações acima de $900 \mathrm{ng} / \mathrm{mL}$ (valor máximo de 1517,1 $\mathrm{ng} / \mathrm{mL})$ e somente 1 apresentou concentração abaixo de $600 \mathrm{ng} / \mathrm{mL}(545,9 \mathrm{ng} / \mathrm{mL})$.

A frequência das concentrações plasmáticas médias de BU no estado de equilíbrio dos pacientes avaliados estão apresentadas na Figura 6.

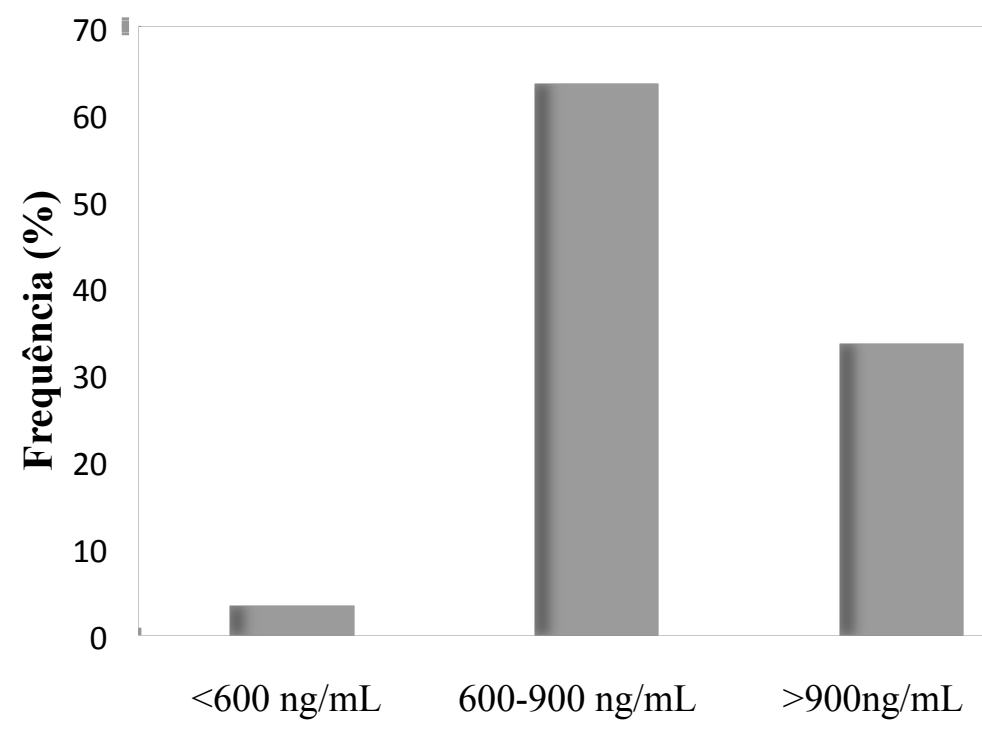

Figura 6. Frequência das $\mathrm{C}^{\text {ss }}$ de $\mathrm{BU}$ de todos os pacientes incluídos no estudo. 
A Tabela 14 apresenta a variabilidade do clearance aparente do BU oral entre e intrapacientes investigados $(\mathrm{n}=30)$.

Tabela 14. Variabilidade do clearance aparente do BU oral na dose teste e na quinta dose $(\mathrm{n}=30)$

\begin{tabular}{|c|c|c|c|}
\hline Paciente & $\begin{array}{l}\text { dose teste BU } \\
\mathrm{Cl} / \mathbf{f}(\mathrm{L} / \mathrm{h})\end{array}$ & $\begin{array}{c}\text { quinta dose BU } \\
\mathrm{Cl} / \mathbf{f} \quad(\mathrm{L} / \mathrm{h})\end{array}$ & $\begin{array}{c}\% \text { de desvio } \\
\text { intrapaciente }\end{array}$ \\
\hline 1 & 10,8 & 7,4 & $-31,5$ \\
\hline 2 & 29,9 & 18,1 & $-39,5$ \\
\hline 3 & 8,3 & 11,2 & 34,9 \\
\hline 4 & 5,3 & 6,4 & 20,7 \\
\hline 5 & 3,2 & 2,9 & $-9,4$ \\
\hline 6 & 7,9 & 7,9 & 0,0 \\
\hline 7 & 9,5 & 8,3 & $-12,6$ \\
\hline 8 & 11,2 & 12,5 & 11,6 \\
\hline 9 & 9,1 & 11,7 & 28,6 \\
\hline 10 & 10,1 & 7,5 & $-25,7$ \\
\hline 11 & 9,3 & 9,9 & 6,4 \\
\hline 12 & 9,3 & 8,1 & $-12,9$ \\
\hline 13 & 7,6 & 7,9 & 3,9 \\
\hline 14 & 14,8 & 14,7 & $-0,6$ \\
\hline 15 & 13,9 & 10,4 & $-25,2$ \\
\hline 16 & 8,4 & 14,9 & 77,4 \\
\hline 17 & 16,1 & 18,6 & 15,5 \\
\hline 18 & 13,5 & 12,7 & $-5,9$ \\
\hline 19 & 12,6 & 15,3 & 21,4 \\
\hline 20 & 18,5 & 16,1 & $-12,9$ \\
\hline 21 & 12,9 & 9,4 & $-27,1$ \\
\hline 22 & 13,9 & 15,9 & 14,4 \\
\hline 23 & 12,8 & 12,9 & 0,8 \\
\hline 24 & 4,1 & 5,1 & 24,4 \\
\hline 25 & 17,1 & 12,8 & $-25,1$ \\
\hline 26 & 12,5 & 10,0 & $-20,0$ \\
\hline 27 & 14,6 & 12,5 & $-14,4$ \\
\hline 28 & 18,3 & 12,6 & $-31,1$ \\
\hline 29 & 9,5 & 10,8 & 13,7 \\
\hline 30 & 13,8 & 14,3 & 3,6 \\
\hline CV (\%) & 42,1 & 33,0 & \\
\hline
\end{tabular}


A variabilidade do clearance aparente do $\mathrm{BU}$ entre a dose teste e a quinta dose, não apresenta uma tendência a diminuir, aumentar ou se manter, como podemos observar nos resultados dos desvios do clearance do BU apresentados na Tabela 14 e na Figura 7.

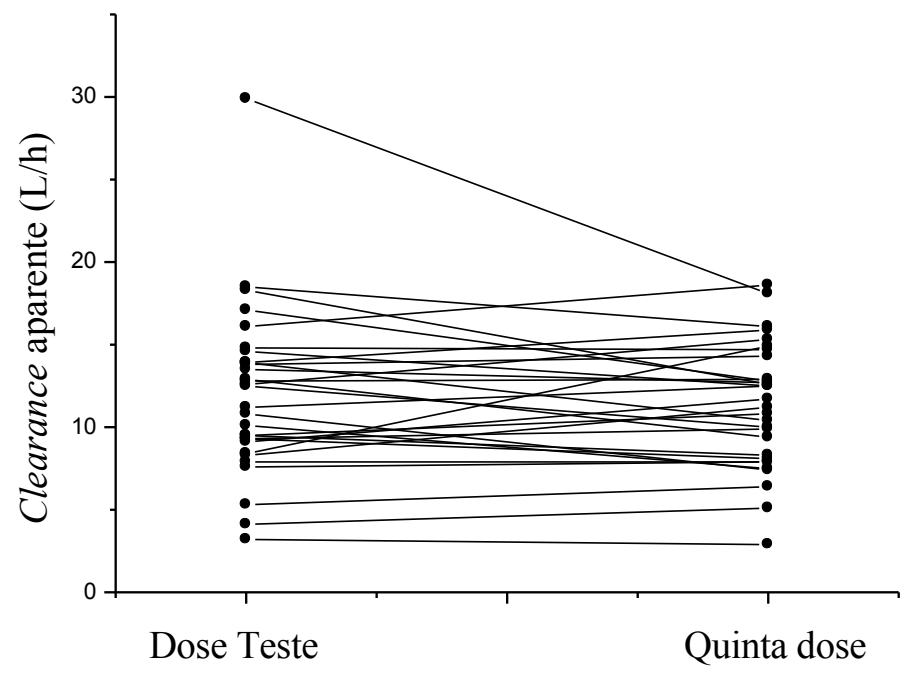

Figura 7. Variabilidade do clearance aparente do BU entre a dose teste e a quinta dose 


\subsection{Polimorfismos no gene GST}

A Tabela 15 apresenta a frequência dos polimorfismos no GSTA1, GSTP1 e GSTM1 nos pacientes investigados $(\mathrm{n}=30)$ e as associações entre os polimorfismos e o clearance aparente do BU calculado na dose teste e entre os polimorfismos e os valores de $\mathrm{AUC}^{0-6}$ do BU avaliados na quinta dose (Testes de Kruskal-Wallis ou Mann-Whitney, $p<0,05$ ). As associações dos polimorfismos com os parâmetros farmacocinéticos $\mathrm{AUC}^{0-6}$ e clearance aparente também estão apresentadas nas Figuras 8, 9 e 10.

Tabela 15. Associação dos polimorfismos da GST com o clearance aparente após dose teste de $\mathrm{BU}$ e $\mathrm{AUC}^{0-6}$ após a quinta dose de BU. Os dados de $\mathrm{Cl} / \mathrm{f}$ e $\mathrm{AUC}^{0-6}$ estão apresentados como mediana $(n=30)$

\begin{tabular}{|c|c|c|c|c|c|}
\hline Polimorfismo & n (\%) & $\begin{array}{c}\mathrm{Cl} / \mathbf{f} \\
(\mathrm{L} / \mathbf{h})\end{array}$ & $\mathbf{p}$ & $\begin{array}{c}\mathrm{AUC}^{0-6} \\
\text { (ng.h/mL) }\end{array}$ & $\mathbf{p}$ \\
\hline \multicolumn{6}{|l|}{ GSTA1 } \\
\hline$* \mathrm{~A} / * \mathrm{~A}$ & $10(33 \%)$ & 12,8 & \multirow{3}{*}{0,98} & 5521,2 & \multirow{3}{*}{0,88} \\
\hline$* \mathrm{~A} / *_{\mathrm{B}}$ & $14(47 \%)$ & 10,6 & & 5021,1 & \\
\hline$* \mathrm{~B} / *^{*} \mathrm{~B}$ & $6(20 \%)$ & 11,0 & & 4462,9 & \\
\hline \multicolumn{6}{|l|}{ GSTP1 } \\
\hline $\mathrm{A} / \mathrm{A}$ & $11(36,7 \%)$ & 12,5 & \multirow{3}{*}{0,20} & 5446,4 & \multirow{3}{*}{0,43} \\
\hline $\mathrm{A} / \mathrm{G}$ & $14(46,7 \%)$ & 11,45 & & 4736,4 & \\
\hline $\mathrm{G} / \mathrm{G}$ & $5(16,7 \%)$ & 9,4 & & 6202,0 & \\
\hline \multicolumn{6}{|l|}{ GSTM1 } \\
\hline Presente & $18(60 \%)$ & 11,45 & \multirow{2}{*}{0,98} & 5604,7 & \multirow{2}{*}{0,34} \\
\hline Ausente & $12(40 \%)$ & 11,65 & & 4920,55 & \\
\hline
\end{tabular}

GSTA1- *A (Alelo selvagem), *B (Alelo mutante) ; GSTP1-Alelo selvagem (A), Alelo mutante (G). Testes de Kruskal-Wallis e Mann-Whitney. 
Figura 8. Associação entre o polimorfismo da GSTM1 (presença ou deleção) e os parâmetros farmacocinéticos clearance aparente e AUC avaliados na dose teste e na quinta dose

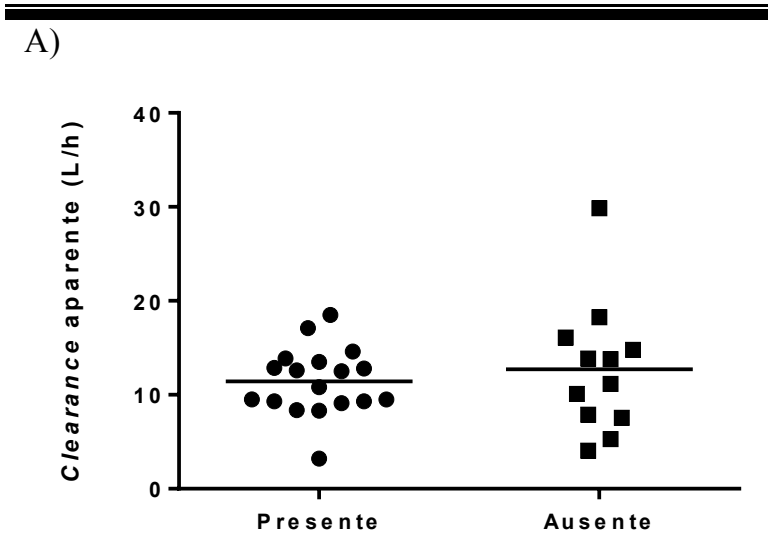

B)
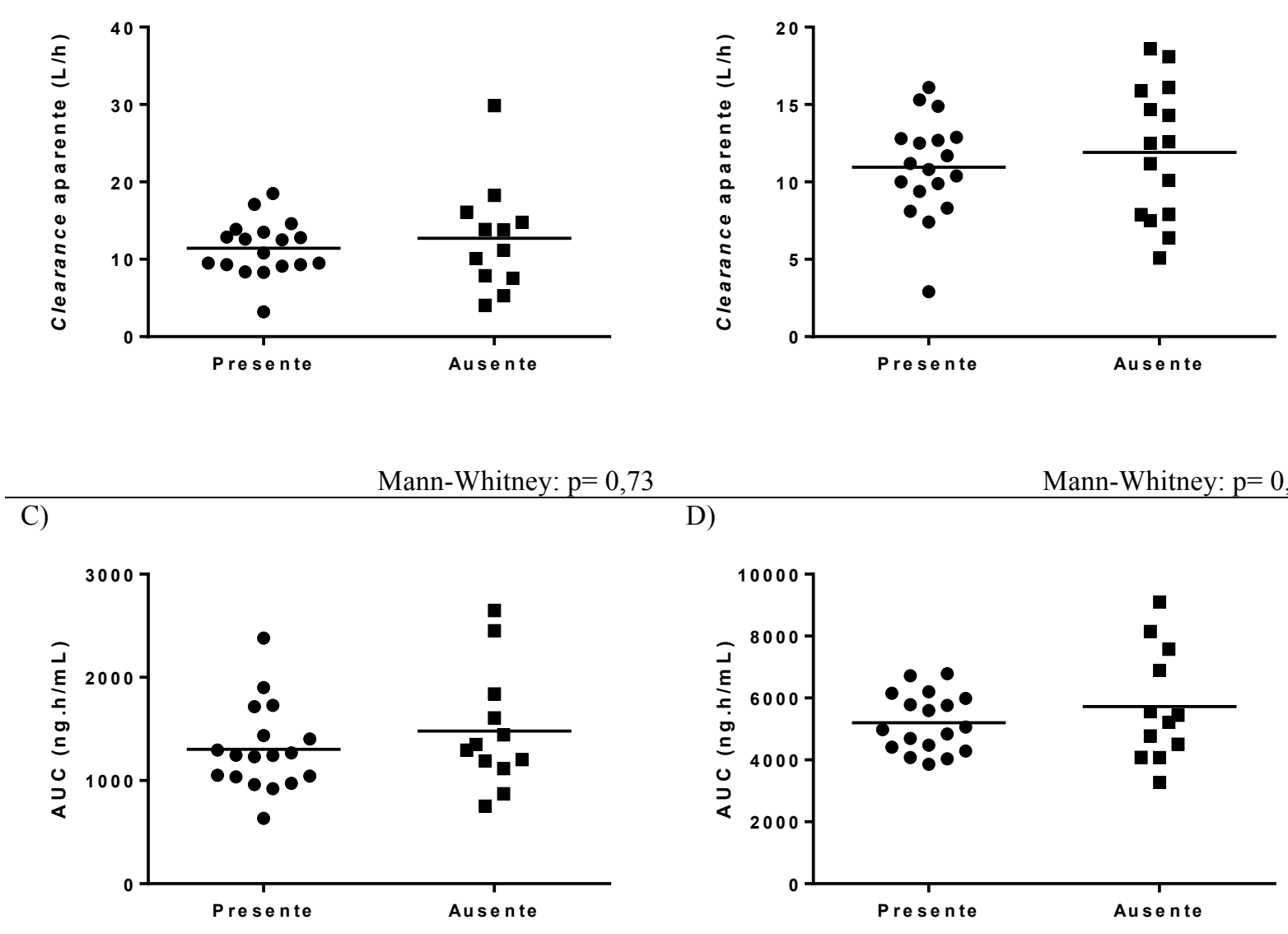

D)

Mann-Whitney: $p=0,79$

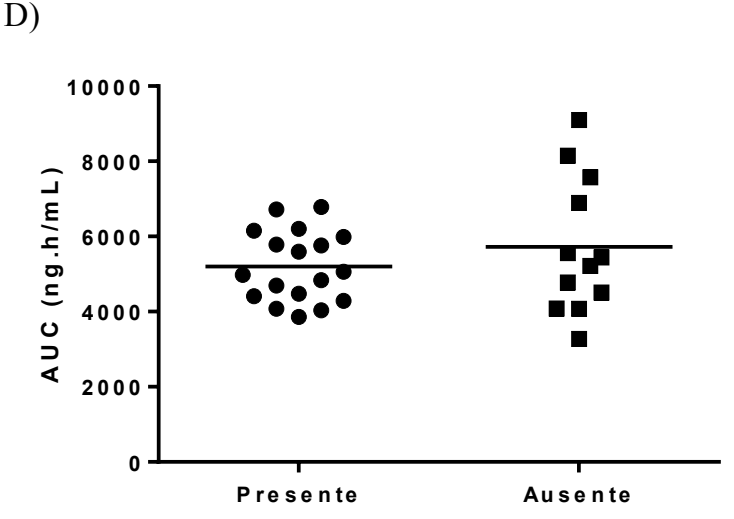

Mann-Whitney: $\mathrm{p}=0,44$

Mann-Whitney: $p=0,63$

A- Clearance aparente dose teste B-Clearance aparente $5^{\text {a dose } \text { C- AUC }}{ }^{0-\infty}$ após dose teste D- AUC ${ }^{0-6}$ após $5^{\text {a }}$ dose 
Figura 9. Associação entre os polimorfismos da GSTP1 e os parâmetros farmacocinéticos clearance aparente e AUC avaliados na dose teste e na quinta dose

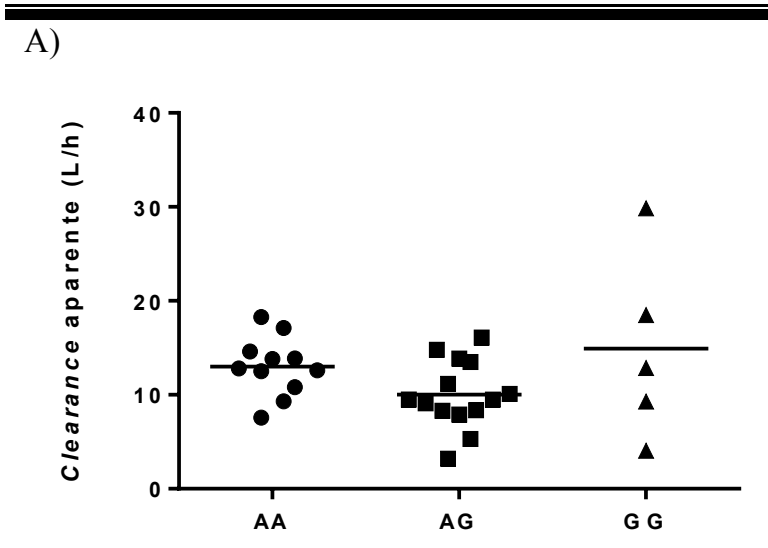

B)

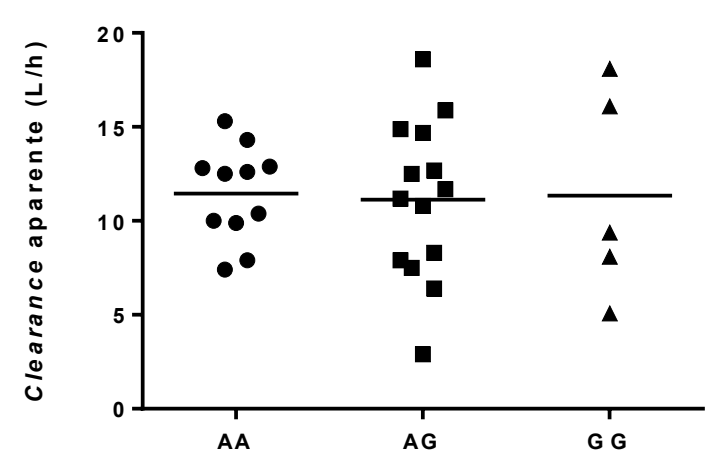

Kruskal-Wallis $\mathrm{p}=0,20$

C)

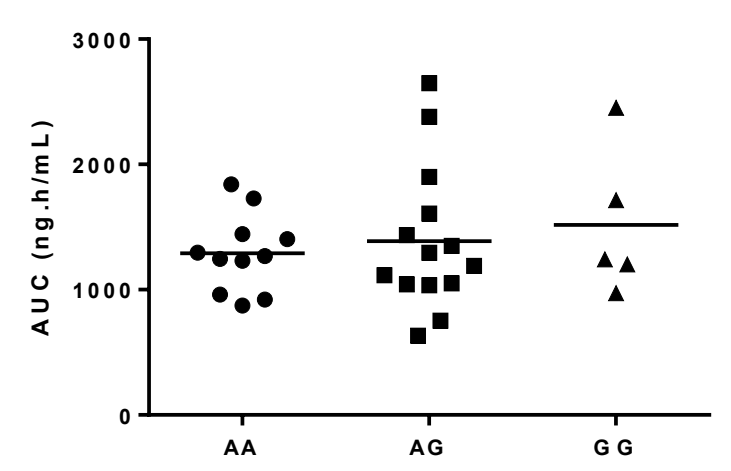

D)

Kruskal-Wallis $\mathrm{p}=0,98$

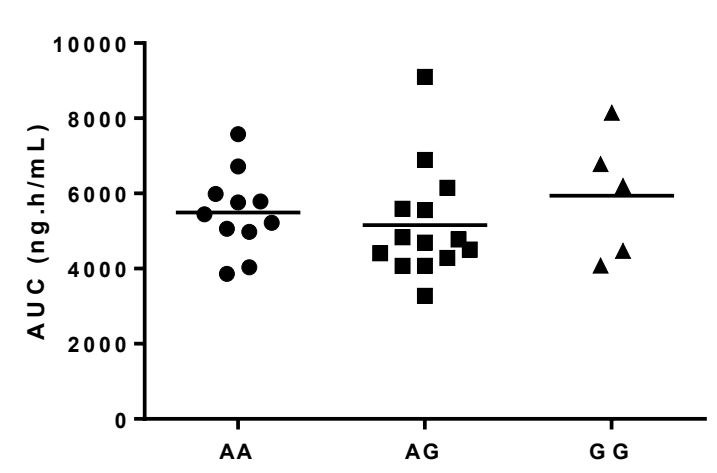


Figura 10. Associação entre os polimorfismos da GSTA1 e os parâmetros farmacocinéticos clearance aparente e AUC avaliados na dose teste e na quinta dose

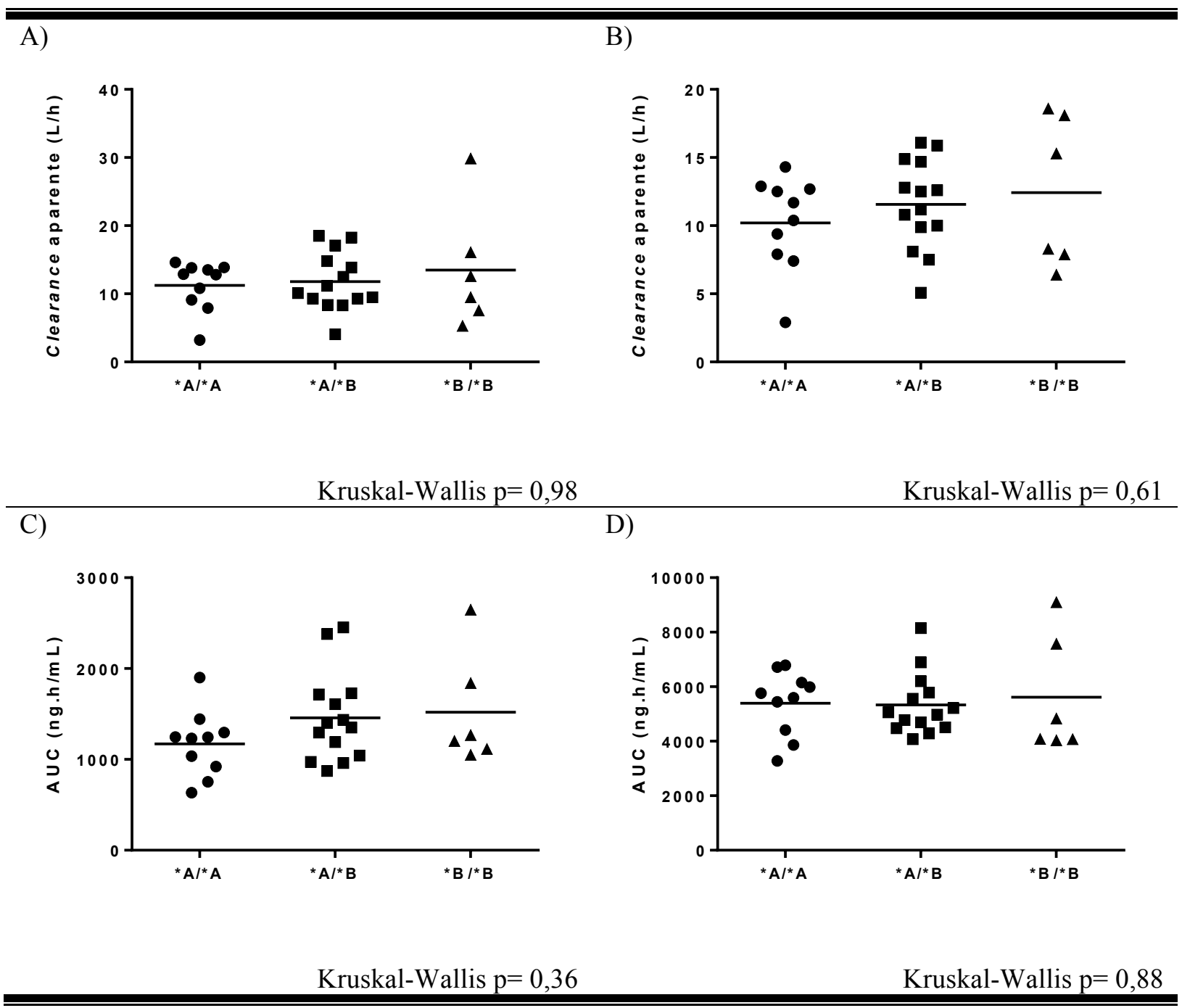

\subsection{Evolução Clínica}

Dentre as possíveis complicações inerentes ao uso do BU podem-se destacar a mucosite, a SOS, as alterações pulmonares e a cistite hemorrágica. Os pacientes foram avaliados conforme os critérios da Common Toxicity Criteria of National Institute (NCI-CTC) versão 2. Os resultados da toxicidade avaliados na evolução pós-TCTH estão apresentados na Tabela 16. 
Tabela 16. Toxicidade do BU avaliada na evolução pós-TCTH (n=30)

\begin{tabular}{|c|c|c|c|c|c|c|c|}
\hline Paciente & Diagnóstico & $\begin{array}{c}C^{s s} B U \\
(n g / m L)\end{array}$ & $\begin{array}{c}\text { Mucosite } \\
\text { (0-IV) }\end{array}$ & $\begin{array}{l}\text { SOS } \\
(0-I)\end{array}$ & $\begin{array}{c}\text { Alteração } \\
\text { Pulmonar } \\
\text { (0-IV) }\end{array}$ & $\begin{array}{c}\text { Cistite } \\
\text { Hemorrágica } \\
(0-I)\end{array}$ & $\begin{array}{c}\text { Situação } \\
\text { atual }\end{array}$ \\
\hline 1 & LMA & 997,0 & 0 & 0 & 0 & 0 & $\mathrm{RC}$ \\
\hline 2 & LMA & 681,1 & II & 0 & 0 & 0 & Recaída \\
\hline 3 & SMD & 715,2 & III & 0 & 0 & 0 & $\mathrm{RC}$ \\
\hline 4 & LMC & 1517,1 & II & 0 & 0 & 0 & $\mathrm{RC}$ \\
\hline 5 & LMA & 932,0 & IV & I & I & 0 & Óbito \\
\hline 6 & $\mathrm{AF}$ & 546,0 & II & 0 & 0 & 0 & $\mathrm{RC}$ \\
\hline 7 & $\mathrm{AF}$ & 807,0 & III & 0 & 0 & 0 & $\mathrm{RC}$ \\
\hline 8 & LMA & 796,5 & II & 0 & 0 & 0 & $\mathrm{RC}$ \\
\hline 9 & LMA & 1025,0 & I & 0 & 0 & 0 & $\mathrm{RC}$ \\
\hline 10 & LMC & 1150,0 & I & 0 & 0 & I & $\mathrm{RC}$ \\
\hline 11 & $\mathrm{AF}$ & 843,7 & II & 0 & 0 & 0 & $\mathrm{RC}$ \\
\hline 12 & SMD & 1033,7 & 0 & 0 & 0 & 0 & $\mathrm{RC}$ \\
\hline 13 & SMD & 1262,9 & I & 0 & 0 & 0 & $\mathrm{RC}$ \\
\hline 14 & SMD & 927,5 & I & 0 & IV & I & Óbito \\
\hline 15 & LMA & 1119,8 & II & 0 & 0 & 0 & $\mathrm{RC}$ \\
\hline 16 & LMA & 782,3 & II & 0 & 0 & 0 & Recaída \\
\hline 17 & LMA & 680,1 & II & 0 & 0 & 0 & $\mathrm{RC}$ \\
\hline 18 & LMA & 735,8 & II & 0 & III & 0 & Óbito \\
\hline 19 & $\mathrm{AF}$ & 672,8 & II & 0 & 0 & 0 & $\mathrm{RC}$ \\
\hline 20 & LMA & 745,9 & I & 0 & 0 & 0 & $\mathrm{RC}$ \\
\hline 21 & LMA & 1131,5 & II & 0 & I & 0 & $\mathrm{RC}$ \\
\hline 22 & LMC & 752,7 & II & 0 & 0 & 0 & $\mathrm{RC}$ \\
\hline 23 & LMC & 643,4 & I & 0 & 0 & I & $\mathrm{RC}$ \\
\hline 24 & $\mathrm{AF}$ & 1359,8 & II & 0 & 0 & 0 & $\mathrm{RC}$ \\
\hline 25 & LMA & 965,0 & 0 & 0 & 0 & 0 & $\mathrm{RC}$ \\
\hline 26 & LMA & 829,1 & I & 0 & 0 & 0 & $\mathrm{RC}$ \\
\hline 27 & $\mathrm{LNH}$ & 960,5 & II & 0 & 0 & 0 & $\mathrm{RC}$ \\
\hline 28 & LMA & 870,0 & I & 0 & 0 & 0 & $\mathrm{RC}$ \\
\hline 29 & LMA & 680,3 & I & 0 & 0 & 0 & $\mathrm{RC}$ \\
\hline 30 & LMA & 907,7 & I & 0 & 0 & 0 & $\mathrm{RC}$ \\
\hline
\end{tabular}

LMA- leucemia mielóide aguda; LMC- leucemia mielóide crônica; AF- anemia falciforme; SMD- síndrome mielodisplásica; LNH-Linfoma não Hodking; SOS- síndrome obstrutiva sinusoidal; RC- remissão clínica. 
Tabela 17. Distribuição de frequências e testes de associação entre a $C^{\text {ss }}$ do $B U$ e os efeitos adversos avaliados (Teste exato de Fisher; $p<0,05$ )

\begin{tabular}{|c|c|c|c|c|}
\hline \multicolumn{5}{|c|}{$\mathrm{C}^{\mathrm{ss}}$ do BU (ng/mL) } \\
\hline & $<600$ & $600-900$ & $>900$ & p-valor \\
\hline \multicolumn{5}{|c|}{ Mucosite } \\
\hline 0 & $0(0,0 \%)$ & $0(0,0 \%)$ & $3(100,0 \%)$ & \multirow{5}{*}{0,45} \\
\hline $\mathrm{I}$ & $0(0,0 \%)$ & $6(60,0 \%)$ & $4(40,0 \%)$ & \\
\hline II & $1(7,2 \%)$ & $8(57,1 \%)$ & $5(35,7 \%)$ & \\
\hline III & $0(0,0 \%)$ & $2(100,0 \%)$ & $0(0,0 \%)$ & \\
\hline IV & $0(0,0 \%)$ & $1(100,0 \%)$ & $0(0,0 \%)$ & \\
\hline \multicolumn{5}{|l|}{ SOS } \\
\hline Não & $1(3,4 \%)$ & $18(62,1 \%)$ & $10(34,5 \%)$ & \multirow{2}{*}{0,89} \\
\hline Sim & $0(0,0 \%)$ & $1(100,0 \%)$ & $0(0,0 \%)$ & \\
\hline \multicolumn{5}{|c|}{ Alteração Pulmonar } \\
\hline 0 & $1(3,8 \%)$ & $15(57,7 \%)$ & $10(38,5 \%)$ & \multirow{5}{*}{0,95} \\
\hline $\mathrm{I}$ & $0(0,0 \%)$ & $1(50,0 \%)$ & $1(50,0 \%)$ & \\
\hline II & $0(0,0 \%)$ & $0(0,0 \%)$ & $0(0,0 \%)$ & \\
\hline III & $0(0,0 \%)$ & $1(100,0 \%)$ & $0(0,0 \%)$ & \\
\hline IV & $0(0,0 \%)$ & $1(100 \%)$ & $0(0,0 \%)$ & \\
\hline \multicolumn{5}{|c|}{ Cistite Hemorrágica } \\
\hline Não & $1(3,7 \%)$ & $15(55,6 \%)$ & $11(40,7 \%)$ & \multirow{2}{*}{0,67} \\
\hline Sim & $0(0,0 \%)$ & $1(33,3 \%)$ & $2(66,7 \%)$ & \\
\hline
\end{tabular}

SOS- síndrome obstrutiva sinusoidal.

Teste exato de Fisher $(\mathrm{p}<0,05)$

\subsection{Farmacocinética Populacional do BU (Análise Compartimental)}

Para descrever a exposição ao BU, foi utilizado um modelo de um compartimento, com primeira ordem de absorção e eliminação. As covariáveis peso ideal ajustado e os valores séricos de ALT foram correlacionadas de forma exponencial com o clearance aparente, enquanto o peso ideal ajustado foi correlacionado exponencialmente com o volume de distribuição aparente. Os parâmetros farmacocinéticos do BU foram re-estimados à partir do modelo de Sandstrom et al. (2001), onde os autores utilizaram como covariáveis o peso, a ALT e a associação com fenitoína. A covariável associação com a fenitoina não foi utilizada no modelo final em função dos dados do presente estudo não mostrar associação entre o uso 
de fenitoína e o clearance aparente do BU. A estrutura hierárquica do modelo compartimental permite a representação da distribuição estocástica dos parâmetros, permitindo desta forma a identificação das diferenças interindividuais no clearance aparente, volume de distribuição aparente e constante de velocidade de absorção. Além disso, para representar a variabilidade entre a dose teste e o tratamento (quinta-dose) utilizou-se um segundo nível hierárquico no modelo, através do qual pode-se descrever diferenças entre os eventos ou ocasiões ( IOV, do inglês inter-occasion variability).

Os parâmetros estimados pelo modelo final estão apresentados na Tabela 18, onde pode-se observar, baseados nos resultados do bootstrap, que os parâmetros estimados foram robustos. A estimativa do clearance aparente e do volume de distribuição aparente foram muito similares com as estimativas do modelo e com baixos valores de coeficiente de variação. Assim, os resultados do bootstrap sugerem que o modelo apresenta estimativas exatas e estáveis.

Tabela 18. Parâmetros farmacocinéticos do modelo populacional final

\begin{tabular}{|c|c|c|c|c|c|c|c|}
\hline \multirow[t]{2}{*}{ Parâmetros } & \multirow{2}{*}{$\begin{array}{c}\text { Modelo } \\
\text { final }^{\mathrm{a}} \\
\text { Estimativa }^{-}\end{array}$} & \multicolumn{2}{|c|}{ Bootstrap } & \multicolumn{2}{|c|}{ Covariáveis } & \multicolumn{2}{|c|}{ Bootstrap } \\
\hline & & Mediana & CV $(\%)$ & Peso & ALT & Mediana & CV $(\%)$ \\
\hline \multicolumn{8}{|l|}{$\begin{array}{c}\boldsymbol{\theta}- \\
\text { Estimativas }\end{array}$} \\
\hline $\mathrm{Cl} / \mathrm{f}(\mathrm{L} / \mathrm{h})$ & 12,3 & 12,27 & 5,02 & $\begin{array}{l}1,35 \\
\text { (exp) }\end{array}$ & $\begin{array}{c}-0,01 \\
\text { (exp) (fixo) }\end{array}$ & 1,48 & $\begin{array}{l}0,01 \\
\text { (fixo) }\end{array}$ \\
\hline $\mathrm{Vd} / \mathrm{f}(\mathrm{L})$ & 48,8 & 48,99 & 5,17 & 2,33 & & 2,40 & 21,96 \\
\hline $\mathrm{Ka}\left(\mathrm{h}^{-1}\right)$ & 3,98 & 3,93 & 20,50 & & & & \\
\hline T Lag (h) & 0,20 & 0,20 & 5,20 & & & & \\
\hline \multicolumn{8}{|l|}{$\begin{array}{c}\boldsymbol{\omega}- \\
\text { Estimativas }\end{array}$} \\
\hline $\begin{array}{l}\mathrm{IIV} \mathrm{Cl} / \mathrm{f} \\
(\mathrm{CV} \%)\end{array}$ & 10,0 & 10,0 & 58,0 & & & & \\
\hline $\begin{array}{l}\text { IIV Vd/f } \\
(\mathrm{CV} \%)\end{array}$ & 3,2 (fixo) & 3,2 & - & & & & \\
\hline IIV Ka (CV\%) & 72,4 & 69,3 & 55,3 & & & & \\
\hline $\begin{array}{l}\mathrm{IOV} \mathrm{Cl/f} \\
(\mathrm{CV} \%)\end{array}$ & 8,0 & 21,6 & 41,6 & & & & \\
\hline $\begin{array}{l}\text { IOV Vd/f } \\
(\mathrm{CV} \%)\end{array}$ & 31,3 & 30,0 & 31,8 & & & & \\
\hline $\begin{array}{l}\text { IOV Ka } \\
(\mathrm{CV} \%)\end{array}$ & 84,2 & 83,6 & 39,9 & & & & \\
\hline \multicolumn{8}{|l|}{$\begin{array}{c}\sigma^{2}- \\
\text { Estimativa }\end{array}$} \\
\hline $\begin{array}{c}\mathrm{RV} \\
\text { proporcional }\end{array}$ & $\begin{array}{c}0,06 \\
14\end{array}$ & 0,06 & 24,5 & & & & \\
\hline
\end{tabular}


A Figura 11 apresenta os gráficos de diagnósticos de qualidade (goodness-of-fit-plots), onde estão apresentadas as concentrações previstas versus concentrações observadas para a população ou estimativa puntual (DV versus PRED) e individual (DV versus IPRED) e o resíduos ponderados condicionais (CWRES, do inglês, conditional weighted residuals) versus PRED e versus tempo. Como pode-se observar, os CWRES estão aleatoriamente distribuídos em torno de zero e de modo geral, as previsões populacionais e individual descrevem os dados de forma adequada.
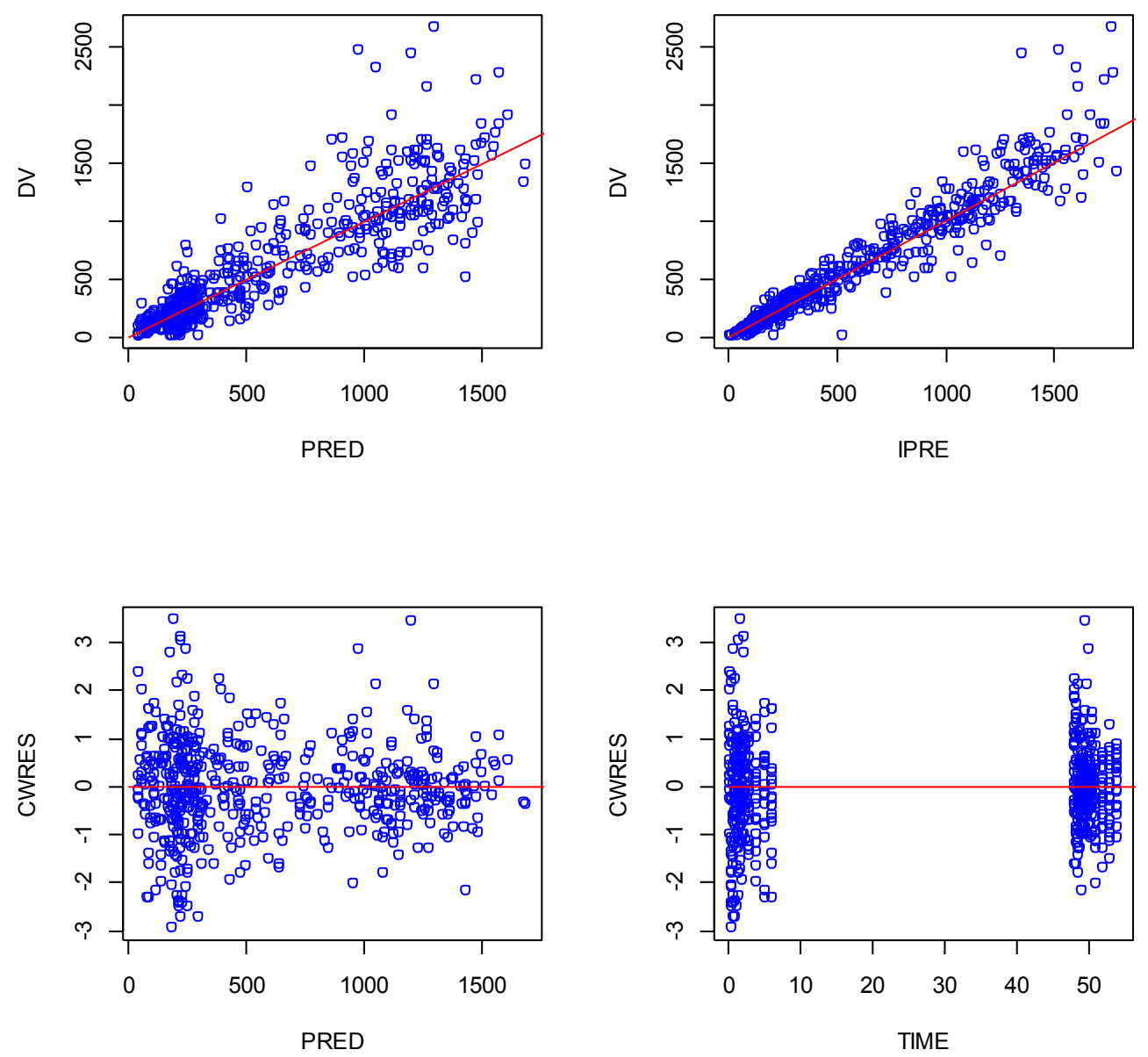

Figura 11. Gráficos de diagnósticos de qualidade do modelo final. Concentrações observadas (DV) versus concentrações populacionais previstas (PRED), concentrações observadas (DV) versus concentrações individuais previstas (IPRED), resíduos ponderados condicionais (CWRES) versus predições populacionais e resíduos ponderados condicionais (CWRES) versus tempo após a administração do BU

A análise do VPC (Visual Predictive Check; Figura 12) confirmou a adequação das estimativas dos parâmetros e indicou um bom desempenho preditivo do modelo. A mediana reflete adequadamente a tendência dos dados observados e o intervalo de confiança de $95 \%$ 
representa bem a variabilidade dos dados observados. Para melhor análise, os gráficos foram dividos de acordo com as ocasiões do estudo (dose teste e quinta dose) com estratificação com base no peso (pacientes com pesos abaixo e acima da mediana de peso). Os resultados do VPC mostraram uma pequeno excesso na variabilidade, principalmente nos pacientes com peso acima da mediana, porém este excesso é claramente aceitável.
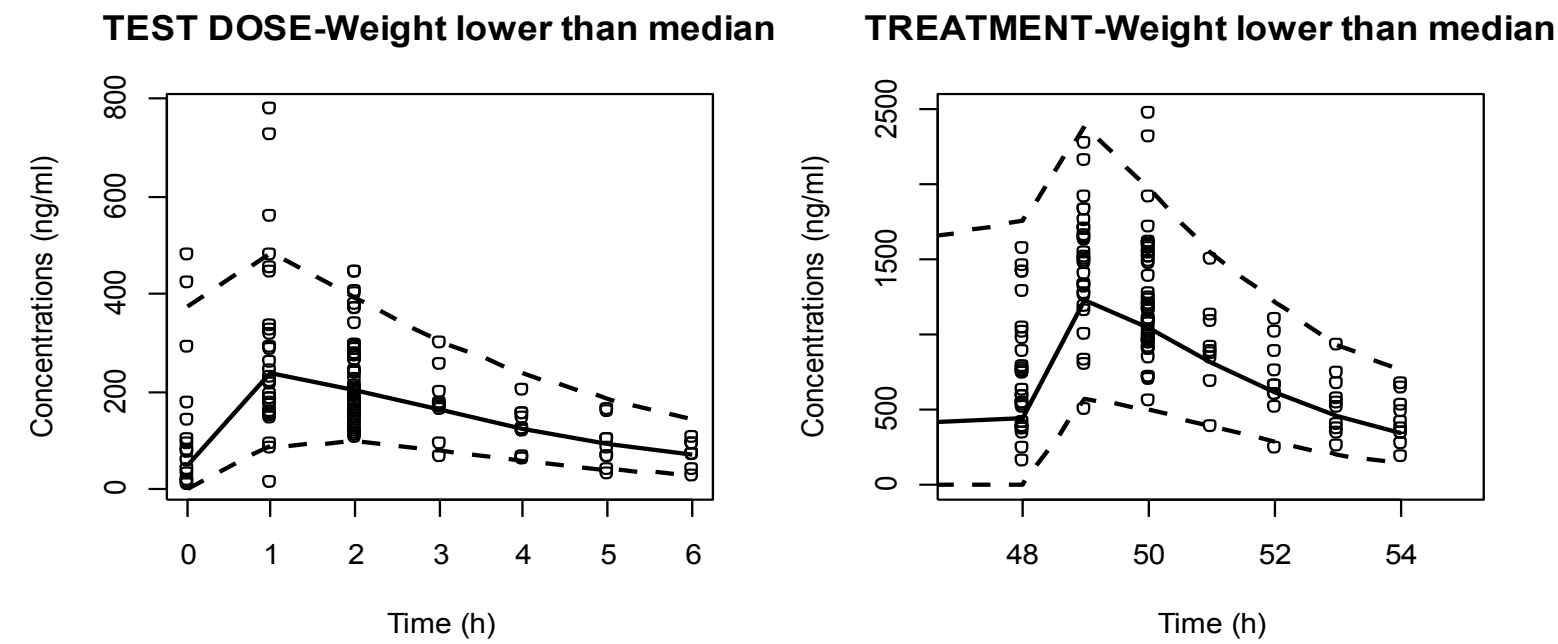

TEST DOSE-Weight higher than median

TREATMENT-Weight higher than mediar
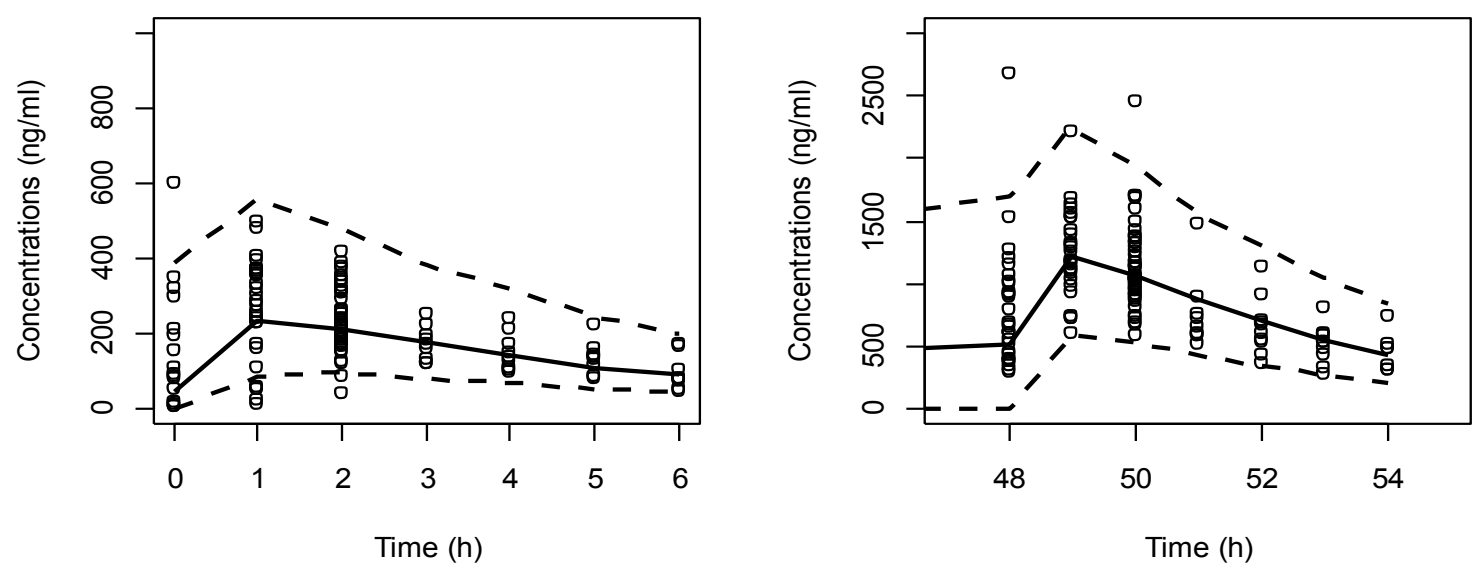

Figura 12. VPC de validação interna $(n=20)$

Linha sólida: mediana dos dados simulados; Linhas tracejadas: percentis 25 e 75 dos dados simulados. 
As predições de AUC de 20 pacientes foram realizadas com base no modelo final e avaliadas durante a dose teste e a quinta dose. Os histogramas (Figura 13) representam a distribuição dos valores de AUC à partir de 1000 simulações. A linha vermelha representa a mediana dos valores de AUC dos dados reais do estudo clínico. A localização das linhas vermelhas nos resultados do PPC (Posterior predictive plot check) revelam que o modelo populacional utilizado descreve com exatidão os valores de AUC observados nos pacientes do estudo clínico nas duas diferentes ocasiões estudadas, dose teste e quinta dose.

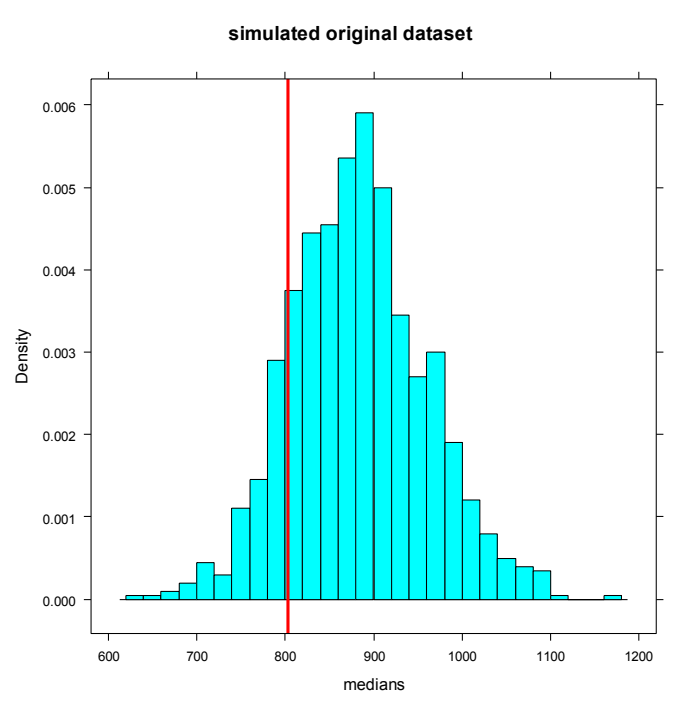

Dose Teste

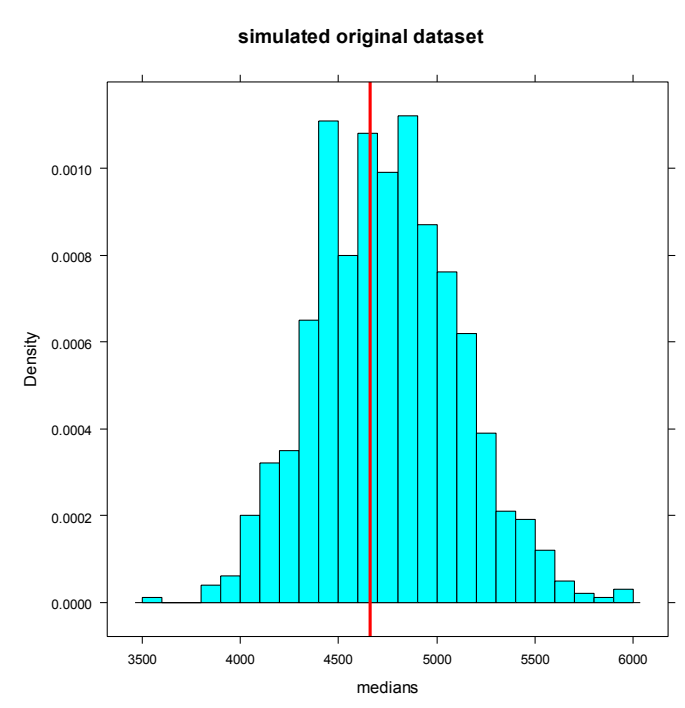

Quinta dose

Figura 13. Distribuição dos valores de AUC preditos pelo modelo (1000 replicatas) por ocasião da dose teste e quinta dose para o grupo de 20 pacientes investigados. As linhas vermelhas representam a mediana dos dados dos pacientes reais.

A análise NPDE (Normalized Prediction Distribution Errors) produz informação sobre o grau de precisão do modelo e prediz o valor médio das observações e a variabilidade dentro deles. Os resultados da NPDE utilizados para a validação interna do modelo popPK do BU estão apresentados na Figura 14, onde pode-se observar que os erros estão distribuídos de forma normal, a variabilidade da população está bem predita pelo modelo independentemente da planilha com dados originais e não há distorções na predição versus concentração ou versus tempo. 
A

Q-Q plot versus $N(0,1)$ for npde

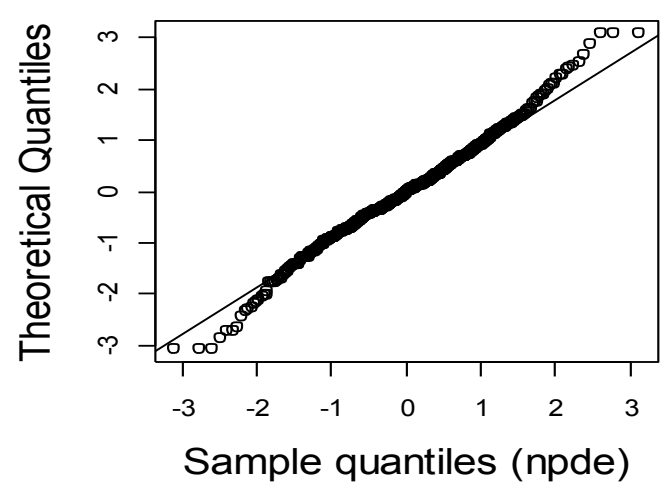

$\mathrm{C}$

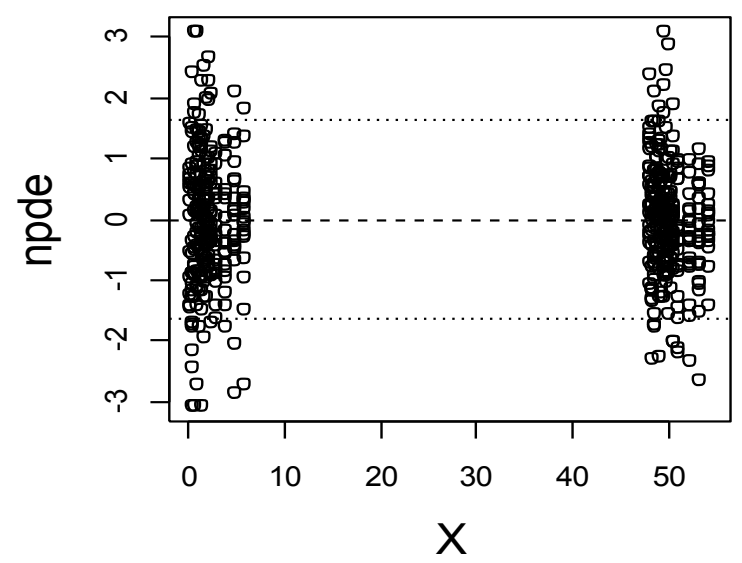

$\mathrm{B}$

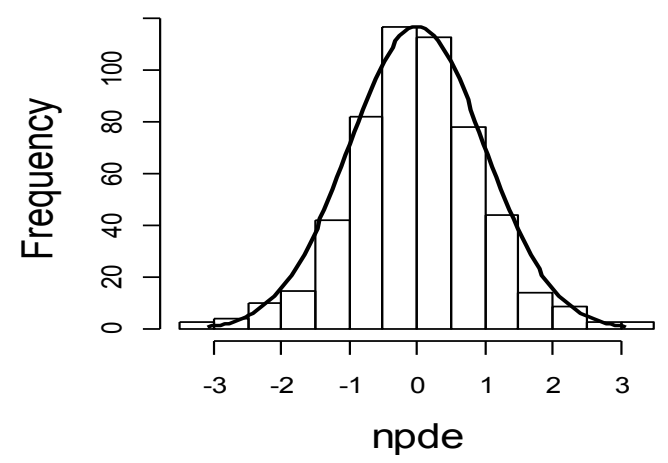

$\mathrm{D}$

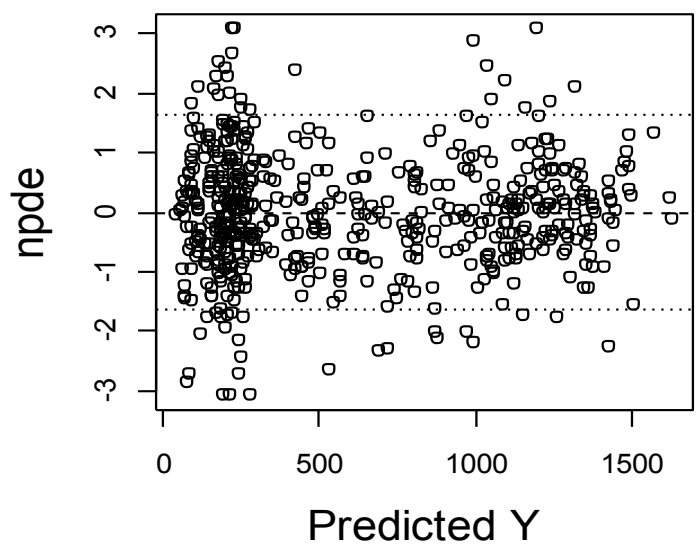

Figura 14. Resultados da validação interna com NPDE. (A) Gráfico quantil-quantil do NPDE versus distribuição normal padrão esperada, (B) Histograma do NPDE com a distribuição normal, (C) distribuição do NPDE versus tempo após a administração da dose teste e após a administração da quinta dose de BU e (D) NPDE versus concentrações preditas. A distribuição normal é representada pela linha sólida. As linhas pontilhadas representam a média-2SD da distribuição normal.

Os gráficos espelhos (mirror-plots) foram usados para avaliar se a estrutura da matriz de variância-covariância representa com exatidão as correlações dos dados originais. Das 10 simulações, 3 delas foram escolhidas de forma aleatória e estão apresentadas nas Figuras 15 e 16, respectivamente, gráficos espelhos das predições populacionais versus dados originais e das predições individuais versus dados originais. 


\section{Observations vs. Population predictions (Run 1)}

Simulated data (\#7)

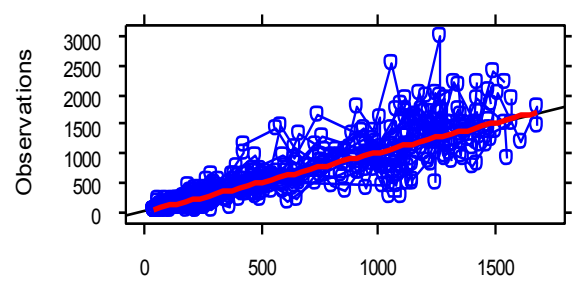

Original data
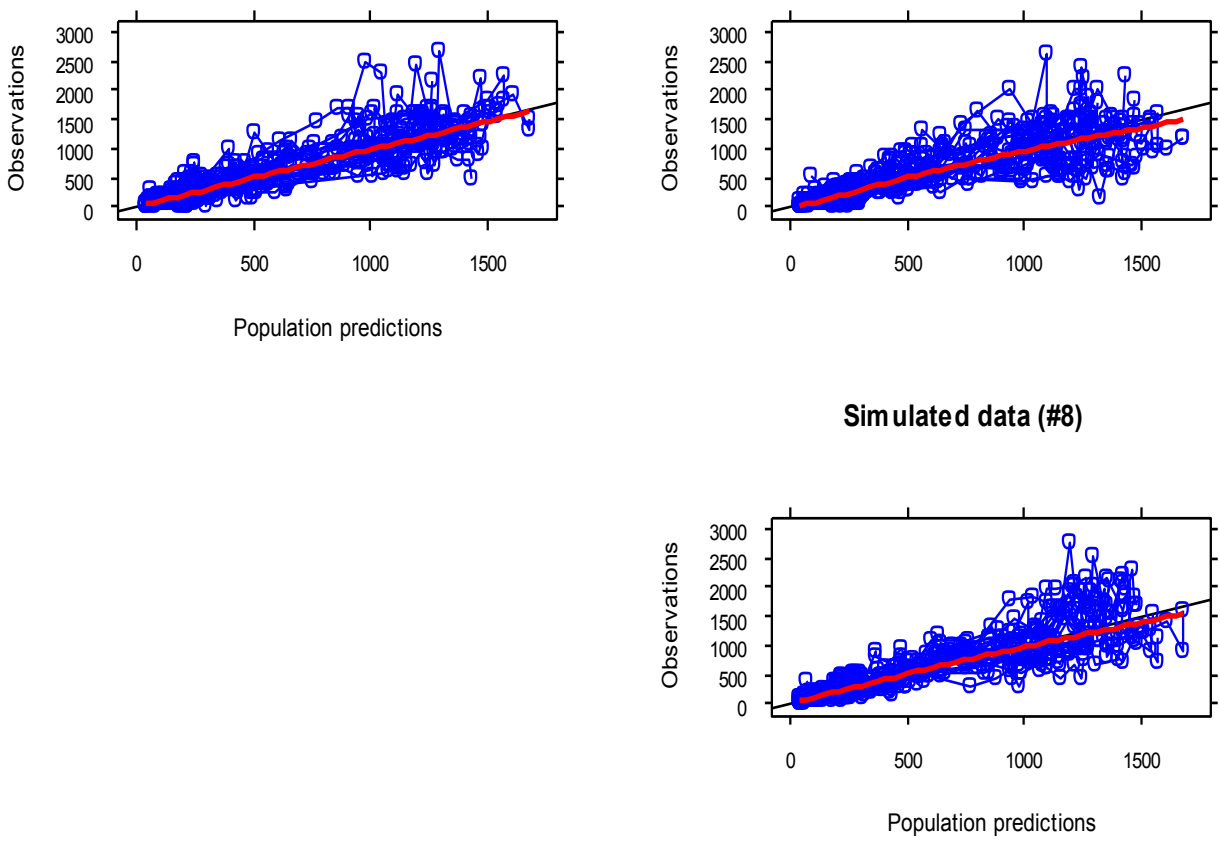

Figura 15. Gráficos espelhos populacionais. Os gráficos à direita e à esquerda, relacionam as concentrações plasmáticas de BU observadas versus as concentrações plasmáticas populacionais previstas pelo modelo popPK. O gráfico à esquerda apresenta a qualidade do ajuste dos dados originais. Os gráficos populacionais à direita foram selecionados de forma aleatória à partir dos dados simulados pelo modelo 
A avaliação do desempenho do modelo, avaliada com base nos resultados dos gráficos espelhos, revelam a similaridade dos dados originais e simulados, tanto para a população (Figura 15) quanto para o indivíduo (Figura 16).

\section{Observations vs. Individual predictions (Run 1)}

Simulated data (\#7)

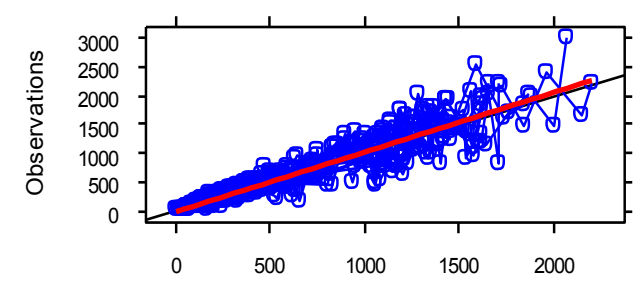

Original data

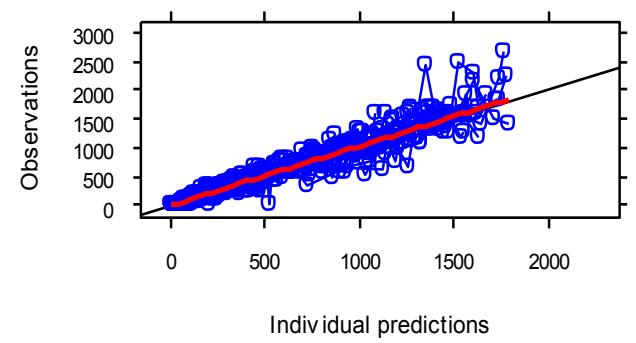

Individual predictions
Simulated data (\#2)

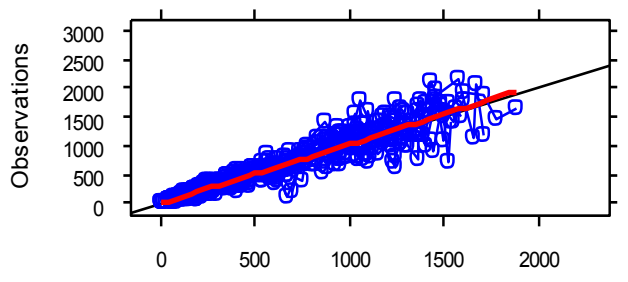

Simulated data (\#5)

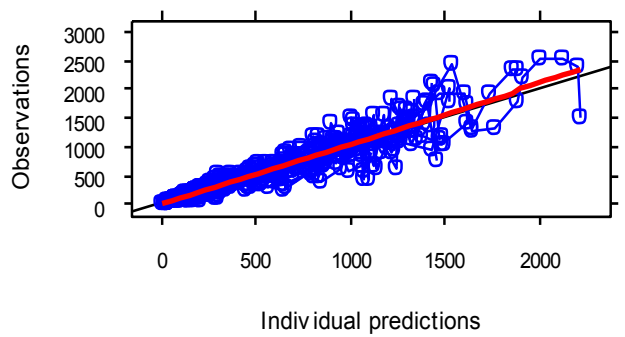

Figura 16. Gráficos espelhos individuais. Os gráficos à direita e à esquerda, relacionam as concentrações plasmáticas de BU observadas versus as concentrações plasmáticas individuais previstas pelo modelo popPK. O gráfico à esquerda apresenta a qualidade do ajuste dos dados originais. Os gráficos de predições individuais à direita foram selecionados de forma aleatória à partir dos dados simulados pelo modelo 


\subsubsection{Validação externa do modelo de Farmacocinética Populacional do BU}

Após validado internamente, foi feita a validação externa do modelo de farmacocinética populacional do BU com outros 9 pacientes investigados não incluídos no desenvolvimento do modelo. A validação externa foi realizada utilizando o método do VPC (Figura 16). Para melhor análise, neste caso também, os gráficos foram avaliados de acordo com as situações de estudo e com os pesos dos pacientes (pacientes com pesos abaixo e acima da mediana de peso).

A análise do VPC (Figura 17) confirma a adequação e indica o bom desempenho preditivo do modelo. A mediana reflete adequadamente a tendência dos dados observados e o intervalo de confiança de $95 \%$ representa bem a variabilidade dos dados observados. Neste caso os resultados do VPC também mostraram um pequeno excesso na variabilidade dos dados, principalmente nos pacientes com peso acima da mediana, porém este excesso também é aceitável. 

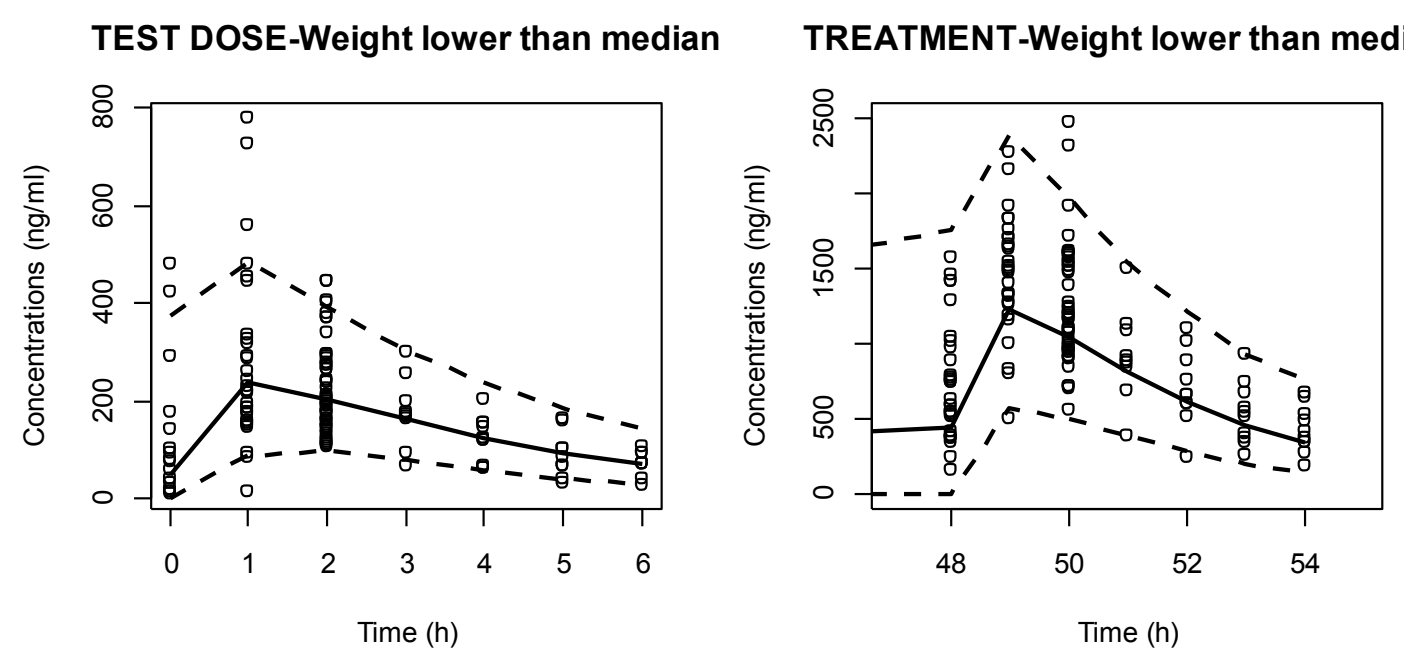

TEST DOSE-Weight higher than median

TREATMENT-Weight higher than mediar
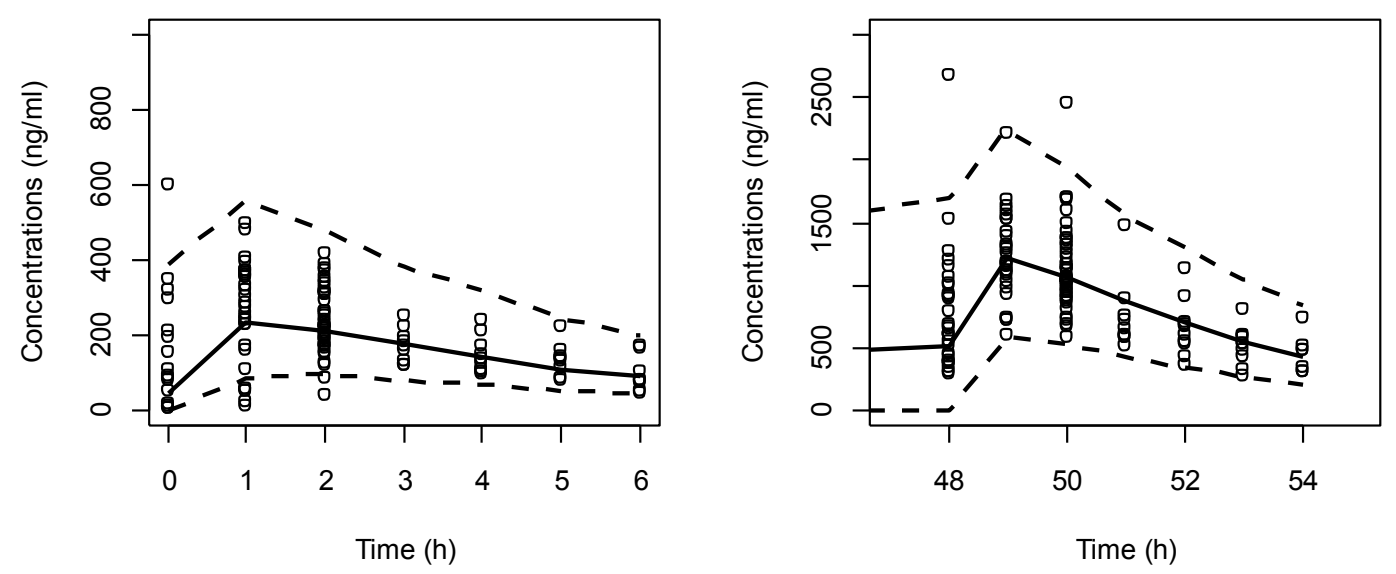

Figura 17. VPC de validação externa $(\mathrm{n}=9)$. Linha sólida: mediana dos dados simulados; Linhas tracejadas: percentis 25 e 75 dos dados simulados. 


\subsection{Estratégia de amostragem esparsa}

O esquema de coletas esparsas proposto pelo programa PopED (ED-optimality) que melhor representou os valores de $\mathrm{AUC}^{0-\infty}$ (dose teste) e $\mathrm{AUC}^{\mathrm{ss}}$ (quinta dose) do BU quando determinados com 15 coletas de sangue foi o de 5 amostras de sangue nos tempos 0,$5 ; 2,25 ; 3$; 4 e 6 horas após a administração do BU oral.

A estimativa do clearance aparente individual do BU com 5 amostras seriadas de sangue foi comparada com a estimativa do clearance aparente individual quando calculado com 15 amostras seriadas de sangue. Com base no intervalo terapêutico do BU (600-900 $\mathrm{ng} / \mathrm{mL}$ ) e considerando como real a estimativa do clearance aparente com 15 amostras seriadas de sangue, o valor de $\pm 20 \%$ de desvio nesta estimativa foi considerado aceitável e definido como limites aceitáveis de desvios. Os desvios relativos às diferenças das estimativas individuais (5 amostras seriadas versus 15 amostras seriadas) estão apresentados na Figura 18 e como pode-se observar todos os pontos encontram-se dentro do intervalo (linhas azuis).

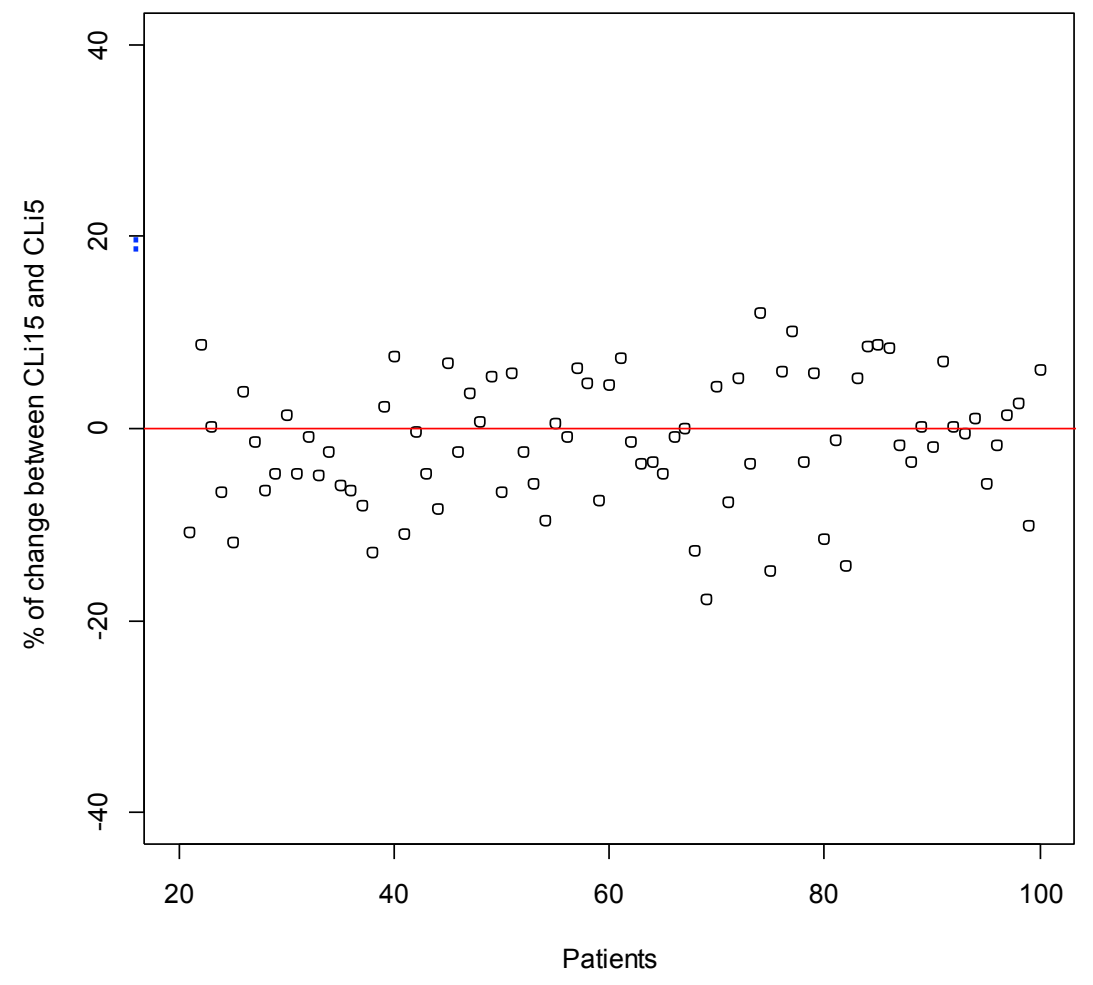

Figura 18. Porcentagem de desvio da estimativa do clearance aparente individual do BU quando calculado com 15 e com 5 amostras seriadas de sangue. As linhas azuis são os limites aceitáveis de \% de desvio na estimativa do clearance individual com 5 amostras 
Para avaliar os tempos de coletas ideais para o monitoramento terapêutico e também a proposta de dosagem baseada no modelo populacional, novas concentrações plasmáticas de BU foram simuladas nos pacientes virtuais. Foram administradas nestes pacientes virtuais, doses testes de $1 / 4$ das doses sugeridas pelo modelo popPK. Diferentemente da dose preconizada de BU onde leva-se em consideração somente o peso ideal ajustado do paciente, o modelo também considera a função hepática, dessa forma, as doses foram baseadas no peso ideal ajustado e nos valores séricos de ALT.

Após a simulação das novas concentrações plasmáticas de BU, os valores de AUC foram calculados pelo método dos trapezóides para os dois cenários com 15 e 5 amostras seriadas de sangue. Os valores de AUC foram comparados e estão apresentados na Figura 19.

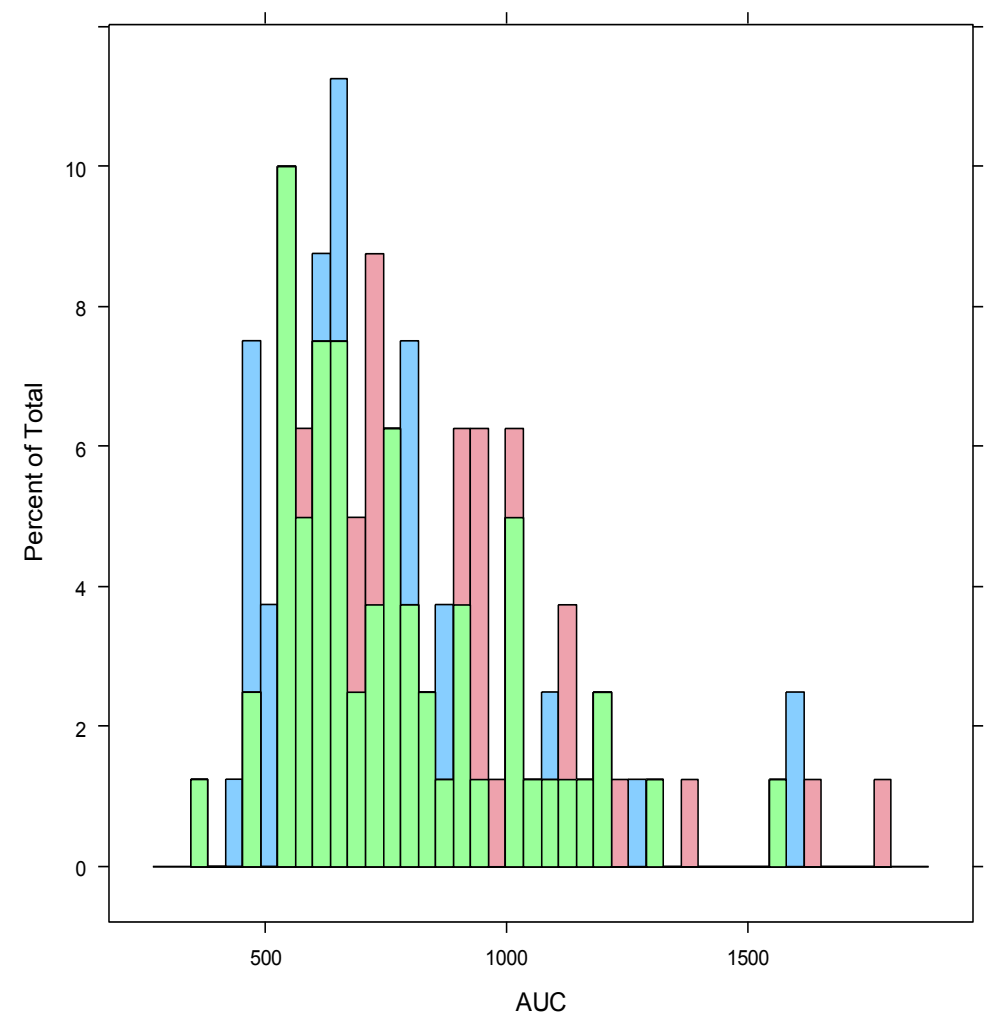

Figura 19. Frequências dos valores de AUC calculados na dose teste para os dois cenários de coletas de amostras seriadas de sangue. As barras azuis representam os valores de AUC calculados com 15 amostras de sangue, as barras rosas representam os valores de AUC calculados com 5 amostras de sangue e as barras verdes são a sobreposição das duas distribuições. 
Com base no clearance aparente individual estimado na dose teste, os pacientes virtuais receberam as doses ideais para atingirem concentrações plasmáticas dentro do intervalo terapêutico. As doses foram administradas, as concentrações simuladas com base no modelo e os valores de AUC foram calculados pelo método dos trapezóides nos dois cenários de coletas, com 15 e 5 amostras seriadas de sangue. Os resultados estão apresentados na Figura 20.

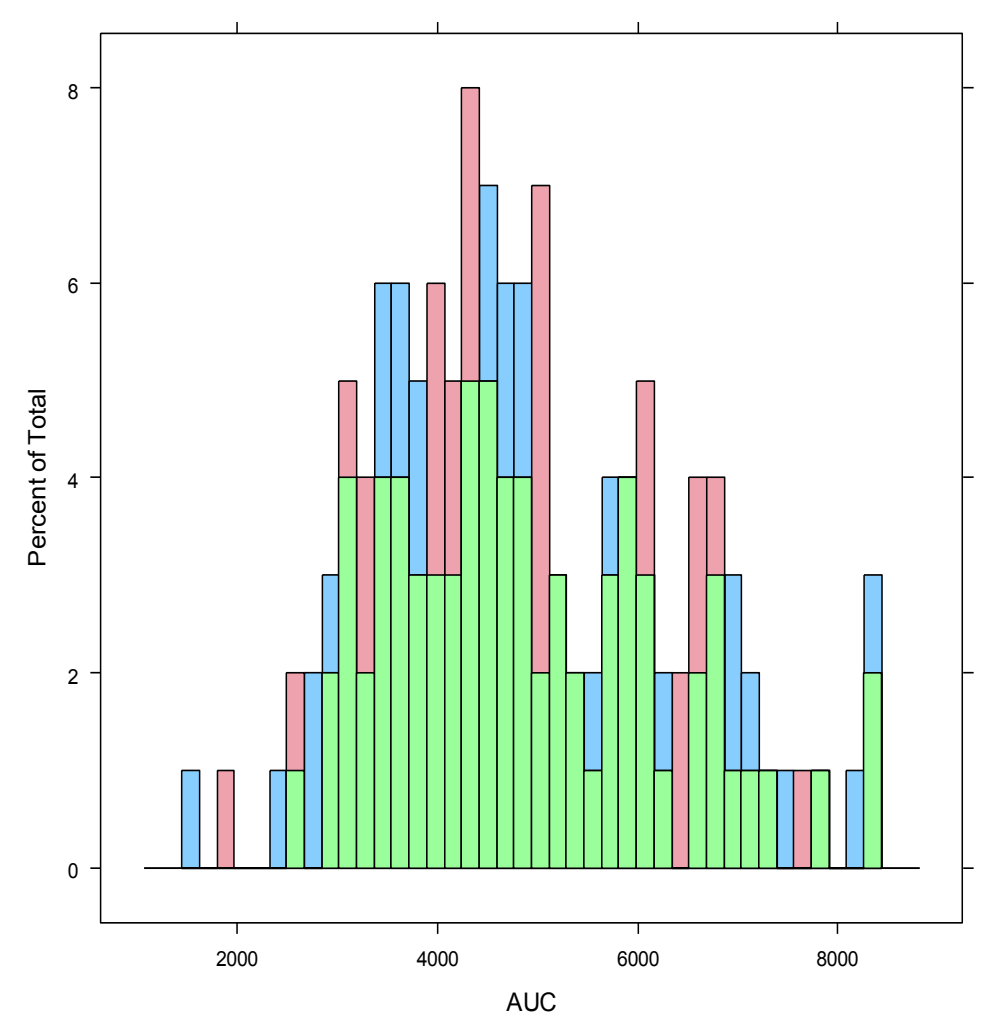

Figura 20. Frequências dos valores de AUC calculados na quinta dose para os dois cenários de amostras seriadas de sangue. As barras azuis representam os valores de AUC calculados com 15 amostras seriadas de sangue, as barras rosas representam os valores de AUC calculados com 5 amostras seriadas de sangue e as barras verdes são a sobreposição das duas distribuições.

As distribuições de $\mathrm{AUC}^{0-6}$ se sobrepõem de forma considerável, confirmando a possibilidade de redução do número de 15 para 5 coletas de amostras de sangue para a realização do monitoramento terapêutico seguro do BU. 


\subsection{Avaliação das implicações clínicas}

Após a avaliação da redução do número de amostras seriadas de sangue para a realização do monitoramento terapêutico do BU, de 15 para 5 amostras, foram avaliadas também as implicações clínicas deste estudo. Foram avaliados 4 diferentes protocolos de dosagem e monitoramento terapêutico do BU, utilizando os mesmos 20 pacientes. Os resultados estão apresentados na Figura 21.

O primeiro caso apresentado no box plot representa os valores de AUC baseados no protocolo clínico de hospitais que não possuem centros de monitoramento terapêutico, ou seja, a dose é administrada com base no peso ideal ajustado e a farmacocinética do BU não é avaliada. No segundo box-plot, o monitoramento terapêutico do BU é feito com a utilização de uma dose teste administrada com base no peso ideal ajustado e a farmacocinética é avaliada com base em modelo não compartimental. O terceiro e quarto casos, apresentam o protocolo onde a dose teste é baseada no modelo popPK e a farmacocinética é calculada pelo modelo de 1 compartimento, porém no terceiro caso o monitoramento terapêutico utiliza 15 amostras, enquanto no quarto caso o monitoramento terapêutico é estimado com apenas 5 amostras seriadas de sangue. 


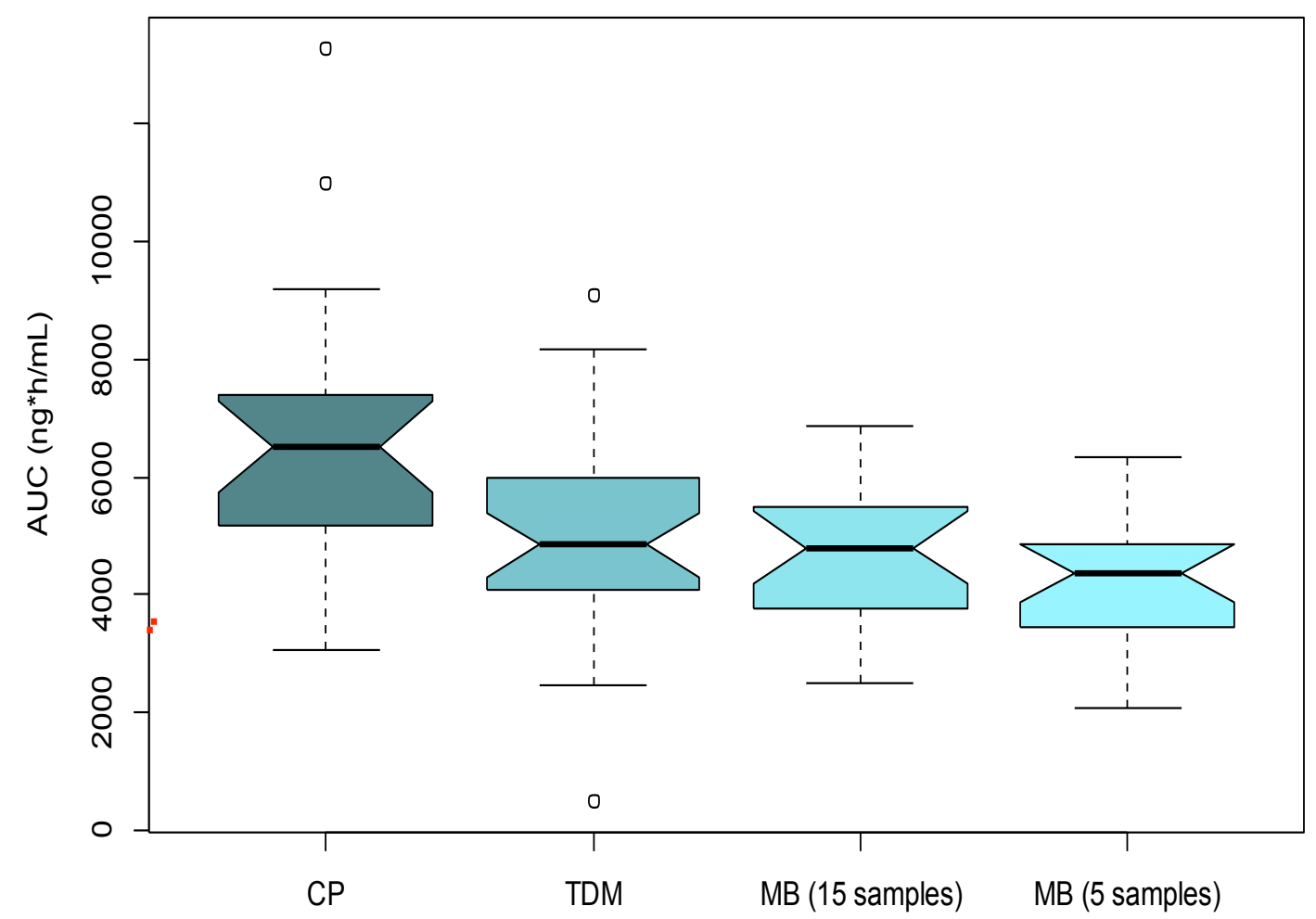

Figura 21. Valores de $A \mathrm{AC}^{0-6}$ baseados nos diferentes protocolos $(\mathrm{n}=20)$. CP- protocolo clinico; TDM- monitoramento terapêutico baseado na farmacocinética não compartimental e dose baseada no peso ideal ajustado; MB- aproximação baseada no modelo populacional. As linhas vermelhas representam o intervalo terapêutico. 
5.Discussão 
A análise do BU em plasma após a administração da dose teste de $0,25 \mathrm{mg} / \mathrm{kg}$ ou após a administração de doses múltiplas de aproximadamente $1 \mathrm{mg} / \mathrm{kg}$ foi realizada empregando LC-MS/MS em função das exigências de sensibilidade e especificidade do estudo. No entanto, inicialmente foi desenvolvido e validado um método de análise empregando HPLCUV.

O método de análise do BU em plasma empregando HPLC-UV mostrou linearidade no intervalo de concentrações plasmáticas de $125-2500 \mathrm{ng} / \mathrm{mL}$, valores não compatíveis com a administração de dose teste de $0,25 \mathrm{mg} / \mathrm{kg}$ em função da observação de concentrações plasmáticas variando de 5,8 $-173,7 \mathrm{ng} / \mathrm{mL}$ até $6 \mathrm{~h}$ após a administração do fármaco para os 30 pacientes investigados (Tabela 11). Logo, considerando a dose teste de BU de 0,25 mg/kg e o grande número de fármacos associados, o estudo exigiu o desenvolvimento e a validação do método de análise do BU em plasma empregando LC-MS/MS. Neste contexto, o BU e seu padrão interno foram resolvidos na coluna C18 Novapak $^{\circledR}$ com fase móvel constituída por mistura de solução aquosa $1 \mathrm{mM}$ de acetato de amônio: metanol: ácido fórmico (60:40:0,1; $\mathrm{v} / \mathrm{v} / \mathrm{v})$. O tempo de corrida cromatográfica foi de aproximadamente $3 \mathrm{~min}$.

A mistura clorofórmio e acetato de etila $(75: 25 ; \mathrm{v} / \mathrm{v})$, empregada na extração do BU do plasma, resultou em valores de recuperação maiores que $89 \%$ (Tabela 10). Não houve efeito da matriz na análise do BU e do PI. Os dados mostraram valores próximos a 100\% quando foram comparadas as áreas dos picos resultantes da injeção de soluções padrão em fase móvel e de soluções padrão adicionadas a extratos de plasma branco (Tabela 9).

O limite de quantificação de BU obtido empregando LC-MS/MS foi de $5 \mathrm{ng} / \mathrm{mL}$ de plasma, cinco vezes menor que o descrito por El-Serafi et al. (2013), vinte vezes menor que o obtido por Ansari et al. (2012), sete vezes menor que o obtido por Bunch et al. (2010) e o mesmo obtido por dos Reis et al. (2005). O BU em plasma se mostrou estável no estudo de três ciclos de congelamento e descongelamento, manutenção pós-processamento e à temperatura ambiente por $5 \mathrm{~h}$ (Tabela 10).

A alta variabilidade na farmacocinética do BU pode ser observada tanto após a administração da dose teste (Tabela 11), onde há poucos fármacos associados, quanto durante a quinta dose do tratamento (Tabela 12).

Conforme demonstrado na Tabela 13, os pacientes que receberam as doses de BU sugeridas com base no clearance aparente obtido na dose teste, $57 \%$ deles apresentaram $C^{\mathrm{ss}}$ BU dentro do intervalo terapêutico $(600-900 \mathrm{ng} / \mathrm{mL})$ e os demais apresentaram $\mathrm{C}^{\mathrm{ss}} \mathrm{BU}$ acima dos valores esperados. Em relação aos 9 pacientes que não receberam a dose de BU sugerida, somente $44 \%$ deles mostraram valores de $C^{\text {ss }}$ dentro do intervalo de concentrações alvo de 
600-900 ng/mL, enquanto os demais pacientes apresentaram concentrações acima do intervalo terapêutico, com exceção de um paciente que apresentou concentração abaixo de $600 \mathrm{ng} / \mathrm{mL}$.

Considerando a frequência geral das $\mathrm{C}^{\mathrm{ss}} \mathrm{BU}$ observadas nos pacientes investigados $\left(\mathrm{n}=30\right.$; Figura 6), observa-se que cerca de $53 \%$ deles mostram valores de $\mathrm{C}^{\text {ss }}$ dentro do intervalo alvo de 600-900 ng/mL.

O emprego da dose teste de BU nos 30 pacientes incluídos no estudo resultou em valores de clearance aparente variando de 3,2-29,9 L/h (Tabela 11). Os valores de clearance aparente observados na $5^{\text {a }}$ dose variaram de 2,9-18,6 L/h (Tabela 12). Os dados apresentados na Tabela 14 mostram que as \% de desvios do clearance aparente do BU foram $\leq 30 \%$, com exceção de 5 pacientes (pacientes 1, 2, 3, 16 e 28). Os valores de variabilidade do clearance aparente calculado no estado de equilíbrio estão de acordo com os valores descritos por Lee et al. (2012), Nath et al. (2008) e Shaw et al. (2004). Embora os valores estejam de acordo com a literatura, os dados permitem inferir alta variabilidade intra-individual na farmacocinética do BU considerando que o clearance aparente do BU pode ser inalterado, reduzido ou aumentado na quinta dose (Figura 7). Ressalta-se também alta variabilidade nos valores de clearance aparente do BU entre os pacientes, tanto durante o uso da dose teste (42\%), quanto na $5^{\text {a }}$ dose (33\%); Tabela 14 .

O BU é metabolizado predominantemente pela conjugação com a GSTA1 e em menor extensão pela conjugação com as isoformas GSTP1 e GSTM1. A relação entre os genótipos da GSTA1, GSTM1 e GSTP1 e a farmacocinética do BU ainda se mantém inconsistente e conflitante. Estudos reportam que pacientes genotipados com GSTA1*B e/ou GSTP1 (313 A/G) mostram redução do clearance do BU endovenoso (KIM et al., 2011; KRIVOY et al., 2012), enquanto outros estudos não observaram relação entre os polimorfismos da GST e a farmacocinética do BU endovenoso ou oral (ABBASI et al., 2011; TEN BRINK et al., 2012). Os pacientes investigados no presente estudo, foram genotipados para essas três isoformas da GST, porém como observado na Tabela 15 e nas Figuras 8, 9 e 10, não foram observadas alterações significativas entre os parâmetros farmacocinéticos do $\mathrm{BU}$ ( $\mathrm{AUC}^{0-6}$ e clearance aparente) e a ocorrência de polimorfismos na GSTA1, GSTP1 e na presença ou deleção da GSTM1.

Os dados apresentados na Tabela 16 mostram que dos 30 pacientes investigados, dois foram a óbito, um teve recaída da doença e os demais permanecem em remissão clínica. Somente 1 paciente apresentou SOS, três pacientes desenvolveram cistite hemorrágica e dois pacientes apresentaram alterações pulmonares graves (grau III e grau IV). Em relação a ocorrência de mucosite, 10 (33,3\%) pacientes apresentaram grau I, 14 pacientes $(46,7 \%)$ grau 
II, dois pacientes $(6,7 \%)$ evoluíram para grau III e somente 1 paciente $(3,3 \%)$ atingiu o grau máximo IV. Diferentemente de prévios estudos (BARTELINK et al., 2009; MCCUNE; GIBBS; SLATTERY, 2000; REZVANI et al., 2013), na presente investigação não foram encontrados indícios de que exista relação entre a $\mathrm{C}^{\mathrm{ss}} \mathrm{BU}$ e as complicações clínicas observadas (Tabela 17). Na fase de planejamento do estudo não foi calculado o tamanho amostral, portanto não se pode afirmar se o tamanho amostral foi adequado para verificar a existência da associação entre as variáveis.

Devido a importância clínica, o monitoramento terapêutico do BU é realizado no mundo todo há mais de 15 anos. Porém, até os dias atuais a dose do BU e os tempos de coletas ideais para a realização do monitoramento terapêutico ainda permanecem sob investigação (CHOE et al., 2012; MCCUNE; HOLMBERG, 2009; MCCUNE et al., 2012; REZVANI et al., 2013). Os dados de variabilidade observados no presente estudo reforçam a importância da individualização do regime de dosagem do BU, principalmente quando a via de administração é a oral (principal formulação disponível, até o momento, nos hospitais públicos brasileiros devido ao alto custo da formulação endovenosa). O inconveniente do método utilizado é que o clearance aparente do BU foi calculado com base na dose teste $(0,25 \mathrm{mg} / \mathrm{Kg})$, antes do início do regime de condicionamento, período em que os pacientes ainda não estão sendo tratados com os fármacos associados que podem alterar o clearance aparente do BU (Tabela 8). Além disso, o monitoramento terapêutico do BU exige o envolvimento de uma equipe muito bem treinada incluindo médicos, enfermeiros e analistas devido a necessidade de um grande número de amostras (aproximadamente 15 coletas de sangue em um período de 6 horas) e rápidas determinações das concentrações plasmáticas, o que não seria viável para ser feito em centros de TCTH que não possuem laboratórios especializados.

Os valores de clearance aparente do BU calculados com auxílio do programa WinNonlin de modo não compartimental (Tabela 12) apresentaram alta variabilidade tanto intra- como interindividual. Em alguns pacientes o clearance aparente do BU após a dose teste se manteve o mesmo durante o tratamento, porém em um dos pacientes a variabilidade foi de $77 \%$. Quando a alteração do clearance do paciente é maior do que a prevista, a probabilidade do paciente apresentar efeitos colaterais é muito elevada e deve ser evitada devido a alta toxicidade do BU que pode levar o paciente a óbito ou a recaída da doença.

Neste estudo, modelos de efeitos mistos não lineares (NONMEM; nonlinear mixedeffects modeling) foi utilizado para caracterizar a farmacocinética do BU. A utilização de modelos popPK que quantificam a variabilidade (IIV e IOV) se tornam muito importantes na 
clínica pois podem prever diferenças na farmacocinética considerando as alterações interindividuais e interocasiões, conhecidas e desconhecidas. Devido ao baixo número de pacientes incluídos no estudo, optou-se pela utilização de um modelo popPK para BU oral previamente publicado por Sandstrom et al. (2001), onde os parâmetros foram re-estimados baseados nos dados disponíveis. O modelo de um compartimento com primeira ordem de absorção e eliminação utilizando como covariáveis o peso ideal ajustado e os valores séricos de ALT foi suficiente para descrever a exposição ao BU após a administração oral. Devido a grande variedade de fármacos associados durante o regime de condicionamento (Tabela 8), não foi possível associá-los à farmacocinética do BU ou mesmo utilizá-los como covariáveis no modelo populacional. A IIV observada no clearance aparente foi maior que a IOV, requisito importante para o monitoramento terapêutico.

A validação dos modelos popPK são de extrema importância, especialmente quando o modelo é desenvolvido para ser utilizado para simulação de dados ou para otimização experimental, pois nestes casos o modelo não deve somente descrever bem os dados, mas também ter um bom poder preditivo. Dessa forma, diferentemente do que já foi apresentado por estudos anteriores, no presente estudo foram utilizadas várias ferramentas para a validação do modelo (BARTELINK et al., 2012; BULLOCK et al., 2006; SANDSTRÖM et al., 2001).

O modelo foi validado internamente $(n=20)$ e externamente $(n=9)$. O resultado do bootstrap (Tabela 18) comprova a robustez do modelo com estimativas dos parâmetros muito similares e baixos valores de $\mathrm{CV}$.

$\mathrm{A}$ exposição ao $\mathrm{BU}$ representada pela $\mathrm{AUC}^{0-6}$ é mais precisa quanto maior o número de amostras seriadas de sangue nas fases de absorção e eliminação. Considerando-se o estreito intervalo terapêutico do BU e a alta variabilidade inter e intrapacientes, inicialmente o estudo foi conduzido com 15 amostras plasmáticas para a determinação do clearance aparente e da AUC $^{0-6}$ dos pacientes. Porém, a utilização de 15 amostras seriadas de sangue gera ainda mais estresse aos pacientes, além de consumir muito tempo e dinheiro para as análises. Dessa forma, foram investigados os melhores esquemas de coletas esparsas para a realização do monitoramento terapêutico do BU de forma segura. O esquema de coletas proposto por Sandstrom et al. (2001) também foi testado, porém não representou boa sobreposição da AUC $^{0-6}$ quando calculada com 15 amostras seriadas de sangue. A estratégia de coletas com 5 tempos $(0,5 ; 2,25 ; 3 ; 4$ e 6 horas após a administração do BU oral) resultou em baixos desvios da estimativa do clearance aparente (Figura 18) e representação adequada da $\mathrm{AUC}^{0-6}$ nas duas ocasiões estudadas (Figuras 19 e 20). A avaliação das amostras colhidas após 0,5 e 2,25 horas da administração oral do BU apresentaram significativa diferença no cálculo da $\mathrm{AUC}^{0-6}$. A 
avaliação da concentração plasmática de BU nestes horários tornaram o modelo de farmacocinética populacional ainda mais seguro e possibilitaram a melhor representação da exposição ao BU.

Foram investigadas também, as implicações de diferentes estratégias de dosagem do BU em pacientes virtuais, mais uma vantagem dos modelos de simulação que permitem a realização de experimentos que não seriam possíveis de serem realizados na prática clínica. A nova proposta de dosagem do BU baseada na administração de uma dose teste (1/4 da dose calculada à partir do modelo popPK) seguida de 5 coletas de sangue para a determinação do clearance aparente para definição da dose ideal para atingir o intervalo terapêutico do BU, demonstrou melhores resultados quando comparada com os demais protocolos avaliados (Figura 21). Grande parte dos pacientes apresentaram valores de $\mathrm{AUC}^{0-6}$ fora do intervalo terapêutico (3600-5400 ng.h/mL) quando a dose de BU foi administrada com base somente no peso ideal ajustado, sem levar em consideração a farmacocinética (box plot 1- Figura 21). Quando a dose de BU foi administrada com base no clearance aparente do paciente após uma dose teste $(0,25 \mathrm{mg} / \mathrm{Kg})$, seguida do monitoramento terapêutico do BU (15 tempos de coleta e farmacocinética não-compartimental), parte dos pacientes se encaixaram dentro do intervalo terapêutico, porém muitos ainda encontraram-se fora do intervalo alvo. No entanto, quando a dose teste foi baseada no modelo populacional, a farmacocinética calculada de forma compartimental levando-se em consideração IIV e IOV e a dose do tratamento baseada no clearance aparente do paciente, independentemente do monitoramento terapêtico ser realizado com 15 ou 5 amostras de sangue, a maior parte dos pacientes encontraram-se dentro do intervalo alvo. O resultado ideal do presente estudo seria que todos os pacientes atingissem concentrações plasmáticas de BU dentro do intervalo terapêutico, porém devido a alta variabilidade na farmacocinética do $\mathrm{BU}$, ao baixo número de pacientes analisados e às poucas covariáveis disponíveis, não foi possível aprimorar o modelo populacional.

Em resumo, os resultados obtidos no presente estudo contribuíram para a determinação dos melhores tempos de coleta esparsas para o monitoramento do BU e para a nova proposta de dosagem do BU, aperfeiçoando de forma significativa o tratamento de condicionamento pré-TCTH, reduzindo os efeitos colaterais do BU e aumentando as chances de sucesso do TCTH.

O fato de ser um método fácil, seguro e que utiliza poucas amostras de sangue, torna este método viável e atrativo para ser utilizado na realização do monitoramento terapêutico do BU nos centros de TCTH. 
6. Conclusões 
1. O método de análise de BU em plasma foi desenvolvido e validado empregando LC-MS/MS e seus limites de confiança são concordantes com a aplicação em monitoramento terapêutico;

2. A farmacocinética do BU exibiu alta variabilidade intra e interindividual, a qual deve estar relacionada a diversos fatores, dentre eles as interações medicamentosas;

3. Não foram observadas significâncias estatísticas nos testes de associação entre os parâmetros farmacocinéticos do BU e os polimorfismos da GSTA1, GSTP1 e GSTM1. Também não foram observadas significâncias estatísticas nos testes de associação entre os valores de $\mathrm{C}^{\mathrm{ss}}$ do BU e a evolução clínica;

4. Considerando a alta variabilidade intra e interindividual no clearance aparente do $\mathrm{BU}$, o uso da dose teste de BU oral como forma de individualização terapêutica auxilia no tratamento, porém não é suficiente para substituir a monitorização terapêutica durante o condicionamento pré-TCTH;

5. O uso do método de coletas esparsas associado a utilização do modelo de farmacocinética populacional e cálculos de farmacocinética compartimental, contribui para viabilizar a monitorização terapêutica do BU nos centros de TCTH, tornando-o um exame de rotina, facilitando o tratamento, reduzindo o índice de mortalidade e favorecendo a evolução clínica dos pacientes. 


\section{CAPÍTULO II}

Enantiosseletividade na disposição cinética e no metabolismo da ciclofosfamida em pacientes portadores de esclerose múltipla ou esclerose sistêmica submetidos a transplante de células tronco hematopoéticas 


\section{Resumo}

Considerando a relevância clínica da utilização da ciclofosfamida (CY) no condicionamento pré-transplante de células tronco hematopoéticas (TCTH), o presente estudo avaliou a farmacocinética da CY e seus principais metabólitos (4-hidroxiciclofosfamida e carboxiciclofosfamida) em pacientes portadores de doenças inflamatórias, esclerose sistêmica $(n=10)$ ou esclerose múltipla (EM), submetidos ao TCTH em regime de condicionamento com $50 \mathrm{mg} \mathrm{CY} / \mathrm{kg} /$ dia durante 4 dias. Foram coletadas amostras seriadas de sangue até 24 horas após a administração da última dose de CY. Os pacientes foram genotipados para as variantes alélicas do CYP2C9*2 e CYP2C9*3 e do polimorfismo G516T do CYP2B6. Dois ensaios específicos baseados na análise por LC-MS/MS foram desenvolvidos e validados para analisar os enantiômeros da CY e seus metabólito 4-hidroxiciclofosfamida (HCY) e carboxiciclofosfamida (CEPM) em plasma humano. A resposta do detector foi linear no intervalo de concentrações plasmáticas 5-2500 ng de cada enantiômero de HCY/mL plasma $(r>0,99)$, com corridas cromatográficas de 15 minutos. A linearidade para as análises dos enantiômeros da $\mathrm{CY}$ foi de $50 \mathrm{ng}$ a $25 \mu \mathrm{g}$ de cada enantiômero/mL de plasma e para as análises dos enantiômeros do CEPM foi de 25 a $2500 \mathrm{ng}$ de cada enantiômero / $\mathrm{mL}$ de plasma. Os parâmetros farmacocinéticos dos enantiômeros da CY e seus metabólitos foram calculados empregando o programa WinNonlin e mostraram acúmulo plasmático dos enantiômeros (S)(-)-CY (AUC 215, 0 vs 186,2 $\mu \mathrm{g} . \mathrm{h} / \mathrm{mL}$ para os paciente EM e 219,1 vs 179,2 $\mu \mathrm{g} . \mathrm{h} / \mathrm{mL}$ para os paciente ES) e HCY (1), provavelmente o (R)-(+)-HCY (AUC 5,6 vs 3,7 $\mu \mathrm{g} . \mathrm{h} / \mathrm{mL}$ para os paciente EM e 6,3 vs 5,6 $\mu \mathrm{g} . \mathrm{h} / \mathrm{mL}$ para os paciente ES) em ambos os grupos de pacientes investigados. A disposição cinética do metabólito CEPM não mostrou enantiosseletividade. A farmacocinética da CY e seus metabólitos HCY e CEPM não diferiu entre os pacientes portadores de EM ou ES. Não foi observado correlação entre o metabolismo da CY e os genótipos avaliados (CYP2B6 e CYP2C9). Não foi possível correlacionar os valores de $\mathrm{AUC}^{0-\infty}$ dos enantiômeros da CY e/ou dos metabólitos HCY e CEPM com a toxicidade ao uso de CY em virtude do pequeno número de pacientes investigados. 
1. Introdução 
A esclerose múltipla (EM) é uma doença inflamatória crônica e desmielinizante do sistema nervoso central (SNC). A EM é uma doença autoimune mediada por células T que infiltram no SNC através de pequenos vasos e provocam a cascata imunológica, que por sua vez, induz eventos inflamatórios e imunes. É tipicamente caracterizada por episódios recorrentes de disfunção neurológica que refletem as alterações imunológicas. A estes períodos de surtos da doença intercalam-se períodos de graus variáveis de remissão clínica. Os sintomas neurológicos na apresentação clínica da doença são manifestações das reações inflamatórias e, em última análise, o reflexo da agressão degenerativa das áreas desmielinizadas em sistemas neurológicos funcionais variados. O tratamento da EM inclui imunomoduladores, corticóide e imunossupressores. Entretanto, alguns pacientes não respondem ao tratamento e necessitam de práticas terapêuticas alternativas. Há estudos publicados desde 1990 apresentando modelos animais e considerações teóricas sobre o TCTH para prevenção e tratamento da EM. Alguns dados clínicos sugerem que altas doses de quimioterapia seguidas de resgate de células tronco hematopoéticas poderiam resetar o distúrbio imunológico. Desde o primeiro transplante relatado por Fassas et al., em 1997, mais de 300 TCTHs foram realizados em pacientes com EM no mundo todo (HAMERSCHALK et al., 2010; NOSEWORTHY, 2000; POSER, 1983).

A esclerose sistêmica (ES) é uma doença multissistêmica crônica, autoimune e caracterizada pela fibrose progressiva da pele e dos órgãos internos. A ES exibe três características fundamentais: inflamação e autoimunidade, vasculopatia e excessiva produção e depósito de matriz extracelular. Na ES, as manifestações cutâneas e dos órgãos, são em geral lentamente progressivas e cronicamente incapacitantes. Entretanto, em alguns pacientes, pode ser rapidamente progressiva e fatal, devido ao envolvimento de órgãos, e ocorrência de pneumonia intersticial, arritmia e insuficiência renal. O TCTH tem sido indicado para pacientes com doenças autoimunes, resultando em grande sucesso, particularmente em portadores de ES (BOHGAKI et al., 2009).

A ciclofosfamida (CY) é um agente alquilante da classe das oxazafosforinas, amplamente utilizada no tratamento de múltiplas formas de câncer e de doenças autoimunes em adultos e crianças (BODDY, 2000). Os agentes alquilantes representam uma classe de moléculas citotóxicas, que possuem em comum a habilidade de se tornarem compostos eletrofílicos fortes, que formam ligações covalentes com os grupos do DNA (GERMANAS, J \& PANDYA, 2002).

A CY muito utilizada em altas doses nos regimes de condicionamento pré TCTH, causa considerável toxicidade, particularmente ao sistema hepático: destruição de células 
endoteliais, deposição de matriz extracelular nos sinusóides e necrose dos hepatócitos (síndrome obstrutiva sinusoidal). As conseqüências clínicas desta lesão hepática incluem icterícia, hepatomegalia, hipertensão portal, ascite, retenção renal de sódio e lesão renal aguda (MCCUNE et al., 2009).

A cistite hemorrágica é uma reação adversa também bastante conhecida e a mais frequente em pacientes que fazem uso de CY. Esta desordem é caracterizada pela inflamação da parede da bexiga com subseqüente hemorragia, o que talvez seja devido à presença do metabólito acroleína, o qual interage com as células uroepiteliais. Outros efeitos tóxicos também muito conhecidos são pneumonite intersticial e insuficiência da excreção líquida, além de possuir potencial carcinogênico e teratogênico (DE JONGE; HUITEMA; TUKKER; et al., 2005; GERMANAS, J \& PANDYA, 2002).

A CY é um pró-fármaco metabolizado a produtos ativos e inativos. Aproximadamente 70-80\% da dose de CY é ativada para 4-hidroxiciclofosfamida, a qual se encontra em equilíbrio com seu tautômero aldofosfamida. A bioativação da CY depende principalmente do CYP2B6 (aproximadamente 45\%), CYP3A4 (aproximadamente 25\%) e do CYP2C9 (aproximadamente 12\%) e em menor extensão do CYP2A6, CYP2C8 e CYP2C19. A 4hidroxiciclofosfamida (HCY) e aldofosfamida (normalmente não distinguidas nas análises usuais) difundem para dentro das células e espontaneamente são decompostas em mustarda de fosforamida, o metabólito citotóxico ativo, e acroleína, a qual é tóxica para a maioria das células. Considerando que a HCY funciona como uma molécula de transporte do metabólito citotóxico para dentro das células, a concentração sistêmica de HCY reflete o estado de ativação intracelular da CY. Alternativamente, a HCY e a aldofosfamida podem ser inativadas com formação, respectivamente, de 4-cetociclofosfamida e carboxifosfamida (CEPM). A formação de CEPM é dependente da atividade da aldeído desidrogenase citossólica ALDH1. Outra via de inativação da CY envolve a oxidação da cadeia lateral pelo CYP3A4 e CYP3A5 com formação de $\mathrm{N}$-descloroetilciclofosfamida e cloroacetaldeído, uma via que representa menos que 5\% da eliminação total de ciclofosfamida (DE JONGE; HUITEMA; TUKKER; et al., 2005; ZHANG et al., 2006). 


$$
\mathrm{Cl}
$$

Cloroacetaldeído

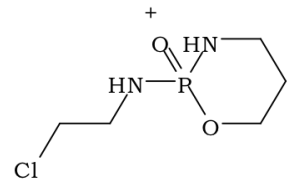

3-Descloroetilciclo fosf am ida

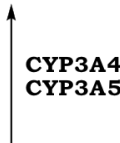

YP3A4
YP3A5
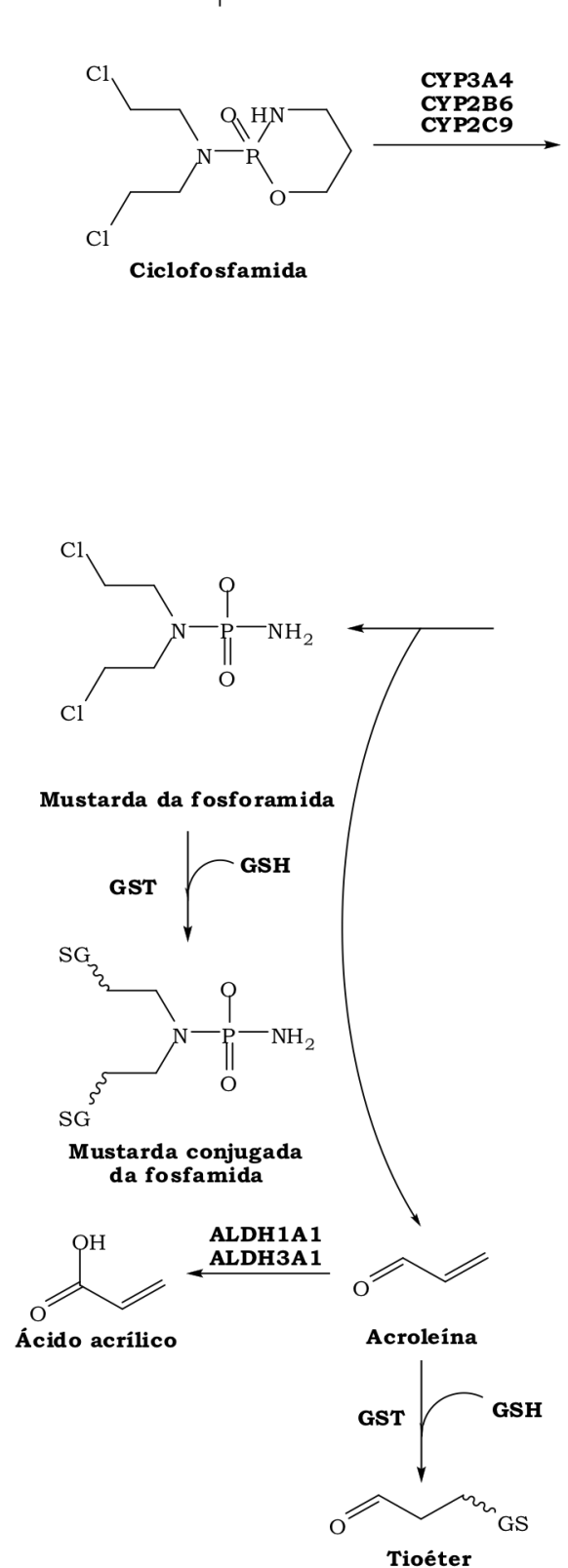

Tioèter
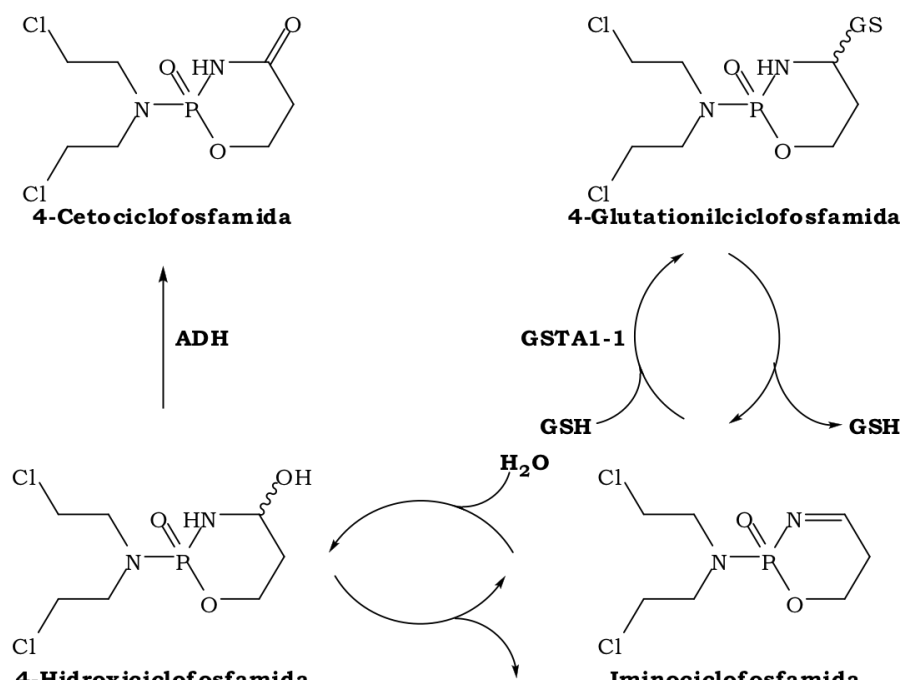

4-Hidroxiciclof osfamida
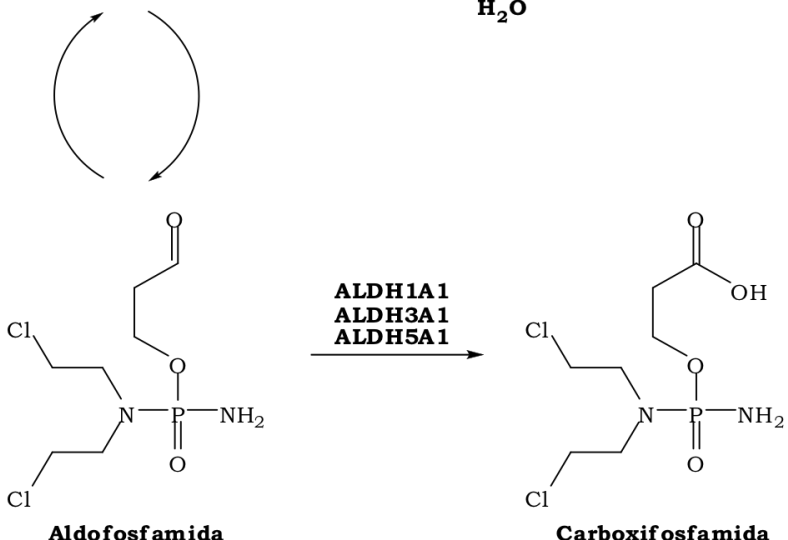

$$
\text { Aldofosfamida Carboxif osfamida }
$$
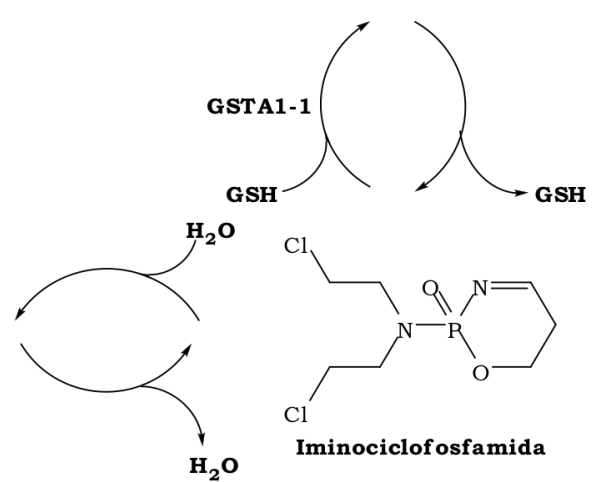$$
\text { ADH }
$$$$
\text { AKRI }
$$

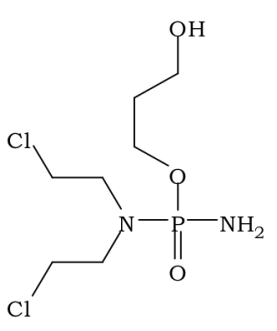

Alcof osfamida

Figura 22. Metabolismo da ciclofosfamida (adaptado de ZHANG et al., 2006) 
O metabolismo da CY exibe alta variabilidade entre os pacientes com observações de alterações no equilíbrio entre as reações de ativação e inativação. As enzimas envolvidas nas reações de ativação (CYP) e inativação (ALDH e GST) da CY exibem polimorfismo genético e são pelo menos parcialmente responsáveis pela alta variabilidade interindividual nos efeitos clínicos (PINTO et al., 2009).

O impacto das variantes alélicas do CYP2B6 no metabolismo da CY foi investigado em 29 pacientes caucasianos com doenças hematológicas (XIE et al., 2006). Os pacientes com a mutação CYP2B6 G516T (n=8) mostraram capacidade de 4-hidroxilação da CY duas vezes maior do que nos pacientes com os alelos selvagens CYP2B6. Todas as variantes alélicas CYP2B6*6, CYP2B6*7, CYP2B6*9, CYP2B6*19, CYP2B6*29 apresentam a mutação G516T. Em pacientes com glomerulonefrite tratados com CY, Joy et al. (2012) relatam a influência do polimorfismo CYP2B6*9 na farmacocinética da CY e do HCY, onde os pacientes com a variante alélica apresentaram aumento da constante de velocidade de eliminação e menores valores de Cmax da CY quando comparados com os alelos selvagens. Por lado, Helsby et al. (2010) reportam baixa capacidade de ativação da CY em pacientes com nefrite lúpica genotipados como CYP2C19*2, CYP2C19*3 ou CYP2B6*5.

A formação do metabólito HCY avaliada em 51 crianças por Raccor et al. (2012) não mostrou associação entre o genótipo CYP2B6 e o clearance da CY ou a razão metabólica $\mathrm{HCY} / \mathrm{CY}$, atribuindo esses resultados devido principalmente a participação das isoformas CYP3A4/5 no metabolismo da CY.

A CY é um potente indutor das enzimas microssomais, além de induzir seu próprio metabolismo depois de repetidas administrações, dentro de um período de diversos dias consecutivos. A auto-indução é detectável dentro de 24 horas após o início do tratamento e resulta em aproximadamente numa diminuição de 2 vezes no valor da $t_{1 / 2}$ da CY (DE JONGE; HUITEMA; VAN DAM; et al., 2005). A associação de fármacos como glucocorticóides, ondansetrona, rifampicina, fenobarbital, também podem alterar o metabolismo da CY (JOY et al., 2012).

Vários estudos demonstram a existência de correlações entre a exposição aos metabólitos da CY, particularmente a CEPM e a $\mathrm{HCY}$, com a manifestação de eficácia ou toxicidade (MCCUNE et al., 2009; MCDONALD et al., 2003, 2005).

Um estudo avaliando 147 pacientes tratados com CY (120 mg/kg) e irradiação corporal total como condicionamento pré-TCTH relatam que a exposição ao metabólito inativo CEPM, avaliada pela AUC, mostra correlação com a toxicidade hepática e com a sobrevida, com aumento de 5,9 vezes na taxa de mortalidade para os pacientes com maiores 
valores de exposição ao metabólito. No entanto, não foram observadas correlações entre a exposição ao metabólito CEPM e a pega do enxerto ou recaída da doença em pacientes com doenças onco-hematológicas. No referido estudo, a AUC do metabólito CEPM variou 16 vezes entre os 147 pacientes investigados (MCDONALD et al., 2003). Em outro estudo posterior, o mesmo grupo de pesquisadores relata que o ajuste de dose da CY para uma exposição alvo de CEPM de $325 \mu \mathrm{mol} / \mathrm{L}$.h (avaliação da exposição de CEPM na primeira dose de CY de $45 \mathrm{mg} / \mathrm{kg}$ e ajuste a partir da segunda dose de CY) resulta em variação na exposição ao metabólito de apenas 1,7 vezes. Os autores relatam que doses de CY de 54-156 $\mathrm{mg} / \mathrm{kg}$ foram necessárias para atingir a exposição alvo do metabólito CEPM de $325 \mu \mathrm{mol} / \mathrm{L} . \mathrm{h}$ e que doses menores que a dose padrão de $120 \mathrm{mg} / \mathrm{kg}$ não alteram a pega do enxerto, mas previnem a toxicidade hepática (MCDONALD et al., 2009).

De Jonge et al. (2006) reportam que de 59 pacientes tratados com altas doses de CY (1-1,5 $\mathrm{g} / \mathrm{m}^{2} /$ dia), 4 manifestaram a síndrome obstrutiva sinusoidal e que a AUC da HCY avaliada no primeiro pulso de CY pode ser considerada como um marcador indicativo da manifestação da doença hepática após múltiplos pulsos de CY. Logo, a dose de CY ajustada para uma concentração alvo de HCY poderia ser útil na prevenção da toxicidade hepática.

A eficácia e segurança do ajuste de dose da CY foram avaliadas em 50 pacientes em tratamento com CY e irradiação corporal total. Os pacientes foram tratados com a primeira dose de CY de $45 \mathrm{mg} / \mathrm{kg}$ e ajuste a partir da segunda dose com base na exposição aos metabólitos CEPM e HCY avaliada na administração da primeira dose de CY. O ajuste de dose foi realizado considerando a exposição alvo (AUC) de $325 \pm 25 \mu \mathrm{mol} / \mathrm{L}$.h para o metabólito CEPM e $50 \mu \mathrm{mol} / \mathrm{L}$.h para o metabólito HCY. Os autores relatam que o ajuste de dose de CY, com base na exposição aos metabólitos e empregando farmacocinética Bayesiana, reduz de maneira significativa os níveis de bilirrubina pós-condicionamento e reduz em 38\% a freqüência de toxicidade renal (MCCUNE et al., 2009).

A CY está disponível na clínica como mistura racêmica dos enantiômeros (S)-(-) e (R)-(+). Particular atenção tem sido prestada à influência da quiralidade na 4-hidroxilação e nos produtos de desintoxicação da CY. A seletividade da CY para células cancerosas é decorrente da estabilidade da HCY, a qual é transportada para os sítios alvos, e ao nível relativamente baixo da aldeído desidrogenase em células cancerosas comparado com células normais (GERMANAS, J \& PANDYA, 2002). Se esta hipótese é verdadeira, então diferenças entre os enantiômeros quanto ao rendimento relativo dos seus metabólitos, podem resultar em diferenças na eficácia terapêutica (JARMAN et al., 1979). Contudo, os dados sobre a enantiosseletividade no metabolismo da CY em humanos são insuficientes para sustentar a 
hipótese de que um dos dois enantiômeros seria superior ao seu antípoda ou ao racemato na quimioterapia do câncer (JARMAN et al., 1979).

Dados pré-clínicos demonstram diferenças na eficácia e toxicidade dos enantiômeros da CY, com o (S)-(-) exibindo maior efeito anti-tumor e maior índice terapêutico quando comparado ao enantiômero (R)-(+) (KUSNIERCZYK et al., 1986; PAPROCKA et al., 1986). As propriedades farmacológicas da CY racêmica e de seus enantiômeros foram estudadas por Kleinrok et al. (1986) que observaram que o (R)-(+) é mais tóxico que o enantiômero (S)-(-), enquanto que o (S)-(-) é mais tóxico quando comparado com o racemato.

Embora os enantiômeros (R)-(+) e (S)-(-) possam diferir na resposta terapêutica e nos efeitos tóxicos, as conseqüências clínicas dessas diferenças ainda não estão adequadamente determinadas. Os estudos clínicos relativos a enantiosseletividade na disposição cinética e no metabolismo da CY ainda são inconclusivos e abrangem pequeno número de pacientes portadores de diferentes estados de doenças e em tratamento com diferentes fármacos associados (FERNANDES et al., 2011; DE MIRANDA SILVA et al., 2009; WILLIAMS et al., 1999; WILLIAMS et al., 1999b; CORLETT \& CHRYSTYN, 1996; HOLM et al., 1990; JARMAN et al., 1979). A farmacocinética da CY administrada por infusão a pacientes com vários tipos de câncer tem sido descrita como não enantiosseletiva (CORLETT \& CHRYSTYN, 1996; HOLM et al., 1990; JARMAN et al., 1979), embora hajam relatos de enantiosseletividade no clearance de formação do metabólito descloroetilciclofosfamida (WILLIAMS et al., 1999). No entanto, em pacientes portadores de câncer de mama e pacientes portadores de nefrite lúpica foram observados acúmulo plasmático do enantiômero (S)-(-) considerado de maior atividade anti-tumor (DE MIRANDA SILVA et al., 2009; FERNANDES et al., 2011)

A farmacocinética da CY e dos metabólitos HCY e CEPM como mistura enantiomérica encontra-se bem definida na administração intravascular a pacientes portadores de câncer. Ressalta-se, no entanto, a ausência de dados relativos a enantiosseletividade e a disposição cinética e metabolismo da $\mathrm{CY}$ em pacientes com doenças inflamatórias como a EM e a ES.

As respostas inflamatórias são complexas e ocorrem em resposta a uma série de doenças, incluindo as doenças autoimunes como EM e ES. Os estímulos inflamatórios podem causar mudanças nas atividades e níveis de expressão de várias isoformas CYP no fígado, bem como em tecidos extra-hepáticos, tais como rins e cérebro (MORGAN, 2001).

O processo inflamatório afeta o metabolismo, a distribuição e a eliminação de certos fármacos em uso na clínica (RENTON et al., 2005). Esses efeitos são resultantes da expressão 
alterada do CYP e transportadores que sofrem down-regulation durante o mecanismo de defesa do hospedeiro. Quando a resposta inflamatória está confinada ao cérebro há perda de CYP e glicoproteína- P, não apenas no cérebro, mas também em teciøgs periféricos. Essa perda, provavelmente, envolve o trânsito rápido de com :érebro para a circulação periférica (ABDULLA et al., 2006).

As doenças inflamatórias estimulam a liberação de citocinas dos monócitos, macrófagos e células do estroma, resultando na modulação da atividade dos fatores de transcrição no fígado. Essas mudanças, em última análise levam a down-regulation da maioria dos genes do CYP. A produção de citocinas também ativa a óxido nítrico-sintase 2 (NOS2) para formar o óxido nítrico (NO), que inibe a atividade de isoformas do CYP diretamente e/ou leva a down-regulation das proteínas CYP via desestabilização (MORGAN et al., 2008).

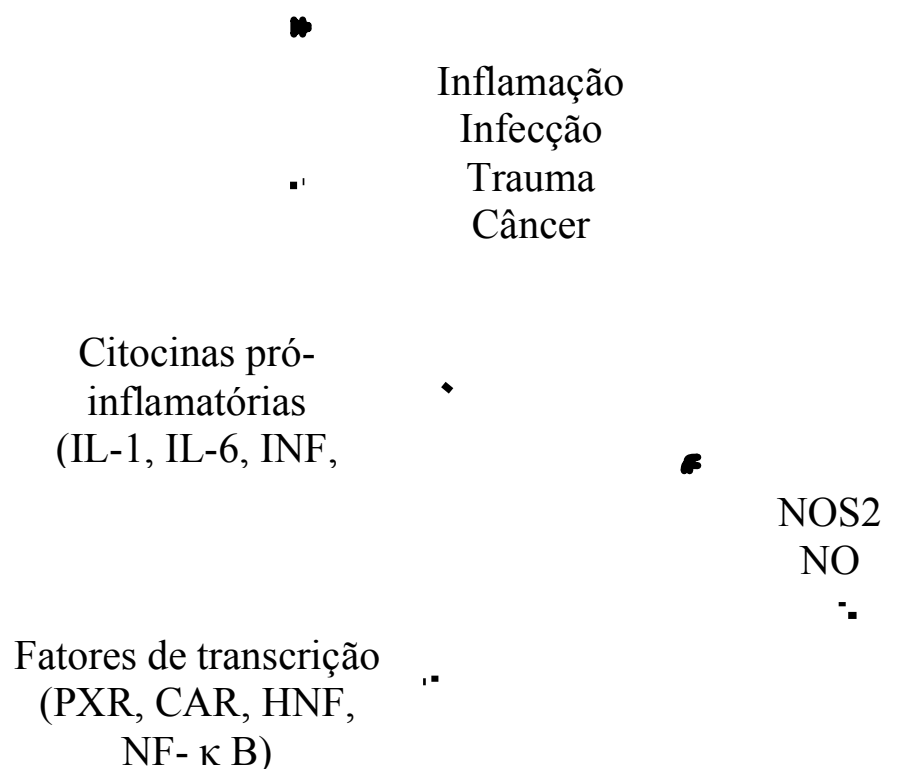

Genes CYP

Enzimas CYP

clearance

Figura 23. Mecanismo de inibição do CYP e de transportadores durante a inflamação. HNF-fator nuclear de hepatócitos; NF- fator nuclear (adaptado de MORGAN et al., 2008).

Pacientes portadores de EM exibem maiores concentrações no plasma de IFN- $\gamma$, IL-17, IL-12, IL-10, TNF- $\alpha$, IL-2, IL-8, IL-4 e TGB- $\beta$ (MIKULKOVA et al., 2011), enquanto 
pacientes portadores de ES expressam maiores concentrações no plasma de TNF- $\alpha$, IL-6 e IFN- $\gamma$ e menores concentrações de IL-17 e IL-23 (GOURH et al., 2009). Machavaram et al. (2013) mostram correlação entre as concentrações plasmáticas da IL-6 em pacientes com artrite reumatoide e em pacientes submetidos ao TCTH e supressão do CYP3A mostrada em função do aumento dos valores de AUC da ciclosporina e sinvastatina.

Considerando a importância do tratamento com CY no regime de condicionamento pré TCTH, o presente estudo visa avaliar a enantiosseletividade da CY e seus metabólitos em pacientes portadores de EM e ES. A investigação dos pacientes portadores de EM e ES está sendo proposta considerando que tais pacientes são tratados com o mesmo regime de dosagem de CY e com os mesmos fármacos associados, e considerando que tais doenças são inflamatórias podendo resultar em down-regulation das isoformas do CYP associadas com o metabolismo da CY. Ressalta-se ainda os relatos de seletividade quanto a citocina induzida em função da doença inflamatória (ES e EM) assim como quanto a seletividade da isoforma do CYP que sofre down-regulation em função da citocina induzida (MORGAN et al., 2008; RENTON, 2004). 
2. Objetivos 


\section{Objetivo Geral}

Investigar a disposição cinética dos enantiômeros da ciclofosfamida e seus metabólitos (4-hidroxiciclofosfamida e carboxifosfamida) em pacientes portadores de esclerose múltipla ou esclerose sistêmica e associar parâmetros farmacocinéticos com parâmetros clínicos (remissão da doença e efeitos adversos) em pacientes submetidos ao transplante de células tronco hematopoéticas.

\section{Objetivos Específicos}

- Desenvolver e validar micrométodo de análise sequencial dos enantiômeros da ciclofosfamida e de seu metabólito carboxiciclofosfamida em plasma humano empregando LC-MS/MS;

- Desenvolver e validar micrométodo de análise dos enantiômeros do metabólito 4hidroxiciclofosfamida em plasma humano empregando LC-MS/MS;

- Investigar a enantiosseletividade na disposição cinética dos enantiômeros da ciclofosfamida e seus metabólitos em pacientes portadores de esclerose múltipla ou esclerose sistêmica submetidos ao TCTH;

- Investigar se o metabolismo dos enantiômeros da ciclofosfamida difere entre os pacientes portadores de esclerose múltipla ou esclerose sistêmica;

- Associar os parâmetros farmacocinéticos dos enantiômeros da ciclofosfamida e seus metabólitos com parâmetros clínicos em pacientes portadores de esclerose múltipla ou esclerose sistêmica submetidos ao TCTH. 
3. Casuística e Métodos 


\section{1 Casuística}

\subsubsection{Aspectos éticos}

O estudo foi aprovado pelo Comitê de Ética em Pesquisa do HCFMRP-USP, de acordo com o Processo $n^{0}$ 911/2010 (ANEXO 1). Os pacientes receberam explicação detalhada dos procedimentos e foram incluídos no estudo após a assinatura do Termo de Consentimento Livre e Esclarecido (ANEXO 2). Foi garantida a liberdade ao paciente de recusar sua participação ou retirar seu consentimento, em qualquer fase da pesquisa, sem penalização ou prejuízo ao seu tratamento.

\subsubsection{Critérios de Inclusão}

Foram incluídos na investigação 20 pacientes adultos portadores de esclerose múltipla ou sistêmica submetidos ao TCTH autólogo na Unidade de Transplante de Medula Óssea do HCFMRP-USP. Todos os pacientes tiveram indicação para uso de CY e com base no protocolo estabelecido no HCFMRP-USP.

\subsubsection{Protocolo Clínico}

Todos os pacientes receberam o regime de condicionamento constituído por CY racêmica injetável $\left(\right.$ Cycram $^{\circledR}$, Meizler, São Paulo, SP), em doses de $50 \mathrm{mg} / \mathrm{kg} / \mathrm{dia}$, administradas com tempo de infusão de $1 \mathrm{~h}$, durante 4 dias.

As amostras seriadas de sangue, para a análise da CY e de seu metabólito CEPM, foram coletadas em tubos contendo EDTA, volumes de aproximadamente $3 \mathrm{~mL}$, nos tempos $0,15,30,45$ e 60 minutos e 1,$15 ; 1,30 ; 2 ; 3 ; 5 ; 8 ; 12 ; 16$ e 24 horas após o início da infusão da última dose de CY. As amostras seriadas de sangue de aproximadamente $2 \mathrm{~mL}$ também foram coletadas nos mesmos tempos, para a análise do metabólito HCY, em seringas contendo solução de cloreto de fenil-hidrazina (4\%) em tampão citrato de sódio $0,05 \mathrm{M}, \mathrm{pH} 6,0$, conforme descrito por Kalhorn et al. (2006). As amostras de plasma foram mantidas em temperatura de $-70^{\circ} \mathrm{C}$ até a análise. 


\subsection{Análise enantiosseletiva da CY e seu metabólito CEPM em plasma humano empregando LC-MS/MS}

\subsubsection{Soluções padrão e reagentes}

A solução estoque de CY racêmica (ISOPAC, pureza $>99,5 \%$, mono-hidratada, Sigma, St. Louis, MO, EUA) foi preparada em etanol na concentração de $1 \mathrm{mg} / \mathrm{mL}$. Posteriormente, a solução estoque foi diluída para obtenção das concentrações de 50; 40; 30; $10 ; 5 ; 1 ; 0,5$ e $0,1 \mu \mathrm{g} / \mathrm{mL}$ de etanol. As soluções padrão foram armazenadas a $-20^{\circ} \mathrm{C}$.

A solução estoque do metabólito CEPM racêmico (Toronto Research Chemicals Inc., Toronto, Canadá) foi preparada em água na concentração de $1 \mathrm{mg} / \mathrm{mL}$. A solução estoque foi diluída para obtenção das concentrações de 5000;3000;2000;1000; 500;200;100; 50 ng/mL de água. As soluções padrão foram armazenadas a $-70^{\circ} \mathrm{C}$.

O fármaco antipirina (Sigma, St. Louis, MO, EUA) foi empregado como padrão interno (PI). A solução foi preparada em metanol na concentração de $100 \mathrm{ng} / \mathrm{mL}$ de metanol e armazenada a $-20^{\circ} \mathrm{C}$.

Todos os solventes utilizados foram grau HPLC e adquiridos da Merck (Darmstadt, Alemanha). O ácido trifluoroacético (pureza $>99 \%$ ) foi adquirido da Sigma. Toda a água utilizada foi destilada e deionizada com o auxílio do sistema de purificação Sinergy UV ${ }^{\circledR}$ (Millipore, Molsheim, França).

O plasma branco fornecido pelo Hemocentro da FMRP-USP foi obtido de voluntários sadios.

\subsubsection{Separação cromatográfica e condições do sistema LC-MS/MS}

O sistema LC-MS/MS foi composto por bomba gradiente binária Waters $1525 \mu$, injetor automático 2777, forno de coluna TCM/CHM e espectrômetro de massas triplo quadrupolo XEVO TQ-S, todos da Waters (Milford, EUA). Os enantiômeros da CY e do CEPM, além do PI antipirina, foram separados na coluna Chiralpak ${ }^{\circledR}$ AD- RH (150 mm x 4,6 $\mathrm{mm}$, tamanho de partícula de $5 \mu \mathrm{m}$, Chiral Technologies, Exton, Filadelfia, EUA) acoplada a uma pré-coluna LiChorpher ${ }^{\circledR} 100$ RP $18(4 \times 4 \mathrm{~mm}$, tamanho de partícula de $5 \mu \mathrm{m}$, Merck, Darmstadt, Alemanha). A fase móvel constituída de mistura de água:acetonitrila:etanol (45:30:25, v/v/v), adicionada de 0,1\% de ácido trifluoroacético, foi empregada na vazão de $0,5 \mathrm{~mL} / \mathrm{min}$. A coluna foi mantida à temperatura de $25 \pm 1^{\circ} \mathrm{C}$. 
A fase móvel proveniente do HPLC foi direcionada para o espectrômetro de massas na vazão de $200 \mu \mathrm{L} / \mathrm{min}$. A temperatura de dessolvatação foi mantida a $200^{\circ} \mathrm{C}$, a fonte de ionização em $150^{\circ} \mathrm{C}$ e a voltagem do capilar foi de $3,4 \mathrm{kV}$. O nitrogênio foi utilizado como gás de nebulização na vazão de $800 \mathrm{~L} / \mathrm{h}$. O argônio foi utilizado como gás de colisão na pressão de aproximadamente $7,0 \times 10^{-3}$ mbar. A voltagem do cone foi mantida em $6 \mathrm{~V}$ para a CY e CEPM e 4 V para o PI. A energia de colisão foi de $16 \mathrm{eV}$ para a CY e CEPM e $30 \mathrm{eV}$ para o PI. As condições de otimização do MS/MS foram obtidas por infusão direta das soluções padrão preparadas na fase móvel e introduzidas com bomba de infusão.

As análises foram executadas no modo MRM (Multiple Reaction Monitoring). As moléculas protonadas $[\mathrm{MH}]^{+}$e seus respectivos íons produtos foram monitorados nas transições 261>140 para a CY, 293>221 para o metabólito CEPM e 189>104 para o PI (ANEXO 4). A aquisição e a quantificação de dados foram realizadas utilizando o programa MassLynx versão 4,1 (Micromass, Manchester, Reino Unido).

\subsubsection{Procedimento de preparo das amostras}

Alíquotas de $25 \mu \mathrm{L}$ de plasma foram enriquecidas com $25 \mu \mathrm{L}$ da solução de PI (antipirina) e $1 \mathrm{~mL}$ de acetato de etila. Os tubos foram agitados em mixer durante 20 segundos e, a seguir, centrifugados (centrífuga refrigerada Beckman, modelo TJ-6) a $5^{\circ} \mathrm{C}$, $2500 \mathrm{rpm}$, por 5 minutos. As fases orgânicas foram transferidas para tubos cônicos e evaporadas até a secura pelo sistema de evaporação a vácuo (RCT90 e modo RC10.22 da Jouan AS, St Herblain, França). Os resíduos foram retomados em $300 \mu \mathrm{L}$ de água, agitados por 5 segundos e mantidos no auto-injetor a $10^{\circ} \mathrm{C}$ até a injeção $(20 \mu \mathrm{L})$ na coluna cromatográfica (Figura 24). 


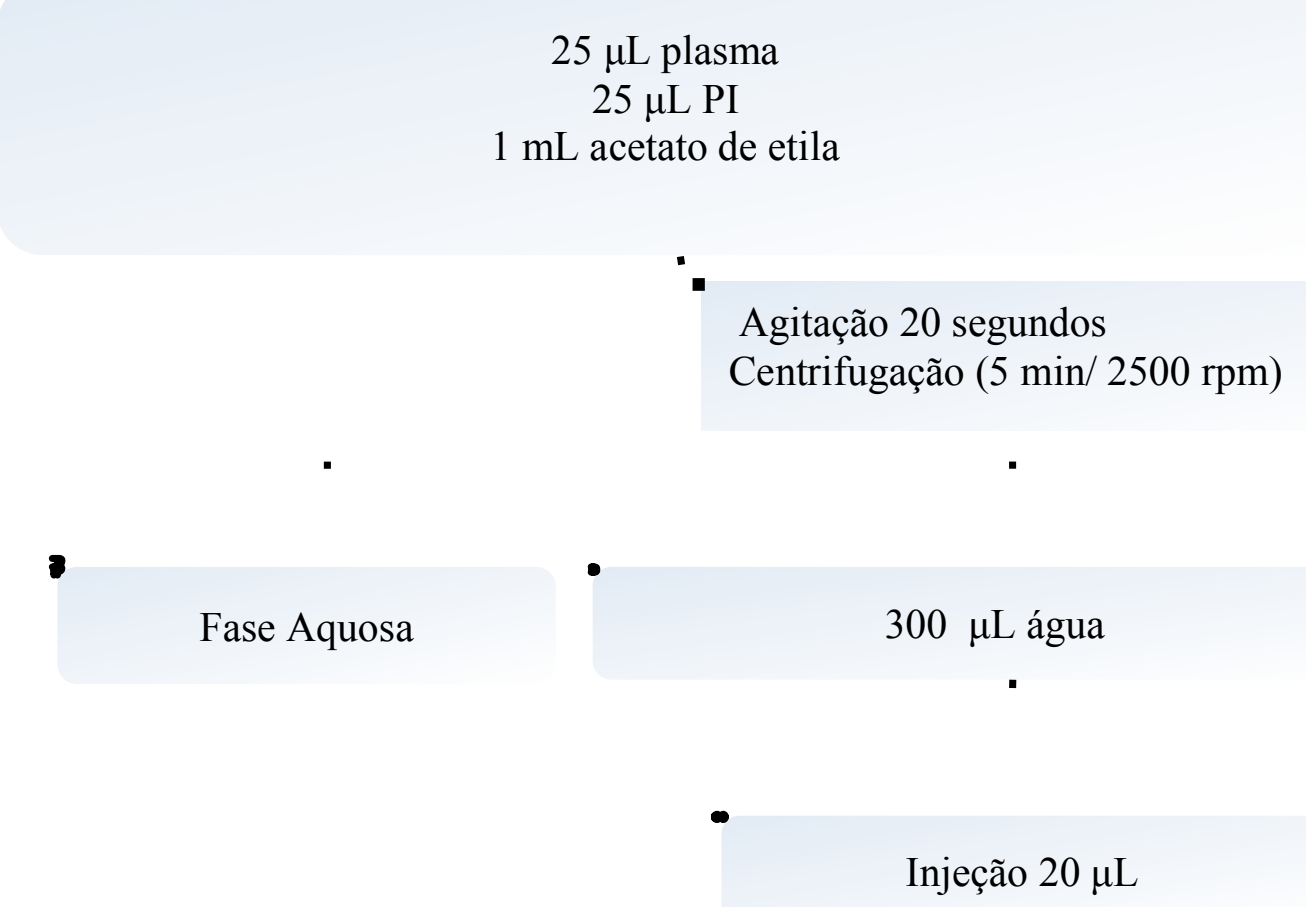

Figura 24. Procedimento de extração líquido-líquido da CY e CEPM em plasma humano.

\subsubsection{Determinação da ordem de eluição dos enantiômeros da CY}

A ordem de eluição dos enantiômeros da CY foi determinada com base na coleta dos picos individuais obtidos da coluna de fase quiral Chiralpak ${ }^{\circledR} \mathrm{AD}-\mathrm{RH}$, seguida de posterior injeção na coluna Chiralcel ${ }^{\circledR} \mathrm{OD}-\mathrm{RH}$, conforme anteriormente descrito pelo grupo de pesquisa (DE MIRANDA SILVA et al., 2009).

Alíquotas de $25 \mu \mathrm{L}$ de solução de CY racêmica $(15 \mu \mathrm{g}$ de cada enantiômero/mL de etanol) foram injetadas na coluna Chiralpak ${ }^{\circledR}$ AD-RH nas condições anteriormente estabelecidas, empregando fase móvel constituída de mistura de água:acetonitrila:etanol (45:30:25, v/v/v), adicionada de $0,1 \%$ de ácido trifluoroacético na vazão de $0,5 \mathrm{~mL} / \mathrm{min}$. Os enantiômeros individuais foram coletados na saída do detector ultravioleta operando no comprimento de onda de $195 \mathrm{~nm}$. As alíquotas coletadas foram extraídas de acordo com as condições previamente citadas, sendo o extrato retomado na fase móvel composta por água:acetonitrila $(75: 25, \mathrm{v} / \mathrm{v})$ adicionada de $0,1 \%$ de ácido fórmico (DE MIRANDA SILVA et al., 2009). 


\subsubsection{Estudo de racemização}

Soluções padrão de CY e CEPM nas concentracões de $30 \mu \mathrm{g} / \mathrm{mL}$ e $1000 \mathrm{ng} / \mathrm{mL}$ foram injetadas na coluna Chiralpak ${ }^{\circledR}$ AD-RH empregando fase móvel constituída de mistura de água:acetonitrila:etanol (45:30:25, v/v/v) adicionada de 0,1\% de ácido trifluoroacético na vazão de $0,5 \mathrm{~mL} / \mathrm{min}$. Os enantiômeros individuais foram coletados na saída da coluna. As frações coletadas foram extraídas da fase móvel com acetonitrila, os extratos evaporados até a secura, retomados em $25 \mu \mathrm{L}$ de plasma branco e submetidos ao processo de extração. Os cromatogramas obtidos foram comparados àqueles obtidos a partir de soluções padrão na mesma concentração não submetidas ao processo de extração.

\subsubsection{Validação do método de análise dos enantiômeros da CY e do metabólito} CEPM em plasma

O método de análise dos enantiômeros da CY e do metabólito CEPM em plasma foi validado de acordo com as recomendações da ANVISA (Agência Nacional de Vigilância Sanitária - Resolução RDC n ${ }^{\circ}$ 27, de 17 de maio de 2012) para métodos bioanalíticos.

\subsubsection{Efeito matriz}

O efeito matriz foi avaliado através da comparação direta das áreas dos picos dos enantiômeros da CY e do CEPM e do PI antipirina, injetados diretamente na fase móvel com as áreas dos picos obtidas de soluções padrão $(0,05 \mu \mathrm{g}$ e $5 \mu \mathrm{g}$ de cada enantiômero da $\mathrm{CY} / \mathrm{mL}$ de plasma, $250 \mathrm{ng}$ e $1 \mu \mathrm{g}$ de cada enantiômero do CEPM/mL de plasma) adicionadas a extratos de plasma branco oriundos de oito diferentes voluntários, sendo quatro plasmas normais, dois lipêmicos e dois hemolisados. O CV dos FMNs (Fator de Matriz Normalizado por Padrão Interno) relativos à todas as amostras deve ser inferior a 15\%.

\subsubsection{Curvas de calibração e linearidade}

As curvas de calibração e linearidade foram construídas em triplicata utilizando alíquotas de $25 \mu \mathrm{L}$ de plasma branco enriquecidas com $25 \mu \mathrm{L}$ de cada solução padrão de uso de CY, do CEPM e do PI e submetidas ao processo de extração descrito anteriormente. 
Assim, as concentrações foram 0,$05 ; 0,25 ; 0,5 ; 2,5 ; 5 ; 15 ; 20 ; 25 \mu \mathrm{g}$ de cada enantiômero de $\mathrm{CY} / \mathrm{mL}$ de plasma e 25, 50, 100, 150, 250, 500, 1000, 1250, 1500 e $2500 \mathrm{ng}$ de cada enantiômero de CEPM/mL de plasma. As equações de regressão linear e os coeficientes de correlação foram obtidos das razões das áreas dos picos padrão/PI plotadas em função das respectivas concentrações plasmáticas.

\subsubsection{Limite de quantificação}

O limite de quantificação foi obtido pela análise em oito replicatas de amostras de plasma enriquecidas com CY e CEPM na concentração de 0,05 $\mu \mathrm{g}$ de cada enantiômero da $\mathrm{CY} / \mathrm{mL}$ de plasma e de $25 \mathrm{ng}$ de cada enantiômero do CEPM/mL de plasma. O limite de quantificação foi definido como a menor concentração plasmática analisada com coeficiente de variação inferior a $20 \%$ e com porcentagem de inexatidão inferior a $15 \%$.

\subsubsection{Precisão e exatidão}

A precisão e a exatidão dos métodos foram avaliadas através de estudos intra e interensaios. As soluções de CY foram preparadas nas concentrações de 0,$05 ; 0,15 ; 10 ; 21$ e $100 \mu \mathrm{g}$ de cada enantiômero/mL de plasma e as soluções de CEPM nas concentrações de 25; 75; 750; 2000; 3000 ng de cada enantiômero/mL de plasma. Essas soluções foram separadas em alíquotas e armazenadas a $-70{ }^{\circ} \mathrm{C}$ até a análise. Para a avaliação da precisão e da exatidão intra-ensaio foram analisadas 5 alíquotas de cada uma dessas soluções em uma mesma corrida analítica. $\mathrm{Na}$ avaliação da precisão e da exatidão interensaios foram analisadas 5 alíquotas de cada uma das soluções de CY e CEPM durante 3 diferentes corridas em dias distintos.

\subsubsection{Estabilidade}

Foram avaliadas as estabilidades após ciclos de congelamento e descongelamento, pósprocessamento e estabilidade de curta duração. Para a avaliação da estabilidade da CY foram preparadas amostras enriquecidas com concentrações de 0,15 e $21 \mu \mathrm{g}$ de cada enantiômero de $\mathrm{CY} / \mathrm{mL}$ de plasma, enquanto que para a avaliação do CEPM foram preparadas amostras enriquecidas nas concentrações 75 e 2000 ng de cada enantiômero/mL de plasma. Para verificar a estabilidade em ciclos de congelamento e descongelamento, as amostras 
enriquecidas foram congeladas a $-70^{\circ} \mathrm{C}$ por pelo menos $24 \mathrm{~h}$, a seguir foram descongeladas e congeladas novamente por $24 \mathrm{~h}$, repetindo-se esse processo até o terceiro ciclo de congelamento quando foram extraídas e analisadas. Para a avaliação da estabilidade pósprocessamento, as amostras extraídas foram mantidas no auto-injetor a $4^{\circ} \mathrm{C}$ durante $24 \mathrm{~h}$ antes da injeção no sistema cromatográfico. Para a avaliação da estabilidade de curta duração as amostras enriquecidas de plasma foram mantidas na bancada do laboratório em temperatura ambiente durante $3 \mathrm{~h}$. Os resultados das estabilidades foram comparados com os resultados das amostras recém preparadas.

\subsection{Análise dos enantiômeros da HCY em plasma humano empregando LC-MS/MS}

\subsubsection{Soluções padrão e reagentes}

As soluções padrão de HCY foram preparadas a partir da oxidação da 4hidroxiperoxiciclofosfamida (Toronto Research Chemicals Inc., Toronto, Canadá) com solução aquosa $1,2 \mathrm{mg} / \mathrm{mL}$ de tiossulfato de sódio (pureza $>98 \%$, Sigma-Aldrich, St. Louis, MO, EUA). Devido a alta instabilidade da HCY, a solução aquosa foi imediatamente derivada com fenil-hidrazina e diluída com solução de fenil-hidrazina e plasma branco na proporção 2:1. A solução de fenil-hidrazina (pureza $>99 \%$, Sigma-Aldrich, St. Louis, MO, EUA) foi preparada na concentração de $4 \%$ em tampão citrato $0,05 \mathrm{M}, \mathrm{pH}=6$. As soluções do metabólito HCY derivado foram diluídas para a obtenção das concentrações 5, 25, 50, 250, 500, 1250, 2500 e 5000 ng de cada enantiômero de $\mathrm{HCY} / \mathrm{mL}$ de plasma e armazenadas a $-70^{\circ} \mathrm{C}$. O PI utilizado foi a antipirina (Sigma, St. Louis, MO, EUA), preparada em metanol na concentração de $100 \mathrm{ng} / \mathrm{mL}$.

Os reagentes metanol, hexano, diclorometano e acetonitrila, grau HPLC, foram adquiridos da Merck (Darmstadt, Alemanha). O ácido fórmico (88\%) foi adquirido da J.T. Baker (Philipsburg, NJ, EUA). Toda a água utilizada foi destilada e deionizada com o auxilio do sistema Milli-Q Plus (Milipore, Bedford, MA, EUA).

O plasma branco fornecido pelo Hemocentro da FMRP-USP foi obtido de voluntários sadios. 


\subsubsection{Separação cromatográfica e condições do sistema LC-MS/MS}

O sistema de cromatografia líquida de alta eficiência foi composto por uma bomba LC10AD e um forno de coluna CTO-10AS da Shimadzu (Kyoto, Japão). Os enantiômeros da HCY e o PI antipirina foram separados na coluna Chiracel ${ }^{\circledR}$ OD-R $(250 \mathrm{~mm} \times$ 4,6 mm, tamanho de partícula de 10 $\mathrm{m}$ ) (Chiral Technologies Inc., Exton, PA, EUA) acoplada a uma pré-coluna LiChorpher ${ }^{\circledR} 100$ RP $18(4 \times 4 \mathrm{~mm}$, tamanho de partícula de $5 \mu \mathrm{m})$ (Merck, Darmstadt, Alemanha). A fase móvel constituída de mistura de água: acetonitrila (45:55, v/v) adicionada de $0,2 \%$ de ácido fórmico foi empregada na vazão de $0,5 \mathrm{~mL} / \mathrm{min}$. A coluna foi mantida à temperatura de $25 \pm 1^{\circ} \mathrm{C}$.

Os enantiômeros da HCY foram detectados com auxílio de um espectrômetro de massas (Quattro Micro LC, Micromass, Manchester, RU) acoplado ao HPLC e equipado com fonte de ionização por eletronebulização operando no modo íon positivo. A fase móvel proveniente do HPLC foi direcionada para o espectrômetro de massas na vazão de $200 \mu \mathrm{L} / \mathrm{min}$. A temperatura de dessolvatação foi mantida a $200^{\circ} \mathrm{C}$, a fonte de ionização em $120^{\circ} \mathrm{C}$ e a voltagem do capilar foi de $3 \mathrm{kV}$. O nitrogênio com fluxo de $450 \mathrm{~L} / \mathrm{h}$ foi utilizado como gás nebulizador e o argônio como gás de colisão em fluxo de $2,30 \times 10^{-3}$ mbar de pressão. As voltagens do cone e de colisão foram ajustadas em $15 \mathrm{~V}$ e $10 \mathrm{~V}$, respectivamente.

As condições do espectrômetro de massas foram otimizadas através da infusão direta do extrato de uma solução padrão de HCY derivada com fenil-hidrazina, diluída em plasma (10ug de cada enantiômero/mL) e submetida ao procedimento de extração líquido-líquido. O extrato foi retomado com $5 \mathrm{~mL}$ da fase móvel (água: acetonitrila 45:55, v/v adicionada de $0,2 \%$ de ácido fórmico) e injetado no espectrômetro de massas com o auxílio de uma bomba de infusão em fluxo de $10 \mu \mathrm{L} / \mathrm{min}$.

Para a quantificação, o espectrômetro de massas foi ajustado para operar no modo MRM (multiple reaction monitoring) de forma a monitorar o PI (transições 189>104) e o metabólito HCY (transições 367>147) (ANEXO 4).

A aquisição de dados e análise quantitativa foi realizada utilizando-se o sistema MassLynx (Micromass, Manchester, Reino Unido) de aquisição de dados, versão 4,1. 


\subsubsection{Procedimento de preparo das amostras}

Alíquotas de $200 \mu \mathrm{L}$ de solução de plasma com fenil-hidrazina (1:2) foram enriquecidas com $25 \mu \mathrm{L}$ da solução de padrão interno (antipirina) e $5 \mathrm{~mL}$ da mistura de hexano/diclorometano $(80: 20 ; \mathrm{v} / \mathrm{v})$. Os tubos foram agitados em agitador horizontal (agitador de mesa reciprocante modelo MA 139/CFT, Marconi) durante' 30 minutos e, a seguir, centrifugados (centrífuga refrigerada Beckman, modelo TJ-6) $\boldsymbol{\vee}^{\circ} \mathrm{C}, 2000 \mathrm{rpm}$, por 10 minutos. As fases orgânicas foram transferidas para tubos cônicos e evaporadas até a secura pelo sistema de evaporação à vácuo (RCT90 e modo RC10.22 da Jouan AS, St Herblain, França). Os resíduos foram retomados em $130 \mu \mathrm{L}$ de fase móvel, agitados por 5 segundos e mantidos no auto-injetor a $16^{\circ} \mathrm{C}$ (SIL-10 AD VP, Shimadzu, Kyoto, Japão) até a injeção (70 $\mu \mathrm{L})$ na coluna cromatográfica (Figura 25 ).

$200 \mu \mathrm{L}$ solução de plasma $25 \mu \mathrm{L}$ PI

$5 \mathrm{~mL}$ solvente extrator (hexano/diclorometano, 80:20, v/v)

Agitação 30 min

Centrifugação (10 min/ $2000 \mathrm{rpm})$

Fase Aquosa

$130 \mu \mathrm{L}$ fase móvel

Injeção $70 \mu \mathrm{L}$

Figura 25. Procedimento de extração líquido-líquido do HCY em solução de plasma humano. 


\subsubsection{Validação}

O método desenvolvido para análise enantiosseletiva do HCY em plasma humano foi validado de acordo com as recomendações da ANVISA para validação de métodos bioanalíticos. Foram avaliados os seguintes parâmetros: limite de quantificação, linearidade, precisão, exatidão, seletividade e estabilidade.

\subsection{Análise Farmacocinética}

A disposição cinética enantiosseletiva da $\mathrm{CY}$ foi avaliada através de cinética não compartimental com o auxílio do programa WinNonlin. Foram obtidos os seguintes parâmetros para cada enantiômero: concentração plasmática máxima (Cmax), tempo para atingir a Cmax (tmax), área sob a curva concentração plasmática versus tempo $\left(\mathrm{AUC}^{0-\infty}\right)$, clearance total $(\mathrm{Cl})$, volume de distribuição $(\mathrm{Vd})$, constante de velocidade de eliminação (Kel) e meia-vida de eliminação (t1/2). A $\mathrm{AUC}^{0-\infty}$ foi determinada no intervalo de 0-24 horas, através do método dos trapezoides e extrapolada para o infinito através da razão entre a ultima concentração plasmática avaliada e a constante de velocidade de eliminação.

A disposição cinética dos enantiômeros dos metabólitos CEPM e HCY foram avaliadas através de cinética de primeira ordem com o auxilio do programa WinNonlin. Foram obtidos os seguintes parâmetros: Cmax, tmax, $\mathrm{AUC}^{0-\infty}, \mathrm{C}^{\mathrm{ss}}$, constante de velocidade de formação (Kf), Kel, t1/2 e meia-vida de formação (t1/2 f).

\subsection{Análise das variantes alélicas do CYP2B6 e do CYP2C9}

As análises das variantes alélicas presentes no CYP2B6 e CYP2C9 foram realizadas no Laboratório de Nefrologia da Faculdade de Medicina de Ribeirão Preto da Universidade de São Paulo. O DNA dos pacientes incluídos no estudo foi extraído da camada leucocitária do sangue através da técnica de salting out (MILLER; DYKES, POLESKY, 1988).

\subsubsection{CY2B6}

A amplificação do DNA dos pacientes portadores de EM e ES e a identificação do polimorfismo de base única 516G>T presente no exon 4 do gene CYP2B6 (cromossomo 19) foi realizada através da técnica RFLP-PCR [Restriction Fragment Lenght Polymorphism Polimerase Chain Reaction (Reação da Cadeia pela Polimerase - PCR)] seguida de digestão 
por enzimas de restrição. Foram utilizadas as sondas R 5'AACTGTACTCACTCCCAGAGT-3' e F 3'-CGCAGACATGTGAAGAATCAG-5', conforme descrito por Jacob et al. (2004). A reação de PCR foi desenvolvida em um volume final de $25 \mu \mathrm{L}$ contendo $2 \mathrm{ng}$ de DNA genômico, 0,4 $\mu \mathrm{M}$ de cada primer, $2 \mathrm{mM}$ de deoxinucleotídeos trifosfato e $0,1 \mathrm{U}$ de Taq polimerase (LGC Biotecnologia, Cotia, Brasil). A termociclagem consistiu de 35 ciclos de 30 segundos a $94^{\circ} \mathrm{C}, 30$ segundos a $53,2^{\circ} \mathrm{C}$ e 60 segundos a $72^{\circ} \mathrm{C}$, seguidos de uma extensão final de 3 minutos a $72^{\circ} \mathrm{C}$.

Os produtos amplificados foram digeridos com a enzima de restrição BsrI (Fermentas, Vilnius, Lituânia), durante $16 \mathrm{~h}$ a $65^{\circ} \mathrm{C}$, produzindo fragmentos de 267 bp, 236 bp e 176 bp no caso da presença da variante polimórfica (alelo T) ou 503 bp e 176 bp no caso do alelo selvagem (alelo $\mathrm{G})$. Os fragmentos foram separados por eletroforese em gel de agarose a $3 \%$ e visualizados após a adição de brometo de etídio, sob luz UV. O alelo selvagem G e a variante alélica $\mathrm{T}$ foram identificados a partir do perfil das bandas reveladas, conforme demonstrado na Figura 26.

$1000 \mathrm{bp}$

$500 \mathrm{bp}$

:

$100 \mathrm{bp}$

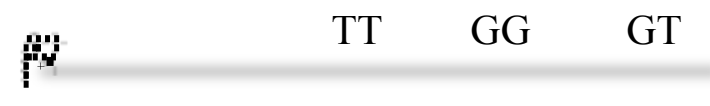

Figura 26. Perfil das bandas na análise das variantes alélicas CYP2B6 


\subsubsection{CYP2C9}

A identificação dos polimorfismos de base única (SNP-single nucleotide polymorfism) 430C $>\mathrm{T}$ (presente no exon 3) e 1075A >C (presente no exon 7 do gene CYP2C9 localizado no cromossomo 10) foi realizada por discriminação alélica através da reação da polimerase em cadeia em tempo real (RT-PCR), utilizando os ensaios do tipo TaqMan ${ }^{\circledR}$, Drug Metabolism Genotyping Assays (Applied Biosystems; Foster City, CA, EUA).

As sondas utilizadas nos ensaios foram desenhadas pela Applied Biosystems, conforme identificadas na Tabela 19. A amplificação do PCR foi realizada utilizando o equipamento Roche LightCycler ${ }^{\circledR}$ 480, programa versão 1,5 (Roche Diagnostics GmbH, Mannheim, Alemanha).

O TaqMan ${ }^{\circledR}$ PCR foi realizado, conforme instruções do fabricante, para um volume final de $10 \mu \mathrm{L}$ contendo $1 \mu \mathrm{L}$ de DNA genômico (30 ng/ $\mu \mathrm{L}), 5 \mu \mathrm{L}$ de Master Mix (2X), 0,5 $\mu \mathrm{L}$ de $\operatorname{Taqman}^{\circledR}(20 \mathrm{X})$ e 3,5 $\mu \mathrm{L}$ de água Milli-Q.

A termociclagem consistiu de um ciclo de desnaturação inicial a $95^{\circ} \mathrm{C}$ por 10 minutos, 40 ciclos de amplificação a $95^{\circ} \mathrm{C}$ por 10 segundos e $60^{\circ} \mathrm{C}$ por 1 minuto e, e um ciclo de resfriamento a $37^{\circ} \mathrm{C}$ por 10 segundos. A análise de controle negativo foi realizada em cada corrida e a discriminação alélica foi realizada pela medida da fluorescência final (Endpoint Genotying Analysis) dos cromóforos VIC $^{\circledR}$ e FAM $^{\circledR}$ ligados no final 5' da sonda Taqman ${ }^{\circledR}$ (Applied Biosystems; Foster City, CA, EUA) e analisadas utilizando o programa do fabricante.

Tabela 19. Sondas utilizadas nos ensaios de genotipagem para o CYP2C9

\begin{tabular}{cccc}
\hline \hline ID do ensaio & Alelo & Polimorfismo & Sequência \\
\hline C_25625805_10 & $* 2$ & $3608 \mathrm{C}>\mathrm{T}$ & $\begin{array}{c}\text { GATGGGGAAGAGGAGCATTGAGGAC }[C / T] G T G T T C A A \\
\text { GAGGAAGCCCGCTGCCT }\end{array}$ \\
C_27104892_10 & $* 3$ & 42614A $>\mathrm{C}$ & $\begin{array}{c}\text { TGTGGTGCACGAGGTCCAGAGATAC[C/A]TTGACCTTC } \\
\text { TCCCCACCAGCCTGCC }\end{array}$ \\
\hline
\end{tabular}

ID- identificação 


\subsection{Análise estatística}

Os cálculos de média, mediana, desvio padrão (DP), coeficiente de variação $(\mathrm{CV})$ e percentis foram realizados com auxílio do programa Excel. Os testes estatísticos (MannWhitney, Wilcoxon, Kruskal-Wallis) foram realizados com o auxílio GraphPad Prisma ${ }^{\circledR}$. O teste qui-quadrado foi utilizado para avaliar o desvio das frequências alélicas dos genes estudados do equilíbrio de Hardy-Weinberg. As frequências alélicas e a determinação dos haplótipos foram realizadas com auxílio do programa PHASE, versão 2. Os parâmetros farmacocinéticos foram calculados com base nas curvas de concentração plasmática do BU versus tempo utilizando o programa WinNonlin, versão 4,0 (Pharsight Corp, Mountain View, Calif, EUA). Os cálculos foram realizados empregando cinética de primeira ordem, modelo monocompartimental para os enantiômeros dos metabólitos CEPM e HCY e modelo não compartimental para os enantiômeros da CY. 
4. Resultados 


\subsection{Dados demográficos}

Foram investigados 20 pacientes, sendo 10 pacientes portadores de ES e 10 pacientes portadores de EM, submetidos ao TCTH. Todos os transplantes foram autólogos, utilizando sangue periférico como fonte de células tronco para o enxerto. A idade dos pacientes investigados variou de 19-51 anos (mediana 36,5 anos) e o IMC de $15,2-30,8 \mathrm{Kg} / \mathrm{m}^{2}$ (mediana $20,6 \mathrm{Kg} / \mathrm{m}^{2}$ ).

Com base no protocolo estabelecido no HCFMRP-USP, no dia da administração da CY e coleta de amostras seriadas de sangue, todos os pacientes fizeram uso dos seguintes fármacos: mesna, fluconazol, aciclovir, sulfametoxazol+trimetoprima, hidrocortisona, maleato de dexclofeniramina, globulina antitimocítica (ATG), ondansetrona e metilpredinisolona (4h antes do tempo de coleta $24 \mathrm{~h}$ ).

Além dos fármacos acima descritos, alguns pacientes também foram tratados com os medicamentos detalhados nas Tabelas 20 e 21.

Tabela 20. Dados demográficos dos pacientes portadores de EM incluídos no estudo $(\mathrm{n}=10)$

\begin{tabular}{ccccc}
\hline \hline Paciente & Sexo & $\begin{array}{c}\text { Idade } \\
\text { (anos) }\end{array}$ & $\begin{array}{c}\text { IMC } \\
\left(\mathbf{K g} / \mathbf{m}^{\mathbf{2}}\right.\end{array}$ & $\begin{array}{c}\text { Fármacos } \\
\text { associados }\end{array}$ \\
\hline $\mathbf{1}$ & M & 38 & 25,4 & 1,2 \\
$\mathbf{2}$ & $\mathrm{F}$ & 27 & 25,7 & $1,5,8,14$ \\
$\mathbf{3}$ & $\mathrm{M}$ & 28 & 20,6 & $1,2,6$ \\
$\mathbf{4}$ & $\mathrm{M}$ & 34 & 28,4 & $1,3,5,18$ \\
$\mathbf{5}$ & $\mathrm{F}$ & 31 & 18,8 & $3,4,5,18$ \\
$\mathbf{6}$ & $\mathrm{M}$ & 27 & 18,1 & 9,10 \\
$\mathbf{7}$ & $\mathrm{M}$ & 54 & 24,3 & $11,12,13$ \\
$\mathbf{8}$ & $\mathrm{M}$ & 37 & 19,7 & 5 \\
$\mathbf{9}$ & $\mathrm{F}$ & 48 & 23,3 & $2,5,17$ \\
$\mathbf{1 0}$ & $\mathrm{F}$ & 50 & 28,3 & $3,5,15,16$ \\
\hline \hline
\end{tabular}

1- furosemida, 2-clonazepam, 3- omeprazol, 4- simeticona, 5-alizaprida, 6- amlodipina, 7-imipramina, 8imipramina, 9- cefalexina, 10- clorpromazina, 11- baclofeno, 12- pantoprazol, 13- cloridrato de bupropiona, 14macrodantina, 15- enalapril, 16- lorazepam, 17-fluoxetina, 18-venlafaxina 
Tabela 21. Dados demográficos dos pacientes portadores de ES incluídos no estudo $(\mathrm{n}=10)$

\begin{tabular}{ccccc}
\hline \hline Paciente & Sexo & $\begin{array}{c}\text { Idade } \\
(\mathbf{a n o s})\end{array}$ & $\begin{array}{c}\text { IMC } \\
\left(\mathbf{k g} / \mathbf{m}^{\mathbf{2}}\right)\end{array}$ & Fármacos associados \\
\hline $\mathbf{1}$ & $\mathrm{F}$ & 43 & 30,8 & $1,3,5,6,7$ \\
$\mathbf{2}$ & $\mathrm{F}$ & 42 & 20,3 & $3,8,9,10$ \\
$\mathbf{3}$ & $\mathrm{M}$ & 47 & 17,5 & $3,4,8$ \\
$\mathbf{4}$ & $\mathrm{F}$ & 51 & 19,8 & $1,2,3$ \\
$\mathbf{5}$ & $\mathrm{M}$ & 28 & 26,4 & $1,11,12,13,14,15$ \\
$\mathbf{6}$ & $\mathrm{F}$ & 36 & 18,9 & $8,16,17$ \\
$\mathbf{7}$ & $\mathrm{F}$ & 19 & 20,6 & $3,8,22,23,24,25,26,27,28$ \\
$\mathbf{8}$ & $\mathrm{M}$ & 38 & 18,9 & $2,3,8,18,19,20,21$ \\
$\mathbf{9}$ & $\mathrm{F}$ & 19 & 15,2 & $2,8,9,24$ \\
$\mathbf{1 0}$ & $\mathrm{M}$ & 27 & 22,4 & 3 \\
\hline \hline
\end{tabular}

1-pantoprazol, 2- alizaprida, 3- furosemida, 4- nifedipina, 5- enalapril, 6- dipirona, 7- clonidina, 8- omeprazol, 9cloridrato de diltiazem, 10- clonazepam, 11-amoxicilina + clavulanato, 12- pentoxifilina, 13- domperidona, 14clonazepam, 15- amiodarona, 16- lorazepam, 17- simeticona, 18- carvedilol, 19- hidroclortiazida, 20clorpromazina, 21- losartana, 22- metoprolol, 23- sertralina, 24- predisona, 25- espironolactona, 26- bosentana, 27- sotalol, 28- alprazolam

\subsection{Análise dos enantiômeros da CY e do metabólito CEPM em plasma}

Os enantiômeros da CY e do CEPM foram separados na coluna Chiralpak ${ }^{\circledR}$ AD-RH empregando fase móvel constituída de mistura de água:acetonitrila:etanol (45:30:25, v/v/v) adicionada de $0,1 \%$ de ácido trifluoroacético na vazão de $0,5 \mathrm{~mL} / \mathrm{min}$. Os íons da CY e do CEPM estão apresentados no Anexo 4, sendo as moléculas protonadas $[\mathrm{MH}]^{+}$da $\mathrm{CY}$ e do CEPM representados, respectivamente, pela razão massa carga $(\mathrm{m} / \mathrm{z}) 261$ e 293 e seus íons produtos representados pela $\mathrm{m} / \mathrm{z} 140$ e 221 .

A Figura 27 mostra os cromatogramas de um plasma branco, um plasma adicionado de CY na concentração de $5 \mu \mathrm{g}$ de cada enantiômero/mL, um plasma adicionado de CEPM na concentração de $500 \mathrm{ng}$ de cada enantiomero/mL e o cromatograma referente a uma amostra de plasma obtida de um paciente portador de EM 1h e 30min após o inicio da infusão de 2,95 $\mathrm{g}$ de ciclofosfamida racêmica. O PI foi eluído com tempo de retenção de 5,41 min, o enantiômero (S)-(-)-(CY) e o enantiômero (R)-(+)-(CY) eluiram, respectivamente, com tempos de retenção de 6,38 e 9,64 min e os enantiômeros do CEPM com tempos de retenção de 4,58 e 4,84 minutos. 
A)

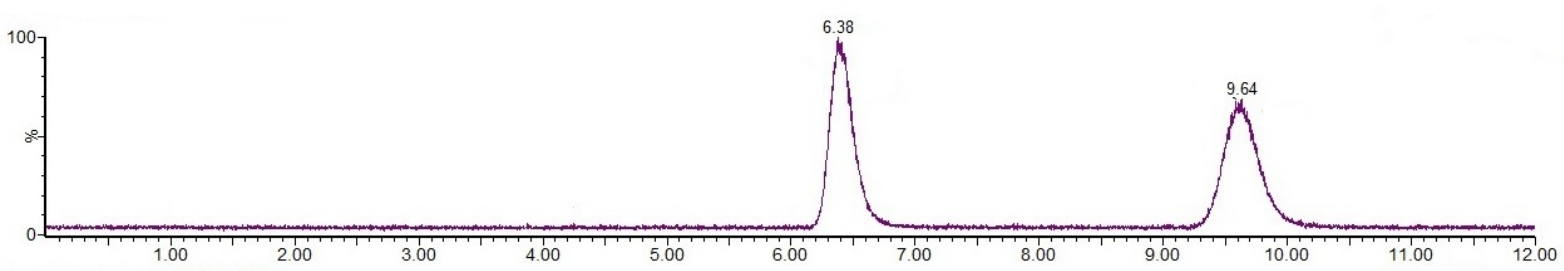

B)

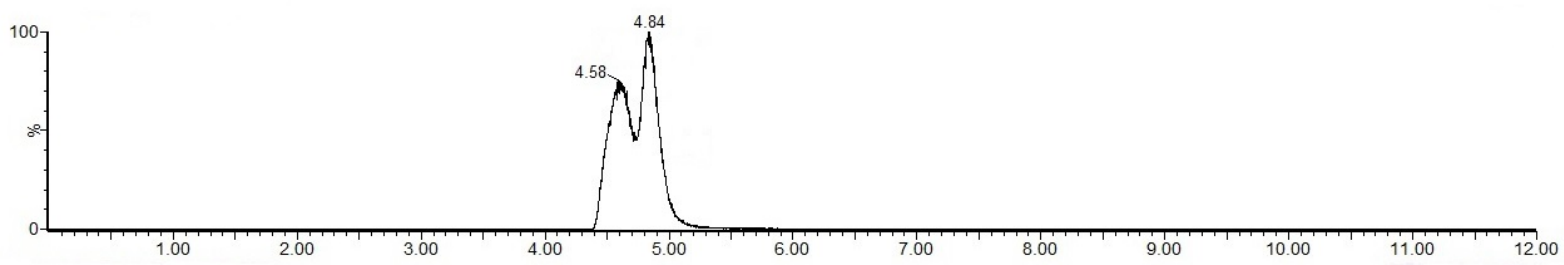

C)

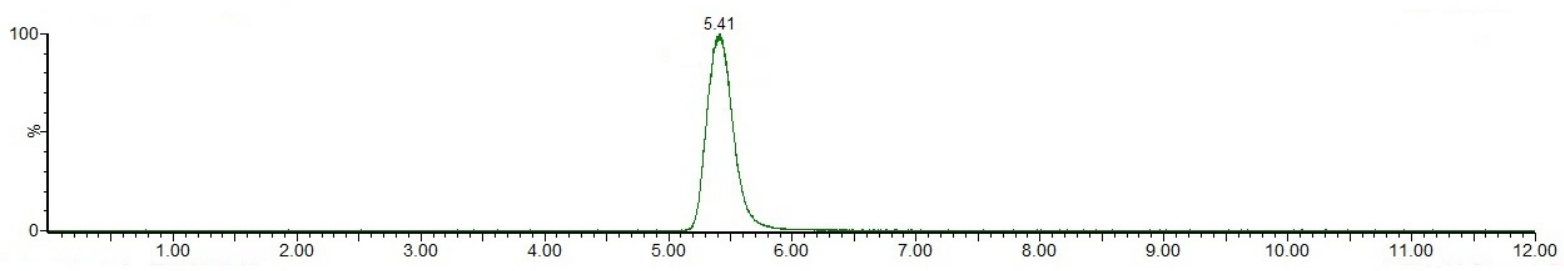

D)

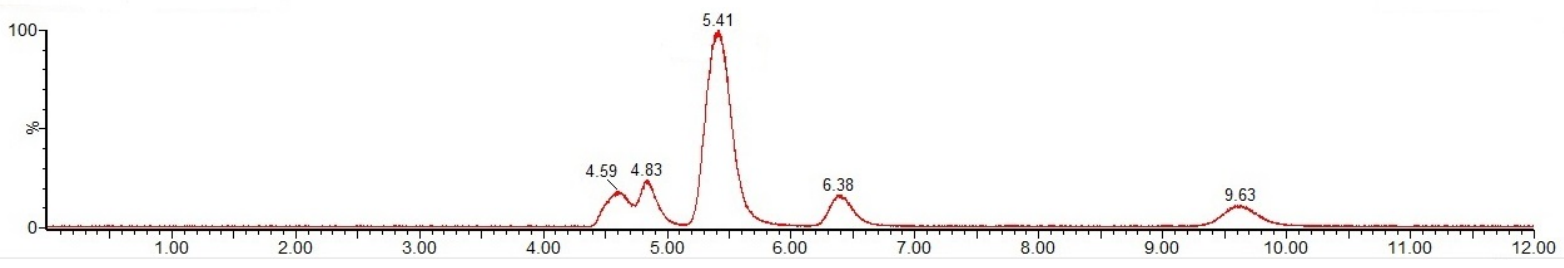

Figura 27. Cromatogramas referentes a (A) Plasma enriquecido com $1000 \mathrm{ng} / \mathrm{mL}$ de cada enantiômero da CY, (B) Plasma enriquecido com $1000 \mathrm{ng} / \mathrm{mL}$ de cada enantiômero do CEPM, (C) Padrão Interno, (D) Plasma de voluntário após infusão de CY.

\subsubsection{Validação do método de análise dos enantiômeros da CY e do CEPM em} plasma

O método foi validado de acordo com as recomendações da Resolução RDC no 27 , de 17 de maio de 2012 da ANVISA (AGÊNCIA NACIONAL DE VIGILANCIA SANITÁRIA, 2012).

Os parâmetros obtidos na validação dos métodos de análise dos enantiômeros da CY e do metabólito CEPM em plasma estão apresentados nas Tabelas 22-25. Os dados 
apresentados na Tabela 22 indicam que o efeito matriz na ionização dos enantiômeros da CY e do CEPM em plasma humano é praticamente ausente. Os dados mostram CV $<15 \%$ entre os valores de FMN (Fator da matriz normalizado por PI) avaliados. Os métodos apresentaram limite de quantificação, precisão e exatidão (Tabelas 23-25) compatíveis com a aplicação em estudos de disposição cinética e metabolismo dos enantiômeros da CY e dos enantiômeros do metabólito CEPM em pacientes tratados com CY durante o condicionamento pré-TCTH.

A ordem de eluição dos enantiômeros do metabólito CEPM não foi realizada, dessa forma, os enantiômeros foram nomeados como CEPM (1) para o enantiômero eluído em 4,58 minutos e como CEPM (2) para o enantiômero eluído com 4,84 minutos.

Tabela 22. Efeito matriz para os enantiômeros da CY e do metabólito CEPM em oito diferentes lotes de plasma humano. Resultados apresentados como CV (\%) dos valores FMN

\begin{tabular}{cc}
\hline \hline Concentração & $\begin{array}{c}\text { FMN } \\
\text { CV (\%) }\end{array}$ \\
\hline (S)-(-)CY & \\
\hline $0,05 \mu \mathrm{g} / \mathrm{mL}$ & 14,9 \\
$5,00 \mu \mathrm{g} / \mathrm{mL}$ & \\
\hline $\mathbf{( R )}-\mathbf{( + )}-\mathbf{C Y}$ & 12,5 \\
\hline $0,05 \mu \mathrm{g} / \mathrm{mL}$ & \\
$5,00 \mu \mathrm{g} / \mathrm{mL}$ & \\
\hline $\mathbf{C E P M}(\mathbf{1})$ & 9,7 \\
\hline $250 \mathrm{ng} / \mathrm{mL}$ & \\
\hline $1000 \mathrm{ng} / \mathrm{mL}$ & 8,4 \\
\hline $\mathbf{C E P M}(\mathbf{2})$ & \\
\hline $250 \mathrm{ng} / \mathrm{mL}$ & \\
\hline $1000 \mathrm{ng} / \mathrm{mL}$ & \\
\hline \hline
\end{tabular}

FMN: Fator da matriz normalizado por PI [(Resposta do analito em matriz/Resposta do PI em matriz)/ (Resposta do analito em solução padrão/Resposta do PI em solução padrão)] CV = coeficiente de variação [(SD FMN/ média FMN) x 100]. 
Tabela 23. Limites de confiança do método de análise dos enantiômeros da CY

\begin{tabular}{|c|c|c|}
\hline & $(\mathbf{S})-(-)-C Y$ & $(\mathbf{R})-(+)-\mathrm{CY}$ \\
\hline Linearidade & $50 \mathrm{ng} / \mathrm{mL}-25 \mu \mathrm{g} / \mathrm{mL}$ & $50 \mathrm{ng} / \mathrm{mL}-25 \mu \mathrm{g} / \mathrm{mL}$ \\
\hline Equação da reta & $y=3,05208 X+0,0573337$ & $Y=3,15162 X+0,0487314$ \\
\hline $\mathrm{r}$ & 0,997229 & 0,9977110 \\
\hline Limite de Quantificação & 50 & 50 \\
\hline \multicolumn{3}{|l|}{$(50 \mathrm{ng} / \mathrm{mL})$} \\
\hline Precisão (CV \%, n = 6) & 12,4 & 5,2 \\
\hline Exatidão (Inexatidão \%) & 5,2 & 3,2 \\
\hline \multicolumn{3}{|c|}{ Precisão intra-ensaio (CV \%) } \\
\hline $50 \mathrm{ng} / \mathrm{mL}(\mathrm{n}=5)$ & 8,3 & 5,6 \\
\hline $150 \mathrm{ng} / \mathrm{mL}(\mathrm{n}=5)$ & 12,4 & 12,4 \\
\hline $10 \mu \mathrm{g} / \mathrm{mL}(\mathrm{n}=5)$ & 7,8 & 9,0 \\
\hline $21 \mu \mathrm{g} / \mathrm{mL}(\mathrm{n}=5)$ & 12,6 & 6,9 \\
\hline $100 \mu \mathrm{g} / \mathrm{mL}(1: 5)(\mathrm{n}=5)$ & 3,8 & 3,0 \\
\hline \multicolumn{3}{|c|}{ Precisão interensaios (CV \%) } \\
\hline $50 \mathrm{ng} / \mathrm{mL}(\mathrm{n}=15)$ & 5,8 & 4,1 \\
\hline $150 \mathrm{ng} / \mathrm{mL}(\mathrm{n}=15)$ & 13,6 & 12,8 \\
\hline $10 \mu \mathrm{g} / \mathrm{mL}(\mathrm{n}=15)$ & 8,0 & 7,2 \\
\hline $21 \mu \mathrm{g} / \mathrm{mL}(\mathrm{n}=15)$ & 7,2 & 7,5 \\
\hline $100 \mu \mathrm{g} / \mathrm{mL}(1: 5)(\mathrm{n}=15)$ & 6,9 & 6,5 \\
\hline \multicolumn{3}{|l|}{ Exatidão intra-ensaio } \\
\hline \multicolumn{3}{|l|}{ (Inexatidão \%) } \\
\hline $50 \mathrm{ng} / \mathrm{mL}(\mathrm{n}=5)$ & 0,5 & 10,3 \\
\hline $150 \mathrm{ng} / \mathrm{mL}(\mathrm{n}=5)$ & 10,0 & 10,0 \\
\hline $10 \mu \mathrm{g} / \mathrm{mL}(\mathrm{n}=5)$ & $-8,2$ & $-5,8$ \\
\hline $21 \mu \mathrm{g} / \mathrm{mL}(\mathrm{n}=5)$ & $-1,8$ & $-4,1$ \\
\hline $100 \mu \mathrm{g} / \mathrm{mL}(1: 5)(\mathrm{n}=5)$ & 6,3 & 12,0 \\
\hline \multicolumn{3}{|l|}{ Exatidão interensaios } \\
\hline \multicolumn{3}{|l|}{ (Inexatidão \%) } \\
\hline $50 \mathrm{ng} / \mathrm{mL}(\mathrm{n}=15)$ & 6,2 & 6,4 \\
\hline 150 ng/mL $(\mathrm{n}=15)$ & 5,7 & 5,0 \\
\hline $10 \mu \mathrm{g} / \mathrm{mL}(\mathrm{n}=15)$ & $-2,9$ & $-5,2$ \\
\hline $21 \mu \mathrm{g} / \mathrm{mL}(\mathrm{n}=15)$ & $-4,3$ & $-9,4$ \\
\hline $100 \mu \mathrm{g} / \mathrm{mL}(1: 5)(\mathrm{n}=15)$ & 7,8 & $-10,2$ \\
\hline
\end{tabular}


Tabela 24. Limites de confiança do método de análise dos enantiômeros do CEPM em plasma

\begin{tabular}{|c|c|c|}
\hline & CEPM (1) & CEPM (2) \\
\hline Linearidade & $25-2500 \mathrm{ng} / \mathrm{mL}$ & $25-2500 \mathrm{ng} / \mathrm{mL}$ \\
\hline Equação da reta & $y=0,0001362 x+0,00073338$ & $y=0,00057393 x-0,00184307$ \\
\hline $\mathrm{r}$ & 0,999606 & 0,999801 \\
\hline Limite de Quantificação & 25 & 25 \\
\hline \multicolumn{3}{|l|}{$(25 \mathrm{ng} / \mathrm{mL})$} \\
\hline Precisão (CV \%, n = 6) & 3,0 & 8,9 \\
\hline Exatidão (Inexatidão \%) & $-2,4$ & $-2,6$ \\
\hline \multicolumn{3}{|c|}{ Precisão intra-ensaio (CV\%) } \\
\hline $25 \mathrm{ng} / \mathrm{mL}(\mathrm{n}=5)$ & 4,8 & 3,6 \\
\hline $75 \mathrm{ng} / \mathrm{mL}(\mathrm{n}=5)$ & 4,4 & 3,5 \\
\hline $750 \mathrm{ng} / \mathrm{mL}(\mathrm{n}=5)$ & 5,7 & 6,3 \\
\hline $2000 \mathrm{ng} / \mathrm{mL}(\mathrm{n}=5)$ & 7,8 & 6,8 \\
\hline $3000 \mathrm{ng} / \mathrm{mL}(1: 5)(\mathrm{n}=5)$ & 4,6 & 5,7 \\
\hline \multicolumn{3}{|c|}{ Precisão interensaios (CV \%) } \\
\hline $25 \mathrm{ng} / \mathrm{mL}(\mathrm{n}=15)$ & 5,6 & 4,1 \\
\hline $75 \mathrm{ng} / \mathrm{mL}(\mathrm{n}=15)$ & 12,4 & 14,3 \\
\hline $750 \mathrm{ng} / \mathrm{mL}(\mathrm{n}=15)$ & 8,0 & 9,1 \\
\hline $2000 \mathrm{ng} / \mathrm{mL}(\mathrm{n}=15)$ & 6,5 & 11,1 \\
\hline $3000 \mathrm{ng} / \mathrm{mL}(1: 5)(\mathrm{n}=15)$ & 5,3 & 3,5 \\
\hline \multicolumn{3}{|l|}{ Exatidão intra-ensaio } \\
\hline \multicolumn{3}{|l|}{ (Inexatidão \%) } \\
\hline $25 \mathrm{ng} / \mathrm{mL}(\mathrm{n}=5)$ & 0,5 & $-1,4$ \\
\hline $75 \mathrm{ng} / \mathrm{mL}(\mathrm{n}=5)$ & $-7,2$ & $-11,0$ \\
\hline $750 \mathrm{ng} / \mathrm{mL}(\mathrm{n}=5)$ & $-9,4$ & $-13,0$ \\
\hline $2000 \mathrm{ng} / \mathrm{mL}(\mathrm{n}=5)$ & $-3,1$ & 0,4 \\
\hline $3000 \mathrm{ng} / \mathrm{mL}(1: 5)(\mathrm{n}=5)$ & $-6,4$ & $-12,2$ \\
\hline \multicolumn{3}{|l|}{ Exatidão interensaios } \\
\hline \multicolumn{3}{|l|}{ (Inexatidão \%) } \\
\hline $25 \mathrm{ng} / \mathrm{mL}(\mathrm{n}=15)$ & $-7,2$ & $-6,8$ \\
\hline $75 \mathrm{ng} / \mathrm{mL}(\mathrm{n}=15)$ & $-10,2$ & $-10,8$ \\
\hline $750 \mathrm{ng} / \mathrm{mL}(\mathrm{n}=15)$ & $-6,1$ & $-10,9$ \\
\hline $2000 \mathrm{ng} / \mathrm{mL}(\mathrm{n}=15)$ & $-4,5$ & $-7,6$ \\
\hline $3000 \mathrm{ng} / \mathrm{mL}(1: 5)(\mathrm{n}=15)$ & $-7,8$ & $-10,3$ \\
\hline
\end{tabular}


Tabela 25. Estudo de estabilidade do método de análise dos enantiômeros da CY e do CEPM em plasma humano

\begin{tabular}{|c|c|c|c|c|c|c|}
\hline \multirow[t]{2}{*}{ Concentração } & \multicolumn{2}{|c|}{$\begin{array}{c}\text { Estabilidade } \\
\text { curta duração } \\
(4 \text { horas }) \\
\end{array}$} & \multicolumn{2}{|c|}{$\begin{array}{c}\text { Estabilidade pós ciclo } \\
\text { cong/descongelamento } \\
(3 \text { ciclos })\end{array}$} & \multicolumn{2}{|c|}{$\begin{array}{c}\text { Estabilidade pós } \\
\text { processamento } \\
(24 \text { horas })\end{array}$} \\
\hline & $\begin{array}{r}\text { Precisão } \\
(\mathrm{CV} \%)\end{array}$ & $\begin{array}{l}\text { Exatidão } \\
(\% \text { inex) }\end{array}$ & $\begin{array}{c}\text { Precisão } \\
\text { (CV \%) }\end{array}$ & $\begin{array}{l}\text { Exatidão } \\
(\% \text { inex })\end{array}$ & $\begin{array}{l}\text { Precisão } \\
\text { (CV \%) }\end{array}$ & $\begin{array}{l}\text { Exatidão } \\
\text { (\% inex) }\end{array}$ \\
\hline $\begin{array}{l}\text { CY (150 ng/mL) } \\
(\mathrm{S})-(-)-C Y \\
(\mathrm{R})-(+)-C Y\end{array}$ & $\begin{array}{l}11,3 \\
10,4\end{array}$ & $\begin{array}{l}11,2 \\
10,4\end{array}$ & $\begin{array}{l}7,2 \\
5,3\end{array}$ & $\begin{array}{c}-12,8 \\
1,1\end{array}$ & $\begin{array}{c}13,3 \\
8,3\end{array}$ & $\begin{array}{c}13,3 \\
8,3\end{array}$ \\
\hline $\begin{array}{l}\text { CY }(21 \mu \mathrm{g} / \mathbf{m L}) \\
(\mathrm{S})-(-)-\mathrm{CY} \\
(\mathrm{R})-(+)-\mathrm{CY}\end{array}$ & $\begin{array}{l}5,3 \\
2,8\end{array}$ & $\begin{array}{l}6,2 \\
3,5\end{array}$ & $\begin{array}{l}6,5 \\
5,4\end{array}$ & $\begin{array}{c}-12,3 \\
2,5\end{array}$ & $\begin{array}{l}4,2 \\
8,4\end{array}$ & $\begin{array}{l}-2,5 \\
13,0\end{array}$ \\
\hline $\begin{array}{l}\text { CEPM (75 ng/mL) } \\
\text { CEPM } 1 \\
\text { CEPM } 2\end{array}$ & $\begin{array}{l}6,5 \\
7,3\end{array}$ & $\begin{array}{c}3,7 \\
-14,6 \\
\end{array}$ & $\begin{array}{l}7,6 \\
4,2 \\
\end{array}$ & $\begin{array}{l}3,5 \\
5,3 \\
\end{array}$ & $\begin{array}{l}4,4 \\
0,5 \\
\end{array}$ & $\begin{array}{r}-4,5 \\
-11,0 \\
\end{array}$ \\
\hline $\begin{array}{l}\text { CEPM }(\mathbf{2 0 0 0} \mathbf{n g} / \mathbf{m L}) \\
\text { CEPM } 1 \\
\text { CEPM } 2\end{array}$ & $\begin{array}{l}6,6 \\
7,8\end{array}$ & $\begin{array}{l}4,3 \\
5,8\end{array}$ & $\begin{array}{c}10,3 \\
8,9\end{array}$ & $\begin{array}{c}10,6 \\
9,3\end{array}$ & $\begin{array}{l}6,4 \\
2,7\end{array}$ & $\begin{array}{c}7,0 \\
13,5\end{array}$ \\
\hline
\end{tabular}

$\mathrm{CV}=$ coeficiente de variação [(SD/ média) x 100]; r=coeficiente de correlação linear.

$\%$ Inexatidão $=\left[\left(\mathrm{C}_{\text {obs }}-\mathrm{C}_{\text {adicionada }}\right) / \mathrm{C}_{\text {adicionada }}\right] \times 100$

\subsection{Análise dos enantiômeros do metabólito HCY em plasma}

Os enantiômeros do metabólito HCY derivado foram separados na coluna Chiracel ${ }^{\circledR}$ OD-R com fase móvel constituída por mistura de acetonitrila e água (55:25, v/v) adicionada de $0,2 \%$ de ácido fórmico. Os íons do HCY estão apresentados no Anexo 4, sendo a molécula protonada $[\mathrm{MH}]^{+}$representado pela razão massa carga $(\mathrm{m} / \mathrm{z}) 367$ e seu íon produto representado pela $\mathrm{m} / \mathrm{z} 147$.

Os experimentos para definição da ordem de eluição dos enantiômeros do HCY empregando dicró́smo circular foram realizados no Laboratório Alma Mater Studiorum, no Departmento de Farmácia e Biotecnologia da Universidade de Bolonha, Itália, porém os testes foram inconclusivos devido às baixas concentracões dos enantiômeros coletados após corridas cromatográficas.

A Figura 28 apresenta os cromatogramas de um plasma branco, um plasma adicionado de HCY na concentração de 1250 ng de cada enantiômero/mL e o cromatograma referente a uma amostra de plasma obtida de um paciente portador de EM 1h e 30min após o inicio da infusão de 2,95 g de ciclofosfamida racêmica. O PI foi eluído com tempo de retenção de 7,43 
min e os enantiômeros do HCY com tempos de retenção de 11,09 (HCY 1) e 12,75 (HCY 2) $\min$.

A)

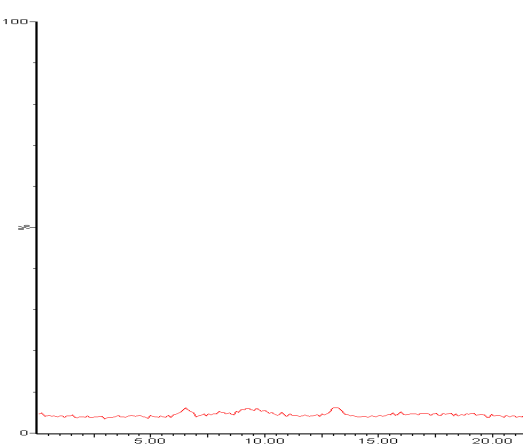

C)

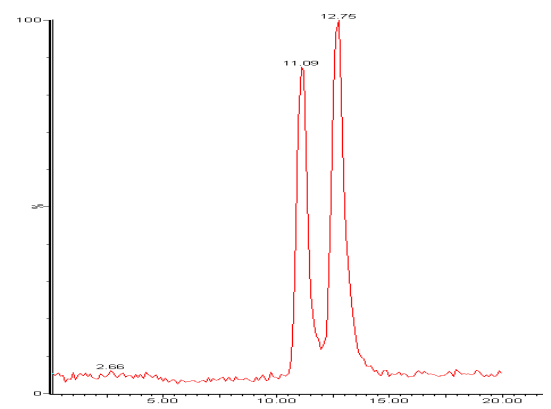

B)

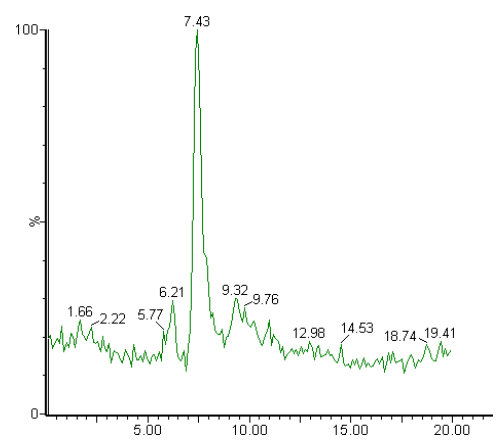

D)

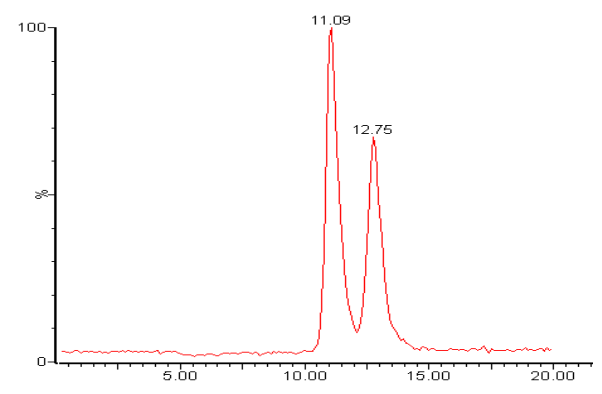

Figura 28. Cromatogramas referentes ao (A) Plasma Branco, (B) Padrão Interno antipirina, (C) Plasma enriquecido com $1000 \mathrm{ng} / \mathrm{mL}$ do derivado de HCY, (D) Plasma de voluntário $1 \mathrm{~h}$ e 30 minutos após o início da infusão de CY.

O método foi validado de acordo com as recomendações da Resolução - RE n 899 de 29 de maio de 2003 da ANVISA (AGÊNCIA NACIONAL DE VIGILANCIA SANITÁRIA, 2003). Os limites de confiança do método de análise dos enantiômeros do HCY em plasma estão apresentados na Tabela 26. Os estudos de precisão e exatidão apresentaram coeficientes de variação e \% de inexatidão menores que $15 \%$. A avaliação da estabilidade em ciclos de congelamento e descongelamento apresentou $\%$ de desvio com valores em torno $15 \%$. 
Tabela 26. Limites de confiança do método de análise dos enantiômeros do HCY

\begin{tabular}{|c|c|c|}
\hline & HCY (1) & HCY (2) \\
\hline Linearidade (ng/mL) & $5-5000$ & $5-5000$ \\
\hline Equação da reta & $y=1,0014 x-1,7089$ & $y=0,9916 x-11,612$ \\
\hline $\mathrm{r}$ & 0,99897 & 0,9998 \\
\hline Limite de quantificação (ng/mL) & 5,0 & 5,0 \\
\hline Precisão (n=6, CV\%) & 11,9 & 13,8 \\
\hline Exatidão (\% inexatidão) & 0,3 & 2,2 \\
\hline \multicolumn{3}{|l|}{ Precisão Interensaios $(C V \%, n=10)$} \\
\hline $20 \mathrm{ng} / \mathrm{mL}$ & 6,7 & 9,1 \\
\hline $1000 \mathrm{ng} / \mathrm{mL}$ & 6,2 & 6,9 \\
\hline $2000 \mathrm{ng} / \mathrm{mL}$ & 6,9 & 8,6 \\
\hline \multicolumn{3}{|l|}{ Precisão Intra-ensaio (CV\%, $n=6)$} \\
\hline $20 \mathrm{ng} / \mathrm{mL}$ & 4,9 & 3,9 \\
\hline $1000 \mathrm{ng} / \mathrm{mL}$ & 11,5 & 7,9 \\
\hline $2000 \mathrm{ng} / \mathrm{mL}$ & 4,48 & 9,8 \\
\hline \multicolumn{3}{|c|}{$\begin{array}{l}\text { Exatidão Interensaios (\% inexatidão, } \\
\mathrm{n}=10)\end{array}$} \\
\hline $20 \mathrm{ng} / \mathrm{mL}$ & 5,35 & $-0,5$ \\
\hline $1000 \mathrm{ng} / \mathrm{mL}$ & $-0,1$ & $+3,9$ \\
\hline $2000 \mathrm{ng} / \mathrm{mL}$ & $-2,9$ & $+2,9$ \\
\hline \multicolumn{3}{|c|}{$\begin{array}{l}\text { Exatidão Intra-ensaio (\% inexatidão, } \\
n=6)\end{array}$} \\
\hline $20 \mathrm{ng} / \mathrm{mL}$ & 9,3 & $-0,5$ \\
\hline $1000 \mathrm{ng} / \mathrm{mL}$ & $-1,2$ & 3,4 \\
\hline $2000 \mathrm{ng} / \mathrm{mL}$ & 6,83 & $-0,9$ \\
\hline \multicolumn{3}{|l|}{ Estabilidade ( $\%$ desvio, $n=6)$} \\
\hline \multicolumn{3}{|l|}{$\begin{array}{l}3 \text { Ciclos de descongelamento (-20 a } \\
\left.25^{\circ} \mathrm{C}\right)\end{array}$} \\
\hline $20 \mathrm{ng} / \mathrm{mL}$ & 6,6 & $-15,9$ \\
\hline $2000 \mathrm{ng} / \mathrm{mL}$ & $-0,3$ & $-15,6$ \\
\hline \multicolumn{3}{|l|}{ Temperatura ambiente (3 h) } \\
\hline $20 \mathrm{ng} / \mathrm{mL}$ & 6,8 & $-14,9$ \\
\hline $2000 \mathrm{ng} / \mathrm{mL}$ & $-9,1$ & $-10,6$ \\
\hline \multicolumn{3}{|l|}{ Pós Processamento $\left(24 \mathrm{~h}\right.$ à $\left.4^{0} \mathrm{C}\right)$} \\
\hline $20 \mathrm{ng} / \mathrm{mL}$ & 9,0 & $-0,5$ \\
\hline $2000 \mathrm{ng} / \mathrm{mL}$ & 6,8 & $-1,9$ \\
\hline
\end{tabular}

CV = coeficiente de variação [(desvio padrão/ média) * 100]; R- coeficiente de correlação;

$\%$ inexatidão $=[($ Cobtida - Creal $) /$ Creal $]$ x 100. 


\subsection{Análise farmacocinética e estatística}

\subsubsection{Avaliação da disposição cinética dos enantiômeros da CY}

A Figura 29 apresenta os perfis farmacocinéticos concentração plasmática vs tempo dos enantiômeros da CY referentes aos pacientes investigados portadores de EM ou ES. A Figura 30 apresenta a curva concentração plasmática vs tempo dos enantiômeros da CY referentes aos pacientes investigados dos dois grupos, EM e ES.

A)

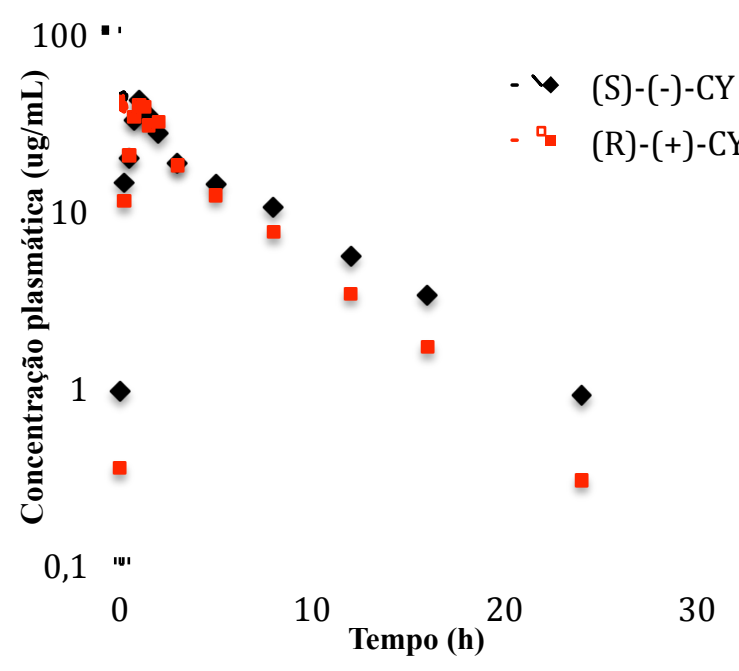

B)

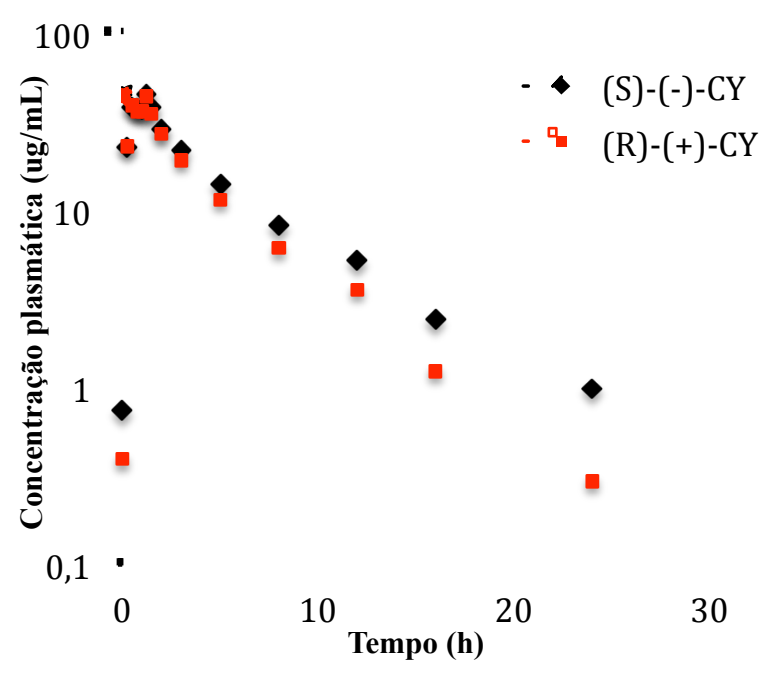

Figura 29. Concentrações plasmáticas versus tempo dos enantiômeros da CY nos pacientes investigados até 24 horas após a infusão de CY racêmica durante 60 minutos. Dados apresentados como mediana para os grupos EM (A; $n=10)$ e ES $(B ; n=10)$.

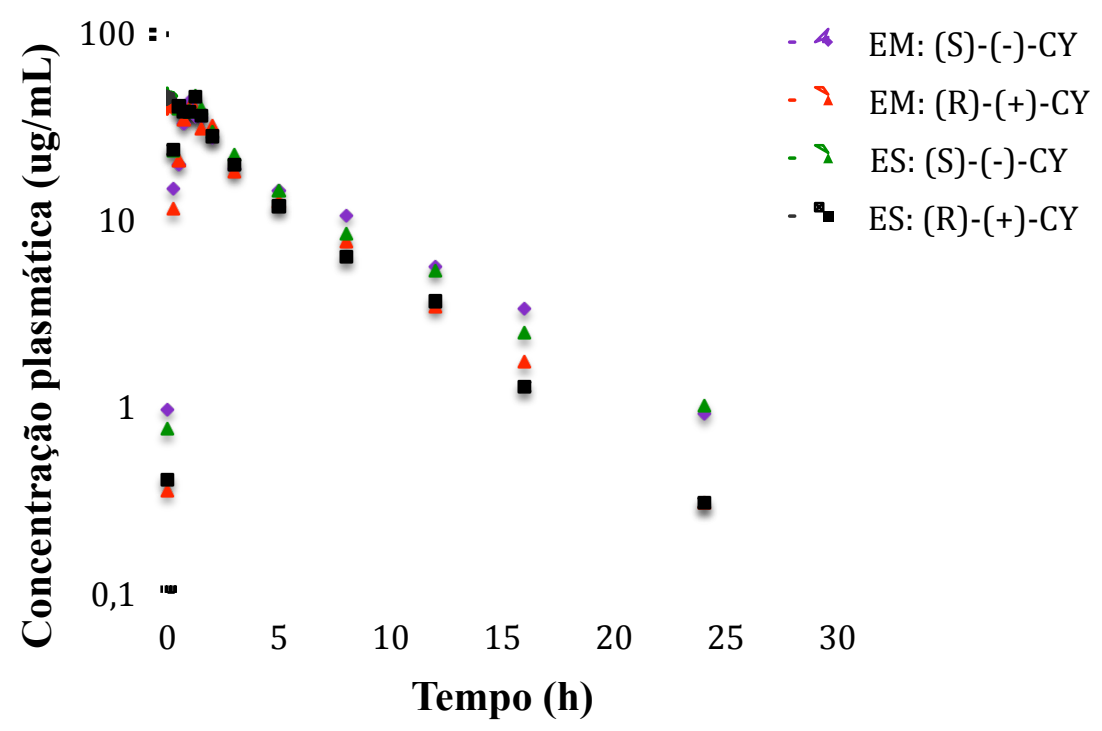

Figura 30. Curvas concentração plasmática versus tempo referentes aos enantiômeros da CY para os pacientes dos grupos EM e ES. Dados apresentados como mediana 
A Tabela 27 apresenta os parâmetros farmacocinéticos referentes aos enantiômeros da CY, no grupo EM $(n=10)$ e no grupo ES $(n=10)$. O teste de Wilcoxon foi empregado para avaliar as razões enantiôméricas (S)-(-)/(R)-(+) diferentes da unidade e o teste Mann-Whitney foi empregado para avaliar diferenças nos parâmetros farmacocinéticos entre os grupos EM e ES. Para ambos os testes foi fixada significância em $\mathrm{p}<0,05$.

Tabela 27. Parâmetros farmacocinéticos dos enantiômeros da CY nos grupos EM e ES, tratados com $50 \mathrm{mg} / \mathrm{Kg}$ de CY racêmica. Os dados estão expressos como mediana e percentis 25 e 75

\begin{tabular}{|c|c|c|c|c|}
\hline Parâmetros & \multicolumn{2}{|c|}{ EM } & \multicolumn{2}{|c|}{ ES } \\
\hline \multirow{3}{*}{$\operatorname{Cmax}(u g / m L)$} & (S)-(-)-CY & $(\mathrm{R})-(+)-\mathrm{CY}$ & (S)-(-)-CY & (R)-(+)-CY \\
\hline & 46,0 & 44,8 & 51,8 & $49,7^{*}$ \\
\hline & $(37,6-57,0)$ & $(36,9-56,9)$ & $(47,1-92,5)$ & $(45,3-86,9)$ \\
\hline \multirow{2}{*}{$\operatorname{tmax}(h)$} & 1,0 & 1,1 & 1,25 & 1,2 \\
\hline & $(1,0-1,3)$ & $(1,0-1,2)$ & $(1,25-1,25)$ & $(1,2-1,2)$ \\
\hline \multirow[t]{2}{*}{$A U C^{0-\infty}(u g . h / m L)$} & 215,0 & $186,2 *$ & 219,1 & $179,2 *$ \\
\hline & $(189,2-280,4)$ & $(141,7-227,6)$ & $(175,9-281,1)$ & $9136,5-209,70$ \\
\hline \multirow[t]{2}{*}{$\mathbf{A U C}(\mathbf{S}) /(\mathbf{R})$} & \multicolumn{2}{|c|}{1,3} & \multicolumn{2}{|c|}{1,3} \\
\hline & \multicolumn{2}{|c|}{$(1,2-1,3)$} & \multicolumn{2}{|c|}{$(1,2-1,3)$} \\
\hline \multirow{2}{*}{ Cl (mL/h.Kg) } & 200,7 & $265,7^{*}$ & 225,5 & $277,7^{*}$ \\
\hline & $(168,7-227,8)$ & $(204,3-335,1)$ & $(174,0-269,9)$ & $(236,0-356,4)$ \\
\hline \multirow{2}{*}{ MRT (h) } & 5,9 & $4,4^{*}$ & 4,9 & $3,9 *$ \\
\hline & $(5,7-6,8)$ & $(4,2-5,1)$ & $(3,5-7,3)$ & $(2,7-5,1)$ \\
\hline \multirow{2}{*}{$\mathrm{V}_{\text {ss }}(\mathrm{mL} / \mathrm{Kg})$} & 1337,1 & 1284,7 & 1104,0 & $1063,2^{*}$ \\
\hline & $(965,2-1676,1)$ & $(932,4-1978,4)$ & $(894,9-1210,2)$ & $(789,7-1222,8)$ \\
\hline
\end{tabular}

$\mathrm{C}_{\max }$ - concentração plasmática máxima; $\mathrm{t}_{\max }$ - tempo para atingir $\mathrm{C}_{\max } ; \mathrm{AUC}^{0-\infty}$ - área sob a curva concentração plasmática versus tempo; $\mathrm{Cl}$ - clearance total; MRT - tempo médio de residência; Vss - volume de distribuição $(\mathrm{Vss}=\mathrm{Cl} . \mathrm{MRT})$

*Teste de Wilcoxon, $\mathrm{p}<0,05$ [(S)-(-)-CY vs (R)-(+)-CY]

$\dagger$ Teste de Mann-Whitney, $\mathrm{p}<0,05$ [EM vs ES] 


\subsubsection{Avaliação da disposição cinética dos enantiômeros do metabólito CEPM}

A Figura 31 apresenta os perfis farmacocinéticos concentração plasmática vs tempo dos enantiômeros do metabólito CEPM referentes aos pacientes investigados nos grupos EM (A) e ES (B). A Figura 32 apresenta a curva concentração plasmática vs tempo dos enantiômeros do metabólito CEPM referentes aos pacientes investigados dos dois grupos, EM e ES.

A)

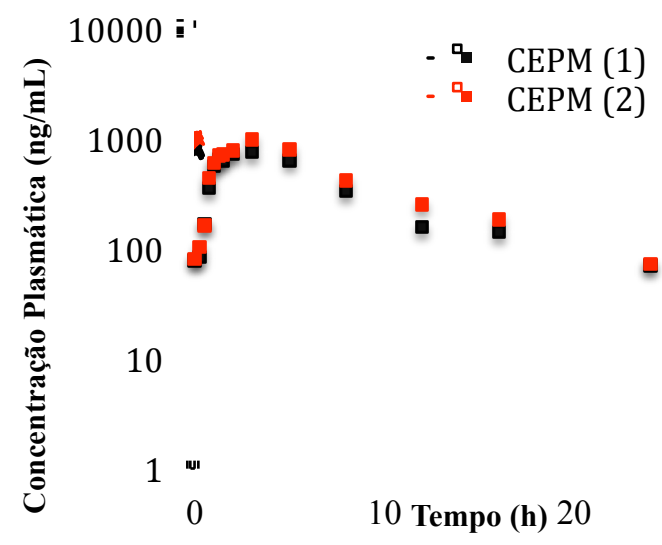

B)

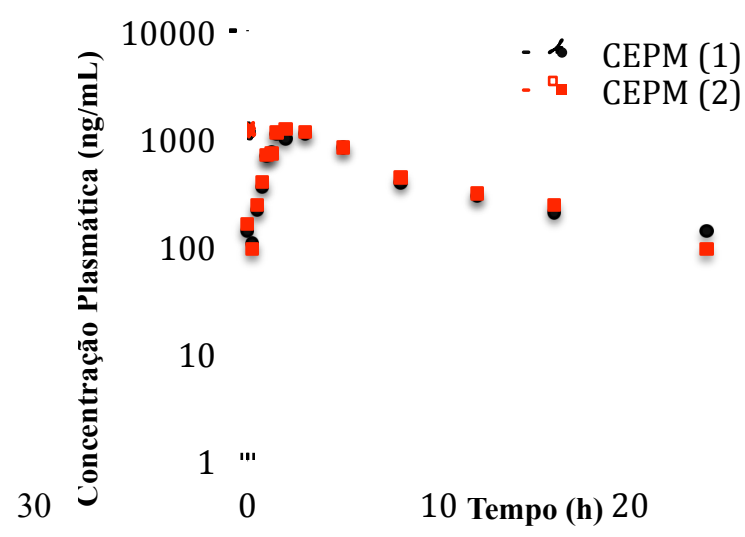

30

Figura 31. Concentrações plasmáticas versus tempo dos enantiômeros do CEPM nos pacientes dos grupos EM (A) e ES (B) investigados até 24 horas após a infusão de CY racêmica durante 60 minutos. Dados apresentados como mediana
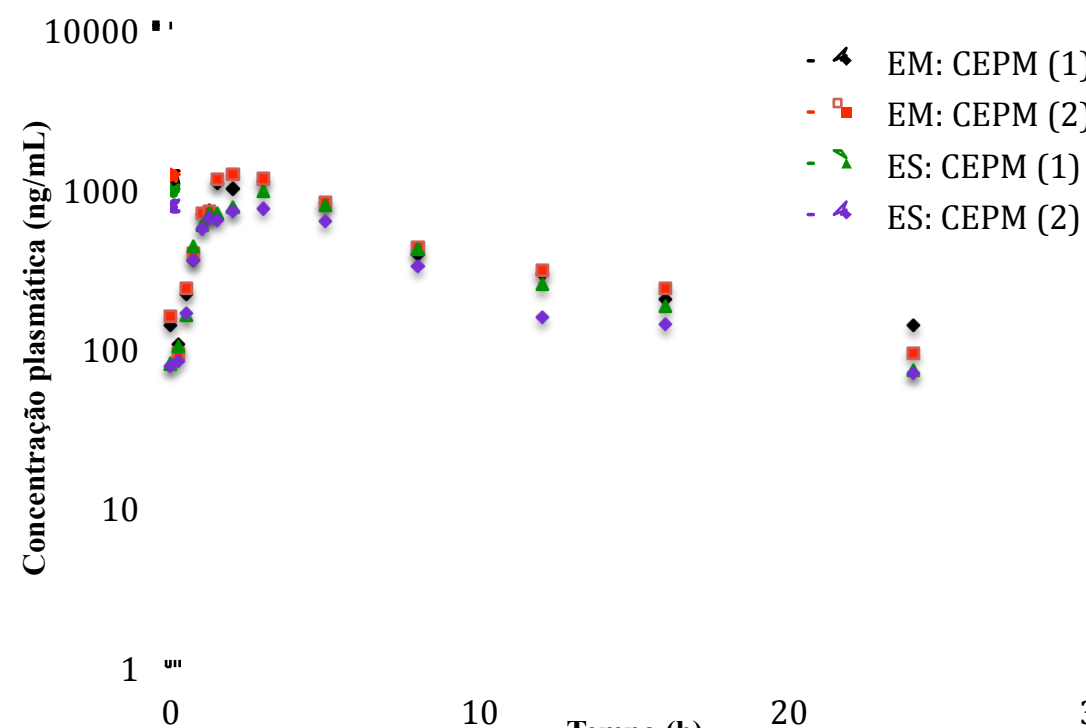

$\begin{array}{lcccc}0 & 10 & \text { Tempo (h) } & 20 & 30\end{array}$

Figura 32. Concentrações plasmáticas versus tempo dos enantiômeros do CEPM nos pacientes dos grupos investigados. Dados apresentados como mediana 
A Tabela 28 apresenta os parâmetros farmacocinéticos referentes aos enantiômeros do CEPM, no grupo EM $(n=10)$ e no grupo ES $(n=10)$. O teste de Wilcoxon foi empregado para avaliar as razões enantiôméricas diferentes da unidade e o teste Mann-Whitney foi empregado para avaliar diferenças nos parâmetros farmacocinéticos entre os grupos. Para ambos os testes foi fixada significância em $\mathrm{p}<0,05$.

Tabela 28. Parâmetros farmacocinéticos dos enantiômeros do CEPM nos grupos investigados, tratados com $50 \mathrm{mg} / \mathrm{Kg}$ de $\mathrm{CY}$ racêmica. Os dados estão expressos como mediana e percentis 25 e 75

\begin{tabular}{|c|c|c|c|c|}
\hline \multirow[b]{2}{*}{ Parâmetros } & \multicolumn{2}{|c|}{ Grupo EM (n=10) } & \multicolumn{2}{|c|}{ Grupo ES $(n=10)$} \\
\hline & CEPM (1) & CEPM (2) & CEPM1 (1) & CEPM (2) \\
\hline \multirow[t]{3}{*}{$\operatorname{Cmax}(n g / m L)$} & 1108,14 & 1137,58 & 825,92 & 761,51 \\
\hline & $(635,79-$ & $(631,3-$ & $(476,11-$ & $(497,72-$ \\
\hline & $2343,59)$ & $2200,07)$ & $1222,58)$ & $1165,04)$ \\
\hline \multirow[t]{2}{*}{$\operatorname{tmax}(h)$} & 3,23 & 3,25 & 2,80 & 2,77 \\
\hline & $(2,26-3,58)$ & $(2,56-3,52)$ & $(2,42-3,25)$ & $(2,42-3,26)$ \\
\hline \multirow[t]{2}{*}{$K f\left(h^{-1}\right)$} & 0,61 & 0,60 & 0,82 & 0,73 \\
\hline & $(0,53-1,11)$ & $(0,52-0,87)$ & $(0,63-0,96)$ & $(0,65-0,91)$ \\
\hline \multirow[t]{2}{*}{$\mathbf{t}_{1 / 2} \mathbf{f}(h)$} & 1,14 & 1,15 & 0,85 & 0,94 \\
\hline & $(0,62-1,31)$ & $(0,79-1,32)$ & $(0,72-1,11)$ & $(0,76-1,07)$ \\
\hline \multirow[t]{3}{*}{$A U C^{0-\infty}(n g . h / m L)$} & 13810,8 & 13865,23 & 9123,90 & 8771,59 \\
\hline & $(8580,14-$ & $(8144,89-$ & $(5358,53-$ & $(4321,13-$ \\
\hline & $24491,96)$ & $22770,23)$ & $14537,04)$ & $14705,42)$ \\
\hline \multirow[t]{2}{*}{$\mathbf{A U C} \mathbf{C}_{1} / \mathbf{A U C} \mathbf{C}_{2}$} & \multicolumn{2}{|c|}{1,0} & \multicolumn{2}{|c|}{1,0} \\
\hline & \multicolumn{2}{|c|}{$(0,9-1,0)$} & \multicolumn{2}{|c|}{$(1,0-1,1)$} \\
\hline \multirow[t]{2}{*}{$\operatorname{Kel}\left(h^{-1}\right)$} & 0,13 & 0,14 & 0,14 & 0,12 \\
\hline & $(0,11-0,14)$ & $(0,11-0,15)$ & $(0,11-0,23)$ & $(0,11-0,21)$ \\
\hline \multirow[t]{2}{*}{$\mathbf{t}_{1 / 2}(h)$} & 5,43 & 5,07 & 5,21 & 5,84 \\
\hline & $(4,79-5,99)$ & $(4,70-6,47)$ & $(3,09-6,39)$ & $(3,43-6,34)$ \\
\hline
\end{tabular}

$\mathrm{C}_{\max }$ - concentração plasmática máxima; $\mathrm{t}_{\max }$ - tempo para atingir $\mathrm{C}_{\max } ; \mathrm{K}_{\mathrm{f}}$ - constante de velocidade de formação; $\mathrm{t}_{1 / 2} \mathrm{f}$ - meia vida de formação; $\mathrm{AUC}^{0-\infty}$ - área sob a curva concentração plasmática versus tempo; $\mathrm{K}_{\mathrm{el}}$ - constante da velocidade de eliminação; $t_{1 / 2}$ - meia vida de eliminação

*Teste de Wilcoxon, $\mathrm{p}<0,05$ [CEPM (1) vs CEPM (2)]

$\dagger$ Teste de Mann-Whitney, $\mathrm{p}<0,05$ [EM vs ES] 


\subsubsection{Avaliação da disposição cinética dos enantiômeros do metabólito HCY}

A Figura 33 apresenta os perfis farmacocinéticos concentração plasmática vs tempo dos enantiômeros do metabólito HCY referentes aos pacientes investigados nos grupos EM (A) e ES (B). A Figura 34 apresenta a curva concentração plasmática vs tempo dos enantiômeros do metabólito HCY referentes aos pacientes investigados dos dois grupos, EM e ES.

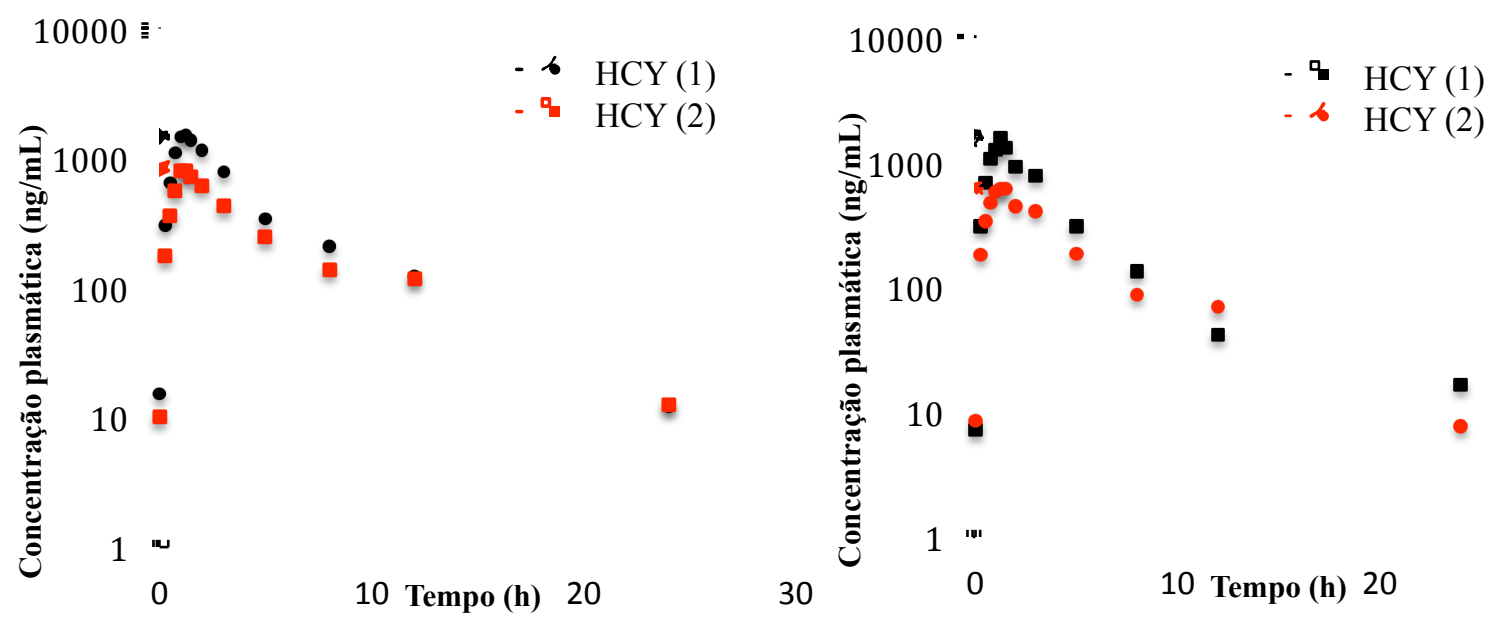

Figura 33. Concentrações plasmáticas versus tempo dos enantiômeros do HCY nos pacientes do grupo EM (A) e ES (B) investigados até 24 horas após a infusão de CY racêmica durante 60 minutos. Dados apresentados como mediana

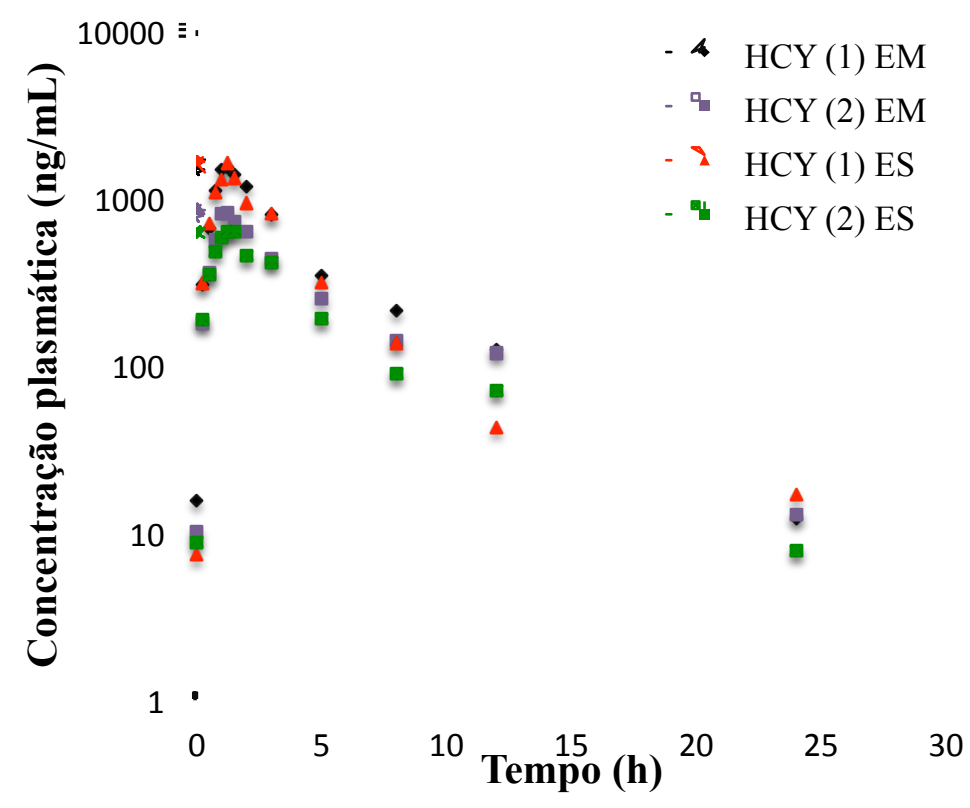

Figura 34. Concentrações plasmáticas versus tempo dos enantiômeros do HCY nos pacientes dos grupos ES e EM investigados. Dados apresentados como mediana 
A Tabela 29 apresenta os parâmetros farmacocinéticos referentes aos enantiômeros do HCY nos grupos EM $(n=10)$ e ES $(n=10)$. O teste de Wilcoxon foi empregado para avaliar a diferença entre os enantiômeros. O teste Mann-Whitney foi empregado para avaliar diferenças nos parâmetros farmacocinéticos entre os grupos. Para ambos os testes foi fixada significância em $\mathrm{p}<0,05$.

Tabela 29. Parâmetros farmacocinéticos dos enantiômeros do HCY nos grupos EM $(n=10)$ e ES $(n=10)$, tratados com $50 \mathrm{mg} / \mathrm{Kg}$ de CY racêmica. Os dados estão expressos como mediana e percentis 25 e 75

\begin{tabular}{|c|c|c|c|c|}
\hline \multirow[b]{2}{*}{ Parâmetros } & \multicolumn{2}{|c|}{ Grupo EM $(n=10)$} & \multicolumn{2}{|c|}{ Grupo ES $(n=10)$} \\
\hline & HCY (1) & HCY (2) & HCY (1) & HCY (2) \\
\hline $\begin{array}{c}\text { Cmax } \\
(\mathrm{ng} / \mathrm{mL})\end{array}$ & $\begin{array}{c}1277,11 \\
(1101,44-1509,61)\end{array}$ & $\begin{array}{c}724,32 * \\
(558,34-845,91)\end{array}$ & $\begin{array}{c}1151,79 \\
(783,96-1875,20)\end{array}$ & $\begin{array}{c}988,6^{*} \\
(360,25-997,85)\end{array}$ \\
\hline $\operatorname{tmax}(h)$ & $\begin{array}{c}1,42 \\
(1,26-1,52)\end{array}$ & $\begin{array}{c}1,56 \\
(1,20-1,81)\end{array}$ & $\begin{array}{c}1,37 \\
(1,23-1,50)\end{array}$ & $\begin{array}{c}1,38 \\
(1,25-1,62)\end{array}$ \\
\hline$K f\left(h^{-1}\right)$ & $\begin{array}{c}1,92 \\
(1,55-2,82)\end{array}$ & $\begin{array}{c}1,94 \\
(1,30-2,44)\end{array}$ & $\begin{array}{c}2,72 \\
(2,17-3,60)\end{array}$ & $\begin{array}{c}2,65 \\
(2,18-3,83)\end{array}$ \\
\hline $\mathbf{t}_{1 / 2} \mathbf{f}(\mathbf{h})$ & $\begin{array}{c}0,42 \\
(0,34-0,46)\end{array}$ & $\begin{array}{c}0,44 \\
(0,33-0,57)\end{array}$ & $\begin{array}{c}0,40 \\
(0,33-0,43)\end{array}$ & $\begin{array}{c}0,41 \\
(0,33-0,46)\end{array}$ \\
\hline $\begin{array}{c}\mathrm{AUC}^{0-\infty} \\
\text { (ng.h/mL) }\end{array}$ & $\begin{array}{c}6117,11 \\
(5660,45-6792,90)\end{array}$ & $\begin{array}{c}3930,02 * \\
(3731,81-5307,64)\end{array}$ & $\begin{array}{c}6310,92 \\
(3716,3-8534,89)\end{array}$ & $\begin{array}{c}5615,55^{*} \\
(2645,48-5968,78)\end{array}$ \\
\hline $\mathbf{A U C}_{\mathbf{1}} / \mathrm{AUC}_{2}$ & $\begin{array}{r}1 \\
(1,45\end{array}$ & $\begin{array}{l}3 \\
1,73)\end{array}$ & & $\begin{array}{l}59 \\
-1,66)\end{array}$ \\
\hline $\operatorname{Kel}\left(h^{-1}\right)$ & $\begin{array}{c}0,23 \\
(0,21-0,25)\end{array}$ & $\begin{array}{c}0,20 \\
(0,19-0,23)\end{array}$ & $\begin{array}{c}0,21 \\
(0,20-0,24)\end{array}$ & $\begin{array}{c}0,21 \\
(0,17-0,24)\end{array}$ \\
\hline $\mathbf{t}_{1 / 2}(\mathrm{~h})$ & $\begin{array}{c}3,16 \\
(3,02-3,27)\end{array}$ & $\begin{array}{c}3,56 \\
(3,40-3,69)\end{array}$ & $\begin{array}{c}3,50 \\
(2,81-4,25)\end{array}$ & $\begin{array}{c}3,64 \\
(3,49-4,53)\end{array}$ \\
\hline $\begin{array}{c}\text { Razão } \\
\text { metabólica } \\
(\%)\end{array}$ & $\begin{array}{c}3,64 \\
(3,47-4,09)\end{array}$ & $\begin{array}{c}1,90^{*} \\
(1,57-2,32)\end{array}$ & $\begin{array}{c}3,27 \\
(1,93-5,25)\end{array}$ & $\begin{array}{c}1,72 * \\
(0,98-3,06)\end{array}$ \\
\hline
\end{tabular}

$\mathrm{C}_{\max }$ - concentração plasmática máxima; $\mathrm{t}_{\max }$ - tempo para atingir $\mathrm{C}_{\max } ; \mathrm{K}_{\mathrm{f}}$ - constante de velocidade de formação; $\mathrm{t}_{1 / 2} \mathrm{f}$ - meia vida de formação; $\mathrm{AUC}^{0-\infty}$ - área sob a curva concentração plasmática versus tempo; $\mathrm{K}_{\mathrm{el}}{ }^{-}$constante de velocidade de eliminação; $\mathrm{t}_{1 / 2}$ - meia vida de eliminação; Razão metabólica $\mathrm{AUC}^{0-\infty} \mathrm{HCY}_{(2)} / \mathrm{AUC}^{0-\infty} \mathrm{CY}_{(\mathrm{S})}$ ou $\mathrm{AUC}^{0-\infty} \mathrm{HCY}_{(1)} / \mathrm{AUC}^{0-\infty} \mathrm{CY}_{(\mathrm{R})}$

*Teste de Wilcoxon, $\mathrm{p}<0,05$ [HCY (1) vs HCY (2)]

$\dagger$ Teste de Mann-Whitney, $\mathrm{p}<0,05$ [EM vs ES] 


\subsection{Análise dos polimorfismos CYP2B6*9, CYP2C9*2 e CYP2C9*3}

A Tabela 30 apresenta as frequências dos polimorfismos dos genes do CYP2B6 e do CYP2C9 nos pacientes portadores de EM $(n=10)$ ou ES $(n=10)$ investigados. A Figura 35 apresenta a associação entre os polimorfismos do CYP2B6 e do CYP2C9 com os valores de $\mathrm{AUC}^{0-\infty}$ do metabólito ativo HCY. O teste qui-quadrado foi utilizado para avaliar o desvio das frequências alélicas dos genes estudados do equilíbrio de Hardy-Weinberg. As frequências alélicas e a determinação dos haplótipos foram realizadas com auxílio do programa PHASE, versão 2 . 
Tabela 30. Frequência dos polimorfismos dos genes CYP2B6 e CYP2C9 nos pacientes investigados $(\mathrm{n}=20)$

\begin{tabular}{cccc}
\hline \hline \multirow{2}{*}{$\begin{array}{c}\text { Pacientes } \\
\text { Grupo EM } \\
(\mathbf{n}=\mathbf{1 0})\end{array}$} & \multicolumn{3}{c}{ Genótipo } \\
\cline { 2 - 4 } CYP2B6*9 & CYP2C9*2 & CY2C9*3 \\
2 & $\mathrm{G} / \mathrm{G}$ & $* 1 / * 1$ & $* 1 / * 1$ \\
3 & $\mathrm{G} / \mathrm{G}$ & $* 1 / * 1$ & $* 1 / * 1$ \\
4 & $\mathrm{G} / \mathrm{T}$ & $* 1 / * 2$ & $* 1 / * 1$ \\
5 & $\mathrm{G} / \mathrm{G}$ & $* 1 / * 1$ & $* 1 / * 1$ \\
6 & $\mathrm{G} / \mathrm{T}$ & $* 1 / * 1$ & $* 1 / * 3$ \\
7 & $\mathrm{G} / \mathrm{T}$ & $* 1 / * 1$ & $* 1 / * 1$ \\
8 & $\mathrm{G} / \mathrm{T}$ & $* 1 / * 1$ & $* 1 / * 3$ \\
9 & $\mathrm{G} / \mathrm{T}$ & $* 1 / * 1$ & $* 1 / * 1$ \\
10 & $\mathrm{G} / \mathrm{G}$ & $* 1 / * 1$ & $* 1 / * 3$ \\
& $\mathrm{G} / \mathrm{T}$ & $* 1 / * 1$ & $* 1 / * 1$
\end{tabular}

\begin{tabular}{cccc}
\hline $\begin{array}{c}\text { Pacientes } \\
\text { Grupo ES } \\
(\mathbf{n}=\mathbf{1 0})\end{array}$ & & & \\
\hline 1 & $\mathrm{G} / \mathrm{G}$ & $* 1 / * 1$ & $* 1 / * 1$ \\
2 & $\mathrm{~T} / \mathrm{T}$ & $* 1 / * 2$ & $* 1 / * 1$ \\
3 & $\mathrm{G} / \mathrm{T}$ & $* 2 / * 2$ & $* 1 / * 1$ \\
4 & $\mathrm{G} / \mathrm{G}$ & $* 1 / * 1$ & $* 1 / * 1$ \\
5 & $\mathrm{G} / \mathrm{T}$ & $* 2 / * 2$ & $* 1 / * 1$ \\
6 & $\mathrm{G} / \mathrm{G}$ & $* 1 / * 1$ & $* 1 / * 1$ \\
7 & $\mathrm{G} / \mathrm{T}$ & $* 1 / * 1$ & $* 1 / * 1$ \\
8 & $\mathrm{G} / \mathrm{T}$ & $* 1 / * 1$ & $* 1 / * 1$ \\
9 & $\mathrm{G} / \mathrm{T}$ & $* 1 / * 1$ & $* 1 / * 1$ \\
10 & $\mathrm{G} / \mathrm{T}$ & $* 1 / * 2$ & $* 1 / * 3$ \\
\hline $\mathrm{n}=20$ & $\mathrm{G} / \mathrm{G}: 35 \%$ & $\mathrm{CC}(* 1 / * 1): 75 \%$ & $\mathrm{AA}(* 1 / * 1): 80 \%$ \\
& $\mathrm{G} / \mathrm{T}: 60 \%$ & $\mathrm{CT}(* 1 / * 2): 15 \%$ & $\mathrm{AC}(* 1 / * 3): 20 \%$ \\
\hline \hline
\end{tabular}

CY2B6*9- G (Alelo selvagem); T (Alelo mutante); CYP2C9*2- *1 (Alelo selvagem); *2 (Alelo mutante); CYP2C9*3- *1 (Alelo selvagem); *3 (Alelo mutante). 
A)

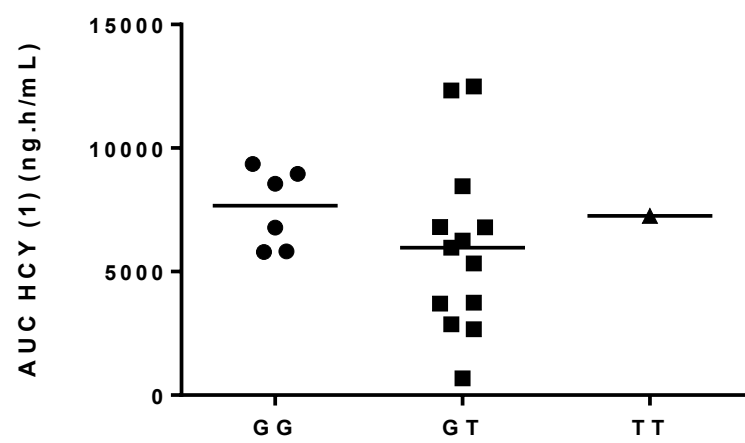

C)

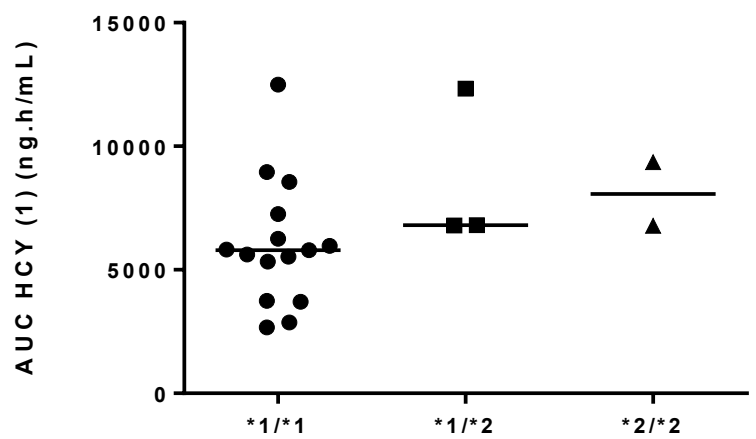

E)

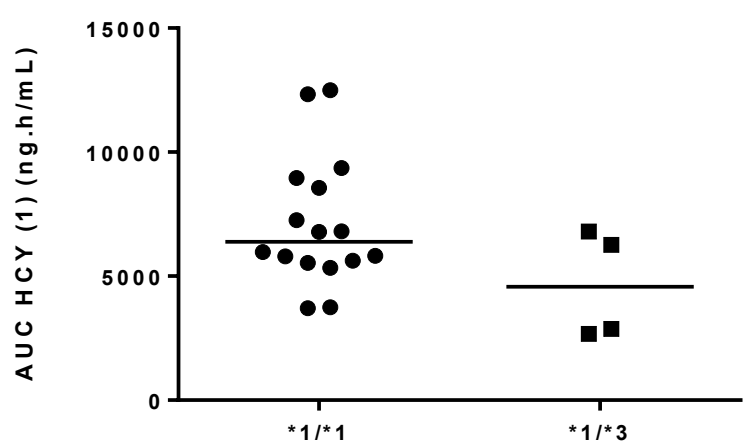

B)

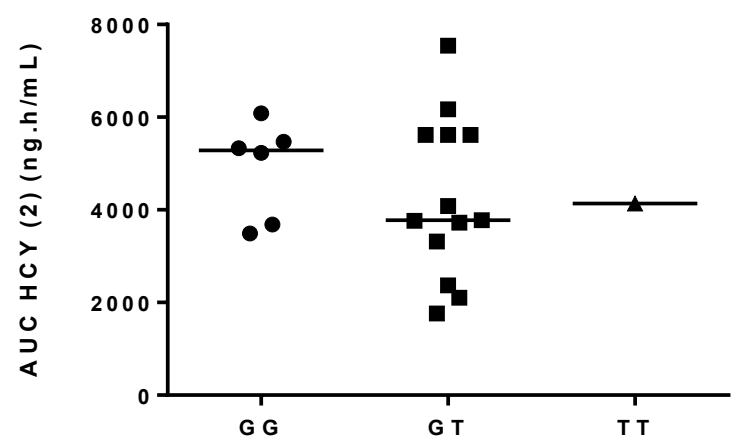

D)

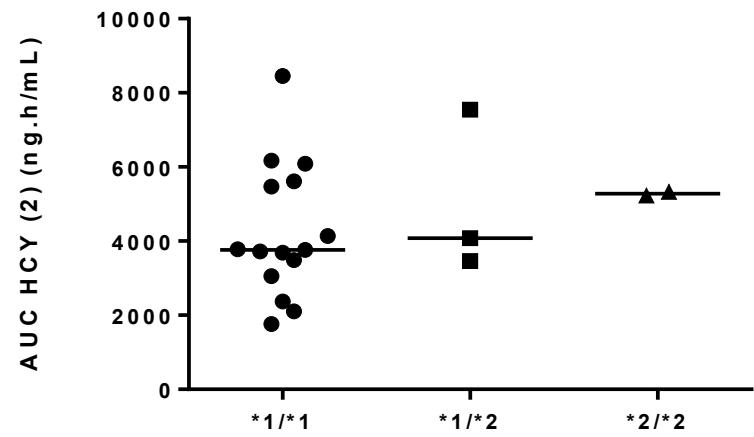

F)

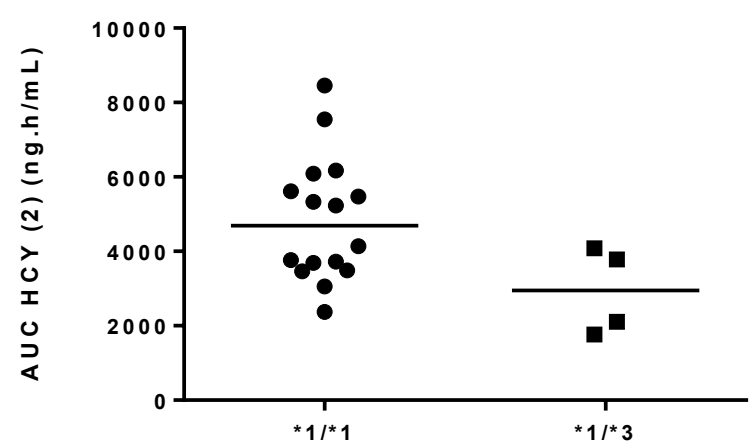

Figura 35. Associação entre os polimorfismos do CYP2B6*9 (A, B), CYP2C9*2 (C, D) e CYP2C9*3 (E, F) com os valores de $\mathrm{AUC}^{0-\infty}$ dos enantiômeros do $\mathrm{HCY}$ 
A)

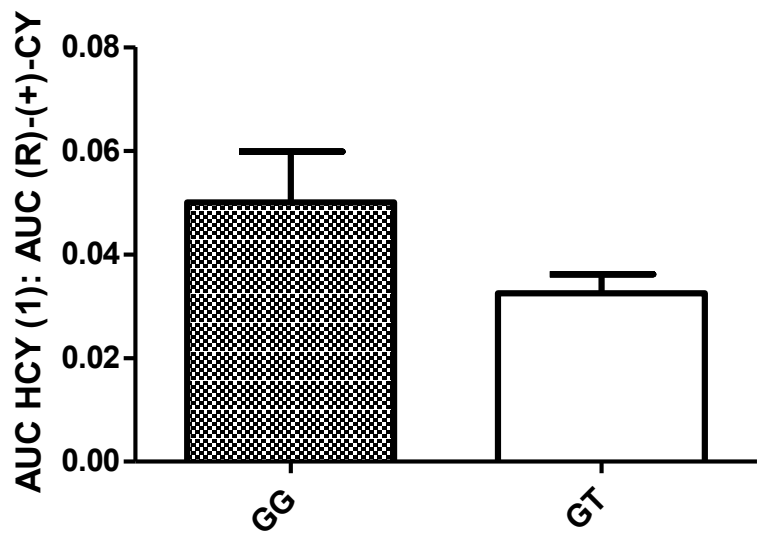

B)

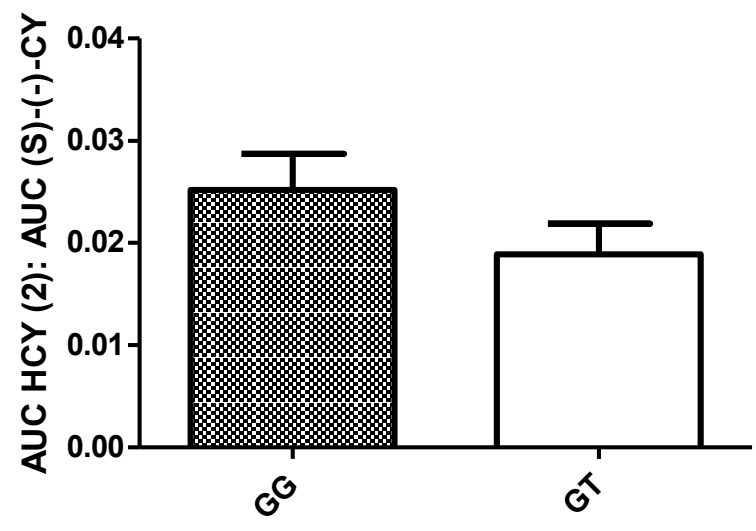

Figura 36. Razão metabólica (A) $A U C^{0-\infty} \mathrm{HCY}(1) / \mathrm{AUC}^{0-\infty}$ (S)-(-)-CY e (B) $A U C^{0-\infty} \mathrm{HCY}(2) /$ $\mathrm{AUC}^{0-\infty}(\mathrm{R})-(+)-\mathrm{CY}$ versus haplótipo CYP2B6*9 nos pacientes investigados portadores de esclerose múltipla ou esclerose sistêmica $(n=20)$ 


\subsection{Evolução Clínica}

Dentre as possíveis complicações, inerentes ao uso da CY, podem-se destacar a SOS, alterações cardiovasculares e cistite hemorrágica. Os pacientes foram avaliados conforme os critérios da "Common Toxicity Criteria of National Institute" (NCI-CTC) versão 2, e os resultados de toxicidade da CY estão apresentados na Tabela 31.

Tabela 31. Toxicidade relacionada o CEPM nos pacientes portadores de EM ou ES ( $n=20)$

\begin{tabular}{|c|c|c|c|c|c|c|}
\hline Paciente & Diagnóstico & $\begin{array}{c}\text { AUC }^{0-\infty} \\
\text { CEPM(1) } \\
(\boldsymbol{\mu g . h} / \mathrm{mL})\end{array}$ & $\begin{array}{c}\operatorname{AUC}^{0-\infty} \\
\text { CEPM(2) } \\
(\mu \mathrm{g} . \mathbf{h} / \mathrm{mL})\end{array}$ & $\begin{array}{l}\text { SOS } \\
(0-I)\end{array}$ & $\begin{array}{c}\text { Alteração } \\
\text { cardiovascular } \\
(0-I V)\end{array}$ & $\begin{array}{c}\text { Cistite } \\
\text { Hemorrágica } \\
\text { (0-I) }\end{array}$ \\
\hline 1 & EM & 14,5 & 15,6 & 0 & 0 & I \\
\hline 2 & EM & 28,4 & 39,5 & 0 & 0 & 0 \\
\hline 3 & EM & 21,6 & 21,4 & 0 & 0 & 0 \\
\hline 4 & EM & 34,3 & 29,1 & 0 & 0 & 0 \\
\hline 5 & EM & 25,4 & 23,2 & 0 & 0 & 0 \\
\hline 6 & EM & 4,3 & 4,8 & 0 & 0 & 0 \\
\hline 7 & EM & 6,5 & 6,3 & 0 & I & 0 \\
\hline 8 & EM & 9,2 & 9,0 & 0 & I & I \\
\hline 9 & EM & 8,3 & 7,8 & 0 & I & 0 \\
\hline 10 & EM & 13,1 & 12,2 & 0 & 0 & 0 \\
\hline 1 & ES & 9,4 & 10,6 & 0 & I & 0 \\
\hline 2 & ES & 17,8 & 17,9 & 0 & 0 & 0 \\
\hline 3 & $\mathrm{ES}$ & 8,8 & 8,4 & 0 & 0 & 0 \\
\hline 4 & $\mathrm{ES}$ & 6,2 & 5,9 & 0 & 0 & 0 \\
\hline 5 & ES & 5,1 & 3,8 & 0 & 0 & 0 \\
\hline 6 & $\mathrm{ES}$ & 3,7 & 3,4 & 0 & 0 & 0 \\
\hline 7 & $\mathrm{ES}$ & 17,6 & 16,2 & 0 & 0 & 0 \\
\hline 8 & $\mathrm{ES}$ & 9,9 & 9,1 & 0 & 0 & 0 \\
\hline 9 & ES & 13,6 & 21,8 & 0 & 0 & 0 \\
\hline 10 & ES & 16,1 & 16,1 & 0 & 0 & 0 \\
\hline
\end{tabular}


Tabela 32. Valores individuais de AUC de CEPM e HCY como mistura enantiomérica. Os resultados estão apresentados em $\mu \mathrm{g} . \mathrm{h} / \mathrm{mL}$ e $\mu \mathrm{mol} . \mathrm{h} / \mathrm{L}$

\begin{tabular}{|c|c|c|c|c|}
\hline $\begin{array}{l}\text { Paciente } \\
\text { (Doença) }\end{array}$ & $\begin{array}{c}\operatorname{AUC}^{0-\infty} \\
\operatorname{CEPM}(\boldsymbol{\mu g} \cdot \mathbf{h} / \mathrm{mL})\end{array}$ & $\begin{array}{c}\mathrm{AUC}^{(0-\infty} \\
\operatorname{CEPM}(\mu \mathrm{mol} . \mathrm{h} / \mathrm{L})\end{array}$ & $\begin{array}{c}\operatorname{AUC}^{0-\infty} \\
\operatorname{HCY}(\mu \mathrm{g} \cdot \mathbf{h} / \mathrm{mL})\end{array}$ & $\begin{array}{c}\mathrm{AUC} \mathbf{C}^{0-\infty} \\
\mathrm{HCY}(\mu \mathrm{mol} . \mathrm{h} / \mathrm{L})\end{array}$ \\
\hline 1 (EM) & 30,1 & 102,7 & 14,7 & 52,8 \\
\hline $2(\mathrm{EM})$ & 67,9 & 231,7 & 14,0 & 50,4 \\
\hline 3 (EM) & 43,0 & 146,7 & 10,9 & 39,1 \\
\hline 4 (EM) & 63,4 & 216,3 & 12,0 & 43,2 \\
\hline 5 (EM) & 48,6 & 165,8 & 10,0 & 34,9 \\
\hline $6(\mathrm{EM})$ & 9,1 & 31,0 & 8,6 & 30,9 \\
\hline 7 (EM) & 12,8 & 43,7 & 10,0 & 36,1 \\
\hline $8(\mathrm{EM})$ & 18,2 & 62,1 & 9,1 & 32,7 \\
\hline $9(\mathrm{EM})$ & 16,1 & 54,9 & 9,5 & 34,1 \\
\hline $10(\mathrm{EM})$ & 25,3 & 86,3 & 14,1 & 50,6 \\
\hline $1(\mathrm{ES})$ & 20,0 & 68,2 & 15,0 & 54,1 \\
\hline $2(\mathrm{ES})$ & 35,7 & 121,8 & 11,4 & 41,0 \\
\hline 3 (ES) & 17,2 & 58,7 & 10,3 & 37,0 \\
\hline $4(\mathrm{ES})$ & 12,1 & 41,3 & 9,3 & 33,5 \\
\hline $5(\mathrm{ES})$ & 8,9 & 30,4 & 19,9 & 71,4 \\
\hline 6 (ES) & 7,1 & 24,2 & 18,7 & 67,1 \\
\hline 7 (ES) & 33,8 & 115,3 & 4,8 & 17,1 \\
\hline 8 (ES) & 19,0 & 64,8 & 4,6 & 16,7 \\
\hline $9(\mathrm{ES})$ & 35,4 & 120,8 & 6,1 & 21,9 \\
\hline $10(\mathrm{ES})$ & 32,2 & 109,9 & 9,3 & 33,6 \\
\hline
\end{tabular}


5. Discussão 
A CY em combinação com diferentes fármacos é amplamente utilizada no tratamento de doenças autoimunes, seja durante os pulsos de tratamento ou no condicionamento préTCTH. A farmacocinética da CY e seus principais metabólitos (CEPM e HCY) como mistura enantiomérica já está bem descrita em pacientes com câncer, porém em pacientes portadores de doenças autoimunes ainda se mantém pouco explorada. Estudos abrangentes da farmacocinética da CY são necessário para guiar a estratégia de doses da $\mathrm{CY}$ em doenças autoimunes. Tais estudos são necessários considerando que o metabolismo da CY pode ser alterado por diversos fatores, tais como interações medicamentosas, doenças hepáticas ou renais, entre outros fatores.

A enantiosseletividade na farmacocinética da CY já foi descrita por diferentes autores em diferentes situações (FERNANDES et al., 2011; DE MIRANDA SILVA et al. 2009), porém a enantiosseletividade no metabolismo da CY ainda não foi avaliada. Assim, a presente investigação propõe pela primeira vez o desenvolvimento e a validação de métodos de análise dos enantiômeros da CY e seus metabólitos CEPM e HCY e propõe também o estudo da farmacocinética dos enantiômeros da CY e seus metabólitos em pacientes portadores de EM ou ES durante o condicionamento pré-TCTH.

A investigação da enantiosseletividade na farmacocinética da CY e seus metabólitos CEPM e HCY em pacientes portadores de EM ou ES exigiu o desenvolvimento e a validação de métodos analíticos seletivos em virtude dos diferentes fármacos associados durante o condicionamento pré-TCTH. Já foram descritos métodos de análise dos enantiômeros da CY, porém os estudos publicados até o momento referem-se apenas à quantificação dos metabólitos CEPM e HCY como mistura enantiomérica e utilizam cerca de $1 \mathrm{~mL}$ de plasma (EKHART et al., 2007; KALHORN et al., 2006; GRISKEVICIUS et al., 2001; BAUMANN et al., 1999; SLATERRY et al., 1996). O método de análise dos enantiômeros da CY e CEPM desenvolvido no presente estudo utiliza apenas $25 \mu \mathrm{L}$ de plasma e o método de análise dos enantiômeros da HCY utiliza 0,2 $\mathrm{mL}$ de solução de plasma (plasma derivado com fenilhidrazina $0,4 \mathrm{M}, 1: 2$ ).

Os enantiômeros da CY e do CEPM foram separados em coluna Chiralpak ${ }^{\circledR}$ AD-RH com fase móvel constituída de água: acetonitrila: etanol (45:30:25 v/v/v) adicionada de 0,1\% de ácido trifluoroacético. Os enantiômeros (S)-(-)-CY e (R)-(+)-CY foram eluídos, respectivamente, com tempos de retenção de 6,38 e 9,64 minutos, enquanto os enantiômeros do CEPM foram eluídos em 4,58 e 4,84 minutos. Os enantiômeros da CY e do CEPM foram recuperados do plasma por procedimento de extração líquido-líquido empregando acetato de etila como solvente extrator, não sendo observado efeito da matriz (Tabela 22). O limite de 
quantificação dos enantiômeros da CY foi de $50 \mathrm{ng}$ de cada enantiômero/mL de plasma, 20 vezes maior do que o limite de 2,5 ng de cada enantiômero/mL de plasma reportado por De Miranda et al. (2009), porém ressalta-se que no referido estudo foram necessários $200 \mu \mathrm{L}$ de plasma.

O método de análise dos enantiômeros da CY e do CEPM se mostrou linear no intervalo de $50 \mathrm{ng}$ a $25 \mu \mathrm{g}$ de cada enantiômero da CY/mL de plasma e entre 25-2500 ng de cada enantiômero de CEPM/mL de plasma, compatível com as concentrações encontradas nos pacientes investigados $(\mathrm{n}=20)$ tratados com $\mathrm{CY}$ endovenosa $50 \mathrm{mg} / \mathrm{kg}$. O método analítico se mostrou preciso e exato, com valores de valores de coeficiente de variação e \% de desvios intra e interensaios menores que $15 \%$ (Tabelas 23 e 24). Os enantiômeros da CY e do metabólito CEPM mostraram-se estáveis em plasma no estudo de três ciclos de congelamento e descongelamento e manutenção à temperatura ambiente por 3 horas (Tabela 25).

O metabólito ativo da CY analisado, o HCY, tautomeriza para aldofosfamida tornando a quantificação da HCY dependente da aldofosfamida. Devido à alta instabilidade do metabólito HCY em plasma, com meia-vida de aproximadamente $4 \mathrm{~min}$, a análise exige rápida derivatização com fenil hidrazina para prevenir a hidrólise à acroleina e mustarda de fosforamida. As amostras de sangue foram coletadas em tubos contendo solução de fenil hidrazina $0,4 \mathrm{M}$, na proporção de 2 volumes de solução de fenil hidrazina para um volume de sangue, conforme descrito por Kalhorn et al. (2006). O método de análise dos enantiômeros do HCY desenvolvido neste estudo utiliza apenas $0,2 \mathrm{~mL}$ de solução de plasma e se mostrou linear dentro do intervalo de 5-5000 ng/mL, apresentando sensibilidade compatível com as concentrações encontradas nos pacientes investigados $(n=20)$ tratados com CY endovenosa $50 \mathrm{mg} / \mathrm{kg}$.

Os enantiômeros do HCY foram separados na coluna Chiracel ${ }^{\circledR}$ OD-R com fase móvel composta por mistura acetonitrila: água $(55: 25, \mathrm{v} / \mathrm{v})$ adicionada de $0,2 \%$ de ácido fórmico. Os enantiômeros do HCY foram eluídos com tempos de retenção de 11,09 e 12,75 minutos. A ordem de eluição dos enantiômeros do HCY ainda não foi determinada, considerando que os experimentos prévios conduzidos com o detector por dicroísmo circular foram inconclusivos provavelmente devido às baixas concentrações dos enantiômeros do HCY nas amostras analisadas. No entanto, considerando que $70-80 \%$ da dose de CY é metabolizada a HCY (DE JONGE et al.; 2005) e considerando os valores de $\mathrm{AUC}^{0-\infty}$ obtidos no presente estudo para a CY, HCY e CEPM (Tabelas 27-29), podemos sugerir que os enantiômeros do HCY foram eluídos da coluna OD-R na sequência (R)-(+) e (S)-(-). 
Os enantiômeros do HCY foram recuperados do plasma por procedimento líquidolíquido empregando a mistura hexano e diclorometano (80:20, v/v) como solvente extrator. O limite de quantificação dos enantiômeros do HCY foi de $5 \mathrm{ng}$ de cada enantiômero/mL de plasma, dez vezes menor que o descrito por Ekhart et al. (2007) e Griskevicius et al. (2001), porém maior do que o limite de $20 \mathrm{fmol} \mathrm{reportado} \mathrm{por} \mathrm{Kalhorn} \mathrm{et} \mathrm{al.} \mathrm{(2006).}$

Os enantiômeros do metabólito HCY derivatizado com fenil hidrazina mostraram-se estáveis em plasma no estudo de três ciclos de congelamento e descongelamento e manutenção à temperatura ambiente por 3 horas (Tabela 26), ressaltando o uso de gelo durante as coletas das amostras de sangue e a rapidez durante as análises.

O presente estudo reporta pela primeira vez a farmacocinética dos enantiômeros da CY e seus metabólitos em pacientes portadores de esclerose. Foram incluídos 20 pacientes portadores de ES ou EM submetidos ao TCTH autólogo. Os pacientes foram tratados durante 4 dias com doses diárias de $50 \mathrm{mg} / \mathrm{kg}$ de CY racêmica e diferentes fármacos associados, de acordo com o protocolo do HCFMRP-USP e conforme a necessidade do paciente (Tabelas 21 e 22). A ondansetrona e os glucorticoides (metilprednisolona, prednisona, prednisolona), fármacos constituintes do protocolo de condicionamento pré-TCTH, são relatados como indutores do metabolismo da CY (CZOK et al., 2005; GILBERT et al., 1998).

Todo os pacientes investigados eram adultos e foram genotipados para os CYP2C9*2, CYP2C9*3 e CYP2B6*9 (G516T). Os pacientes foram divididos em 2 grupos, de acordo com a doença, EM ou ES, em função das diferentes características inflamatórias das doenças, onde há expressão de diferentes citocinas, as quais podem estar relacionadas com a up ou downregulation de diferentes isoformas CYPs e consequentemente alterar o metabolismo da CY (MIKULKOVA et al, 2011; GOURH et al., 2009). Amostras de plasma para a quantificação de citocinas foram colhidas em todos os dias de tratamento com a CY (tempos 0, 15, 30, 45 e 60 min e 1,$15 ; 1,3 ; 2 ; 3 ; 5 ; 8 ; 12 ; 16$ e 24 h após o início da infusão de CY) e encontram-se armazenadas para futuras análises e correlações com o metabolismo da CY.

A análise farmacocinética dos enantiômeros da CY e seus metabólitos foi realizada no quarto dia de tratamento, utilizando amostras seriadas de plasma obtidas até $24 \mathrm{~h}$ após a infusão da última dose de CY, portanto na situação de auto-indução do metabolismo da $\mathrm{CY}$ (de JONGE et al., 2005).

A disposição cinética dos enantiômeros da CY (Tabela 27) mostra maiores valores de $\mathrm{AUC}^{0-\infty}$ e menores valores de clearance para o enantiômero (S)-(-) quando comparado ao enantiômero (R)-(+), tanto para os pacientes portadores de EM (AUC: 215,0 vs 186,2 $\mu \mathrm{g} . \mathrm{h} / \mathrm{mL}$ e Cl: 200,7 vs $265,7 \mathrm{~mL} / \mathrm{h} / \mathrm{Kg}$ ) quanto para os pacientes portadores de ES (AUC: 
219,1 vs 179,2 $\mu \mathrm{g} . \mathrm{h} / \mathrm{mL}$ e Cl: 225,5 vs 277,7 mL/h/Kg). As razões enantioméricas de AUC (S)/(R) foram de 1,3 em ambos os grupos investigados (Tabela 27, Figuras 29 e 30).

O acúmulo plasmático do (S)-(-)-CY nos dois grupos investigados está de acordo com estudos previamente publicados em pacientes portadores de nefrite lúpica (doses de 750-1300 mg durante 120 min de infusão) ou câncer de mama (doses de 900-1000 mg durante 60 min de infusão), em que a farmacocinética da CY foi avaliada na primeira dose administrada (FERNANDES et al., 2011; DE MIRANDA SILVA et al., 2009). No entanto, Corlett \& Chrystyn (1996) e Williams et al. (1999) não relatam enantiosseletividade nos valores de clearance total da CY na investigação de pacientes portadores de câncer.

Os estudos de avaliação da farmacocinética da CY e seus metabólitos durante o condicionamento pré-TCTH foram até então conduzidos com métodos que não discriminam entre os enantiômeros. Os valores de clearance da CY como mistura enantiomérica relatados por Slattery et al. (1996) na investigação de pacientes portadores de doenças oncohematológicas tratados com doses de aproximadamente $45 \mathrm{mg} / \mathrm{Kg}$ durante o condicionamento pré-TCTH foram de $180 \mathrm{~mL} / \mathrm{h} . \mathrm{Kg}$.

Ressalta-se que os valores de clearance dos enantiômeros da CY obtidos no presente estudo para os pacientes portadores e EM ou ES são maiores que os reportados por De Miranda Silva et al. (2009) (3,3 vs 3,9 respectivamente para os enantiômero (S)-(-) e (R)-(+)) e por Fernandes et al. (2011) (5,1 vs 5,7 L/h, respectivamente para os enantiômero (S)-(-) e (R)-(+)) em estudos de avaliação da CY na primeira dose. Este fato pode ser explicado pela pela auto-indução no metabolismo da CY que ocorre em situações de altas doses de CY quando administradas de forma consecutiva, como no caso de condicionamentos pré-TCTH (DE JONGE et al., 2005).

Não há dados na literatura relativos a farmacocinética dos enantiômeros do HCY. Os trabalhos citados (EKHART et al., 2007; KALHORN et al., 2006; GRISKEVICIUS et al., 2001; BAUMANN et al., 1999) referem-se apenas ao desenvolvimento e validação do método analítico do HCY como mistura enantiomérica. Os estudos relativos a farmacocinética do HCY como mistura enantiomérica são escassos e em sua maioria descrevem apenas a disposição cinética do metabólito $\mathrm{HCY}$ em pacientes portadores de câncer. O estudo de Slattery et al. (1996) relativo a investigação de pacientes tratados durante 2 dias com doses de CY $60 \mathrm{mg} / \mathrm{kg} /$ dia mostra razões de AUC HCY/dose CY de 0,568 $\pm 0,246$ h.kg/L. Um outro estudo com inclusão de 18 pacientes tratados durante 2 dias com $60 \mathrm{mg} / \mathrm{kg} / \mathrm{dia}$ de CY mostra razão média de AUC HCY/dose CY de 0,47 h.Kg/L (REN et al., 1998). Recentemente, Joy et al. (2012) reportaram a farmacocinética do HCY em pacientes portadores de glomerulonefrite, 
com sugestão de acúmulo plasmático do metabólito em pacientes com glomerulonefrite quando comparado com pacientes portadores de câncer tratados com doses de CY.

Os valores de razões de AUC HCY/dose CY obtidos no presente estudo, considerando a soma dos dois enantiômeros do metabólito HCY, são de 0,20 h.Kg/L no grupo EM e de 0,24 h.Kg/L no grupo ES. As razões metabólicas AUC HCY (1)/ AUC (R)-(+)-CY e AUC HCY (2)/AUC CY (S)-(-)-CY, apresentadas na Tabela 29 para os pacientes portadores de EM ou $\mathrm{ES}$, mostram valores próximos àquelas descritas como misturas enantioméricas por Joy et al.

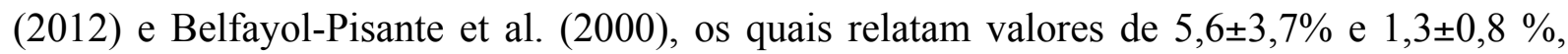
respectivamente.

Os dados apresentados na Tabela 29 mostram favorecimento na formação do enantiômero HCY(1) (provavelmente o enantiômero (R)-(+)-HCY), com maiores valores de Cmax e AUC nos dois grupos avaliados. As razões enantioméricas $\mathrm{AUC}_{1} / \mathrm{AUC}_{2}$ (provavelmente $\mathrm{AUC}_{\mathrm{R})} / \mathrm{AUC}(\mathrm{s})$ ) foram de 1,63 para os pacientes portadores de EM e 1,59 para os pacientes portadores de ES. Considerando que aproximadamente $80 \%$ da dose de CY é ativada a HCY e que não há indícios de enantiosseletividade na formação dos enantiômeros da CEPM (Tabela 28), sugere-se que o acúmulo plasmático do enantiômero (S)-(-)-CY esteja relacionado ao metabolismo preponderante do enantiômero $(\mathrm{R})-(+)-\mathrm{CY}$ para $(\mathrm{R})-(+)-\mathrm{HCY}$.

A farmacocinética dos enantiômeros da CY e seus metabólitos CEPM e HCY não mostrou diferenças entre os grupos EM e ES, com observações de acúmulo plasmático do enantiômero (S)-(-)-CY, ausência de enantiosseletividade na disposição cinética do metabólito CEPM e acúmulo plasmático do enantiômero (R)-(+)-HCY em ambos os grupos (Tabelas 2729). Assim, os estudos de associação entre a farmacocinética, a farmacogenética e as reações adversas foram conduzidos com todos os pacientes investigados $(n=20)$.

O estudo da farmacogenética em pacientes tratados com CY justificou-se em função do fármaco ser eliminado por metabolismo dependente principalmente dos polimórficos CYP2B6 e CYP2C9, embora haja contradições. Deste modo, polimorfismos no CYP2B6 e CYP2C9 foram avaliados nos 20 pacientes portadores de doenças autoimunes investigados. $\mathrm{Na}$ genotipagem para o CYP2B6*9, foram encontrados 7 pacientes homozigotos para o alelo selvagem $(\mathrm{G} / \mathrm{G}), 12$ pacientes heterozigotos $(\mathrm{G} / \mathrm{T})$ e 1 paciente homozigoto para o alelo mutante $(\mathrm{T} / \mathrm{T})$ (Tabela 30$)$, correspondendo às frequências de $35 \%$ para o alelo selvagem e $65 \%$ para o alelo mutante. O polimorfismo G516T encontra-se presente nos alelos CYP2B6*6, CYP2B6*7 e CYP2B6*9, CYP2B6*19 e CYP2B6*29. A frequência do SNP mutante (T) em caucasianos é de 28,2\% (JACOB et al., 2004) e do alelo CYP2B6*6 é de 15,9\% em coreanos (KLEIN et al., 2005), 17,6\% em japoneses (GATANAGA te al., 2007), 
21\% na população da Mongólia (DAVAALKHAM et al., 2009) e 32,8\% em afro-africanos (KLEIN et al., 2005). Para o gene CYP2C9, o alelo *1 foi o mais frequente (55\%), seguido dos alelos *2 (25\%) e *3 (20\%). No Brasil, Vianna-Jorge et al. (2004) genotiparam 662 indivíduos e encontraram as seguintes frequências: $84,9 \%$ para o alelo $* 1,8,6 \%$ para o alelo *2 e 6,5\% para o alelo*3. As frequências nos polimorfismos do CYP2C9 encontradas neste estudo estão de acordo com a literatura onde observam-se maior porcentagem de *1 e menor frequência de $* 2$ e $* 3$ (Tabela 30 ). Não foram observadas diferenças significativas entre os valores de AUC dos enantiômeros da CY e seu metabólito HCY em termos dos genótipos avaliados (Figura 35), resultados provavelmente relacionados ao baixo número de pacientes avaliados.

As razões metabólicas em função do polimorfismo genético do CY2B6*9 foram comparadas entre os pacientes tipo selvagem (GG) e os que apresentavam a variante alélica mutante (GT) (Figura 36). Embora a diferença não tenha sido significativa, observa-se a tendência à menor razão metabólica nos pacientes que carregam a variante alélica mutante quando comparados com os pacientes tipo selvagem para o CYP2B6*9, dados que conflitam com os reportados por Xie et al. (2006). A falta de correlação entre os polimorfismos genéticos avaliados e a farmacocinética da CY estão de acordo com os observados por Kim et al. (2011) em seu estudo de farmacocinética populacional e com os estudos de Raccor et al. (2012), De Miranda et al. (2009) e Fernandes et al. (2011) que investigaram pacientes portadores de câncer ou glomérulo nefrite lúpica.

Em um estudo envolvendo 147 pacientes submetidos ao TCTH, McDonald et al. (2003) observaram forte associação entre os pacientes que manifestaram a síndrome obstrutiva sinusoidal em grau moderado a grave com o aumento dos valores de $\mathrm{AUC}^{0-48}$ do metabólito CEPM. No entanto, os referidos autores não observaram associação entre os valores de AUC da CY e seus metabólitos com a pega do enxerto e a recaída da doença. Os autores reportam que o metabólito CEPM pode ser considerado um melhor indicador da exposição real do fígado aos metabólitos formados a partir do HCY com base em duas considerações importantes. A primeira consideração refere-se ao fato de que a HCY no fígado é convertida a iminiciclofosfamida e consequentemente conjugada com a glutationa para formar o 4-glutationilciclofosfamida (Figura 22), um metabólito com eliminação dependente do transportador ABCC2 (QIU; KALHORN; SLATTERY, 2004). É provável que a clivagem do conjugado 4-glutationilciclofosfamia resulte novamente na formação da iminociclofosfamida e subsequentemente da HCY. A segunda consideração refere-se a eliminação do HCY do hepatócito a partir da formação dos metabólitos instáveis acroleína e 
mustarda de fosforamida. Logo, a formação do metabólito CEPM no fígado, dependente da aldeído desidrogenase, representa um indicador da exposição do fígado aos metabólitos oriundos do HCY.

Assim, McDonald et al. (2005) avaliaram em 20 pacientes a individualização da dose de CY necessária para atingir valores alvo de AUC do CEPM de $325 \pm 25 \mu \mathrm{mol} / \mathrm{L}$.h, os quais de acordo com o estudo de McDonald et al. (2003) estão associados com menor risco de manifestação da hepatotoxicidade e maior garantia de sucesso do TCTH.

Os dados de toxicidade da CY apresentados nas Tabelas 31 e 32 não mostram manifestação de toxicidade hepática para os 20 pacientes investigados portadores de EM ou ES. Os valores de AUC do metabólito CEPM, apresentados na Tabela 32 como mistura enantiomérica, variaram de 24,2-231,7 $\mu \mathrm{mol} / \mathrm{L} . \mathrm{h}$, quando considerados todos os pacientes investigados $(\mathrm{n}=20)$. Os valores de AUC do metabólito HCY, também apresentados na Tabela 32 como mistura enantiomérica, variaram de 17,1-71,4 $\mu$ mol/L.h, sendo que dos 20 pacientes investigados, 6 deles apresentaram concentrações $>50 \mu \mathrm{mol} / \mathrm{L} . \mathrm{h}$.

A comparação dos valores de AUC referentes aos metabólitos CEPM e HCY obtidos na presente investigação de pacientes submetidos ao TCTH autólogo (Tabela 32) com dados da literatura referentes a pacientes com doenças onco-hematológicas submetidos ao TCTH alogênico associado a irradiação corporal total (MCCUNE et al., 2009; MCDONALD et al., 2005), permite sugerir diferenças importantes no metabolismo da CY entre as duas situações.

O metabolismo da CY é muito complexo, há o envolvimento de diferentes isoformas das enzimas CYP, aldeído desidrogenase, GST, além do transportador ABCC2. No condicionamento pré-TCTH para doenças onco-hematológicas há associação de fármacos diferentes dos utilizados no processo de TCTH autólogo para doenças autoimunes, além disso deve-se ressaltar as diferentes características das doenças. Dessa forma, sugere-se que a ausência de toxicidade hepática nos pacientes investigados no presente estudo, esteja relacionada com os menores valores de AUC do metabólito CEPM quando comparados aos valores alvo de $325 \pm 25 \mu \mathrm{mol} / \mathrm{L}$.h descritos por McDonald et al (2005) e McCune et al. (2009), além das características dos condicionamentos utilizados nos diferentes tipos de TCTH e das doenças envolvidas.

Concluindo, a farmacocinética da CY e seu metabólito HCY é enantiosseletiva em pacientes portadores de EM ou ES submetidos ao TCTH autólogo com acúmulo plasmático dos enantiômeros (S)-(-)-CY e HCY(1), provavelmente o (R)-(+)-HCY. No entanto, a disposição cinética do metabólito CEPM não difere entre os enantiômeros. A farmacocinética da CY e seus metabólitos HCY e CEPM não difere entre os pacientes portadores de EM ou 
ES. Os parâmetros farmacocinéticos da CY e seus metabólitos não mostram associação com as variantes alélicas CYP2B6*9, CYP2C9*2 e CY2C9*3, sugerindo que a genotipagem destes polimorfismos não contribui no ajuste do regime de dosagem da $\mathrm{CY}$. 
6. Conclusões 
1. O micrométodo de análise dos enantiômeros da CY e seu metabólito CEPM em plasma humano, empregando coluna quiral acoplada ao sistema LC-MS/MS, apresenta limites de confiança compatíveis com a aplicação em estudo clínico de disposição cinética da CY.

2. O micrométodo de análise dos enantiômeros da HCY em plasma humano, empregando coluna quiral acoplada ao sistema LC-MS/MS, apresenta limites de confiança compatíveis com a aplicação em estudo clínico de disposição cinética da CY.

3. A disposição cinética da CY é enantiosseletiva em pacientes portadores de ES ou EM com acúmulo plasmático do enantiômero (S)-(-)-CY em função da formação preferencial de um dos enantiômeros do metabólito HCY.

4. A disposição cinética do metabólito CEPM não é enantiosseletiva em pacientes portadores de ES ou EM.

5. A disposição cinética dos enantiômeros da CY e seus metabólitos HCY e CEPM não difere entre os pacientes portadores de EM ou ES.

6. Os parâmetros farmacocinéticos da $\mathrm{CY}$ e seu metabólito HCY não mostram associação com os polimorfismos CYP2B6*9, CYP2C9*2 e CYP2C9*3. 
Referências Bibliográficas 
ABBASI, N. et al. Pharmacogenetics of intravenous and oral busulfan in hematopoietic cell transplant recipients. Journal of clinical pharmacology, v. 51, n. 10, p. 1429-38, 2011.

ABDULLA, D.; GORALSKI, K.B.; RENTON, K.W. The regulation of cytochrome P4502E1 during LPS-induced inflammation in the rat. Toxicology and Applied Pharmacology, v.216, n.1, p. 1-10, 2006.

ANDERSSON, B. S. et al. Busulfan systemic exposure relative to regimen-related toxicity and acute graft-versus-host disease: defining a therapeutic window for i.v. BuCy2 in chronic myelogenous leukemia. Biology of blood and marrow transplantation : journal of the American Society for Blood and Marrow Transplantation, v. 8, n. 9, p. 477-85, 2002.

AGÊNCIA NACIONAL DE VIGILÂNCIA SANITÁRIA. Resolução RE $\mathbf{n}^{\mathbf{0}} 899$ de 29 de maio de 2003 e Resolução RDC $n^{0} 27$ de 17 de maio de 2012. Disponíveis em http://www.anvisa.gov.br

ANSARI, M. et al. A simplified method for busulfan monitoring using dried blood spot in combination with liquid chromatography/tandem mass spectrometry. Rapid communications in mass spectrometry : RCM, v. 26, n. 12, p. 1437-46, 2012.

BAUMANN, F. et al. Determination of cyclophosphamide and its metabolites in human plasma high-performance liquid chromatography-mass spectrometry. Journal of Chromatography B: Biomedical Sciences and Applications, v. 729, p. 297-305, 1999.

BARTELINK, I. H. et al. Association between busulfan exposure and outcome in children receiving intravenous busulfan before hematologic stem cell transplantation. Biology of blood and marrow transplantation : journal of the American Society for Blood and Marrow Transplantation, v. 15, n. 2, p. 231-41, 2009.

BARTELINK, I. H. et al. Body weight-dependent pharmacokinetics of busulfan in paediatric haematopoietic stem cell transplantation patients: towards individualized dosing. Clinical pharmacokinetics, v. 51, n. 5, p. 331-45, 2012.

BERI, R. et al. Reliability of a pretransplant i.v. BU test dose performed 2 weeks before myeloablative FluBu conditioning regimen. Bone marrow transplantation, v. 45, n. 2, p. 249-53, 2010.

BLEYZAC, N. et al. Improved clinical outcome of paediatric bone marrow recipients using a test dose and Bayesian pharmacokinetic individualization of busulfan dosage regimens. Bone marrow transplantation, v. 28, n. 8, p. 743-51, 2001.

BLEYZAC, N.; BAROU, P.; AULAGNER, G. Rapid and sensitive high-performance liquid chromatographic method for busulfan assay in plasma. Journal of chromatography. B, Biomedical sciences and applications, v. 742, n. 2, p. 427-32, 2000.

BODDY, A.V.; YULE, S.M. Metabolism and Pharmacokinetics of Oxazaphosphorines. Clinical Pharmacokinet, v. 38, n. 4, p. 291-304, 2000. 
BOHGAKI, T. et al. Immunological reconstitution after autologous hematopoietic stem cell transplantation in patients with systemic sclerosis: relationship between clinical benefits and intensity of immunosuppression. The Journal of rheumatology, v. 36, n. 6, p. 1240-8, 2009.

BOUZAS, L. F. S. Transplante de medula óssea em pediatria e transplante de cordão umbilical. Revista Medicina, Ribeirão Preto, v.33, p. 241-263, 2000.

BOWEN, J. D. et al. sclerosis : long-term results. v. 47, n. 7, p. 946-951, 2013.

BULLOCK, J. M. et al. Development of a pharmacokinetic and Bayesian optimal sampling model for individualization of oral busulfan in hematopoietic stem cell transplantation. Therapeutic drug monitoring, v. 28, n. 1, p. 62-6, 2006.

BURT, R. K. et al. Non-myeloablative stem cell transplantation for autoimmune diseases. Springer seminars in immunopathology, v. 26, n. 1-2, p. 57-69, 2004.

CHOE, S. et al. A simple dosing scheme for intravenous busulfan based on retrospective population pharmacokinetic analysis in korean patients. The Korean journal of physiology \& pharmacology : official journal of the Korean Physiological Society and the Korean Society of Pharmacology, v. 16, n. 4, p. 273-80, 2012.

CHOW, D. S. et al. Stability-indicating high-performance liquid chromatographic assay of busulfan in aqueous and plasma samples. Journal of chromatography B, Biomedical sciences and applications, v. 704, n. 1-2, p. 277-88, 1997.

CIUREA, S. O.; ANDERSSON, B. S. Busulfan in hematopoietic stem cell transplantation. Biology of blood and marrow transplantation : journal of the American Society for Blood and Marrow Transplantation, v. 15, n. 5, p. 523-36, 2009.

CORLETT, S.A. \& CHRYSTYN, H. High-performance liquid chromatographic determination of the enantiomers of cyclophosphamide in serum. Journal of chromatography B, Biomedical sciences and applications, v. 682, p. 337-342, 1996.

COURI, C. E. B.; DE OLIVEIRA, M. C.; SIMÕES, B. P. Risks, benefits, and therapeutic potential of hematopoietic stem cell transplantation for autoimmune diabetes. Current diabetes reports, v. 12, n. 5, p. 604-11, 2012.

CZERWINSKI, M.; GIBBS, P.; SLATTERY, T. Busulfan conjugation. Drug metabolism and disposition: the biological fate of chemicals, v. 24, n. 9, p. 1015-1019, 1996.

DAVAALKHAM, J. et al.Allele and genotype frequencies of cytochrome P450 2B6 gene in a Mongolian population. Drug Metabolism Disposition, v.37, n.10, p.1991-1993, 2009.

DE JONGE, M. E. et al. Accuracy, feasibility, and clinical impact of prospective Bayesian pharmacokinetically guided dosing of cyclophosphamide, thiotepa, and carboplatin in highdose chemotherapy. Clinical cancer research: an official journal of the American Association for Cancer Research, v. 11, n. 1, p. 273-83, 2005.

DE JONGE, M. E. et al. Significant induction of cyclophosphamide and thiotepa metabolism by phenytoin. Cancer chemotherapy and pharmacology, v. 55, n. 5, p. 507-10, 2005. 
DE MIRANDA SILVA, C. et al. Influence of glomerular filtration rate on the pharmacokinetics of cyclophosphamide enantiomers in patients with lupus nephritis. Journal of clinical pharmacology, v. 49, n. 8, p. 965-72, 2009.

DELANEY, M.; BALLEN, K. K. Umbilical Cord Blood Transplantation: Review of Factors Affecting the Hospitalized Patient. Journal of intensive care medicine, 2013.

ETTE, E. I.; WILLIAMS, P. J.; LANE, J. R. Population pharmacokinetics III: design, analysis, and application of population pharmacokinetic Studies. The Annals of pharmacotherapy, v. 38, n. 12, p. 2136-44, 2004.

EKHART, C. et al. Simultaneous quantification of cyclophosphamide and its active metabolite 4-hydroxycyclophosphamide in human plasma by high-performance liquid chromatography coupled with electrospray ionization tandem mass spectrometry (LCMS/MS). Journal of chromatography. B, Analytical technologies in the biomedical and life sciences, v. 854, p. 345-9, 2007.

EKHART, C. et al. Relations between polymorphims in drug-metabolising enzymes and toxicity of chemotherapy with cyclophosphamide, thiotepa and carboplatin. Pharmacogenetic Genomics, v. 18, n. 11, p. 1009-15, 2008.

FASSAS, A. et al. Peripheral blood stem cell transplantation in the treatment of progressive multiple sclerosis: first results of a pilot study. Bone Marrow Transplantation, v.20, n.8, p. 631-638, 1997.

FERNANDES, B. J. D. et al. Pharmacokinetics of cyclophosphamide enantiomers in patients with breast cancer. Cancer Chemotherapy and Pharmacology, v. 68, n. 4, p. 897-904, 2011.

GALAUP, A.; PACI, A. Pharmacology of dimethanesulfonate alkylating agents: busulfan and treosulfan. Expert opinion on drug metabolism \& toxicology, v. 9, n. 3, p. 333-47, 2013.

GEDDES, M. et al. High busulfan exposure is associated with worse outcomes in a daily i.v. busulfan and fludarabine allogeneic transplant regimen. Biology of blood and marrow transplantation: journal of the American Society for Blood and Marrow Transplantation, v. 14, n. 2, p. 220-8, 2008.

GERMANAS, J \& PANDYA, A. Alkylating agents. Dermatologic Therapy, v. 15, p. $317-$ 324, 2002.

GILBERT, C. J. et al. Pharmacokinetic interaction between ondansetron and cyclophosphamide during high-dose chemotherapy for breast cancer. Cancer chemotherapy and pharmacology, v. 42, n. 6, p. 497-503, 1998.

GOURH, P. et al. Plasma cytokine profiles in systemic sclerosis: associations with autoantibody subsets and clinical manifestations. Arthritis research \& therapy, v. 11, n. 5, p. $147,2009$.

GRISKEVICIUS, L.; MEURLING, L. HASSAN, M. Simple method based on fluorescent detection for the determination of 4-hydroxycyclophosphamide in plasma. Therapeutic Drug Monitoring, v. 24, p. 405-9, 2002. 
HAMERSCHLAK, N. et al. Brazilian experience with two conditioning regimens in patients with multiple sclerosis: BEAM/horse ATG and $\mathrm{CY} /$ rabbit ATG. Bone marrow transplantation, v. 45, n.2, p. 239-48, 2010.

HELSBY, N. et al. The combined impact of CYP2C19 and CYP2B6 pharmacogenetics on cyclophosphamide bioactivation. British Journal of Clinical Pharmacology, v.70, n.6, p. 844-53, 2010.

HOLLOMAN, J. P. et al. The development of hematopoietic and mesenchymal stem cell transplantation as an effective treatment for multiple sclerosis. American journal of stem cells, v. 2, n. 2, p. 95-107, 2013.

HOLM, K.A. et al. Stereoselective pharmacokinetics and metabolism of the enantiomers of cyclophosphamide. Preliminary results in humans and rabbits. Biochemical Pharmacology, v. 39, p. 1375-1384, 1990.

HOMSI, C. M. Complicações precoces do transplante autogênico de células tronco hematopoéticas. Prática Hospitalar, v. 48, n. 4, p. 29-33, 2006.

JACOB, R. et al. Identification of CYP2B6 sequence variants by use of multiplex PCR with allele-specific genotyping. Clinical Chemstry, v. 50, n.8, p. 1372-1377, 2004.

JARMAN, M.et al. Comparative metabolism of 2-[Bis(2-chloroethyl) amino] tetrahydro-2H1,3,2-oxazaphosphorine-2-oxide (Cyclophosphamide) and its enantiomers in humans. Cancer Research, v. 39, p. 2762-2767, 1979.

JOERGER, M. Covariate pharmacokinetic model building in oncology and its potential clinical relevance. The AAPS journal, v. 14, n. 1, p. 119-32, 2012.

JOHNSON, L. et al. Glutathione S-transferase A1 genetic variants reduce busulfan clearance in children undergoing hematopoietic cell transplantation. Journal of clinical pharmacology, v. 48, n. 9 , p. $1052-62,2008$.

JOHNSON-DAVIS, K. L. et al. Which dose of busulfan is best? Clinical chemistry, v. 56, n. 7, p. 1061-4, 2010.

JOY, M. S. et al. Cyclophosphamide and 4-hydroxycyclophosphamide pharmacokinetics in patients with glomerulonephritis secondary to lupus and small vessel vasculitis. British journal of clinical pharmacology, v. 74, n. 3, p. 445-55, 2012.

KALHORN, et al. Rapid quantitation of cyclophosphamide metabolites in plasma by liquid chromatography-mass spectrometry. Journal of chromatography. B, Analytical technologies in the biomedical and life sciences, v.835, p. 105-13, 2006.

KIM, A. H. et al. Evaluating pharmacokinetics and pharmacodynamics of intravenous busulfan in pediatric patients receiving bone marrow transplantation. Pediatric transplantation, v. 13 , n. 8, p. 971-6, 2009.

KIM, S.-D. et al. Influence of GST gene polymorphisms on the clearance of intravenous busulfan in adult patients undergoing hematopoietic cell transplantation. Biology of blood 
and marrow transplantation : journal of the American Society for Blood and Marrow Transplantation, v. 17, n. 8, p. 1222-30, 2011.

KLEIN, K. et al. Genetic variability of CYP2B6 in populations of African and Asian origin: allele frequencies, novel functional variants, and possible implications for anti-HIV therapy with efavirenz. Pharmacogenetics and Genomics, v.15, n.12, p. 861-73, 2005.

KLEINROK, Z. et al. Comparison of pharmacological properties of cyclophosphamide and its enantiomers. Archivum Immunologiae et Therapia Experimentalis, v. 34, n. 3, p. 263-273, 1986.

KLETZEL, M.; JACOBSOHN, D.; DUERST, R. Pharmacokinetics of a test dose of intravenous busulfan guide dose modifications to achieve an optimal area under the curve of a single daily dose of intravenous busulfan in children undergoing a reduced-intensity conditioning regimen with hematopoietic s. Biology of blood and marrow transplantation : journal of the American Society for Blood and Marrow Transplantation, v. 12, n. 4, p. 472-9, 2006.

KRIVOY, N. et al. Pharmacokinetic and pharmacogenetic analysis of oral busulfan in stem cell transplantation: prediction of poor drug metabolism to prevent drug toxicity. Current drug safety, v. 7, n. 3, p. 211-7, 2012.

KUSNIERCZYK, H. et al. Antitumor activity of optical isomers of cyclophosphamide, isofosfamide and trofosfamide as compared to clinically used racemates. International Journal of Immunopharmacology, v.8, n.4, p. 455-80, 1986.

LEE, J. W. et al. Highly variable pharmacokinetics of once-daily intravenous busulfan when combined with fludarabine in pediatric patients: phase I clinical study for determination of optimal once-daily busulfan dose using pharmacokinetic modeling. Biology of blood and marrow transplantation: journal of the American Society for Blood and Marrow Transplantation, v. 18, n. 6, p. 944-50, 2012.

LINDBOM, L. et al. PsN-Toolkit--a collection of computer intensive statistical methods for non-linear mixed effect modeling using NONMEM. Computer methods and programs in biomedicine, v. 79, n. 3, p. 241-57, 2005.

LINDLEY, C. et al. Intraindividual variability in busulfan pharmacokinetics in patients undergoing a bone marrow transplant: assessment of a test dose and first dose strategy. p. 453-459, 2004.

LIU, Q.-F et al. Peripheral blood stem cell transplantation compared with bone marrow transplantation from unrelated donors in patients with leukemia: a single institutional experience. Blood cells, molecules \& diseases, v. 45, n. 1, p. 75-81, 2010.

MACHAVARAM, K.K. et al. A Physiologically based pharmacokinetic modeling approach to predict disease-drug interactions: suppression of CYP3A by IL-6. Clinical Pharmacology \& Theraputics. doi:10.1038/clpt.2013.79

MALÄR, R. et al. Therapeutic drug monitoring is essential for intravenous busulfan therapy in pediatric hematopoietic stem cell recipients. Pediatric transplantation, v. 15 , n. 6 , p. 5808, 2011. 
MCCUNE, J. S. et al. Personalized dosing of cyclophosphamide in the total body irradiationcyclophosphamide conditioning regimen: a phase II trial in patients with hematologic malignancy. Clinical pharmacology and therapeutics, v. 85, n. 6, p. 615-22, 2009.

MCCUNE, J. S. et al. Variation in Prescribing Patterns and Therapeutic Drug Monitoring of Intravenous Busulfan in Pediatric Hematopoietic Cell Transplant Recipients. Journal of clinical pharmacology, 2012.

MCCUNE, J. S.; GIBBS, J. P.; SLATTERY, J. T. of Busulfan Does It Improve Clinical Outcome? Clinical Pharmacokinetic v. 39, n. 2, p. 155-165, 2000.

MCCUNE, J. S.; HOLMBERG, L. A. Busulfan in hematopoietic stem cell transplant setting. Expert opinion on drug metabolism \& toxicology, v. 5, n. 8, p. 957-69, 2009.

MCDONALD, G. B. et al. Cyclophosphamide metabolism, liver toxicity, and mortality following hematopoietic stem cell transplantation. v. 101, n. 5, p. 2043-2048, 2003.

MCDONALD, G. B. et al. Metabolism-based cyclophosphamide dosing for hematopoietic cell transplant. Clinical pharmacology and therapeutics, v. 78, n. 3, p. 298-308, 2005.

MIKULKOVA, Z. et al. Imbalance in T-cell and cytokine profiles in patients with relapsingremitting multiple sclerosis. Journal of the neurological sciences, v. 300, n. 1-2, p. 135-41, 2011.

MORGAN, E. T. Regulation of cytochrome p450 by inflammatory mediators: why and how? Drug metabolism and disposition: the biological fate of chemicals, v. 29, n. 3, p. 207-12, 2001 .

MORGAN, E. T. et al. Regulation of Drug-Metabolizing Enzymes and Transporters in Infection, Inflammation, and Cancer. Drug Metabolism and Disposition, v. 36, n. 2, p. 205-216, 2008.

MORGAN, E. T. Impact of infectious and inflammatory disease on cytochrome P450mediated drug metabolism and pharmacokinetics. Clinical pharmacology and therapeutics, v. 85, n. 4 , p. 434-8, 2009.

NATH, C. E. et al. Variability in the pharmacokinetics of intravenous busulphan given as a single daily dose to paediatric blood or marrow transplant recipients. British journal of clinical pharmacology, v. 66, n. 1, p. 50-9, 2008.

NATH, C. E.; SHAW, P. J. Busulphan in blood and marrow transplantation: dose, route, frequency and role of therapeutic drug monitoring. Current clinical pharmacology, v. 2, n. 1, p. 75-91, 2007.

NGUYEN, L. Integration of modelling and simulation into the development of intravenous busulfan in paediatrics: an industrial experience. Fundamental \& clinical pharmacology, v. 22, n. 6, p. 599-604, 2008.

NOSEWORTHY, J.H. et al. Multiple Sclerosis. The New England Journal of Medicine, v. 343, n. 13 , p. 938-952, 2000. 
OLSON, M. T.; LOMBARDI, L.; CLARKE, W. Clinical consequences of analytical variance and calculation strategy in oral busulfan pharmacokinetics. Clinica chimica acta; international journal of clinical chemistry, v. 412, n. 23-24, p. 2316-21, 2011.

PAPROCKA, M. et al. Comparative studies on biological activity of $/+/ \mathrm{R}$ and $/-/ \mathrm{S}$ enantiomers of cyclophosphamide and ifosfamide. I. Antitumour effect of cyclophosphamide and ifosfamide enantiomers. Archivum Immunologiae et Therapia Experimentalis, v. 34, n. 3, p. 275-284, 1986.

PARKE, J.; HOLFORD, N. H.; CHARLES, B. G. A procedure for generating bootstrap samples for the validation of nonlinear mixed-effects population models. Computer methods and programs in biomedicine, v. 59, n. 1, p. 19-29, 1999.

PATON, E. J. A.; COUTINHO, M. A.; VOLTARELli, J. C. AGUDAS DO TRANSPlante DE CÉLUlAS. Revista Medicina, Ribeirao Preto, v. 33, p. 264-277, 2000 .

PERKINS, J. B. et al. Maximally tolerated busulfan systemic exposure in combination with fludarabine as conditioning before allogeneic hematopoietic cell transplantation. Biology of blood and marrow transplantation : journal of the American Society for Blood and Marrow Transplantation, v. 18, n. 7, p. 1099-107, 2012.

PINTO, N.; LUDEMAN, S.M.; DOLAN, M.E. Pharmacogenetic studies related to cyclophosphamide-based therapy. Pharmacogenomics, v.10, n. 12, p. 1897-903, 2009.

POSER, C.M. et al. New diagnostic criteria for multiple sclerosis: guidelines for research protocols. Annals of Neurology, v. 13, n. 3, p. 227-31, 1983.

QIU, R.; KALHORN, T. F.; SLATTERY, J. T. ABCC2-Mediated Biliary Transport of 4Glutathionylcyclophosphamide and Its Contribution to Elimination of 4Hydroxycyclophosphamide in Rat. Journal of Pharmacology and Experimental Therapeutics, v. 308, n. 3, p. 1204-1212, 2004.

QIU, R. et al. Disminishing the risk of nonrelapse mortalty in hematopoietic stem cell transplantation: prediction of exposure to the cyclophosphamide metabolite carboxyethylphospharamide mustard. Clinical Pharmacology \& Therapeutics, v. 76, n. 3, p. 270-280, 2004.

RACCOR B.S. et al. Potential contribution of cytochrome P450 2B6 to hepatic 4hydroxycyclophosphamide formation in vitro and in vivo. Drug Metabolism Disposition, v. 40, n. 1, p. $54-63,2012$.

REN, S. et al. Pharmacokinetics of cyclophosphamide and its metabolites in bone marrow transplantation patients. Clinical Pharmacology \& Therapeutics, v. 64, n. 3, p.289-301, 1998.

RENTON, K. W. Alteration of drug biotransformation and elimination during infection and inflammation. Pharmacology \& therapeutics, v. 92, n. 2-3, p. 147-63, 2001.

RENTON, K.W. Cytochrome P450 Regulation and Drug Biotransformation during Inflamations and Infection. Current Drug Metabolism, v. 5, p. 235-43, 2004. 
RENTON, K.W. Regulation of drug metabolism and disposition during inflammation and infection. Expert Opin Drug Metab Toxicol., v.1, n.4, p.629-640, 2005.

REZVANI, A. R. et al. Cyclophosphamide Followed by Intravenous Targeted Busulfan for Allogeneic Hematopoietic Cell Transplantation: Pharmacokinetics and Clinical Outcomes. Biology of blood and marrow transplantation : journal of the American Society for Blood and Marrow Transplantation, v. 19, n. 7, p. 1033-1039, 2013.

RUSSELL, J. A et al. Once-daily intravenous busulfan given with fludarabine as conditioning for allogeneic stem cell transplantation: study of pharmacokinetics and early clinical outcomes. Biology of blood and marrow transplantation: journal of the American Society for Blood and Marrow Transplantation, v. 8, n. 9, p. 468-76, 2002.

SANDSTRÖM, M. et al. Population pharmacokinetic analysis resulting in a tool for dose individualization of busulphan in bone marrow transplantation recipients. Bone marrow transplantation, v. 28, n. 7, p. 657-64, 2001.

SLATTERY, J.T. et al. Conditioning regimen-dependent disposition of cyclophosphamide and hydroxycyclophosphamide in human marrow transplantation patients. Journal of Clinical Oncolology v.14, n.5, p. 1484-94, 1996.

STRACIERI, A. B. P. L. ASPECTOS IMUNOLÓGICOS DOS TRANSPLANTES DE. Revista Medicina, Ribeirao Preto, v. 33, p. 443-462, 2000.

TAKAMATSU, Y. et al. An evaluation of busulfan pharmacokinetics in patients undergoing hematopoietic stem cell transplantation. Japanese journal of clinical oncology, v. 35, n. 7, p. 400-3, 2005.

TAKAMATSU, Y. et al. Individual dose adjustment of oral busulfan using a test dose in hematopoietic stem cell transplantation. International journal of hematology, v. 86, n. 3, p. 261-8, 2007.

TEN BRINK, M. H. et al. Effect of genetic polymorphisms in genes encoding GST isoenzymes on BU pharmacokinetics in adult patients undergoing hematopoietic SCT. Bone marrow transplantation, v. 47, n. 2, p. 190-5, 2012.

TRAME, M. N. et al. Population pharmacokinetics of busulfan in children: increased evidence for body surface area and allometric body weight dosing of busulfan in children. Clinical cancer research : an official journal of the American Association for Cancer Research, v. 17, n. 21, p. 6867-77, 2011.

VAN LAAR, J. M. et al. Autologous HSCT for systemic sclerosis. Lancet, v. 381, n. 9883, p. 2079-80, 2013.

VIANNA-JORGE R., et al. CYP2C9 genotypes and the pharmacokinetics of tenoxicam in Brazilians. Clin Pharmacol Ther. St. Louis, v. 76, n. 1, p.18-26, 2004

WILLIAMS M.L. et al.Enantioselective induction of cyclophosphamide metabolism by phenytoin. Chirality, v. 11, p. 569-574, 1999. 
WILLIAMS, M.L. et al Pharmacokinetics of (R) and (S)- cyclophosphamide and theirs dechoroetylated metabolites in cancer patients. Chirality, v.11, p. 301-308, 1999b.

XIE, H. et al. Pharmacogenetics of cyclophosphamide in patients with hematological malignancies. European journal of pharmaceutical sciences : official journal of the European Federation for Pharmaceutical Sciences, v. 27, n. 1, p. 54-61, 2006.

ZHANG, J. et al. Reversal of resistance to oxazaphosphorines. Current cancer drug targets, v. 6, n. 5, p. 385-407, 2006. 
ANEXOS 
ANEXO 1. Aprovação do comitê de ética em pesquisa do HCFMRP-USP

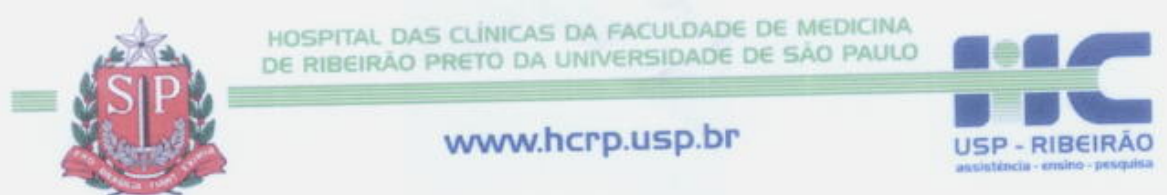

Ribeirāo Preto, 31 de março de 2010

Oficio $\mathrm{n}^{\circ} 911 / 2010$

$\mathrm{CEP} / \mathrm{MGV}$

Prezadas Senhoras,

O trabalho intitulado "ENANTIOSSELETIVIDADE NA DISPOSIÇÃO CINÉTICA E NO METABOLISMO DA CICLOFOSFAMIDA E AJUSTE DE DOSE DO BUSSULFANO EM PACIENTES SUBMETIDOS A TRANSPLANTE DE CÉLULAS TRONCO HEMATOPOÉTICAS" foi analisado pelo Comitê de Ética em Pesquisa, em sua $304^{a}$ Reuniāo Ordinária realizada em 29/03/2010 e enquadrado na categoria: APROVADO, bem como o Termo de Consentimento Livre e Esclarecido, de acordo com o Processo HCRP n ${ }^{\circ}$ 14369/2009.

Este Comitê segue integralmente a Conferência Internacional de Harmonização de Boas Práticas Clínicas (IGH-GCP), bem como a Resolucão $n^{\circ}$ 196/96 CNS/MS.

Lembramos que devem ser apresentados a este CEP, O Relatório Parcial e o Relatório Final da pesquisa.

Atenciosamente.

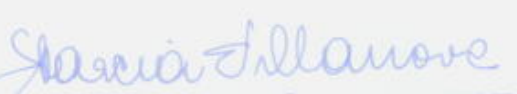

DR ${ }^{\alpha}$ MARCIA GUIMARĀES VILLANOVA

Vice-Coordenadora do Comitê de Ética em Pesquisa do HCRP e da FMRP-USP

Ilustríssimas Senhoras

FRANCINE ATTIÉ DE CASTRO

PROF $^{\text {a }}$ DR $^{\text {a }}$ VERA LÚCIA LANCHOTE (Orientadora)

Faculdade de Ciências Farmacêuticas de Ribeirão Preto-USP

Comitê de Ética em Pesquisa HCRP e FMRP-USP - Campus Universitário

FWA - 0000 2733: IRB - 00002186 e Registro SISNEP/CONEP $n^{\circ} 4$

Fone (16) 3602-2228 - E-mail : cep $@$ herp.usp.br 
ANEXO 2. TERMO DE CONSENTIMENTO LIVRE E ESCLARECIDO

\section{HOSPITAL DAS CLÍNICAS DA FACULDADE DE MEDICINA DE RIBEIRÃO PRETO- UNIVERSIDADE DE SÃO PAULO}

PESQUISA CIENTÍFICA

TERMO DE CONSENTIMENTO LIVRE E ESCLARECIDO

NOME DO PACIENTE/ IDADE:

REGISTRO E/OU DOCUMENTO DE INDENTIFCAÇÃO:

NOME DA PESQUISA: "Enantiosseletividade na disposição cinética e no metabolismo da ciclofosfamida e ajuste de dose do bussulfano em pacientes submetidos a transplante de células tronco hematopoéticas".

RESPONSÁVEL CLÍNICO: Profa. Dra. Belinda Pinto Simões (Departamento de Clínica Médica, Divisão de Hematologia HC-FMRP-USP) - CRM 57.383.

RESPONSÁVEL PELA APLICAÇÃo DO TCLE: Francine Attié de Castro (aluna de doutorado da FCFRP-USP)

TELEFONE PARA CONTATO: (16) 36022663 ou (16) 3602-4195

OBSERVAÇÕES: Projeto Integrado Faculdade de Medicina de Ribeirão Preto-USP e Faculdade de Ciências Farmacêuticas de Ribeirão Preto-USP

Convidamos você a participar, como paciente, da pesquisa que tem o nome "Enantiosseletividade na disposição cinética e no metabolismo da ciclofosfamida e ajuste de dose do bussulfano em pacientes submetidos a transplante de células tronco hematopoéticas".

O Bussulfano é um dos medicamentos usados no processo do transplante de medula óssea; você tomará este medicamento numa fase muito importante do seu tratamento. Como este medicamento só é tomado pela boca como comprimido nem sempre é possível saber quanto foi realmente absorvido e chega até seu sangue. Sabemos que concentrações muito elevadas do medicamento no sangue podem ser tóxicas para você e concentrações muito baixas podem não ser suficiente para eliminar sua doença. Por esse motivo a dosagem do nível do medicamento no seu sangue se torna tão importante.

Esta pesquisa tem finalidade de entender o curso deste medicamento em seu organismo e auxiliar seu tratamento, tornando-o individualizado. 
Caso concorde em participar, o seu tratamento não será mudado em nada, você só irá tomar uma dose pequena desse remédio um dia antes do início do seu tratamento, para estudarmos a dose ideal para você e serão feitas coletas de sangue em alguns horários após você ter tomado o remédio. Você não será picado nenhuma vez, pois vamos pegar o sangue direto do catéter. As coletas serão feitas do meio dia até as seis da tarde. Serão feitas 15 coletas de sangue ao todo. Cada vez será tirado cerca de $2 \mathrm{~mL}$ de sangue (aproximadamente uma colher de café).

Os pesquisadores vão responder qualquer dúvida que você tiver e ajudar você em qualquer problema que possa ocorrer durante o estudo.

Seu nome será mantido totalmente em segredo.

Se você não quiser participar, o seu tratamento não será prejudicado de forma alguma. Você tem liberdade de escolher não participar.

Você pode desistir de participar em qualquer momento. A sua desistência também não vai prejudicar ou interferir no seu tratamento.

Declaro que em ............................. concordei voluntariamente em participar, como paciente do projeto de pesquisa acima referido.

Assinatura do paciente ou responsável

Profa. Dra. Belinda Pinto Simões

CRM 57.383

\section{TESTEMUNHAS NÃO LIGADAS À PESQUISA}

$1-$

Assinatura

Identificação

$2-$

Assinatura

Identificação 
ANEXO 2. TERMO DE CONSENTIMENTO LIVRE E ESCLARECIDO

\section{HOSPITAL DAS CLÍNICAS DA FACULDADE DE MEDICINA DE RIBEIRÃO PRETO- UNIVERSIDADE DE SÃO PAULO}

\section{PESQUISA CIENTÍFICA}

\section{TERMO DE CONSENTIMENTO LIVRE E ESCLARECIDO}

NOME DO PACIENTE/ IDADE:

\section{REGISTRO E/OU DOCUMENTO DE INDENTIFCAÇÃO:}

NOME DA PESQUISA: "Enantiosseletividade na disposição cinética e no metabolismo da ciclofosfamida e ajuste de dose do bussulfano em pacientes submetidos a transplante de células tronco hematopoéticas".

RESPONSÁVEL CLÍNICO: Prof. Dr. Julio Cesar Voltarelli (Departamento de Clínica Médica, Divisão de Imunologia HC-FMRP-USP) - CRM 19042.

RESPONSÁVEL PELA APLICAÇÃO DO TCLE: Francine Attié de Castro (aluna de doutorado da FCFRP-USP)

TELEFONE PARA CONTATO: (16) 36022663 ou (16) 3602-4195

OBSERVAÇÕES: Projeto Integrado Faculdade de Medicina de Ribeirão Preto-USP e Faculdade de Ciências Farmacêuticas de Ribeirão Preto-USP

Convidamos você a participar, como paciente, da pesquisa que tem o nome "Enantiosseletividade na disposição cinética e no metabolismo da ciclofosfamida e ajuste de dose do bussulfano em pacientes submetidos a transplante de células tronco hematopoéticas".

A ciclofosfamida é um dos medicamentos usados no processo do transplante de medula óssea; você tomará este medicamento numa fase muito importante do seu tratamento. A ciclofosfamida é dada na veia, porém a sua doença pode alterar o curso do remédio em seu organismo e prejudicar o tratamento. Sabemos que concentrações muito elevadas desses medicamentos no sangue podem ser tóxicas para você e concentrações muito baixas podem não ser suficiente para eliminar sua doença. Por esse motivo a dosagem do nível do medicamento no seu sangue se torna tão importante.

Esta pesquisa tem finalidade de entender se a sua doença modifica a quantidade deste remédio no seu sangue e assim o resultado do seu tratamento. 
Caso concorde em participar, o seu tratamento não será mudado em nada, só serão acrescentadas coletas de sangue durante o seu tratamento. Será feita 1 coleta de sangue diária, de cerca de $2 \mathrm{~mL}$ (aproximadamente 1 colher de café), durante os 4 dias de tratamento. Você não será picado nenhuma vez, pois o sangue será retirado pelo catéter central.

No último dia de seu tratamento, pré-transplante de medula óssea, as coletas serão feitas após o início da última infusão do medicamento até 24 horas, ou seja, serão feitas 15 coletas de sangue ao todo após a última infusão. Cada vez será tirado cerca de $5 \mathrm{~mL}$ de sangue (aproximadamente meia colher de sopa).

Os pesquisadores vão responder qualquer dúvida que você tiver e ajudar você em qualquer problema que possa ocorrer durante o estudo.

Seu nome será mantido totalmente em segredo.

Se você não quiser participar, o seu tratamento não será prejudicado de forma alguma. Você tem liberdade de escolher não participar.

Você pode desistir de participar em qualquer momento. A sua desistência também não irá prejudicar ou interferir no seu tratamento.

Declaro que em ............................. concordei voluntariamente em participar, como paciente do projeto de pesquisa acima referido.

Assinatura do paciente ou responsável

Prof. Dr. Júlio Cesar Voltarelli

CRM 19042

\section{TESTEMUNHAS NÃO LIGADAS À PESQUISA}

$1-$

Assinatura

Identificação

$2-$

Assinatura

Identificação 
ANEXO 3. RMN DO PADRÃO INTERNO DO BU

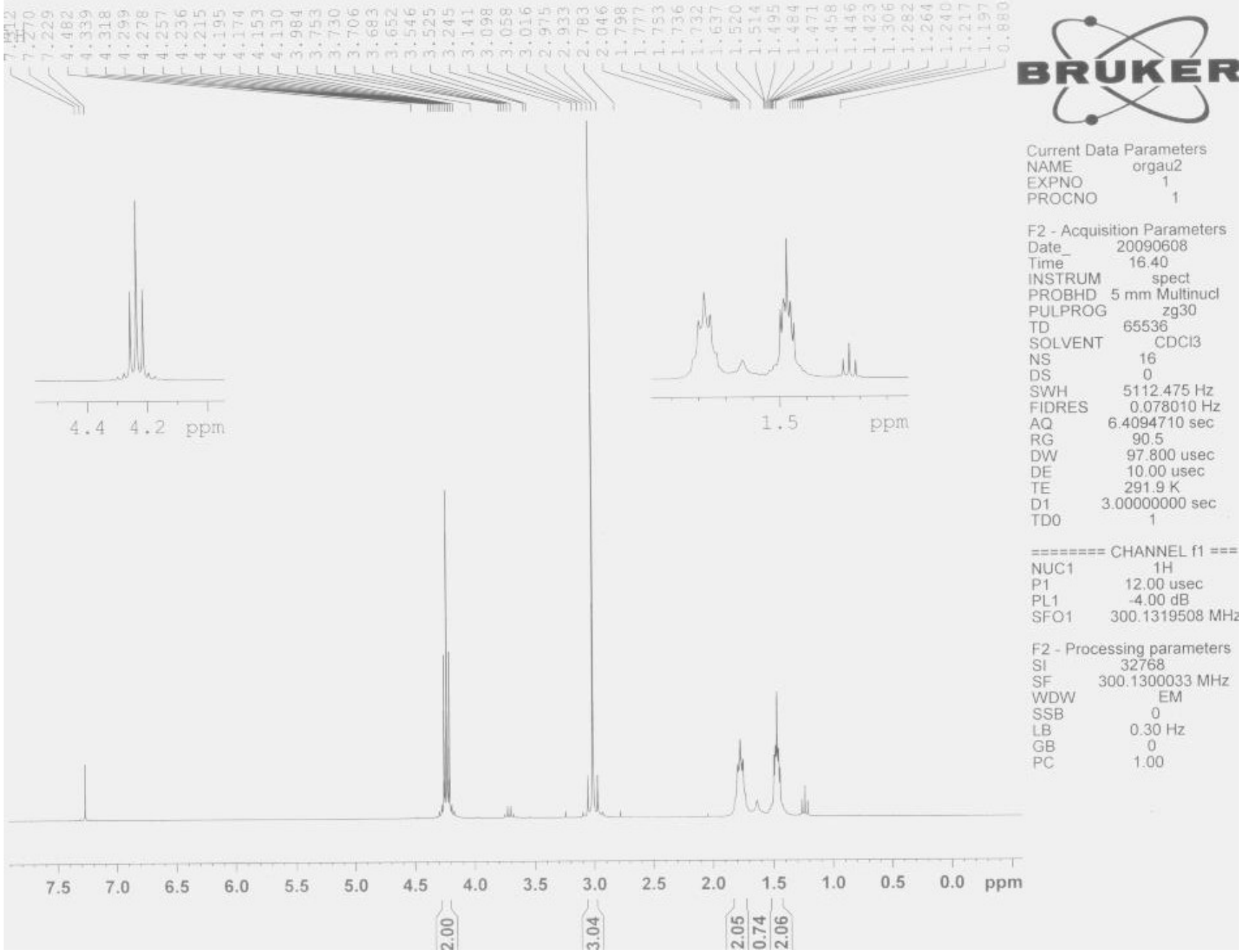


ANEXO 4. Espectros de massas da molécula protonada da HCY derivada com fenilhidrazina (A) e seu íon-produto (B).
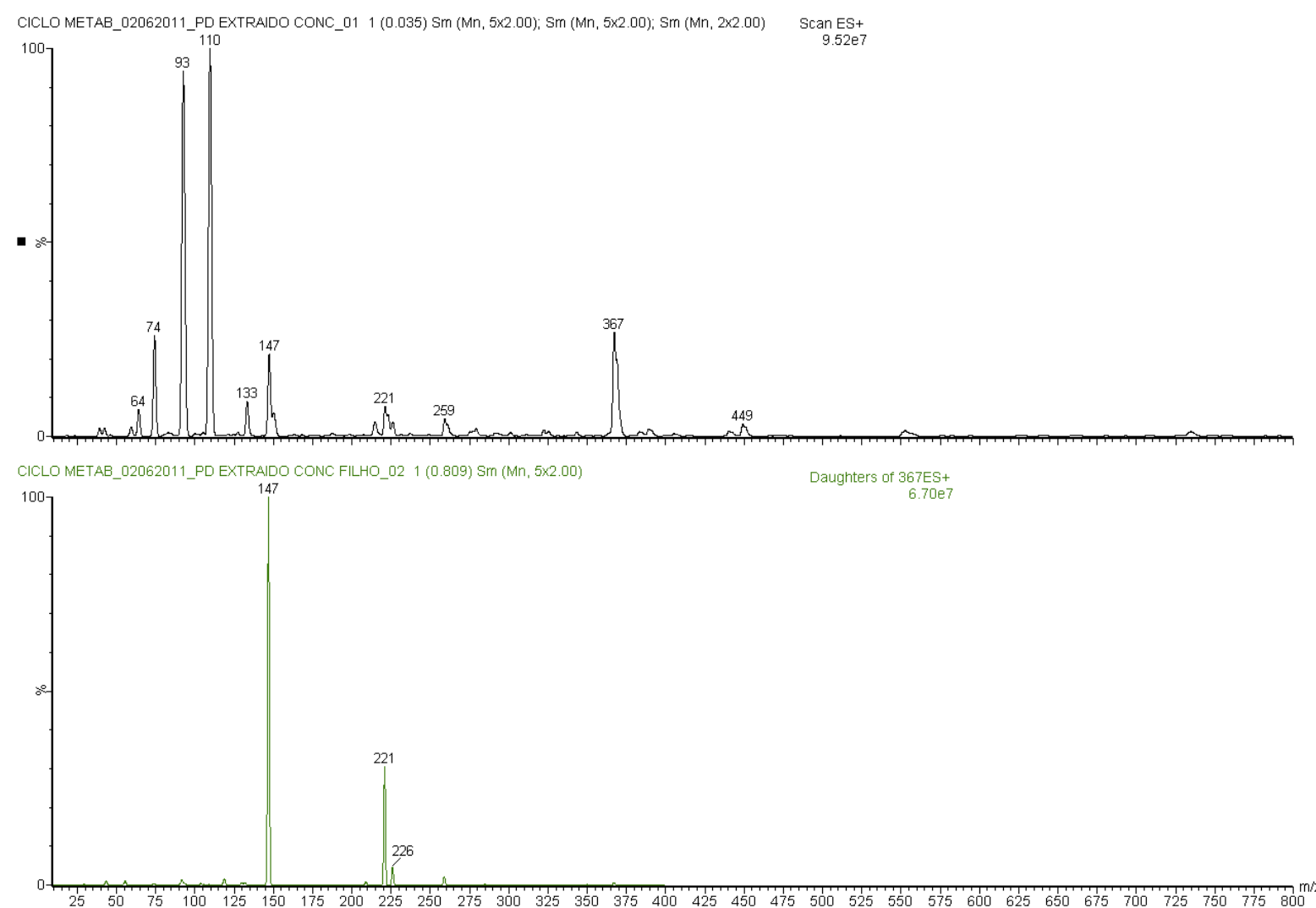

Espectros de massas do íon-produto da molécula protonada da carboxiciclofosfamida (A).

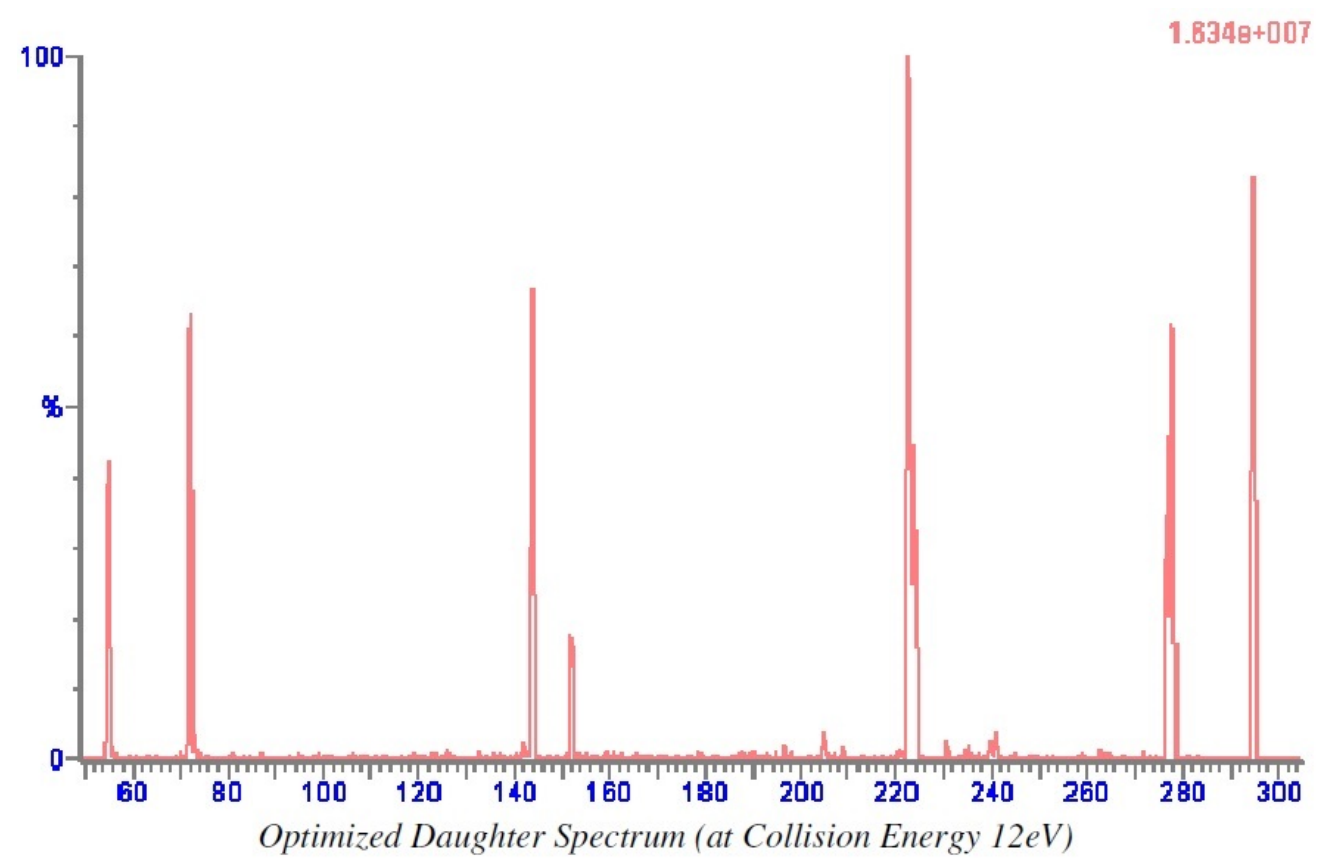

Transition 3: ES+, m/z 293.10 -> 221.1 
ANEXO 5. Reação de derivação da Aldofosfamida (Adaptado de Habib et al., 1995).

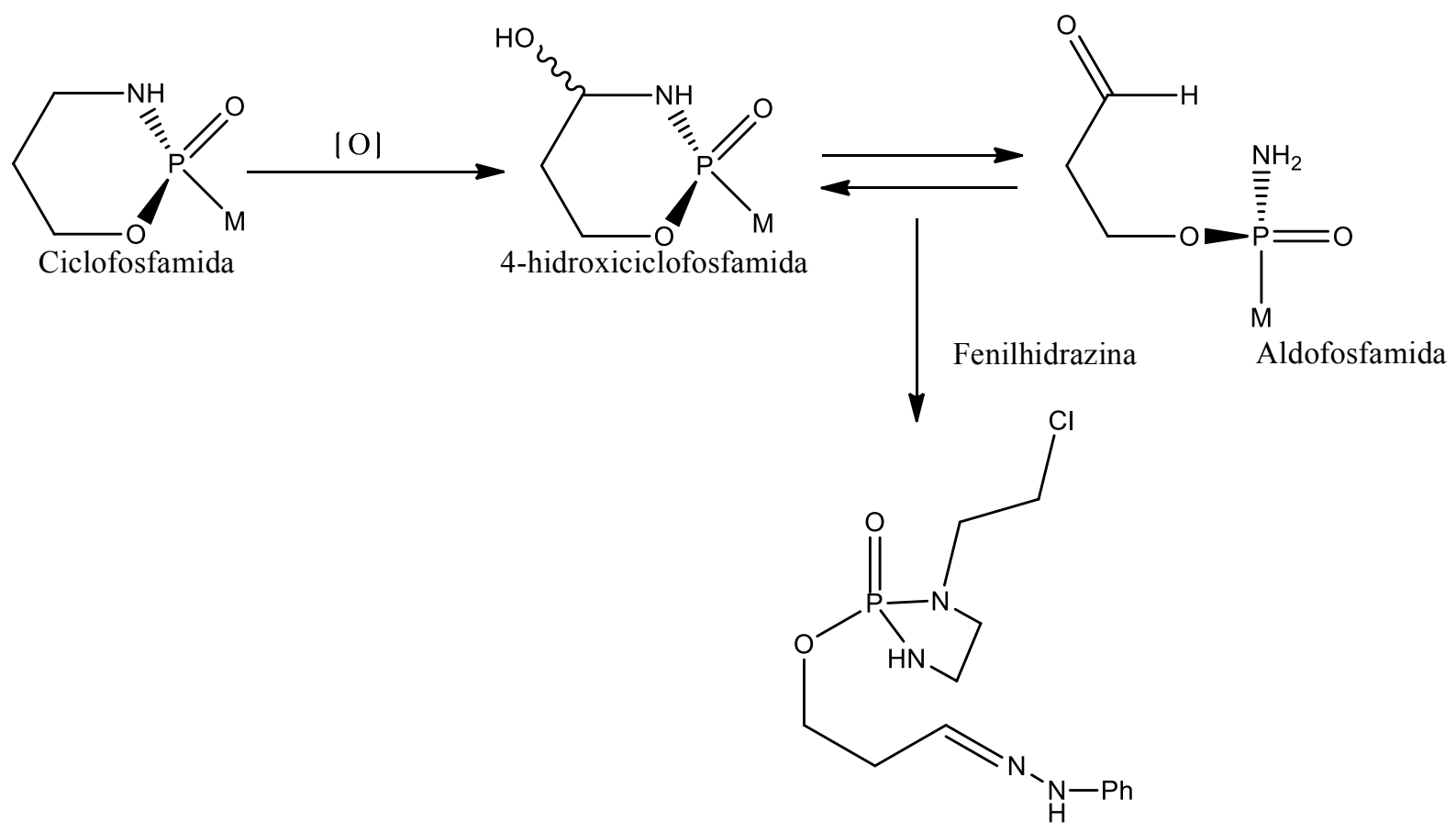


Anexo 6 - Curvas individuais da concentração plasmática versus tempo para os enantiômeros da CY e seus metabólitos (HCY e CEPM), nos pacientes portadores de EM ou ES.
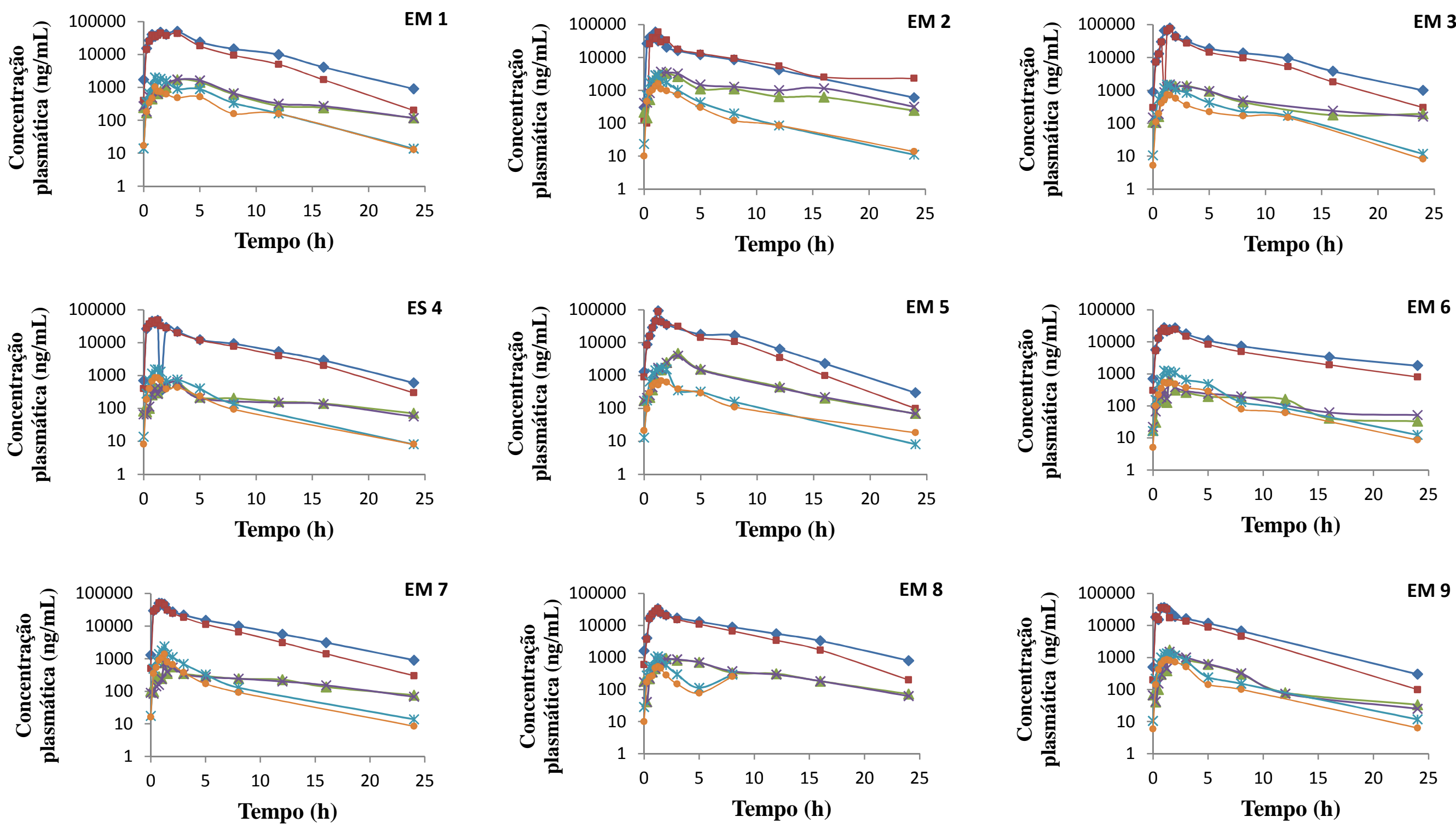

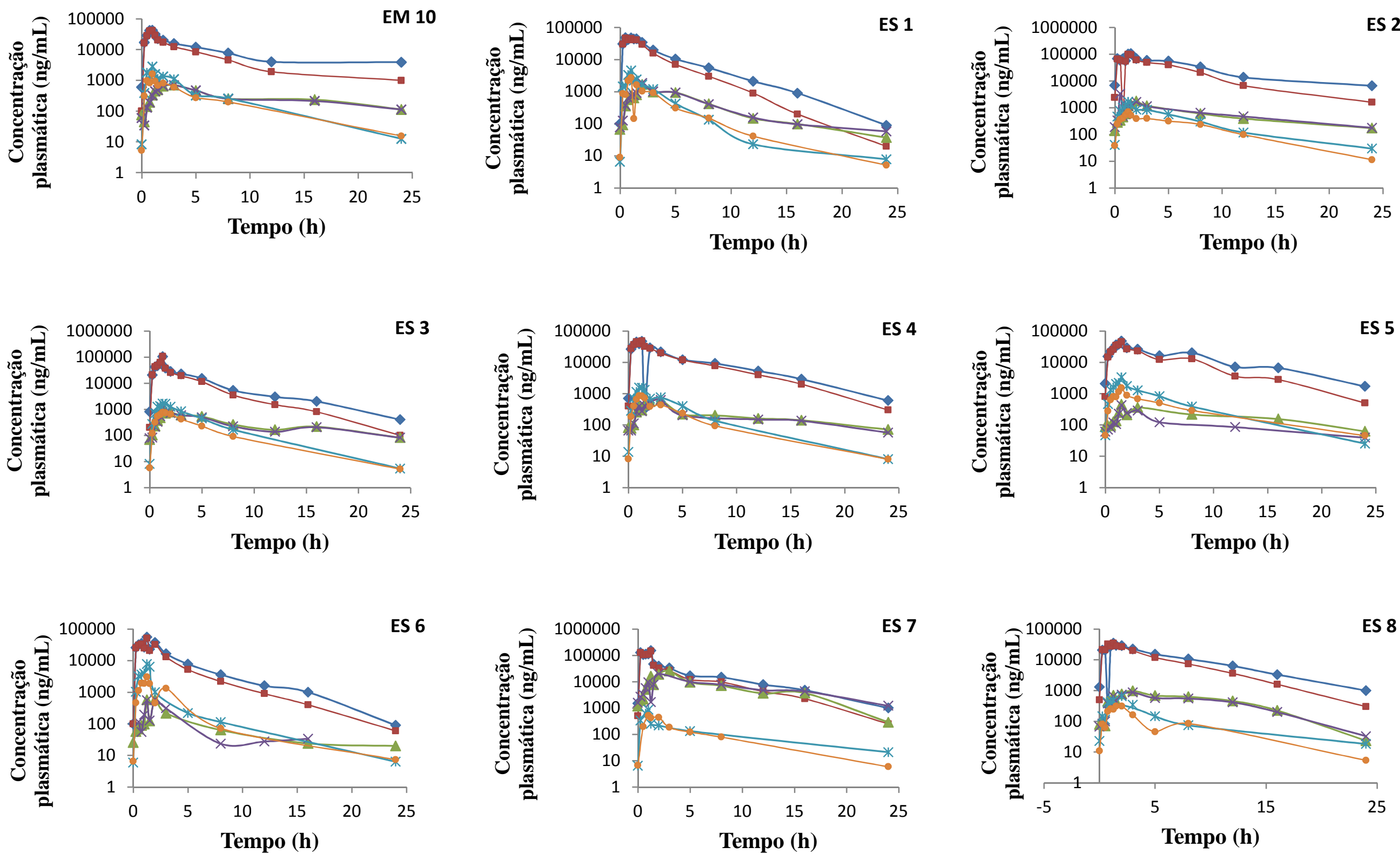

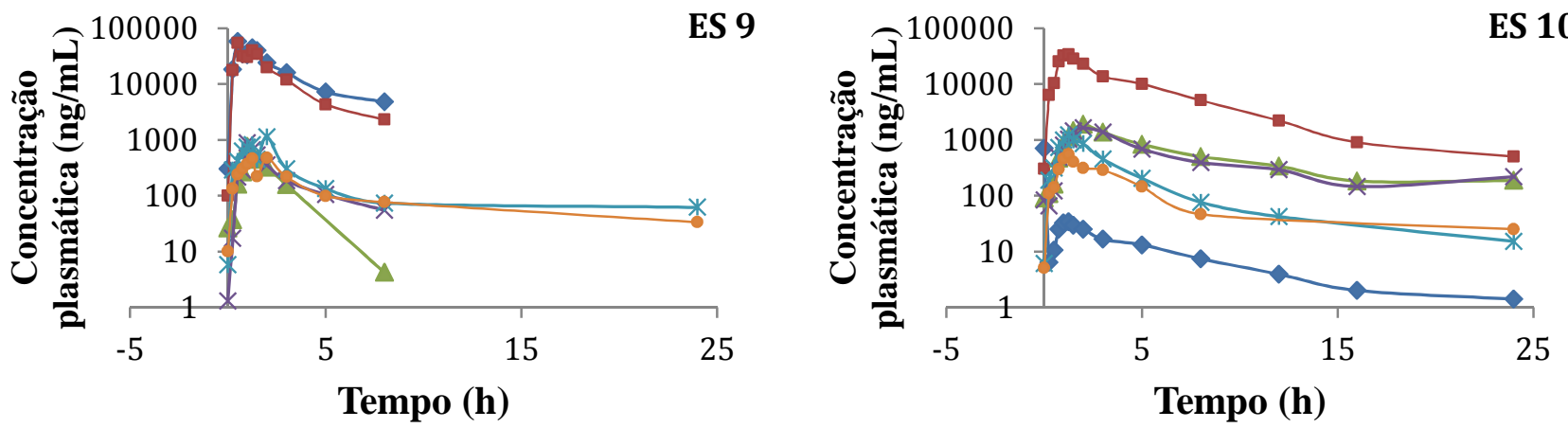

Figura 37. Curvas individuais da concentração plasmática versus tempo para os enantiômeros da CY $\rightarrow-(\mathrm{R})-(+)-\mathrm{CY}, \rightarrow-(\mathrm{S})-(-)-\mathrm{CY} \quad \mathrm{HCY} \rightarrow \mathrm{HC}-\mathrm{HCY} 1$, $\rightarrow$ HCY 2 ; e CEPM $\leadsto$ CEPM $1, \nsucc$ CEPM 2 nos pacientes do grupo de EM e ES. 